ESCUELA TÉCNICA SUPERIOR DE EDIFICACIÓN DE MADRID

TESIS DOCTORAL

\title{
CARACTERIZACIÓN MECÁNICA DE MORTEROS Y HORMIGONES FABRICADOS CON ESCORIAS DE INCINERADORAS URBANAS Y SU INFLUENCIA SOBRE LA CORROSIÓN DE LAS ARMADURAS
}

\author{
AUTOR: $\quad$ RITA MARÍA ÁVILA ÁVILA \\ DIRECTORES: Dr. EDUARDO MEDINA SÁNCHEZ \\ Dr. DAVID MARTÍNEZ BASTIDAS
}




\section{AGRADECIMIENTOS}

Deseo agradecer a mis directores de tesis, el Dr. D. Eduardo Medina Sánchez, profesor de la Escuela Técnica Superior de Edificación de Madrid y el Dr. D. David Martínez Bastidas, Investigador de Ramón y Cajal del Centro Nacional de Investigaciones Metalúrgicas CENIM-CSIC, por su apoyo continuo durante estos años de trabajo.

A la Escuela Técnica Superior de Edificación de Madrid y al Departamento de Construcciones Arquitectónicas y su Control, por los medios prestados en todo momento.

Al Laboratorio de Materiales de Construcción de la Escuela, por la disponibilidad y total colaboración, en especial a D. Santiago Villa Ortega, cuyo apoyo y ayuda es fundamental en la elaboración de las probetas tanto de morteros como de hormigones y la realización de los ensayos mecánicos. trabajo.

Al personal del CENIM-CSIC, por su amabilidad para el desarrollo del

A mi familia (a mi madre Transito). 


\section{RESUMEN}

Los Residuos Sólidos Urbanos (RSU) generados en las ciudades se han convertido en el siglo XXI en una preocupación a nivel mundial por el impacto medioambiental que ocasionan. En las estrategias modernas de eliminación de los RSU, es una prioridad el logro de reducir, reutilizar y reciclar (3 R) los mismos.

Una alternativa ventajosa para la reducción tanto de volumen como de masa es la implementación del proceso de incineración de los RSU, donde se obtienen dos subproductos, las cenizas volantes y las escorias. En cuanto a las cenizas, se debe controlar su eliminación como residuo peligroso, aunque pueden ser reutilizadas para la elaboración de cementos. Sin embargo, en el caso de las escorias, hay pocos estudios que aborden su posible reutilización como sustituto del árido natural en la elaboración de hormigones o morteros.

En este trabajo de Tesis Doctoral, se ha estudiado el comportamiento mecánico de morteros y hormigones de cemento Portland elaborados con escorias procedentes de la incineración de Residuos Sólidos Urbanos (RSU) como sustitución total o parcial del árido natural.

Entre otros componentes, las escorias de RSU contienen cloruros, por lo que en este trabajo también se han realizado mediciones electroquímicas, durante un periodo de tres años, para cuantificar su posible influencia en la corrosión de las armaduras, utilizando para ello cuatro aceros corrugados, el tradicional acero al carbono B-500-SD y tres aceros inoxidables: el austenítico AISI 304 (EN 1.4301), el dúplex AISI 2304 (EN 1.4362) y el dúplex de bajo contenido en níquel AISI 2001 (EN 1.4482), embebidos en morteros elaborados sólo con escorias como sustituto del árido natural. Los cuatro aceros han sido embebidos también en moteros elaborados con árido natural (mortero de referencia o convencional) para contrastar los datos con los valores equivalentes.

La utilización de armaduras de acero inoxidable es una alternativa en consideración cada vez mayor para prolongar la vida útil de las estructuras, por su resistencia a la corrosión en ambientes agresivos, incluso con ataques de cloruros. Sin embargo, el alto coste económico de los aceros inoxidables limita su uso, lo que se puede compensar parcialmente si se utilizan aceros dúplex de bajo contenido en níquel, más económicos que los tradicionales austeníticos pero con similar comportamiento mecánico, estructural y frente a la corrosión. 
De los resultados obtenidos en esta Tesis Doctoral se deduce que la utilización como áridos de las escorias procedentes de la incineración de RSU, mejoran sensiblemente las características de resistencia del convencional mortero y hormigón elaborados sólo con árido natural. En cuanto al estudio de corrosión de las armaduras, las mediciones electroquímicas demuestran que los aceros permanecen en estado pasivo durante todo el periodo analizado, tanto el acero al carbono como los aceros inoxidables utilizados. 


\section{ABSTRACT}

Municipal Solid Waste Residues (MSW) residues generated in the cities have become in the 21st century a worldwide concern for the environmental impact they cause. In modern strategies for the elimination of MSW, it is a priority to reduce, reuse and recycle (3R) those MSW.

An advantageous alternative for the reduction of both volume and mass is the implementation of the MSW incineration process, where two by-products, fly ash and slag are obtained. As regard to ashes, their disposal should be controlled as a hazardous waste, although they may be reused for the manufacture of cements. However, in the case of slags, there are few studies that address their possible reuse as a substitute for natural aggregates in the processing of concrete or mortars.

In this Ph.D. Thesis work it has been studied the mechanical behavior of mortars and concretes made with Portland cement mixed with slag from the incineration of MSW as a total or partial replacement of the natural arid.

Among other components, MSW slags contain chlorides, so that in this work electrochemical measurements were also carried out over a three-year period to quantify their possible influence on the corrosion of the reinforcement, using four corrugated steels, the traditional B-500-SD carbon steel, and three stainless steel (SS) grades rebars, austenitic SS AISI 304 (EN 1.4301), duplex AISI 2304 (EN 1.4362) and low nickel duplex AISI 2001 (EN 1.4482), embedded in mortar made only with slag as a substitute for the aggregate natural. The four steels have also been embedded in mortars made with natural arid (used as reference or conventional mortar) for comparative purpose.

The use of SS reinforcements is an alternative in increasing consideration to extend the service lifetime of reinforced concrete structures, for their resistance to corrosion in aggressive environments, even with attack of chlorides. However, the high economic cost of SS rebars limits its use, which can be partially offset by the use of low-nickel duplex SS, which are cheaper than traditional austenitic SS but with similar mechanical, structural and corrosion behavior. 
From the results obtained in this Ph.D. Thesis it is concluded that the use of slag as aggregates from the incineration of MSW, significantly improve the resistance properties of conventional mortar and concrete made only with natural arid. From the corrosion studies performed, the electrochemical measurements showed that the reinforcements remain in passive state throughout the analyzed period, both the carbon steel and the stainless steels used. 


\section{ÍNDICE}

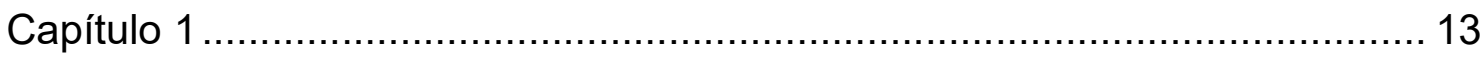

\section{MOTIVACIÓN Y OBJETIVOS}

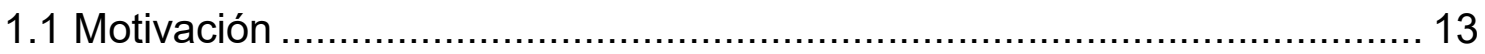

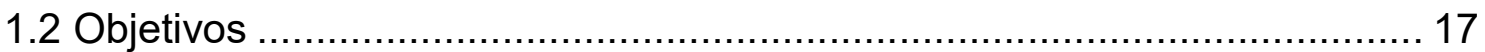

1.3 Hipótesis de partida............................................................ 18

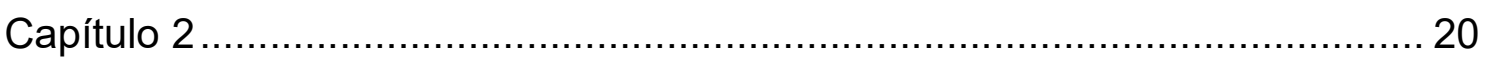

\section{INTRODUCCIÓN}

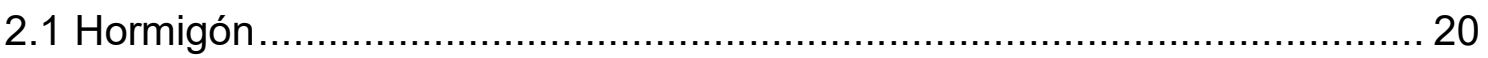

2.2 Otros componentes del hormigón objeto de investigaciones .................... 23

2.2.1 Otras posibles adiciones al cemento, mortero u hormigón ................. 24

2.2.1.1 Escorias de alto horno granuladas ...................................... 24

2.2.1.2 Cenizas volantes de carbón ................................................ 25

2.2.1.3 Cenizas volantes de incineradora de residuos sólidos urbanos .... 26

2.2.1.4 Escorias de incineradora de residuos sólidos urbanos ................. 30

2.2.2 Materiales sustitutos de los áridos naturales ................................. 31

2.2.2.1 Áridos reciclados (procedentes de demoliciones de estructuras de hormigón) f................................................................. 32

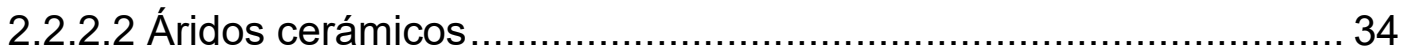

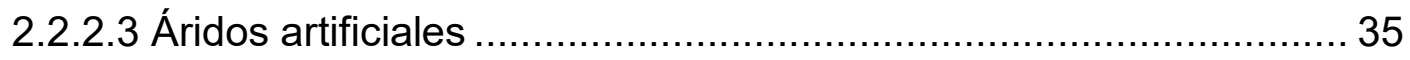

2.3 Escorias de incineradoras de residuos sólidos urbanos, estudios sobre posible reutilización como árido en morteros y hormigones ............40 40

2.3.1 RSU y la incineración............................................................. 41

2.3.1.1 Las incineradoras de RSU ............................................... 44 
2.3.1.2 Las escorias de incineradora de residuos sólidos urbanos 45

2.3.2 Valorización de escorias de incineradoras de RSU 49

2.3.2.1 Inconvenientes para la reutilización de las escorias de RSU como árido 51

2.3.2.2 Solución de inconvenientes para la reutilización de las escorias de RSU como árido 52

2.3.2.3 Condiciones de reutilización de escorias de RSU como árido de hormigón 54

2.3.2.4 Utilización conjunta de cenizas volantes y escorias de RSU en morteros y hormigones 56

2.4 Durabilidad de las estructuras de hormigón armado ............................. 57

2.5 La corrosión de las armaduras de hormigón ........................................ 59

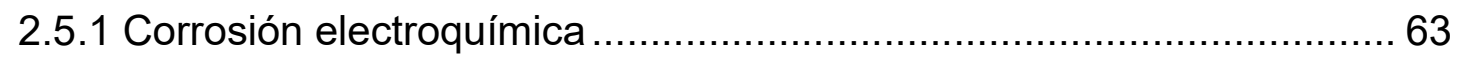

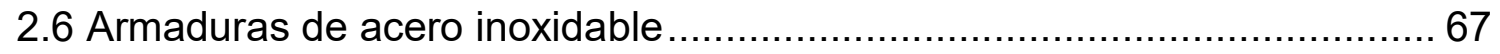

2.6.1 Definición y clasificación de los aceros.......................................... 67

2.6.2 Aceros inoxidables .................................................................... 68

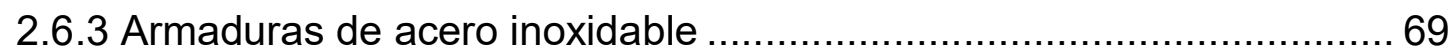

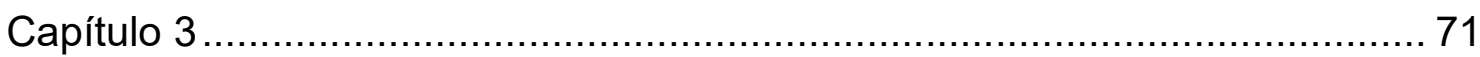

\section{TÉCNICAS EXPERIMETALES}

3.1 Análisis químico de las escorias de RSU ....................................... 71

3.2 Casificiacón granulométrica de las escorias de RSU ............................ 72

3.3 Caracterización mecánica de morteros de cemento Portland ...................73 73

3.3.1 Ensayos de rotura a flexión de morteros ....................................... 73

3.3.2 Ensayos de rotura a compresión de morteros ............................... 74

3.4 Caracterización mecánica de hormigones de cemento Portland.................76 76

3.4.1 Determinación de la consistencia del hormigón............................... 76

3.4.2 Ensayo de resistencia a compresión del hormigón...........................77

3.4.2.1 Comparación de las probetas cilíndricas y cúbicas de hormigón.. 79

3.5 Técnicas electroquímicas para el estudio de la corrosión en las armaduras embebidas en morteros elaborados con escorias de RSU ...... 82

3.5.1 Potencial de corrosión ............................................................ 84

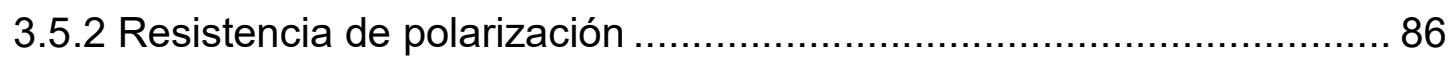


Capítulo 4

TRABAJO EXPERIMENTAL

4.1 Características de las escorias de rsu................................................. 94

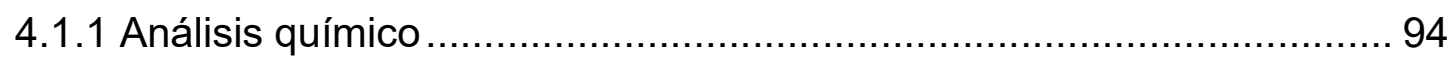

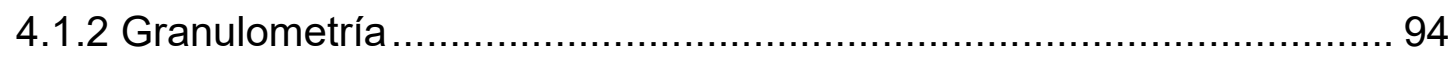

4.2 Estudio de morteros con escorias de RSU ......................................... 95

4.3 Estudio de hormigones con escorias de RSU ................................... 102

4.4 Estudio de corrosión de armaduras embebidas en morteros elaborados

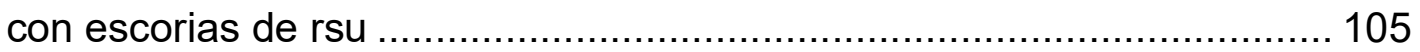

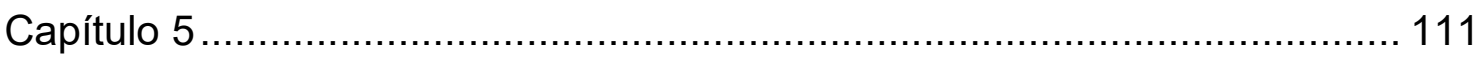

\section{RESULTADOS Y DISCUSIÓN}

5.1 Las escorias de RSU.................................................................... 111

5.1.1 Análisis químico .................................................................... 111

5.1.2 Granulometría ................................................................... 113

5.2 Estudio de morteros con escorias de RSU ....................................... 114

5.3 Estudio de hormigones con escorias de RSU ..................................... 119

5.4 Estudio de corrosión de armaduras embebidas en morteros elaborados con escorias de RSU

Capítulo 6

CONCLUSIONES

Capítulo 7

FUTURAS LÍNEAS DE INVESTIGACIÓN

BIBLIOGRAFÍA 


\section{Capítulo 1}

\section{MOTIVACIÓN Y OBJETIVOS}

\subsection{MOTIVACIÓN}

En una sociedad con problemas medioambientales, ya es real que entre las consecuencias se evidencia el calentamiento del planeta. Hoy se pretende satisfacer las necesidades de la humanidad respetando los recursos naturales, lo que se puede lograr disminuyendo la degradación ambiental, evitando la contaminación entre otros, sobre todo pensando en las próximas generaciones.

La incidencia de la actividad humana sobre el medio ambiente se ha hecho sentir de modo preocupante en diversas ocasiones; el espacio de las actividades se transforma planteándose una problemática compleja en torno a la actividad antrópica como foco y origen principal del proceso. De los numerosos problemas que se derivan de la presencia y actuación del hombre sobre determinadas zonas, se destacan los asociados a los productos materiales, sustancias o desechos que dan lugar a restos o residuos no directamente utilizables por él y que por lo tanto se vierten en el territorio de manera muchas veces incontrolada; surge entonces el problema de la contaminación "presencia y persistencia de materias, cualesquiera que sea su composición, en ambientes que de modo natural no les correspondan" [Otero, I., et al; 1991]

Entre los desechos o los residuos generados por la actividad humana, se encuentran los denominados residuos sólidos urbanos (RSU), siendo necesaria una adecuada gestión de los mismos, adquiriendo mayor importancia cuando la población aumenta, y en las últimas décadas el porcentaje de residuos crecen en mayor cantidad en periodos muy cortos, evidenciándose en las grandes ciudades del mundo.

La Unión Europea ha establecido la normativa de reciclado bajo la Directiva Marco de Residuos (en España están regulados por la Ley 22 de 2011) con la que se pretende lograr una futura sociedad europea más sostenible, para lo que se plantea la reducción en origen de los residuos y el empleo de determinadas corrientes residuales como materias primas. 
Se trata de promocionar el reciclado y el empleo de residuos como fuentes secundarias de productos, reduciendo el consumo de fuentes naturales y limitando la cantidad de residuos depositados en vertederos.

Sin embargo, el tratamiento y la eliminación de los RSU sigue siendo complejo, y requiere tomar medidas para evitar perjudicar el medio ambiente y la salud de las personas, en cuestiones como son los malos olores en el vertedero, la posible explosión resultante de gases combustibles y la contaminación de las aguas subterráneas y del suelo por compuestos orgánicos peligrosos y metales pesados [Li, M., et al; 2004].

Una solución para minimizar las altas cantidades de RSU, es la incineración, que es considerada artificial en cuanto al volumen, la reiteración o las temperaturas que la caracterizan. Es un tratamiento que cada vez se aplica más, sobre todo en los países más desarrollados, donde los porcentajes de incineración pueden variar rápidamente. Este cambio se produce como consecuencia del cambio de los hábitos de consumo, unida a la mejora de la calidad de vida y a determinadas técnicas de ventas, que conlleva el aumento de los embalajes, elevando el contenido en componentes combustibles de los RSU.

Desde el punto de vista económico, los costes de las incineradoras son importantes, pero en la mayoría de los casos suelen resultar menores que su eliminación en vertederos. Al evolucionar las tecnologías de la incineración, se garantiza la correcta eliminación de RSU, cumpliendo las normativas más exigentes [Saiz de Omecaña, J.A. y Saiz de Omecaña, J.; 1996].

En la incineración de los RSU no reciclables se obtienen dos subproductos, las escorias y las cenizas volantes. Las escorias constituyen entre el 75 y el $80 \%$, y las cenizas volantes el resto. Las escorias son los residuos que quedan en el fondo del horno después de la combustión, son de color grisáceo y tienen apariencia porosa, contienen pequeñas cantidades de materia orgánica residual, trozos de vidrio, cerámica, minerales y metales. Se consideran residuos no peligrosos, ricas en óxido de calcio y sílice con cantidades mínimas de metales pesados.

Las cenizas volantes son partículas muy finas arrastradas por la corriente de gases al exterior de la cámara de combustión [Siddique, R.; 2010 a], con temperatura superiores a $850^{\circ} \mathrm{C}$, y se componen de partículas finas con un alto contenido de metales pesados, compuestos orgánicos y cloruros. Se clasifican como residuos peligrosos y requieren una gestión adecuada para reducir al mínimo su efecto sobre el medio ambiente [Ginés, O., et. al; 2009].

Las características físicas y químicas de las escorias y las cenizas volantes dependen de muchos factores, además de la propia composición original de los RSU, como son las condiciones de operación de la incineración, el dispositivo de control de contaminación del aire y la eficacia de la combustión 
[Li, M., et al; 2004] y el tipo de horno de combustión, que puede ser de parrilla, rotativo o en lecho fluidizado.

En algunos países europeos como es el caso de Alemania y Dinamarca, se generó la necesidad de reutilizar las escorias de RSU por falta de espacio para el vertido.

Después de algunas investigaciones, las escorias se comenzaron a utilizar en cantidades considerables en diferentes aplicaciones tales como bases de carreteras, terraplenes o bloques de hormigón prefabricados, en todos los casos después de un tratamiento previo. En los Países Bajos, las escorias son reutilizadas en porcentajes inferiores [CEDEX; 2007].

Sin embargo, en España aún es bajo el porcentaje reutilizado de escorias, y de seguir así, a medio plazo será necesario espacio adicional para su depósito. Actualmente, las escorias son usadas mayoritariamente en España en subbases de carreteras y soleras de hormigón [Castell, X.E.; 2000].

Algunas posibles aplicaciones tanto de las cenizas volantes como de las escorias de RSU, según los estudios de Polettini, A., et al. (2001) y Aubert, J.E., et al. (2006) han demostrado que el cemento mantiene su resistencia con una adición máxima del $20 \%$ de cenizas volantes de RSU [Polettini, A., et al; 2001] [Aubert, J.E., et al; 2006].

Y el estudio realizado por los autores Goñi, S., et al. (2011), en la viabilidad de obtener fases cementantes ("cementos ecoeficientes" o "amigables" con el medio ambiente), a partir de materia prima secundaria, donde se ha utilizado muestras de escorias y cenizas volantes de dos incineradoras españolas de RSU, donde el innovador proceso favorece el desarrollo sostenible de la industria, el proceso implica una rebaja de temperatura de clinkerización $\left(>1100^{\circ} \mathrm{C}\right)$ y minimización de las emisiones de $\mathrm{CO}_{2}$ [Goñi, S., et al; 2011].

La reutilización más extendida actualmente de las escorias es como sustitutos de áridos para las sub-bases de carreteras, pero otra posible es como árido para hormigón. Rashid, R.A. y Frantz, G.A. (1992).

Al igual que Pera, J., et al. (1997) demuestran que una sustitución de grava natural de hasta un $50 \%$ por escorias es posible sin afectar a la durabilidad o la resistencia del hormigón, [Rashid, R.A. y Frantz, G.A.; 1992] [Pera, J., et al; 1997], y Juric, B., et al. (2006) consideran aceptable reemplazar en la elaboración del hormigón el $15 \%$ de cemento por escorias molidas [Juric, B., et al; 2006]. 
Entre los beneficios de reutilizar las escorias de incineradoras como árido, están la reducción de la explotación de las canteras para obtener la arena natural, que se hace a través de minería a cielo abierto, reducir el consumo de energía utilizada (por la maquinaria), y minimizar el impacto en el paisaje, en el medio, la modificación topográfica, la pérdida de suelo, la contaminación atmosférica (polvo y gases), la contaminación acústica, la contaminación de las aguas (superficiales y subterráneas) y del aire; y la afección a los ecosistemas.

Por lo tanto, la aplicación eficaz de la reutilización de las escorias permitirá disminuir o mitigar los impactos negativos generados en la explotación de áridos (arena y grava), reducir las escorias de incineradoras de RSU arrojadas a vertederos y finalmente analizar nuevas fuentes de productos en la elaboración del hormigón, todo ello en beneficio y contribución al desarrollo sostenible y la conservación del medio ambiente.

En las últimas décadas, la construcción de estructuras de cualquier tipo ha sido mayoritariamente de hormigón armado, gracias a su menor coste económico, su versatilidad y mínimo mantenimiento, lo que lo han convertido en el material más empleado. Pero a la vez exige un exhaustivo control tanto de los materiales que lo componen como de su ejecución y puesta en obra, para garantizar la vida útil para la que ha sido proyectado. Uno de los principales problemas a este respecto es la corrosión de las armaduras embebidas en el hormigón, especialmente en las estructuras expuestas a agentes agresivos, lo que influye de manera negativa en su durabilidad. La corrosión de las armaduras también genera graves problemas medioambientales y económicos.

En este trabajo de Tesis Doctoral, se evalúa la caracterización mecánica de morteros y hormigones fabricados con escorias de RSU sustituyendo parcial o totalmente los áridos naturales y la influencia de las escorias en la corrosión de las armaduras. 


\subsection{OBJETIVOS}

El objetivo de la presente Tesis Doctoral es estudiar la caracterización mecánica de morteros y hormigones elaborados con escorias de incineradoras de RSU y su influencia sobre la corrosión de las armaduras. Para lo cual se harán los siguientes estudios:

- Estudio de morteros elaborados con escorias de RSU, con el fin de ensayar la resistencia a flexión y a compresión, de probetas de mortero endurecido, elaboradas para comprobar si se puede utilizar como sustitución del árido natural las escorias de incineradora de RSU (granulometría similar de la arena) con varias dosificaciones.

- Estudio de hormigones elaborados con escorias de RSU, para comprobar cómo influye en la resistencia a compresión en diferentes edades de curado, las probetas de hormigón elaboradas con diferentes porcentajes de escorias de incineración de RSU en sustitución de la arena y la grava.

- Estudio de la corrosión de armaduras embebidas en morteros elaborados con escorias de RSU, para medir la resistencia a la corrosión de barras corrugadas del tradicional acero al carbono B-500-SD y barras corrugadas de los tres aceros inoxidables AISI 2001, AISI 304 y AISI 2304, embebidas en probetas de mortero elaboradas con cemento Portland y escorias finas. Durante el periodo de tres años se realizarán las mediciones electroquímicas para comparar los resultados obtenidos entre los cuatro aceros. El estudio se ha llevado a cabo monitorizando el potencial de corrosión y aplicando el método de la resistencia de polarización lineal. 


\subsection{HIPÓTESIS DE PARTIDA}

Las escorias se podrían utilizar como sustitución del árido natural (arena o grava), en dosificación total o parcial para la elaboración de morteros y de hormigones armados. En función de cómo varíen las resistencias mecánicas de las probetas con diferentes porcentajes de escorias de RSU, se determinará cuál es la dosificación de escorias más adecuada, por los siguientes motivos:

- Son residuos que quedan en el fondo del horno después de la combustión, son de color grisáceo y tienen apariencia porosa, y contienen pequeñas cantidades de materia orgánica residual, trozos de vidrio, cerámica, minerales y metales. Se consideran residuos no peligrosos, ricas en óxido de calcio y sílice con cantidades mínimas de metales pesados [Del ValleZermeño, R., et al; 2013].

- Actualmente, la práctica más extendida para la reutilización de las escorias de RSU es su utilización como sustitutos de áridos naturales para las sub-bases de carreteras. Otra reutilización posible de las escorias es como áridos para el hormigón. Rashid, R.A. y Frantz, G.A. (1992), al igual que Pera, J., et al. (1997) demuestran que una sustitución de grava natural de hasta un $50 \%$ por escorias es posible sin afectar a la durabilidad o la resistencia del hormigón [Rashid, R.A. y Frantz, G.A.; 1992] [Pera, J., et al; 1997].

- Sin embargo, Pera, J., et al. (1997) especifica que al mezclar directamente las escorias en el hormigón se presentan problemas de hinchazón y agrietamiento por la reacción entre el cemento y el aluminio, por lo tanto, han propuesto un tratamiento con hidróxido de sodio mediante la inmersión de las escorias durante 15 días previo a su reutilización [Pera, J., et al; 1997]. El reciclado previo de los embases de aluminio elimina este problema.

- Otros investigadores como Juric, B., et al. (2006) han estudiado reemplazar en la elaboración del hormigón parcialmente el cemento por escorias (molidas convenientemente), donde la sustitución de hasta un $15 \%$ se considera aceptable [Juric, B., et al; 2006] [Ginés, O., et al; 2009].

- Reutilizar las escorias de RSU por su composición tanto química como física bien definida y por ser un producto ambientalmente seguro, en aplicaciones de construcción (como material secundario) es una opción viable [Chimenos, J.M., et al; 2003], [Del Valle-Zermeño, R., et al; 2014b]. 
En cuanto a las armaduras del hormigón se tendrán en consideración la influencia que podrían tener en ellas las escorias de RSU, por los siguientes aspectos:

- Tradicionalmente se utiliza el acero al carbono en las estructuras de hormigón armado, pero el uso de las escorias de RSU, debido al contenido en cloruros (en diversos porcentajes según su origen) puede aumentar el riesgo de corrosión de las armaduras.

Por esta razón, se contempla la opción de utilizar armaduras de acero inoxidable para aumentar la durabilidad de las estructuras de hormigón elaboradas con escorias de RSU.

- Al no existir riesgo de corrosión galvánica por contacto entre el acero al carbono y el acero inoxidable [Abreu, C.M., et al; 2002] [Qian, S.; 2006] [Pérez-Quiros, J.T., et al; 2008], es viable la combinación de ambos tipos de armadura en la misma estructura para abaratar costes, utilizando las de acero inoxidable con aquellos hormigones elaborados con escorias de RSU con una considerable cantidad de cloruros (de acuerdo a un análisis químico de las escorias que se realizara previamente a su reutilización). 


\section{Capítulo 2}

\section{INTRODUCCIÓN}

\subsection{HORMIGÓN}

El hormigón es una piedra artificial formada por áridos naturales (grava y arena) cementados por una pasta conglomerante hidráulica. La pasta conglomerante hidráulica más usada son los cementos, y se llaman hidráulicos porque fraguan tanto expuestos al aire como sumergidos en agua y a temperatura ambiente. El hormigón puede contener adiciones y aditivos que mejoran sus cualidades.

La normativa vigente que regula las estructuras de hormigón en España, publicada en el año 2008 mediante el Real Decreto 1247/2008, es la Instrucción de Hormigón Estructural (EHE-08) [Comisión Permanente del Hormigón; 2008].

Los componentes del hormigón son:

- Áridos: los áridos son materiales minerales, sólidos e inertes (rocas obtenidas en procesos industriales), que deben tener granulometrías adecuadas para ser empleados en la elaboración del hormigón [López, C.; 1994].

Según el art. 28 de la EHE-08, se pueden emplear áridos gruesos (gravas de tamaños entre 2 a $64 \mathrm{~mm}$ ), áridos finos (arenas de tamaños entre 0,063 a $4 \mathrm{~mm}$ ), y de acuerdo a la UNE-EN 12620, rodados o procedentes de rocas machacadas, así como escorias siderúrgicas enfriadas por aire y, en general, cualquier otro tipo de árido cuya evidencia de buen comportamiento haya sido confirmado por la práctica y justificado debidamente.

- Cemento: la fabricación del cemento es un proceso en el que las materias primas minerales se trituran y muelen, está mezcla da lugar al clinker formando minerales sintéticos que le dan las propiedades hidráulicas al cemento. 
Los cementos en España están regulados por la $R C$-08 que coincide con las normas UNE y armoniza los cementos españoles con la normativa europea. Los cementos Portland se obtienen por molturación conjunta de clínker y piedra de yeso natural en pequeñas cantidades, la cual se añade al clínker para regular el fraguado del mismo. De acuerdo a los componentes del cemento, se distinguen varios tipos:

- Cementos tipo I (Portland puro): los componentes del cemento son únicamente clínker y piedra de yeso.

- Cementos tipo II (Portland con adiciones): se sustituye una parte de clínker por escorias siderúrgicas, humo de sílice, puzolana, ceniza volante o filler calizo.

- Cementos tipo III (De horno alto), tipo IV (Puzolánicos) y tipo V (Compuestos).

De los cementos mencionados anteriormente, los que más interesan son los cementos Portland con adiciones (tipo II), por ser los más empleados en estructuras de hormigón armado en edificación. Según la EHE-08, el cemento debe ser capaz de proporcionar al hormigón las características exigidas, y ser conformes con la reglamentación especifica vigente, que cumplan las limitaciones de uso establecidas y pertenezcan a la clase resistente 32,5 o superior.

- Agua: para la preparación del hormigón es necesario el agua, que es utilizada tanto para el amasado, como para el curado del hormigón en obra, no debe contener ningún ingrediente en cantidades tales que perjudiquen las propiedades del hormigón o a la protección de las armaduras frente a la corrosión.

- Adiciones: son productos que se añaden al hormigón o, preferiblemente, al clínker Portland, para mejorar algunas de sus propiedades. El empleo de estas adiciones tiene ventajas medioambientales al ser residuos 0 productos secundarios. La EHE-08, en el momento de la fabricación del hormigón únicamente contempla la utilización de:

- Cenizas volantes: se producen en centrales termoeléctricas que queman carbones pulverizados, son residuos sólidos que se recogen de los polvos que acompañan a los gases de combustión, la cantidad máxima de adición es el $35 \%$ del peso del cemento.

Los beneficios en el hormigón son: reducción del coste, mejoran la trabajabilidad y la impermeabilidad, aumenta la resistencia a los ataques químicos, disminuye la resistencia inicial y aumenta la final. Cuando se utilizan las cenizas volantes es necesario que se cumpla el artículo 29.2 de la EHE. 
- Humo de sílice: es un subproducto que se recoge en los filtros electrostáticos de los hornos eléctricos que produce silicio y ferrosilicio a partir del cuarzo, la cantidad máxima adicionada no excederá el $10 \%$ del peso del cemento.

Las propiedades aportadas al hormigón son: una elevada compacidad y aumento de la resistencia mecánica, aunque puede reducir el $\mathrm{pH}$ del hormigón, por lo que disminuye la protección de las armaduras en ambientes con carbonatación.

Es de destacar que las adiciones hacen que el hormigón sea más sensible al curado, pero realizándose correctamente se consigue un hormigón más impermeable y durable.

- Aditivos: son sustancias o productos, ya sean pulverulentos o líquidos, que incorporados al hormigón antes del amasado, en una proporción no superior al $5 \%$ del peso del cemento, producen la modificación deseada, en estado fresco o endurecido del hormigón, de alguna de las características, propiedades o comportamientos.

En los hormigones armados o pretensados no podrán utilizarse como aditivos el cloruro cálcico, ni en general, productos en cuya composición intervengan cloruros, sulfuros, sulfitos u otros componentes químicos que puedan ocasionar o favorecer la corrosión de las armaduras (EHE-08).

La resistencia a compresión del hormigón depende de diversos factores como la cantidad y tipo de cemento, aditivos y adiciones empleados, dosificación en general y las características de los áridos.

Las propiedades que definen las características y calidad del hormigón son: su elevada resistencia a la compresión y la durabilidad frente a numerosos medios naturales e industriales.

El hormigón al ser un material pétreo trabaja muy bien a compresión, pero es poco apto en el trabajo a tracción, su empleo en construcción hace necesario utilizarlo con otro material que resista bien a las tracciones, como las barras corrugadas, ofreciendo unas propiedades excepcionales para la industria de la construcción.

La unión acero-hormigón permite aprovechar la elevada resistencia a tracción del acero con la resistencia a compresión del hormigón, que resisten esfuerzos tanto a flexión, como a compresión. Actualmente la resistencia más utilizada en el hormigón, es de $25 \mathrm{~N} / \mathrm{mm}^{2}$ y el acero más empleado en estructuras de hormigón tiene una resistencia de $500 \mathrm{~N} / \mathrm{mm}^{2}$ [Medina, E.; 2009]. 
El coste relativamente bajo de los componentes del hormigón armado, unido a la ilimitada adaptabilidad para las formas más diversas, logran que pueda aplicarse en casi todo tipo de construcciones, compitiendo con la piedra, el acero y la madera [Miranda, M. y López, W.; 1988].

Entre las características responsables del éxito del hormigón como material para construir estructuras de edificación o de obra civil están:

- Protección frente a la corrosión de las armaduras convencionales de acero al carbono.

- Coeficiente de dilatación del hormigón similar al acero, siendo despreciables las tensiones internas por cambio de temperaturas.

- Se genera un fenómeno de confinamiento con el hormigón que rodea a las barras de acero, impidiendo el pandeo, optimizando el empleo estructural.

\subsection{OTROS COMPONENTES DEL HORMIGÓN OBJETO DE INVESTIGACIONES}

El reciclaje de los residuos industriales, como materia prima secundaria en la fabricación del hormigón es de interés creciente en todo el mundo, debido al alto impacto ambiental tanto de los residuos como de la industria del cemento y del hormigón, y por el aumento de la demanda de infraestructuras en los países industrializados y en vía de desarrollo, lo que eleva considerablemente el consumo de materias primas.

En la tecnología del hormigón se pueden emplear grandes cantidades de residuos industriales como materias primas secundarias. Ejemplo de ello son los cementos clínker producidos con adición de cenizas volantes de carbón, el humo de sílice, o las escorias de alto horno granuladas.

Estas adiciones minerales, que empezaron a utilizarse inicialmente para reciclar desechos, han resultado beneficiosas con respecto a las propiedades del hormigón, si se sustituye parte activa del clínker, por las adiciones minerales, permiten ahorrar energía y materias primas en la fabricación del cemento, reduciendo la contaminación atmosférica [Bertolini, L.; 2004]. 


\subsubsection{OTRAS POSIBLES ADICIONES AL CEMENTO, MORTERO U HORMIGÓN}

Además de las cenizas volantes y el humo de sílice citados antes, que se utilizan como adición en la elaboración de los cementos, hay otros posibles materiales o productos que pueden utilizarse, o son objeto de investigaciones, como adición al cemento o como componentes de los morteros y los hormigones, como son las escorias granuladas de horno alto, las cenizas volantes del carbón, las cenizas volantes de incineradoras de residuos sólidos urbanos y las escorias de incineradora de residuos sólidos urbanos.

\subsubsection{Escorias de alto horno granuladas}

Dichas escorias son generadas en la industria siderúrgica (en la fusión y reducción de mineral de hierro). Del horno a $1.500^{\circ} \mathrm{C}$ salen dos productos, el arrabio y las escorias, que son separados por su diferente densidad. Las escorias se vierten después en balsas de agua, enfriándolas bruscamente, por lo que se pulverizan [Medina, E.; 2009]. Está técnica da origen a las escorias granuladas, que sirven de adición del cemento [CEDEX; 2011].

La producción de acero a partir del siglo XIX, ha llevado a una descompensación entre los productos fabricados y las escorias generadas en las industrias siderúrgicas, donde se evidencia una falta de reutilización de dichas escorias, y en la actualidad generan un problema importante medioambiental al permanecer en vertederos durante años.

La sensibilización social respecto a los problemas ambientales, han hecho que sea necesario la incorporación en el proceso productivo de nuevas técnicas que permitan el reciclaje de los productos generados en la fabricación del acero, para integrarlos en la producción de nuevos productos.

Pero a nivel económico se presentan inconvenientes por la importante inversión de las acerías y por la transformación de las escorias en reutilizables a un coste razonable.

En la industria siderometalúrgica las materias primas utilizadas son minerales de hierro (oligisto y limonita) o hierro procedente de elementos reciclados. En este proceso se generan diferentes residuos de escorias siderúrgicas, polvos de acería, cascarillas de laminación, arenas de fundición y material refractario.

Las escorias siderúrgicas presentan un primer problema por falta de homogeneidad, dependiendo del proceso de fabricación, tipo de técnica y de los diferentes productos fabricados (hierro, acero al carbono, fundiciones, etc.), lo que produce escorias con diferente composición, características y propiedades. 
La escasa estabilidad volumétrica es otro factor que dificulta su aprovechamiento [Moth, H. y Geiseler. J.; 2001].

Los estudios realizados por Bakker, R. (1980) y Mehta, P. (1981), han demostrado que algunas escorias granuladas de alto horno de hierro trituradas, ya sea cuando se utilizan en el cemento mezclado o cuando se adicionan al hormigón en la mezcladora, aumentan considerablemente la expectativa de vida del hormigón expuesto a ataques por sulfatos. Muchas escorias reducen significativamente la permeabilidad del hormigón [Bakker, R.; 1980] [Mehta, P.; 1981].

De acuerdo a las técnicas empleadas en el proceso de enfriamiento, se obtienen materiales con características de utilización diferenciada entre ellas las escorias granuladas que son reutilizadas en los cementos, en obras en edificación y obra pública, como ejemplo están:

- $\quad$ La ampliación del Puerto de Bilbao.

- Obras de Saneamiento y Abastecimiento del Consorcio de Aguas de Bilbao

- Recrecimiento del Canal de Lodosa entre otras [CEDEX; 2011].

\subsubsection{Cenizas volantes de carbón}

Las cenizas volantes de carbón, al igual que las escorias son residuos, originadas en centrales termoeléctricas. Definidas según la norma española UNE-EN 450-1 [AENOR; 2013], como "un polvo fino con partículas principalmente esféricas, cristalinas, originadas por la combustión del carbón pulverizado, con o sin materiales de co-combustión, que tiene propiedades puzolánicas y que está compuesto fundamentalmente de $\mathrm{SiO}_{2}$ y $\mathrm{Al}_{2} \mathrm{O}_{3}$ ".

Cuando están secas, las cenizas volantes presentan un aspecto arenoso o polvo muy fino, suave al tacto y de color gris más o menos claro. Entre el $80 \%$ y $95 \%$ de las partículas tienen tamaño de limo.

Las cenizas volantes de carbón también se caracterizan por un alto contenido de cloruros superior al $10 \%$ y cantidades significativas de sustancias peligrosas, metales pesados y compuestos orgánicos. Para desechar las cenizas volantes de carbón en un vertedero es necesario antes tratarlas en una matriz de cemento, orgánica o vítrea [Bertolini, L., 2004]. 
En EE.UU, se utilizan las cenizas volantes de carbón en un porcentaje considerable en la industria del cemento, como materiales complementarios en el hormigón. La sustitución de un porcentaje de cemento Portland por cenizas volantes de carbón, es beneficioso porque mejora la manipulación y el rendimiento de los materiales de hormigón, reduciendo la necesidad de producción de cemento natural.

En los cementos hidráulicos se permite el reemplazo del $21 \%$ a $35 \%$ por las cenizas volantes de carbón con la denominación europea CEM II / BV. Los niveles de reemplazo de las cenizas volantes en la industria del hormigón estadounidense oscilan entre el $15 \%$ y el $25 \%$ de la fracción total del cemento [ACl, 1993]; y cuando se utilizan grandes cantidades de hormigón, el reemplazo de cemento por cenizas volantes aumenta, para minimizar el agrietamiento, y el ataque de sulfato o reacciones alcali-silicato [ACl, 2003] [Kosson, D., et al; 2015].

En España los datos de producción y reutilización del volumen de residuos correspondiente a cenizas volantes de carbón, fueron de 916.000 toneladas en el año 2010. La utilización de dicho residuo para el mismo año en construcción y carreteras, fue de 761.000 toneladas sobre el total producido. El sector cementero, es con gran diferencia el principal cliente de las cenizas.

En España se ha utilizado cenizas volantes de carbón en:

- Las obras de conservación y rehabilitación del Jardín "El Capricho" (s. XVIII) en la Alameda de Osuna (Madrid), es un caso de aplicación de morteros con cenizas volantes en obra.

- En la construcción de la Torre Picasso de Madrid, de 171 m de altura, donde se empleó hormigón bombeado con adición de cenizas volantes, cuya dosificación variaba en función de la altura [CEDEX; 2011].

\subsubsection{Cenizas volantes de incineradora de residuos sólidos urbanos (RSU)}

Una vez incinerados los RSU producen subproductos, uno de ellos son las cenizas volantes que están en el aire, son partículas muy finas arrastradas por la corriente de gases al exterior de la cámara de combustión y se recogen en el electrofiltro. Terminado el proceso de incineración, las cenizas volantes constituyen entre el $20 \%$ y el $25 \%$ del total de los subproductos [Siddique, R.; $2010 \mathrm{a}-\mathrm{b}]$.

Las cenizas volantes suele ser un material de color gris a negro ó gris oscuro, cuyas partículas finas por lo general contiene altos niveles de metales pesados tóxicos como plomo y compuestos de cadmio, así mismo contiene materiales orgánicos (dioxinas) y cloruros con un contenido incluso superior a un $10 \%$. 
Las cenizas volantes son consideradas un residuo peligroso, que debe ser estabilizado correctamente antes de la disposición final en vertederos controlados. Pero el tratamiento de las cenizas volantes de RSU se hace de acuerdo a la legislación vigente de cada país [Ginés, O., et al; 2009].

Las cenizas volantes requieren una gestión adecuada para reducir al mínimo su efecto sobre el medio ambiente, por lo tanto, es importante controlar la contaminación del aire, contaminantes orgánicos y sales alcalinas en forma de polvo [Del Valle-Zermeño, R., et al; 2013].

Las cenizas volantes de RSU tienen cierta analogía con las adiciones minerales tradicionales (cenizas volantes de carbón y humo de sílice ó escorias de alto horno granuladas) [Bertolini, L.; 2004]. Aunque la composición de las cenizas volantes de RSU puede variar por la tecnología empleada en el proceso de incineración [Ginés, O., et al; 2009], su calidad depende en gran medida de la naturaleza de los residuos, del equipo de combustión y del dispositivo de control de la contaminación del aire.

Analizando la composición química de las cenizas volantes, se puede comprobar que es muy similar a la composición del clínker de cemento Portland, sobre todo respecto a los componentes mayoritarios ( $\mathrm{CaO}, \mathrm{SiO}_{2}, \mathrm{Fe}_{2} \mathrm{O}_{3}$ y $\mathrm{Al}_{2} \mathrm{O}_{3}$ ) [Pan, J.R.; 2008]. Aunque otros autores han encontrado valores inferiores y en el $\mathrm{Al}_{2} \mathrm{O}_{3}$, incluso superiores. En la Tabla 2.1 se resume la composición aportada por diferentes autores.

De igual manera en la misma tabla, de acuerdo a los datos obtenidos en los años 2007, 2008, 2009 y 2013, se refleja que el Cl varía entre 16,80\% y $8,38 \%$ independientemente del país de origen. 
Tabla 2.1 Comparación de composición química [\%] de las cenizas volantes de RSU, según algunos investigadores.

\begin{tabular}{|c|c|c|c|c|c|c|c|}
\hline \multirow{3}{*}{$\begin{array}{l}\text { Literatura } \\
\text { Año } \\
\text { Origen }\end{array}$} & \multirow{3}{*}{$\begin{array}{c}\begin{array}{c}\text { Bertolini, } \\
\text { L. }\end{array} \\
2004 \\
\text { Udine } \\
\text { (Italia) }\end{array}$} & \multirow{2}{*}{\multicolumn{2}{|c|}{$\frac{\text { Goñi, S. et al. }}{2007}$}} & \multirow{3}{*}{$\begin{array}{c}\text { Pan, J.R. } \\
2008 \\
\text { Hsinchu } \\
\text { (Taiwán) }\end{array}$} & \multirow{3}{*}{$\begin{array}{l}\text { Ing-Jia, } \\
\text { C. } \\
2009 \\
\begin{array}{c}\text { Taoyuan } \\
\text { (Taiwán) }\end{array}\end{array}$} & \multicolumn{2}{|c|}{$\begin{array}{l}\text { Chimenos, J.M. } \\
\text { et al. }\end{array}$} \\
\hline & & & & & & 2009 & 2013 \\
\hline & & $\begin{array}{l}\text { Valdemingómez } \\
\text { (Madrid) }\end{array}$ & $\begin{array}{l}\text { Melilla } \\
\text { (España) }\end{array}$ & & & \multicolumn{2}{|c|}{$\begin{array}{c}\text { Tarragona } \\
\text { (España) }\end{array}$} \\
\hline $\mathrm{SiO}_{2}$ & 14,71 & 14,40 & 12,80 & 13,60 & 5,55 & 6,35 & 6,19 \\
\hline $\mathrm{CaO}$ & 37,32 & 44,90 & 23,40 & 45,42 & 40,40 & 43,05 & 38,74 \\
\hline $\mathrm{Cl}$ & - & 13,00 & 16,80 & 9,73 & 14,40 & 8,38 & 14,78 \\
\hline $\mathrm{Fe}_{2} \mathrm{O}_{3}$ & 2,60 & 1,10 & 1,80 & 3,83 & 0,51 & 0,63 & 0,75 \\
\hline $\mathrm{Na}_{2} \mathrm{O}$ & 11,34 & 2,00 & 9,40 & 4,16 & 3,45 & 5,80 & 6,57 \\
\hline $\mathrm{Al}_{2} \mathrm{O}_{3}$ & 10,72 & 11,30 & 10,00 & 0,92 & 0,77 & 3,50 & 3,64 \\
\hline $\mathrm{MgO}$ & 3,30 & 1,90 & 3,10 & 3,16 & 0,15 & 1,38 & 1,26 \\
\hline $\mathrm{K}_{2} \mathrm{O}$ & 6,94 & 2,60 & 4,90 & 3,85 & 3,91 & 4,59 & 5,34 \\
\hline $\mathrm{SO}_{3}$ & 8,49 & 3,90 & 7,60 & 6,27 & 4,40 & 4,64 & 7,10 \\
\hline $\mathrm{P}_{2} \mathrm{O}_{5}$ & 1,55 & - & - & 1,72 & 0,89 & - & 1,06 \\
\hline $\mathrm{MnO}_{2}$ & 0,05 & - & - & - & - & - & - \\
\hline $\mathrm{CuO}$ & - & - & - & 0,25 & - & - & - \\
\hline $\mathrm{ZnO}$ & - & - & - & 2,32 & - & 1,41 & 1,04 \\
\hline $\mathrm{Zn}(\mathrm{g} / \mathrm{kg})$ & - & 3,60 & 6,20 & - & - & - & - \\
\hline $\mathrm{Cd}(\mathrm{g} / \mathrm{kg})$ & - & 0,01 & 0,00 & - & - & - & - \\
\hline $\mathrm{TiO}_{2}$ & - & - & - & 3,12 & 0,31 & - & 0,99 \\
\hline $\mathrm{PbO}$ & - & - & - & 0,57 & - & - & 0,18 \\
\hline $\mathrm{Pb}(\mathrm{g} / \mathrm{kg})$ & - & 3,80 & 2,20 & - & - & - & - \\
\hline $\mathrm{Cr}_{2} \mathrm{O}_{3}$ & - & - & - & 0,19 & - & - & - \\
\hline $\mathrm{NiO}$ & - & - & - & $\mathrm{Nd}$ & - & - & - \\
\hline $\mathrm{Br}$ & - & - & - & 0,35 & - & - & - \\
\hline
\end{tabular}

Los residuos peligrosos, por su composición química requieren un proceso previo de separación, solidificación/estabilización y tratamiento térmico [Del Valle-Zermeño, R., et al; 2013].

Los métodos térmicos pueden suponer costes elevados [Quina, M.J., et al; 2008], son tres:

- El método de sinterización: consiste en aumentar la temperatura hasta que los componentes químicos puedan lograr una reconfiguración. Las temperaturas de este rango suelen estar entre $900^{\circ} \mathrm{C}$ a $1000^{\circ} \mathrm{C}$, y se obtiene un producto más denso. 
- El método de vitrificación: en este método el material se funde con aditivos, para fijar los contaminantes en la matriz final. Las temperaturas implicadas son de $1100^{\circ} \mathrm{C}$ a $1500^{\circ} \mathrm{C}$, el material se enfría para formar una fase sólida. Es un tratamiento caro, que no se aplica de manera generalizada.

- El método de fusión: es un proceso similar al de vitrificación, pero no se utilizan aditivos, y el cristal formado puede no ser homogéneo. Según Sakai, S. y Hiraoka, M. (2000), el sistema de fusión se divide en dos: sistemas de combustión de fusión y sistemas de fusión eléctricos [Sakai, S. y Hiraoka, M.; 2000].

Las aplicaciones posibles de las cenizas volantes de RSU se encuentran en el reemplazo de algún componente en la producción de cemento, mortero, u hormigón entre otros, de la siguiente manera:

- Cemento: Las cenizas volantes de RSU se utilizan como tratamiento base del cemento, es la práctica más extendida, no solo por factores económicos, sino por su fácil aplicación. Se ha evaluado la relación estabilidad/solidificación entre cenizas volantes y cemento Portland, se considera el efecto de la carbonatación como una manera de estabilizar la disposición final.

Otros investigadores Alba, N., et al. (2002) y Saikia, N., et al. (2007) han demostrado que en la producción de cemento se puede emplear entre un $30 \%-40 \%$ de cenizas volantes.

Sin embargo, otros estudios de Polettini, A., et al. (2001) y Aubert, J.E., et al. (2006) han señalado que el cemento mantiene su resistencia con un máximo de $20 \%$ de cenizas volantes (depende de la tecnología aplicada en la producción y la naturaleza de las mismas) [Polettini, A., et al; 2001] [Aubert, J.E., et al; 2006].

- Mortero: las cenizas volantes de RSU, se podrían emplear adecuadamente como reemplazo parcial del cemento en el mortero. La sustitución parcial de hasta el $10 \%$ no afecta significativamente a la resistencia a comprensión del mortero y del cemento, tampoco afecta la contracción y la pérdida de masa.

La sustitución de cemento por cenizas volantes de RSU, en mortero aumento considerablemente el flujo y los tiempos de fraguado inicial y final, existe un aumento dramático en los tiempos de fraguado cuando se incrementa del $10 \%$ al $15 \%$ el contenido [Siddique, R.; 2010 b].

- Hormigón: según Collivignarelli, C. y Sorlini, S. (2002) se ha demostrado la posibilidad de elaborar un hormigón con una resistencia a la compresión superior a $15 \mathrm{MPa}$ reemplazando árido natural por escorias y cenizas 
volantes de RSU es factible. Incluyendo el uso innovador en la producción de hormigón polimérico, los resultados han demostrado que el hormigón polimérico de buena calidad se puede producir con las cenizas volantes de RSU [Collivignarelli, C. y Sorlini, S.; 2002].

Y Juric, B., et al. (2006) consideran aceptable, para la elaboración de hormigón de hasta $40 \mathrm{MPa}$ de resistencia a compresión, reemplazar hasta el $15 \%$ de cemento por cenizas volantes de RSU, porque han obtenido como resultado que, a los 28 días, las resistencias a flexión y a compresión disminuyeron linealmente sólo 0,03 y 0,02 $\mathrm{MPa}$ respectivamente por cada $1 \%$ de incremento en peso de la dosificación de cenizas volantes de escorias de RSU [Juric, B., et al; 2006].

- Pavimento: para las carreteras, las cenizas volantes de RSU se utilizan, como sustituto en la arena y/o cemento estabilizando bases y sub-bases de carreteras.

- Y además las cenizas volantes de RSU se emplean, en terraplén, estabilización de suelos, fabricación de cerámica, vidrio y vitrocerámica [Siddique, R.; 2010 a].

\subsubsection{Escorias de incineradora de residuos sólidos urbanos (RSU)}

Su estudio y reutilización es mucho menor que el de las cenizas. Según una investigación de Lin et al, al sustituir el cemento entre un $10 \%$ y un $20 \%$ por escorias de RSU en la elaboración del hormigón, las características hidráulicas latentes de las escorias desarrollan una resistencia a la compresión a los 90 días similar a la del cemento Portland ordinario. Como con el aumento de las edades de curado los tamaños de los poros aumentan y el tamaño de los poros capilares disminuye, se concluye que las escorias de RSU se pueden procesar por fusión para recuperar las escorias puzolánicas y se pueden emplear para reemplazar parcialmente el cemento [Lin, K.L., et al; 2008].

En un estudio, Cheng, A. (2012) empleó dos muestras de escorias, una de escorias de RSU incinerados y otra con pulverización de las escorias, cuyos tamaños eran entre 4,75 y 0,074 mm. Para la elaboración del hormigón se sustituyó tanto la arena como el cemento Portland por escorias en cantidades de $0 \%$ a $40 \%$ como máximo en peso. Cuando se termina el estudio se observa que las escorias causan una reducción en la resistencia a la compresión del hormigón, reducción de unidad de peso, y disminución de los valores de fluidez [Cheng, A.; 2012]. 
En esta tesis se quiere comprobar si las escorias de RSU se pueden emplear como sustitutas total o parcial de los áridos naturales en la elaboración de los morteros y hormigones de cemento Pórtland, y si su dosificación puede afectar a la resistencia de los mismos y/o a la corrosión de las armaduras.

\subsubsection{MATERIALES SUSTITUTOS DE LOS ÁRIDOS NATURALES}

Los áridos naturales resultan imprescindibles en la construcción de edificaciones, obra civil e infraestructuras de cualquier país, indicador de su economía y desarrollo socioeconómico.

Según el Instituto de Estadística Minera de España en el año 2012, la producción nacional de áridos de construcción ha descendido un 22,3\% respecto al año 2011. Desde el inicio de la crisis en el año 2008, el consumo de áridos ha caído. En la Tabla 2.2 se desglosa la producción nacional en toneladas de los productos granulados silíceos (arenas, cantos y gravas) y las piedras de machaqueo, durante el periodo 2008-2012 [IGME; 2012].

Tabla 2.2 Producción nacional de áridos de construcción (t.) [IGME; 2012].

\begin{tabular}{|c|c|c|c|c|c|}
\hline \multirow{2}{*}{$\begin{array}{c}\text { Áridos } \\
\text { construcción }\end{array}$} & \multicolumn{5}{|c|}{ Año } \\
\hline & 2008 & 2009 & 2010 & 2011 & 2012 \\
\hline Granulados & 119.989 .756 & 97.100 .992 & 73.765 .882 & 60.603 .982 & 41.834 .967 \\
\hline Machaqueo & 275.219 .997 & 219.872 .609 & 180.105 .140 & 143.579 .886 & 96.056 .496 \\
\hline Total & 395.209 .753 & 316.973 .601 & 253.871 .022 & 204.183 .868 & 137.891 .463 \\
\hline
\end{tabular}

Aunque es evidente el descenso del consumo de áridos, existe otro aspecto a tener en cuenta en la obtención de los áridos, y es la minería a cielo abierto que ocasiona un impacto ambiental considerable, en diversos grados, como en el lugar de la explotación, lugares próximos y también un poco alejados, siendo en la mayoría de los casos difícil de restaurar.

Dependiendo del recurso extraído tienen unas características concretas, junto con las rocas que lo acompañan, entre los que están la magnitud de las explotaciones, métodos de extracción, tratamiento posterior y factores locales como el clima, situación geológica y geográfica.

En las últimas décadas se ha dado mayor importancia a este aspecto ambiental y se han plateado normativas, para conseguir cierto control de la contaminación y otras formas de degradación ambiental, y por lo tanto mejores condiciones para la conservación de los recursos naturales (aire, estabilidad 
climática, aguas continentales y oceánicas, morfología y suelos, vegetación y fauna, ecosistemas y paisajes).

Además de asignar el mejor uso posible a dichos recursos, son bienes que se han ido volviendo progresivamente más escasos [Saiz de Omeñaca, J., et al; 1996].

Con el fin de alcanzar en la elaboración del hormigón un desarrollo sostenible y aprovechamiento medioambiental, se viene estudiando desde hace años la sustitución total o parcial de los áridos naturales por otros materiales procedentes del reciclado o desechos de la industria.

En la actualidad, esos materiales son principalmente áridos reciclados procedentes de demoliciones, escorias siderúrgicas procedentes de la industria metalúrgica y escorias procedentes de las centrales termoeléctricas de carbón.

En esta tesis se propone y estudia la utilización también de las escorias procedentes de las incineradoras de residuos sólidos urbanos (RSU).

\subsubsection{1 Áridos reciclados (procedentes de demoliciones de estructuras de hormigón)}

La demolición de antiguas estructuras de hormigón, que actualmente son numerosas después de más de 80 años de normativa al respecto, plantea la posible utilización de los materiales resultantes, con el fin de contribuir a la construcción sostenible.

Los áridos reciclados que son obtenidos tanto en demoliciones como en procesamientos de construcción, son clasificados en, áridos reciclados procedentes de hormigón, áridos de cerámicas ó áridos mixtos cuando proceden de una mezcla de residuos de distinta naturaleza.

En la EHE-08 se fomenta la incorporación de sostenibilidad al proyecto y ejecución de las estructuras de hormigón, con criterios medioambientales, entre los que están la prevención de impacto sobre el medio ambiente en la ejecución de estructuras, el empleo de hormigones reciclados, y el uso de subproductos industriales como materiales componentes del hormigón.

En el Anejo 15 se recogen las recomendaciones de utilización de hormigones reciclados. Para la elaboración del hormigón se sustituye el árido grueso por el producto del machaqueo de residuos de hormigón.

La norma recomienda limitar el contenido de árido grueso reciclado al $20 \%$ en peso sobre el contenido total en árido grueso, para mantener sus propiedades finales y que apenas cambie respecto al hormigón convencional. 
Sin embargo, la norma excluye algunos hormigones reciclados, para el correcto funcionamiento de las estructuras de hormigón. Y se tendrá en cuenta, la presencia de impurezas como madera, cerámica, vidrio, yeso, asfalto entre otros, el contenido máximo se detalla en la Tabla 2.3.

Tabla 2.3 Contenido máximo de impurezas en el árido reciclado.

\begin{tabular}{lc}
\hline \multicolumn{1}{c}{ Impureza } & $\begin{array}{c}\text { Contenido máximo [\%] del peso total de } \\
\text { las muestras }\end{array}$ \\
\hline Material cerámico & 5 \\
Partículas ligeras & 1 \\
Asfalto & 1 \\
Otros: vidrio, plásticos, metales, etc. & 1 \\
\hline
\end{tabular}

El hormigón reciclado tiene una fracción fina que se caracteriza por presentar un elevado contenido de mortero, afectando negativamente al hormigón. El diámetro permitido para el árido reciclado es de $4 \mathrm{~mm}$ (el contenido mínimo que pasa por el tamiz de $4 \mathrm{~mm}$ no será superior al $5 \%$ ). El árido reciclado tiene una elevada absorción de agua, se recomienda utilizar los áridos en condiciones de saturación.

Los hormigones reciclados tienen menor densidad que el convencional, por el mortero que permanece adherido al árido reciclado, disminuyendo así la durabilidad. Si se sustituye la totalidad de árido grueso por reciclado, su densidad puede bajar hasta un 15\%. Según el estudio de Thomas, C. (2013), los valores de densidad son de $5 \%$ menor al adicionar $20 \%$ de árido reciclado y los resultados recomiendan disminuir la relación agua/cemento 0,1 puntos en los hormigones elaborados con el $100 \%$ de árido reciclado, para todas las clases generales de exposición. En los entornos de carbonatación, la reducción debe ser de 0,05 puntos.

El árido reciclado tiene mayor porosidad y hace que el hormigón sea más susceptible de ser atacado por efectos del ambiente, por ello hay que tomar precauciones cuando el árido reciclado sea superior a $20 \%$, especialmente en ambientes que no sean I o Ilb, como aumento de contenido de cemento, reducción de la relación agua/cemento o aumento de recubrimientos de las armaduras.

La retracción del hormigón reciclado es superior a la del convencional, hasta 1,5 veces para un $100 \%$ de árido grueso reciclado. También aumenta la fluencia, hasta 1,25 veces. La resistencia característica del hormigón no será superior a $40 \mathrm{~N} / \mathrm{mm}^{2}$. 
Como la resistencia a cortante se ve mermada, la separación máxima entre estribos será de $20 \mathrm{cms}$, en vez de $30 \mathrm{~cm}$ como se establece para el hormigón con áridos naturales.

También disminuye ligeramente la capacidad adherente de las armaduras, por lo que se deben tomar las siguientes longitudes básicas de anclaje [2.1]:

$$
L_{b l}=1,1 \cdot m \cdot \varnothing^{2} \quad \text { y } \quad L_{b l l}=1,55 \cdot m \cdot \varnothing^{2}
$$

Por la mayor heterogeneidad que suelen presentar los áridos reciclados, la norma incrementa la frecuencia de los ensayos a realizar para el control de producción del hormigón. Los hormigones reciclados presentan una mayor variabilidad en sus propiedades que los convencionales, por lo que el control del hormigón debe ser más intenso.

La EHE recomienda, para elementos estructurales de especial responsabilidad, o para hormigones con más de $20 \%$ de árido reciclado, reducir los tamaños de los lotes de control.

La dosificación con áridos reciclados tiene mayor influencia en la resistencia a fatiga del hormigón que en la resistencia a compresión. Si el hormigón con árido reciclado se dosifica para una resistencia menor que el convencional, como los procesos de daños por fatiga se rigen por las características de la pasta, la resistencia a fatiga apenas varía. Si el hormigón con árido reciclado es de resistencia superior, entonces sí influye en la resistencia a fatiga la proporción de árido reciclado.

Al analizar las propiedades físicas, mecánicas y de durabilidad del hormigón que incorpora árido reciclado de residuos de construcción y demolición, hay un aspecto desconocido como es el de la durabilidad en ambientes agresivos. Debido a la gran heterogeneidad de los áridos reciclados, a la relación agua/cemento y a los tipos de cemento, la literatura encontrada no es comparable [Thomas, C., et al; 2013].

\subsubsection{2 Áridos cerámicos}

Se están realizando diferentes estudios para el aprovechamiento de los residuos cerámicos procedentes de demoliciones, pero aún es limitada la información y hasta el momento, los resultados se muestran negativos.

En los áridos reciclados cerámicos la resistencia a compresión de este tipo de hormigones es reducida, el rango es 10 - $200 \mathrm{~N} / \mathrm{mm}^{2}$ [CEDEX; 2010]. 
Según el estudio de Martínez-Lage, I., et al. (2012), el hormigón elaborado con árido reciclado cerámico como sustituto parcial o total del árido natural, precisa tener en cuenta diversos factores, entre otros requiere mayor cantidad de agua de amasado, la densidad disminuye linealmente con la dosificación de árido cerámico, disminuye la resistencia a compresión del hormigón entre un $20 \%$ y $30 \%$, si la sustitución de árido es total disminuye el módulo de elasticidad entre un 30\% y 40\% [Martínez-Lage, I., et al; 2012].

\subsubsection{3 Áridos artificiales}

Los áridos artificiales se producen a partir de fuentes secundarias generadas en paralelo al proceso industrial, que suponen una modificación térmica u otra. Como ejemplo, está el caso de las cenizas derivadas de la combustión de carbón y las escorias de la producción de hierro y de acero. Ambos procesos industriales involucran una transformación química de las materias primas.

Los áridos artificiales o sintéticos que presentan formas que se aproximan a una esfera o elipsoide se emplean en los hormigones ligeros estructurales, por lo que se reduce la importancia de los límites impuestos al coeficiente de forma.

Cuando se emplean áridos ligeros para producir hormigones estructurales, es necesario establecer recomendaciones diferentes 0 complementarias, ya que las prescripciones y requisitos de la instrucción EHE08 se refieren al empleo de áridos de peso normal.

Así mismo, se puede obtener una amplia gama de densidades y propiedades mecánicas teniendo en cuenta que la sustitución de árido de peso normal por árido ligero puede hacerse en forma parcial, reemplazando solamente la fracción gruesa del árido, o total, reemplazando la arena por árido fino ligero.

\section{Hormigones de escorias siderúrgicas (o escorias de horno alto)}

Las escorias se pueden utilizar como árido tanto en morteros como en hormigones, comprobando que carecen de compuestos que afecten a la estabilidad de volumen. En la normativa de áridos para hormigón se especifica que se deben hacer ensayos de acuerdo con la norma UNE-EN 1744-1 [AENOR; 1999]. Para la utilización en mortero, además de cumplir las especificaciones generales establecidas para los áridos naturales, se presta atención a la perdida por calcinación y sustancias solubles en agua. 
Según la EHE-08, en el caso de utilizar áridos siderúrgicos se permite aquellos que son apropiados, por ejemplo, las escorias siderúrgicas granuladas de alto horno, y dentro de estas se pueden incluir las escorias siderúrgicas enfriadas por aire (según AENOR UNE-EN 12620:2003+1A; 2009) siempre que se compruebe previamente que son estables (sin contenido de silicatos inestables, ni compuestos ferrosos inestables). Dada su peligrosidad, solo se permite el empleo de áridos en una proporción muy baja de sulfuros oxidables.

Las escorias subproducto de la industria siderúrgica que sale del horno a $1.500^{\circ} \mathrm{C}$, que se enfrían lentamente al vapor de agua, dilatan tomando un aspecto parecido a la piedra pómez al triturarlas, son empleadas para hormigones ligeros. Las escorias más idóneas son las que tienen alto contenido de cal y sílice. Otras resultan incompatibles, porque podrían reaccionar con el cemento.

Las escorias más ligeras se reutilizan en la fabricación de bloques y hormigones para aislamiento térmico y las más pesadas se pueden utilizar para el hormigonado de losas armadas [Medina, E.; 2009].

Las escorias de alto horno bien granuladas y trituradas mejorarán la trabajabilidad del hormigón. La resistencia del hormigón con una correcta dosificación elaborada con puzolana o escorias puede igualar o superar la de hormigones de cementos Pórtland a los 28 días. Se debe utilizar escorias de alto horno, adecuadas que no aumenten la contracción por el secado y $30 \%$ o más (en masa) del árido grueso compuesto por caliza no reactiva [ACl 210.2R-01; 2001].

Las escorias según las técnicas empleadas en el proceso de enfriamiento, generan otro subproducto las escorias cristalizadas que se reutiliza en el hormigón, en algunas obras:

- En Asturias se han empleado escorias cristalizadas en la construcción de terraplenes sobre suelos blandos, por sus buenas propiedades mecánicas.

- En carreteras a nivel nacional se ha utilizado principalmente en Asturias y el País Vasco y algunas obras en Cantabria y León [CEDEX; 2011].

\section{Escorias de acería de horno de arco eléctrico}

A principios del siglo XX la llegada de la electricidad industrial contribuyó a la aparición de hornos eléctricos. Mejorando progresivamente los equipos que fueron aumentando de tamaño paulatinamente, consiguiendo hornos de arco eléctrico de 300 toneladas de capacidad. 
Los hornos Martín-Siemens fueron desapareciendo, porque la productividad era muy baja, en cuanto a la calidad y costes no eran comparables a los hornos eléctricos, además de los problemas medioambientales que ocasionaban dichos hornos.

Los hornos eléctricos de acero suelen ser cilíndricos y están recubiertos por material refractario. En la parte superior tiene una bóveda móvil donde se introducen las materias primas, por lo general chatarra reciclada (aproximadamente entre 50\%-90\%) y prerreducidos de hierro, y otros materiales añadidos en las fases como ferroaleaciones, cal, espato-flúor, coke y oxígeno.

El proceso de fabricación del acero se compone de dos etapas, una primera denominada metalurgia primaria o etapa de fusión (donde hay fusión de las materias primas en el horno alto), con fases de oxidación y defosforación de los caldos, al final de la cual se extraen las escorias negras, y otra segunda etapa, denominada metalurgia secundaria o afino (inicia en el horno eléctrico y termina en el horno cuchara) cuya principal materia prima es la chatarra de hierro dulce o acero, con fases de desoxidación y desulfuración y descarburación del acero, dando lugar a las escorias blancas [CEDEX; 2011].

Para poder reutilizar como áridos los residuos siderúrgicos (escorias blancas y negras), existen estudios de autores españoles [Frías, M., et al; 2010] que evidencia que los compuestos expansivos de los áridos siderúrgicos (óxido de cal y magnesio libre), se reducen con un proceso de envejecimiento (principalmente efectivo durante los primeros 45 días) y se hace a través de someter el material a ciclos de humectación-secado en una superficie amplia.

Después del tratamiento las escorias analizadas presentaban concentraciones de dichos compuestos expansivos inferiores a los máximos especificados en la Instrucción EHE-08.

En cuanto a la aplicación de las escorias blancas, son reutilizadas en las fábricas de cemento en sustitución de la marga. $Y$ para las escorias negras una vez trituradas, se han elaborado estudios que demuestran que podrían ser utilizadas en la elaboración de morteros, sustituyendo el árido natural, los resultados arrojan una buena resistencia a compresión cuando los morteros tienen porcentajes de escorias entre un $30 \%-40 \%$.

Para la aplicación en el hormigón, los estudios señalan que, con la granulometría adecuada, después de un proceso de envejecimiento previo, al remplazar el $100 \%$ de arena por escorias negras de horno eléctrico, los ensayos realizados obtuvieron hormigones de mayor densidad $\left(2.770 \mathrm{~kg} / \mathrm{m}^{3}\right)$, con resistencia a compresión y carga de rotura similar al hormigón convencional y de mayor fragilidad. 
Los hormigones con escorias de acerías requieren una mayor demanda de agua en la obtención de determinada consistencia, a mayor cantidad de escorias más cantidad de agua se utiliza.

La resistencia del hormigón con escorias suele ser inferior a la del convencional a edades tempranas (hasta 3 días), aunque a mayores edades se obtiene una resistencia similar o incluso superior al convencional. Pero presentan menor retracción. Se debe utilizar aditivos aireantes para un adecuado comportamiento de durabilidad frente a ciclos hielo-deshielo

Entre las obras realizadas en España con escorias negras en hormigón está el proyecto 'Kubit', la construcción de infraestructura de Labein-Tecnalia en Parque Tecnológico de Vizcaya. Donde se empleó árido siderúrgico en diferentes elementos estructurales tal como losas de cimentación y muros de sótano [CEDEX; 2011].

\section{Escorias de acería LD}

Las escorias de Linz-Donawitz (LD) se originan en el proceso de afinado del arrabio, obtenido en el horno alto (fabrica siderúrgica) para la transformación de la fundición del hierro en acero, el afino se lleva a cabo inyectando oxígeno a presión en el baño que contiene las materias primas y adiciones para la formación de escorias (cal, dolomía y espato). La misión de las escorias es atrapar las impurezas (fósforo y azufre).

Terminado el proceso de transformación del hierro, las escorias en forma semipastosa sobre nadando en el acero, se separan de este enviándolas a un foso, donde se riegan hasta alcanzar temperaturas inferiores a $50^{\circ} \mathrm{C}$, luego se transportan a la planta de procesado, allí se separan mediante electroimanes, las que son superiores a $80 \mathrm{~mm}$ son chatarra, y el material restante va a la instalación de machaqueo, pasando a tamaños inferiores a $50 \mathrm{~mm}$. El proceso finaliza con el envejecimiento de las escorias, regándolas con agua para conseguir hidratar los elementos inestables.

El proceso de envejecer se utiliza, debido a la presencia de cal libre y magnesia, constituye un factor potencial de inestabilidad. Dichos óxidos tienden a hidratarse desprendiendo calor y produciendo un hinchamiento que puede provocar la disgregación del material, evolucionado la granulometría de las escorias hacia tamaños más pequeños.

Las escorias LD tienen aplicaciones importantes en agricultura y en obra civil como árido de calidad. Previa a la utilización se tiene en cuenta la granulometría adecuada, el proceso de envejecimiento, para que el contenido de cal no rebase un porcentaje de $4 \%-5 \%$ y control de la inestabilidad volumétrica de las escorias con un ensayo de hinchamiento. Se utilizan como áridos para 
bases en carreteras y subbases granulares, mezclas bituminosas, lechadas 0 tratamientos superficiales.

Las escorias LD se han utilizado como árido para mezclas bituminosas, para carreteras en Asturias, y el escombro de las mismas ha sido utilizado como relleno en la misma provincia de España, finalmente existe una amplia experiencia en utilizar escorias LD como corrector de suelos de cultivos (abonos) [CEDEX; 2007].

\section{Escorias de carbón}

Las escorias de carbón son residuos originados de la producción de energía eléctrica a partir de centrales termoeléctricas que emplean carbón como combustible. Las escorias de carbón están formadas por partículas angulares con textura superficial muy porosa y rugosa, tienen un tamaño que varía entre grava fina y arena fina, con bajo porcentaje de finos [Orna, M., et al; 2010].

En España la producción de escorias en el año 2010 fue en torno a 293.000 toneladas y se reutilizaron 231.000 toneladas, la gran mayoría en la industria cementera [CEDEX; 2011].

En el proceso para la fabricación de cementos $u$ hormigones, no es necesario someter las escorias a ningún tratamiento, aunque para obtener un material más homogéneo se realiza un proceso de trituración previo.

Para la aplicación de las escorias de carbón, se ha llevado a cabo un estudio en la universidad de Zaragoza, sobre sustitución del árido natural, con un límite de tamaño tanto para el árido fino (0-4 mm), como para el árido grueso (4-10 mm), por escorias de la central térmica convencional de Andorra (Teruel), en la elaboración de hormigones para prefabricados, con diferentes rangos de dosificaciones.

El requisito marcado es la resistencia a $24 \mathrm{~h}$, por el proceso de desmolde que se hace en las piezas prefabricadas. En la Tabla 2.4 se recogen los resultados obtenidos: 
Tabla 2.4 Caída de resistencia a 24 h para cada porcentaje de sustitución de arena y grava en hormigones fabricados con escorias de central térmica.

\begin{tabular}{lcc}
\hline Árido & Porcentaje [\%] de sustitución & Caída de la resistencia [\%] \\
\hline \multirow{3}{*}{ Fino } & 25 & 30 \\
& 50 & 45 \\
& 75 & 50 \\
\multirow{3}{*}{ Grueso } & 25 & 45 \\
& 50 & 50 \\
& 75 & 65 \\
\hline
\end{tabular}

En los resultados obtenidos se observa que a mayor cantidad de sustitución más disminuye la resistencia del hormigón. Se desecha el empleo de escorias finas por no interesar la rentabilidad económica en la cantidad a utilizar. Por lo tanto, la dosificación idónea es la sustitución del árido grueso por un $30 \%$ de escorias (fracción 4-10 mm), por la bajada de resistencia [Orna, M., et al; 2010].

En el año 2008, países como Bélgica, Francia y Países Bajos, reflejan que uno de los mayores usos de las escorias fue la fabricación de bloques ligeros de hormigón para su aplicación en construcción, en un porcentaje de $37 \%$ a $41 \%$ en construcción de carreteras, terraplenes, rellenos y finalmente un $18 \%$ en cemento y hormigón (de los cuales $15,5 \%$ cemento y $2,7 \%$ hormigón).

Deben estudiarse las escorias por su contenido de sal $(\mathrm{NaCl}) \mathrm{y}$, a veces el bajo $\mathrm{pH}$, debido a que pueden ocasionar problemas de corrosión a los elementos metálicos [Alonso, M.C. y De Luxan, M.P.; 1995].

\subsection{ESCORIAS DE INCINERADORAS DE RESIDUOS SÓLIDOS URBANOS (RSU), ESTUDIOS SOBRE POSIBLE REUTILIZACIÓN COMO ÁRIDO EN MORTEROS Y HORMIGONES}

Otro subproducto obtenido de la incineración de residuos sólidos urbanos (RSU) son las escorias. Dichas escorias se consideran residuos no peligrosos, son ricas en óxido de calcio y sílice con cantidades mínimas de materiales pesados (aluminio, silicio y hierro).

Las escorias de RSU son más gruesas que las procedentes de los residuos sólidos del carbón, pero tienen menos cloruros y otros productos químicos [Bertolini, L.; 2004]. 


\subsubsection{RSU Y LA INCINERACIÓN}

Los Residuos Sólidos Urbanos (RSU) son generados en las oficinas, domicilios particulares, comercios, servicios, y aquellos lugares que no tengan calificación de peligrosos, que por su naturaleza o composición puedan asimilarse a los producidos en los anteriores lugares [Ley 10/1998]. Un residuo es cualquier sustancia u objeto cuyo poseedor se desprenda o que tenga la intención u obligación de hacerlo, con la Directiva Marco de Residuos y la Ley 22/2011 que la traspone en España.

En la Unión Europea se generaron en el año 2012, la cantidad de 2.515 millones de toneladas de residuos, de los cuales, unos 100,1 millones de toneladas son residuos peligrosos (4\% del total). Equivalen a 5 toneladas (4.984 $\mathrm{kg}$ ) de residuos sólidos por habitante [EUROSTAT; 2015].

Existe una correlación entre la renta per cápita de un país y la generación de residuos. En la Figura 2.1, se comprueba que el país que es más rico o más industrializado presenta una mayor producción de residuos [Castell, X.E.; 2000].

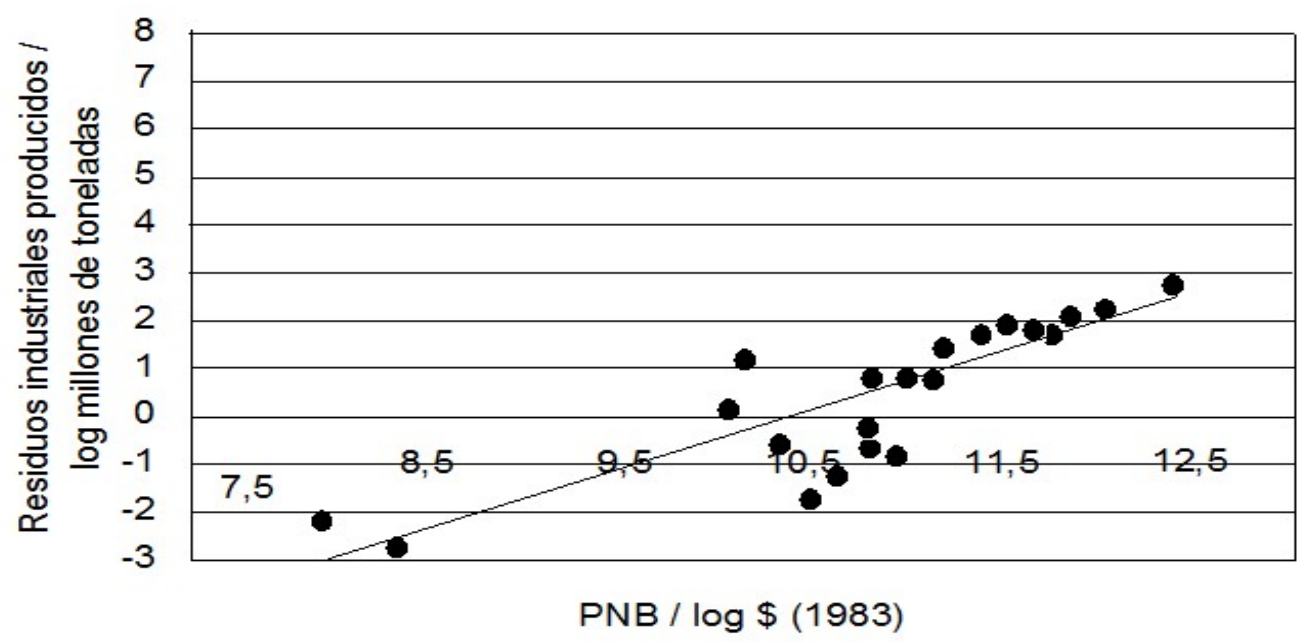

Figura 2.1 Producto Nacional Bruto y producción de residuos [Castell, X.E.; 2000].

En España se recogieron 24,4 millones de toneladas de RSU en el año 2010, de los cuales 19,4 millones corresponden a residuos mezclados y aproximadamente 5 millones a recogida selectiva. $Y$ las empresas de tratamiento tanto de residuos urbanos como no urbanos gestionaron 53,4 millones de toneladas de residuos no peligrosos, del total de los residuos el $49 \%$ se destinó al reciclado, el $46,6 \%$ al vertido y el $4,4 \%$ a la incineración [INE; 2012]. 
En España, los RSU están formados principalmente por los componentes que se detallan en la Figura 2.2 [CONAMA; 2014].

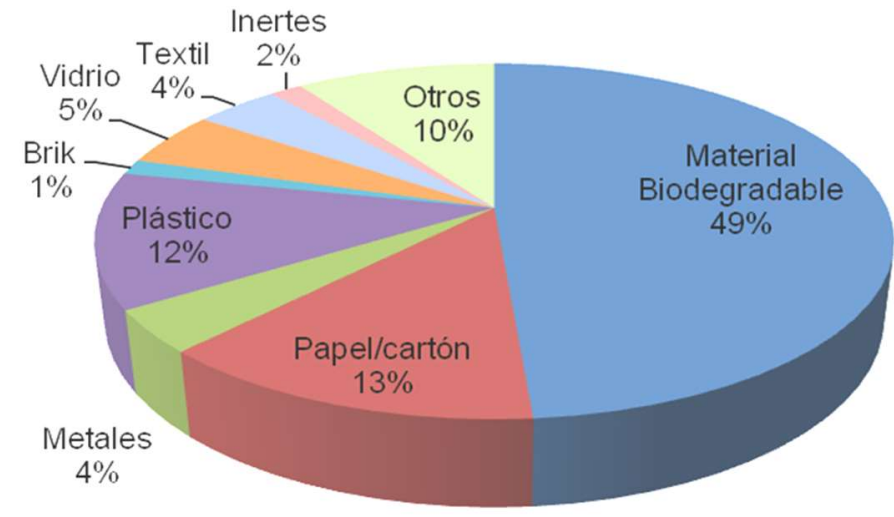

Figura 2.2 Composición de RSU en España [CONAMA; 2014].

En Madrid, en el año 2012 se produjeron 1.254.111 toneladas de residuos urbanos, lo que supone un 5,66\% menos que en el año 2011, debido, fundamentalmente, a la disminución de los residuos generados en los hogares de los habitantes de la ciudad [DGPTV; 2012].

La planta de tratamiento de RSU de Madrid es el Parque Tecnológico de Valdemingómez. En el año 2009, de los residuos que ingresaron, un $78 \%$ fueron tratados y el $22 \%$ excedente se llevó directamente a un vertedero controlado.

El proceso aplicado para su tratamiento es:

- Se separa y clasifica más del $75 \%$ del total de los RSU que entran en el parque tecnológico de Valdemingómez.

- Se trata por encima del $90 \%$ de la materia orgánica de los residuos.

- Se incinera en torno al $21 \%$ de los residuos después de separar los materiales reciclables.

En la Comunidad de Madrid se presta poco interés al reciclaje y la recuperación de residuos sólidos urbanos (RSU), con solo un $15,96 \%$ en el año 2013 [Greenpeace; 2015].

Además de causar daños medioambientales los RSU, en su proceso de eliminación (vertido), generan un coste económico que debe tenerse en cuenta, como ejemplo esta la Ley 5 de 2003 de residuos de la Comunidad de Madrid, donde se establece una tarifa única de $25,20 €$ por cada tonelada de residuos. 
Hace más de 30 años se implementó una solución ventajosa o una herramienta valiosa, para la gestión de residuos sólidos urbanos (domésticos), que se generan en las ciudades, sin lugar a dudas es la incineración en hornos con y sin recuperación de energía [Goñi, S., et al; 2007].

Una técnica cada día más utilizada ya que las nuevas regulaciones europeas prohíben el almacenamiento de residuos sin tratar en vertederos [Müller, U. y Rübner, K.; 2006].

La incineración es la solución más simple, más higiénica, más radical y también la más costosa, pero suele resultar considerablemente menor que los vertidos.

La heterogeneidad de los RSU, hace necesario una preclasificación de los residuos, separando el material que irá a la incineradora del que tendrá otro destino, y el más aconsejable por los grandes volúmenes de RSU, será el reciclaje y compostaje de residuos que sean viables.

En los inicios de la incineración se incluían todos los residuos, sin embargo, en la actualidad gracias a las nuevas técnicas se pueden separar y reciclar previamente algunos de los residuos.

Una de las técnicas es la práctica cada vez más habitual de la separación de los RSU antes de la incineración, en los centros de tratamiento de los residuos, en las cintas transportadoras se puede separar los envases o elementos de aluminio automáticamente mediante el principio de fuerzas de Van der Waals, igualmente es más común el reciclar estos envases y los de vidrio en contenedores específicos (incluso en origen) para su posterior reutilización.

Con la evolución de las tecnologías de incineración hay una abúndate oferta de equipos que garantizan una correcta incineración de los residuos, equipos complementados con otros de tratamientos de gases que garantizan las emisiones de acuerdo a las normativas, evitando la contaminación atmosférica.

Las técnicas de limpieza de los gases emitidos por las incineradoras, una vez filtrados (o limpiados mediante precipitadores electróstaticos), existentes son tres: seco, semi-seco, húmedo.

En todos los casos se generan residuos problemáticos. Los costes ambientales dependen de la incineración, y se pueden minimizar a través de un control adecuado de la combustión y sus productos [Saiz de Omecaña, J.A., y Saiz de Omecaña, J; 1996]. 
Las ventajas más notables de la incineración de RSU son la reducción significativa tanto del volumen, aproximadamente un $90 \%$, como de la masa, alrededor del 70\%, [Chimenos, J.M., et al; 1999] [Del Valle-Zermeño, R., et al; 2013], la desinfección completa de los residuos [Li, M., et al; 2004] y la recuperación de energía, se produce energía a partir de la combustión de calor [Lam, C.H.K., et al; 2010].

En el año 2011, según EUROSTAT en España se incineraron 1,1 millones de toneladas de RSU, esta cifra representa el $4,8 \%$ del total de los RSU generados en el mismo año. $Y$ de acuerdo a las mismas estadísticas, un aumento promedio del $16 \%$ en la producción de RSU desde el año 1998, ha llevado a un aumento del $60 \%$ en la tasa de incineración.

A pesar de una reducción sustancial de los residuos que se logra por esta técnica (incineración), un promedio del $30 \%$ son subproductos tanto de escorias como de cenizas volantes, y la eliminación se hace por métodos de estabilización y solidificación, [Del Valle-Zermeño, R., et al; 2014 b].

Una planta de tamaño medio puede tratar 200.000 toneladas de RSU al año, la cantidad de escorias producida sería 44.000 toneladas. cifra considerable, haciendo necesario nuevas vías de valorización o utilización como subproducto de las escorias [Castell, X.E.; 2000].

\subsubsection{Las incineradoras de RSU}

Las incineradoras, según el tipo de horno de combustión utilizado, se diferencian entre [IDAE; 2011]:

- Incineración en el horno de parrilla, consiste en transportar los residuos mediante una estructura variable. La parrilla tiene las siguientes funciones: avance de los residuos, mezclar los residuos y atizar la llama.

- Incineración en horno rotativo, se hace en un cuerpo cilíndrico ligeramente inclinado en su eje horizontal. El cilindro se localiza sobre rodillos para permitir que el horno rote alrededor de su eje en un movimiento reciproco.

- Incineración en horno de lecho fluidizado, se realiza en una cámara cilíndrica y vertical, cuya parte inferior contiene el material de lecho, debe ser inerte, pequeño y esférico capaz de fluidizar al introducir gas para tal finalidad. De acuerdo al movimiento del lecho son diferenciados en:

Lecho fluidizado burbujeante: se pasa aire por la parte inferior del horno a través de una placa de distribución para hacer burbujear el lecho mantenido en suspensión. 
- Lecho fluidizado circulante: desarrollado para mejorar el lecho burbujeante y lograr una combustión más completa, con un mayor control de la temperatura.

- Lecho fluidizado "Revolving type": con el objetivo de mejorar el contacto de las partículas en el lecho en continuo movimiento. El lecho es del tipo fluidizado burbujeante, donde el aire es inyectado de manera no uniforme, creando zonas diferenciadas para el paso del aire.

El secado, la volatilización, la ignición y la combustión de los residuos, tienen lugar en el interior del lecho fluidizado.

La temperatura que se alcanza por encima del lecho está entre $850^{\circ} \mathrm{C}$ y $950^{\circ} \mathrm{C}$, permitiendo la retención de gases en la zona de combustión, en el interior del lecho la temperatura es menor alrededor de $650^{\circ} \mathrm{C}$.

\subsubsection{Las escorias de incineradora de residuos sólidos urbanos (RSU)}

Una vez incinerados los RSU, se produce otro subproducto, las escorias que son grandes y pesadas total o parcialmente quemadas, se descargan en la parrilla del horno. Cuando culmina el proceso de incineración las escorias constituyen entre el $75 \%-80 \%$ es la más significativa.

Las escorias son en apariencia porosas, de color grisáceo, arena, limo con grava, y contiene pequeñas cantidades de material orgánico no quemado y trozos de metal. Las escorias se componen principalmente de vidrio, cerámica, metales ferrosos y no ferrosos y minerales [Siddique, R.; 2010 a], incluyen también los materiales más finos que caen entre los intersticios de la parrilla.

Las escorias tienen una amplia distribución granulométrica de partículas con un elevado grado de humedad, que confiere cierta adherencia entre ellas, y morfología muy dispar. Las escorias son más porosas y menos resistentes que los áridos naturales, pudiéndose considerar como árido de calidad media [CEDEX; 2007].

Las escorias de RSU requieren una gestión adecuada para reducir al mínimo su efecto sobre el medio ambiente [Del Valle-Zermeño, R., et al; 2013] [Ginés, O., et al; 2009]. 


\section{Composición física y química de las escorias de RSU}

Las características físicas y químicas de las escorias incineradas procedentes de los RSU, dependen de varios factores, la composición de RSU incinerados, el tipo de incineradora, la eficacia de la combustión, el dispositivo de control de la contaminación y las condiciones de operación [Li, M., et al; 2004].

Finalmente depende del tamaño de las partículas; sugiriendo que los mecanismos y la cinética de erosión natural son también una función de tamaño de partícula, entre otros [Chimenos, J.M., et al; 2003].

En la Tabla 2.5 se recogen algunos datos de la composición química de las escorias de RSU, de diferentes países, comparándolos con los estudios llevados a cabo por los autores Goñi, S., et al. (2007) y Ginés, O., et al. (2009), Del Valle-Zrmeño, R., et al. (2013), (2014) en España, [Goñi, S., et al, 2007] [Ginés, O., et al: 2009] [Del Valle-Zermeño, R., et al: 2013] [Del Valle-Zermeño, R., et al: 2014].

En los países que facilitan los datos, se analiza que las escorias en las diferentes composiciones químicas, tienen diferencias notables en algunos elementos, por la diversidad de la composición de los RSU, y por los procesos de incineración, desde el año 1997 al año 2014.

En países como Taiwan el Cl varía entre 3,20\% y 0,90\%, mientras que en España se encuentra entre 3,60\% (2007) y 0,14\% (2014). En todos los casos muy inferiores a los resultados obtenidos de $\mathrm{Cl}$ en las cenizas volantes de RSU. 


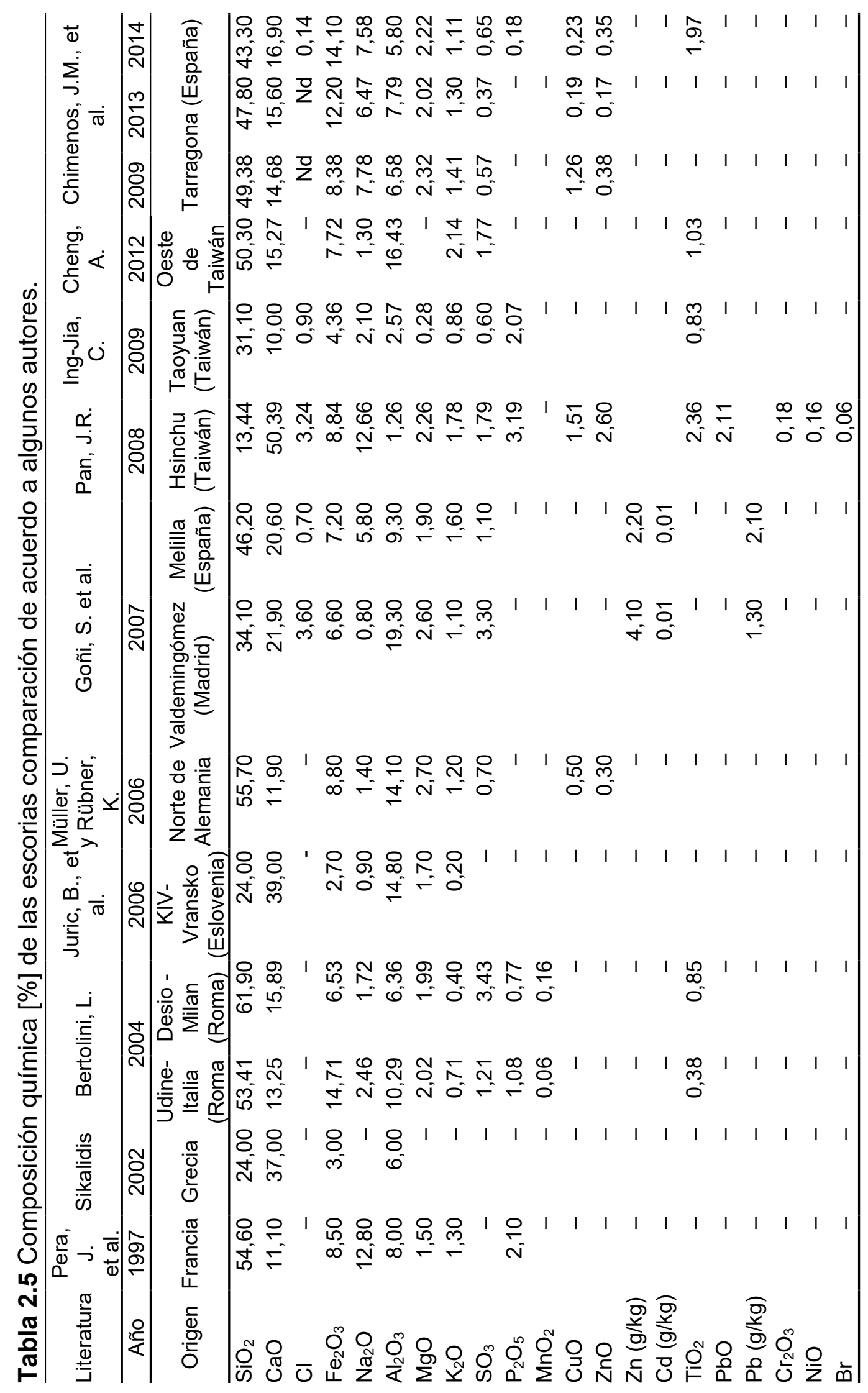


De igual manera, en la Tabla 2.6 se presentan los datos de la composición química de las escorias analizadas por los autores [Chimenos, J.M.; 2015] en la incineradora de Tarragona (España), con diferentes diámetros para comparar la variación de sus componentes.

Tabla 2.6 Composición química [\%] de las escorias de RSU de la incineradora de Tarragona (España) en función del diámetro [Chimenos, J.M.; 2015].

\begin{tabular}{crrrrrr}
\hline Compuesto & $<0,25 \mathrm{~mm}$ & $<0,50 \mathrm{~mm}$ & $<1,00 \mathrm{~mm}$ & $<2,00 \mathrm{~mm}$ & $<4,00 \mathrm{~mm}$ & $<8,00 \mathrm{~mm}$ \\
\hline $\mathrm{SiO}_{2}$ & 27,40 & 28,60 & 31,40 & 39,90 & 48,40 & 55,10 \\
$\mathrm{CaO}$ & 26,10 & 25,10 & 22,10 & 18,60 & 14,60 & 13,60 \\
$\mathrm{Fe}_{2} \mathrm{O}_{3}$ & 5,30 & 6,60 & 7,00 & 7,10 & 5,40 & 8,20 \\
$\mathrm{Na}_{2} \mathrm{O}_{3}$ & 1,90 & 2,40 & 3,10 & 4,60 & 8,00 & 9,20 \\
$\mathrm{Al}_{2} \mathrm{O}_{3}$ & 7,70 & 9,90 & 10,20 & 6,70 & 5,40 & 5,20 \\
$\mathrm{MgO}$ & 3,10 & 3,50 & 3,70 & 3,10 & 1,70 & 1,90 \\
$\mathrm{P}_{2} \mathrm{O}_{5}$ & 3,30 & 3,00 & 2,60 & 2,50 & 1,20 & 1,20 \\
$\mathrm{~K}_{2} \mathrm{O}$ & 1,70 & 1,90 & 1,70 & 1,50 & 1,00 & 1,10 \\
$\mathrm{SO}_{3}$ & 2,40 & 2,90 & 2,20 & 1,10 & 0,90 & 0,90 \\
$\mathrm{TiO}_{2}$ & 0,90 & 0,50 & 1,00 & 0,60 & 0,50 & 0,50 \\
$\mathrm{ZnO}$ & 0,30 & 0,30 & - & 0,30 & - & - \\
$\mathrm{Cl}$ & 0,60 & 0,60 & 0,60 & 0,20 & - & - \\
$\mathrm{PbO}$ & - & - & - & - & - & 1,80 \\
$\mathrm{CuO}$ & 0,20 & 0,10 & - & 1,90 & - & - \\
$\mathrm{P}_{2} \mathrm{O}_{5}$ & 0,30 & 3,00 & 2,60 & 2,50 & 1,20 & 1,30 \\
\hline
\end{tabular}

Las partículas con un diámetro $>1 \mathrm{~mm}$ presentes en las escorias de la incineración de RSU se caracterizan por la identificación de los principales elementos que componen a las escorias, se pueden utilizar para evaluar las posibles aplicaciones de las escorias y posibles peligros ambientales, evaluando la eficiencia de las posibilidades de reciclaje de sus principales componentes.

Los principales componentes de las escorias son vidrio, metales magnéticos, minerales, cerámica, sintéticos, metales paramagnéticos y la materia orgánica no quemada. La fracción de tamaño 4-25 mm representa aproximadamente el $50 \%$ del peso de las escorias (esta fracción comprende $>50 \%$ vidrio, $>26 \%$ cerámica y sintéticos y $>8 \%$ minerales), y por lo tanto parecen ser apto para su reutilización como material secundario de construcción o para el reciclaje de vidrio. 
Los metales magnéticos se acumulan en la fracción de tamaño de partícula 1-6 mm (6\%), y los metales pesados se acumulan en la fracción por debajo de $1 \mathrm{~mm}$, fracción soluble en ácido que disminuya a medida que el tamaño de la partícula disminuye [Chimenos, J.M., et al; 1999].

\subsubsection{VALORIZACIÓN DE ESCORIAS DE INCINERADORAS DE RSU}

Ley 22/2011 en España, incorpora en su articulado el concepto de Fin de Condición de Residuo, que trata de armonizar desde la Unión Europea, los requisitos que han de satisfacer los áridos procedentes de residuos, para perder esta consideración y adquirir la de producto.

En la actualidad se llevan a cabo numerosos estudios e investigaciones sobre la búsqueda de aplicaciones de las escorias de RSU como subproducto de otros elementos [Goñi, S., et al; 2007], en lugar de ser eliminadas en vertederos, [Lin, K.L., et al; 2008],

Por las técnicas actuales de incineración y por la composición tanto química como física de las escorias bien definida y al ser un producto ambientalmente seguro, tienen alto potencial, para reutilizarlas o emplearlas en materiales o estructuras de construcción de cemento es una opción viable sobre otras técnicas [Chimenos, J.M., et al; 2003], [Del Valle-Zermeño, R., et al; 2014 b], ya sea como áridos, adiciones, en bloques de construcción, o en carreteras, y en muchos países las escorias son ampliamente utilizadas sobre todo como material de grava de base compactada de carreteras.

La reutilización de las escorias se considera un aporte al desarrollo sostenible, por el ahorro de recursos naturales y disminución de volumen de residuos [Müller, U. y Rübner, K.; 2006].

De acuerdo a las diferentes investigaciones o estudios, algunas aplicaciones de las escorias de los residuos sólidos urbanos son:

- Las escorias de textura normalmente gruesa, vidriosa hace que sea un sustituto ideal para áridos naturales, ahora también se emplea como sustituto de bajo costo para la arena más cara en la producción de bloque de hormigón [Lin, K.L., et al; 2008].

- Se ha demostrado que las escorias de RSU pueden ser sintetizadas junto con otros materiales de desecho, para formar cuerpos de cerámica de vidrio, con posible aplicación en azulejos o material de ladrillo [Müller, U. y Rübner, K.; 2006].

- Una reutilización importante de las escorias de RSU, es como árido para el hormigón. Rashid, R.A. y Frantz, G.A. (1992), al igual que Pera, et al. (1997) demuestran que una sustitución de grava natural de hasta un $50 \%$ 
por escorias (realizando un tratamiento previo de hidróxido de sodio) es posible sin afectar a la durabilidad o la resistencia del hormigón, para una resistencia a compresión de $25 \mathrm{MPa}$ a los 28 días [Rashid, R.A. y Frantz, G.A.; 1992] [Pera, et al; 1997].

Juric, B., et al. (2006) han estudiado la reutilización de las escorias como sustitutivo del cemento, donde la sustitución de hasta el $15 \%$ se considera aceptable [Juric, B., et al; 2006] [Ginés, O., et al; 2009].

- En muchos países desarrollados es una práctica común, la reutilización de escorias (RSU), en aplicaciones como carreteras y construcciones subterráneas, terraplenes o como sustituto de agregados.

La búsqueda de soluciones viables al fenómeno de corrosión inducida por cloruro en hormigón armado fabricado con escorias de RSU, es una tarea importante que debe realizarse para garantizar su estabilidad a largo plazo y, por lo tanto, su sostenibilidad [Del Valle-Zermeño, R., et al; 2017].

La reutilización de las escorias procedente de RSU, es un beneficio para el medio ambiente, por las siguientes ventajas:

- Disminución del número de explotaciones necesarias para el suministro de la materia prima (áridos naturales tanto arena como grava), así se protegen los recursos naturales, debido a que una cantidad es sustituida por el residuo (escorias).

- Reducción del impacto ambiental que provoca las extracciones de arcilla a cielo abierto.

- Se valoriza el residuo evitando que las escorias vayan a un depósito controlado [Castell, X.E.; 2000].

Para el empleo de las escorias en un proceso en particular, se pueden hacer intentos por variar los métodos de reprocesamiento, para lo cual los residuos tienen que ser tratados previamente a la incorporación de los materiales de construcción [Goñi, S., et al; 2007].

En España, específicamente en Cataluña, la Generalitat ha regulado su utilización en la Orden del 12 de diciembre de 1996 sobre valorización de escorias.

Aunque son pocas las obras realizadas para dicha experiencia, a finales de 2005 y principios de 2006, después de los estudios de laboratorio para la utilización de las escorias de incineradora de RSU, como sub-bases para firmes de urbanización, se construyó un tramo de prueba representativo y finalmente se ejecutó una obra real en el término municipal de Les Franqueses. 
Y en las Islas Baleares se han realizado pruebas de utilización, como material para el terraplenado de $200 \mathrm{~m}$ de un camino interior de sus instalaciones y en la ejecución de los terraplenes y explanada de la estación de transferencia de residuos sólidos de Manacor-San Lorenzo [CEDEX; 2012].

Los residuos sólidos urbanos (RSU) en especial las escorias no están contempladas en ninguna norma española, porque hasta el momento, solo existen estudios de su posible reutilización en la fabricación de hormigones.

En la investigación para nuestro trabajo de Doctorado, las escorias son trituradas, para obtener una granulometría parecida a los áridos naturales, pero no se hará ningún tratamiento técnico por su coste, comprobando que sea interesante su utilización desde el punto de vista económico.

\subsubsection{Inconvenientes para la reutilización de las escorias de RSU como árido}

Sin embargo, los inconvenientes que presentan las escorias para su uso en el hormigón como árido, se han investigado y la reacción más importante observada ha sido la formación de hidróxidos de aluminio, aluminatos y liberación de gas hidrógeno a partir de granos de aluminio (específicamente la cantidad de óxidos de aluminio en las escorias), que reaccionan con el cemento Portland, debido a su alta alcalinidad [Müller, U. y Rübner, K.; 2006].

Por lo tanto, la reacción de aluminio fue identificada como una causa principal de la extensa exfoliación en la superficie del hormigón, provocando expansión y agrietamiento del hormigón [Pecqueur, G., et al; 2001]. Además, debido al contenido de vidrio en las escorias, detectado que provoca una reacción álcali-sílice en el hormigón, pero menos grave que los compuestos de aluminio [Müller, U. y Rübner, K.; 2006].

Otro inconveniente es el alto contenido en zinc, cobre, plomo, cromo, [Del Valle-Zermeño, R., et al; 2014 a] cloruros, sulfatos y otros aniones de las escorias [Ginés, O., et al; 2009] presentes ampliamente en la composición de los RSU [Siddique, R.; 2010 a]. El alto contenido de cloruros presentes en algunas escorias y su posible afección en la corrosión de las armaduras, ha sido estudiado por Prieto, M.I., et al. (2013) [Prieto, M.I., et al; 2013].

Siendo necesario, buscar herramientas que eliminen el aluminio reduciendo la porosidad y expansión del hormigón, así mismo minimizar la cantidad de vidrio por la reacción álcali-sílice [Müller, U. y Rübner, K.; 2006]. 


\subsubsection{Solución de inconvenientes para la reutilización de las escorias de RSU como árido}

Las técnicas vigentes de separación de RSU antes de la incineración, hacen que se pueda reutilizar escorias cuyo contenido en óxidos de aluminio sea muy reducido, así como la cantidad de vidrio, minimizando el riesgo de expansión y agrietamiento del hormigón.

Hay limitaciones para la reutilización de las escorias, que se pueden subsanar, mediante los efectos del envejecimiento natural a corto plazo de las escorias de RSU, en función del tamaño de las partículas de las escorias mediante el procedimiento de ensayo de lixiviación DIN, sobre los metales pesados (principalmente $\mathrm{Pb}, \mathrm{Cu}$ y $\mathrm{Zn}$ ), ya que es una de las principales limitaciones para la reutilización de las escorias, como se indica en las regulaciones ambientales.

Entre los resultados obtenidos de diferentes autores de las investigaciones o estudios realizados, después de la intemperie de las escorias de RSU incinerados, están los siguientes:

- La composición química y física de las escorias varía de acuerdo al tamaño de las partículas, influyendo los mecanismos y la cinética de la erosión natural. Al analizar los efectos del envejecimiento natural a corto plazo sobre la lixiviación de metales pesados del residuo, (principalmente aluminio, hierro, cobre), las concentraciones iniciales de dichos metales fueron más altas para las fracciones más pequeñas, pero estos valores cayeron dramáticamente durante los primeros 50 días a la intemperie antes de estabilizarse.

Las principales diferencias entre fracciones de tamaño pequeño estaban en el $\mathrm{pH}$ y la solubilidad del calcio y de aluminio. En las etapas iniciales antes del tamizado y durante la intemperie de las fracciones de tamaño pequeño $(<4 \mathrm{~mm})$, el $\mathrm{pH}$ se controla y permanece sobre 12 , y es el mecanismo que bloquea la liberación de metales pesados.

En este corto periodo de tiempo, la precipitación de calcita, que constituye el mineral recién formado más extendido en las escorias y la neoformación de aluminosilicatos amorfos, parece ser capaz de atrapar metales más pesados a través de mecanismos de adsorción. En cuanto, a las fracciones más grandes de $6 \mathrm{~mm}$, la formación de etringita es la reacción que controla el $\mathrm{pH}$ y la solubilidad de los sulfatos, de aluminio y de calcio.

Las fracciones pequeñas de escorias, también se pueden reutilizar como material de construcción secundario, cumpliendo las reglamentaciones ambientales [Chimenos, J.M., et al; 2003]. 
- Después del proceso de intemperie de las escorias se considerará un material no tóxico, de acuerdo con la legislación medioambiental más restrictiva de seguridad ambiental de la reutilización de las escorias y sus lixiviados correspondientes, cumpliendo todos los requisitos de la orden de Generalitat de Cataluña [DOGC; 1996].

Se ha hecho una evaluación de las escorias de RSU incinerados físicamente en cuanto al contenido de humedad, densidad aparente de las escorias, coeficiente de forma entre otros. Así como de las propiedades mecánicas, en lo que se refiere a granulometría, resistencia a la abrasión, resistencia al impacto etc.

Además de un estudio de lixiviación en función del tiempo de almacenamiento. Se demuestra que las escorias almacenadas durante al menos un mes cumplen las normativas ambientales, en cuanto a contenido de metal y lixiviados [Forteza, R., et al; 2004].

- Las propiedades de lixiviación de las escorias utilizadas como sustituto de árido en capas de pavimento no unidas son aceptables, por el comportamiento mecánico, pero tiene limitaciones ambientales, en el uso de las escorias como materia en la construcción de carreteras.

Se hacen pruebas de lixiviación en laboratorio y en condiciones de campo de un tramo de pavimento, comparándolas se evidencia que las predicciones se cumplen y pueden ser muy realistas, porque las concentraciones iniciales de lixiviados de un número de elementos principalmente en $\mathrm{Na}, \mathrm{Ca}, \mathrm{K} \mathrm{Cl}^{-}$y SO${ }_{4}^{2-}$, son significativas, con el tiempo las emisiones disminuyeron. Deduciendo que después del proceso de lixiviación existe una alta posibilidad de que las escorias no sean perjudiciales para el medioambiente [Izquierdo, M.; 2007].

- Dejar las escorias a la intemperie durante 90 días, reduce el lixiviado de metales pesados, estabiliza el $\mathrm{pH}$, y posibilita su utilización como material secundario para edificación [Chimenos, J.M., et al; 2000].

En cuanto a los cloruros, el estudio de Goñi, S., et al. (2007), donde se ha utilizado muestras de escorias y cenizas volantes de dos incineradoras españolas de RSU, la de Valdemingómez (horno de lecho fluidizado) y Melilla (horno de parrilla), han reflejado un contenido de cloruros en las escorias en la primera de $3,6 \%$ y en la segunda de $0,7 \%$ porcentaje en peso [Goñi, S., et al; 2007]. 
Se concluye del proceso de intemperie de las escorias de RSU, que los principales inconvenientes se pueden subsanar dejando las escorias a la intemperie entre 30 y 90 días, periodo en el cual se produce la oxidación de algunos metales, la disolución y precipitación de los hidróxidos y sales de los cationes principales, la carbonatación, la neutralización del $\mathrm{pH}$, la disminución del contenido de cloro y finalmente, la neoformación de minerales arcillosos de vidrio [Chimenos, et al.; 2003]. Los autores Forteza, R., et al. (2004) han concluido que almacenando durante al menos un mes las escorias, sus propiedades mecánicas se asimilan a la de los áridos naturales [Forteza, R., et al; 2004].

\subsubsection{Condiciones de reutilización de escorias de RSU como árido de hormigón}

Una condición para la reutilización de las escorias de incineradora como árido es que no contenga elementos férreos, y el contenido de materia orgánica debe ser mínimo porque puede dar lugar a la inestabilidad mecánica [Castell, X.E.; 2000], que se reduce tanto con el reciclaje, como con el envejecimiento (a la intemperie) de las escorias.

El paso a seguir es la trituración hasta obtener tres tamaños de grano. El objetivo es lograr que este árido pueda constituir un alto porcentaje del total de los áridos de hormigón. Hay que evitar el polvo, ya que al margen de no ser útil como árido, contiene mayor cantidad de materiales pesados. Una vez trituradas las escorias los datos se reflejan en la Tabla 2.7 (composición estándar) y en la Tabla 2.8 (propiedades físicas) [Castell, X.E.; 2000].

Tabla 2.7. Caracterización de escorias de incineradora de RSU trituradas [\%] [Castell, X.E.; 2000].

\begin{tabular}{lrrr}
\hline \multicolumn{1}{c}{ Fracción } & $5,50-8,00[\mathrm{~mm}]$ & $8,00-11,50[\mathrm{~mm}]$ & $11,50-16,00[\mathrm{~mm}]$ \\
\hline Escoria magnética & - & - & - \\
Escoria no magnética & 45,00 & 55,60 & 50,60 \\
Vidrio & 44,90 & 40,00 & 45,90 \\
Materiales cerámicos & 1,30 & 2,40 & 3,40 \\
Piedras & 8,70 & 2,00 & 10,10 \\
Papel & 0,10 & - & - \\
\hline
\end{tabular}


Tabla 2.8 Propiedades físicas de escorias de incineradora de RSU trituradas [Chimenos, J.M., et al; 1999] [Berge, E.R., y Neal, J.A.; 1998].

\begin{tabular}{lcc}
\hline \multicolumn{3}{c}{ Escorias } \\
\hline & Diámetro [mm] & {$[\%]$} \\
& $0,00-1,00$ & 18,00 \\
& $1,00-2,00$ & 14,00 \\
Granulometría y porcentaje en peso & $2,00-4,00$ & 21,00 \\
& $4,00-6,00$ & 15,00 \\
& $6,00-16,00$ & 24,00 \\
& $16,00-40,00$ & - \\
\hline Densidad de conjunto [g/cm $\left.{ }^{3}\right]$ & & $1,00-1,10$ \\
Absorción de agua [\%] & 2,36 \\
Valor de abrasión de los Ángeles [\%] & & 40,00 \\
\hline
\end{tabular}

La aplicación más extendida para la utilización de las escorias, es como material a granel para compactaciones. Los ensayos arrojaron que el problema más importante en el uso de las escorias es el lixiviado. Cuando son empleadas como sub-base de carretera, los lixiviados contienen: sulfatos, cloruros, Zn, Al, $\mathrm{Ni}, \mathrm{Cu}, \mathrm{Pb}, \mathrm{Cr}$ y Cd [Castell, X.E.; 2000].

Debido a la variedad de escorias que existe y a su diferente naturaleza fisioquímica, la agencia central de Medio Ambiente sueca creó un protocolo de aplicación, se sintetiza, en:

- Cribado inicial para separar los materiales magnéticos.

- No usar tamaño de grano superior a $50 \mathrm{~mm}$.

- No emplear más del $10 \%$ de partículas de tamaño inferior a 0,06 mm.

- Poseer una perdida por calcinación inferior al 4\%.

- El material debe estar almacenado un mínimo de 3 meses.

- No usar escorias cuyos ensayos de laboratorio denoten una lixiviación de metales que pueden darse en el proyecto definitivo.

A partir de estas normas generales la aplicación debería ser:

- Uso de escorias para sub-bases, o rellenos en general (espesor no exceda $3 \mathrm{~m}$ ).

- Las escorias deben colocarse por encima del nivel del agua y por debajo del pavimento. 
- Empleo para rellenar, preferentemente, los cimientos de las edificaciones livianas.

- Uso para fabricación de sub-bases de carreteras con tráfico ligero.

Se recomienda donde sea posible la estabilización de las escorias a base de cemento o cenizas volantes de centrales térmicas [Castell, X.E.; 2000].

Para que la aplicación como sustituto del árido natural por escorias de RSU sea posible, se deben cumplir algunos condicionantes previos:

- Que no se reduzca de forma significativa la resistencia del hormigón, con escorias que sean aceptables desde el punto de vista técnico y medioambiental.

- Que el tratamiento que haya que realizar a las escorias para su aprovechamiento sea el mínimo posible (año 2007) [CEDEX; 2007].

- Que los contenidos en cloruros u otros agentes corrosivos no supongan un peligro para las armaduras de acero al carbono en la estructura, y como medida preventiva se puedan utilizar armaduras de acero inoxidable.

\subsubsection{Utilización conjunta de cenizas volantes y escorias de RSU en morteros y hormigones}

Hay estudios que consideran la combinación de escorias y cenizas volantes de RSU en la formulación del mortero, en diferentes porcentajes mezclado con áridos naturales (rara vez han sido analizados). En este caso el uso adecuado de ambos subproductos podría corregir el bajo contenido de material fino que caracteriza a las escorias, mejorando la compactación del hormigón [Ginés, O., et al; 2009].

Collivignarelli, C. y Sorlini, S. (2002) han elaborado pruebas para determinar las propiedades de las proporciones mixtas en la relación de escorias/cenizas volantes de RSU, las formulaciones adecuadas después de varias mezclas han sido $95 / 5$ y 90/10, los resultados han sido dos pruebas de lixiviación comprobando menor cantidad de metales liberados, para los efectos ambientales, y una vez elaborado el hormigón las propiedades mecánicas de resistencia a compresión [Collivignarelli, C. y Sorlini, S.; 2002]. 


\subsection{DURABILIDAD DE LAS ESTRUCTURAS DE HORMIGÓN ARMADO}

La importancia de la durabilidad de las estructuras de hormigón armado, es fundamental para el uso sostenible de recursos naturales. La reducción del impacto ambiental se puede lograr si se actúa modificando la composición del hormigón o actuando en el componente que más huella medioambiental tiene el cemento [Flatt, R.J., et al; 2012].

Así mismo, la sociedad reclama una mayor durabilidad de las construcciones, no solo por la importante inversión económica, sino también por motivos medioambientales y de sostenibilidad, además los conocimientos técnicos actuales lo pueden garantizar. Esa durabilidad depende de varios factores como el diseño, la calidad de ejecución, y se encuentra limitada por agentes que deterioran el hormigón y los que corroen sus armaduras [Medina, E. y Bastidas, D.M.; 2013].

La Instrucción de Hormigón Estructural EHE-08 (2008, art. 37) define la durabilidad de una estructura de hormigón como su capacidad para soportar durante la vida útil para la que ha sido proyectada, las condiciones físicas y químicas a las que está expuesta, y que podrían llegar a provocar su degradación, como consecuencia de efectos diferentes a las cargas y solicitaciones consideradas en el análisis estructural.

La vida útil de una estructura de hormigón armado depende principalmente de la composición de los materiales, del tiempo y de las condiciones de exposición, de la relación agua/cemento, de la cantidad de cemento y de la resistencia mínima del hormigón empleado [Andrade, C. y Alonso, M.C.; 1998].

Entre los agentes que deterioran el hormigón se encuentran los sulfatos y los efectos de las heladas y la erosión. Se pueden evitar confeccionando hormigones de buena calidad, utilizando cementos resistentes a los sulfatos, usando aditivos para crear poros de pequeño diámetro y poco espaciado o eligiendo áridos adecuados [Fernández Cánovas, M.; 2007].

Los áridos del hormigón se consideran inertes, aunque no siempre es así. Algunos áridos pueden reaccionar con los álcalis del cemento, provocando expansión y deterioró. Una de las soluciones es extraer los áridos de fuentes adecuadas y usar cementos de bajo contenido en álcalis, puzolanas previamente ensayadas o escorias trituradas.

Las estructuras pueden verse afectadas por reacciones químicas de los áridos, algunas son favorables, otras pueden dañar seriamente al hormigón, provocando expansiones internas anormales: fisuración, desplazamiento de elementos que forman parte de estructuras mayores y perdida de resistencia [ACl 210.2R-01; 2001] [Woods, H.; 1968]. 
Las reacciones químicas más importantes que pueden ocasionar los áridos son:

- Reacción álcali-sílice: involucra una reacción entre el ión $\mathrm{OH}^{-}$asociado con álcalis $\left(\mathrm{Na}_{2} \mathrm{O}\right.$ y $\left.\mathrm{K}_{2} \mathrm{O}\right)$ del cemento y otras fuentes, con ciertos componentes silíceos que pueden estar presentes en los áridos. Las señales de advertencia son fisuración y grandes expansiones que en ocasiones permiten remediar el problema de manera oportuna. Las temperaturas elevadas aceleran las reacciones químicas, a bajas temperaturas las reacciones pueden permanecer latentes.

- Reacción álcali-carbonato: ciertas rocas carbonatadas participan en reacciones con los álcalis, en algunos casos estas reacciones producen expansión y fisuración perjudiciales. Para minimizar los efectos, evitar rocas reactivas eligiendo áridos en lugares adecuados, utilizar un menor tamaño nominal y cemento de muy bajo contenido de álcalis (inferior a $\left.0,6 \% \mathrm{Na}_{2} \mathrm{O}\right)$.

- Otras reacciones: químicas perjudiciales que involucran a los áridos incluyen la oxidación o hidratación de ciertos óxidos, sulfatos o sulfuros inestables producidos cuando los áridos son incorporados al hormigón. [ACl 210.2R-01; 2001].

La corrosión es el principal problema de durabilidad de las estructuras de hormigón, y el más difícil de evitar, aunque el recubrimiento del hormigón que las rodea las protege doblemente, actuando como barrera física y como barrera química por la capa de óxido pasivante que se forma en la interfase acerohormigón.

El recubrimiento del hormigón es una barrera física que separa el acero del contacto directo con el medio exterior más o menos agresivo, evitando el ingreso de agua, oxígeno, cloruros, entre otros agresivos. Por lo tanto, su espesor y permeabilidad son los dos factores que controlan su eficacia.

Sin embargo, la red continua de poros en la masa del hormigón creada durante el fraguado por la evaporación del agua de amasado, y las inevitables fisuras que se forman en la superficie por la retracción del hormigón, su contracción térmica y la deformación propia de la estructura, favorece a largo plazo el acceso de los mencionados agentes agresivos [Medina, E. y Bastidas, D.M.; 2013]. 


\subsection{LA CORROSIÓN DE LAS ARMADURAS DE HORMIGÓN}

Las armaduras deberían estar exentas de corrosión para tener la longevidad deseada durante la vida útil de la estructura, porque el óxido aumenta en volumen agrietando el hormigón. Este deterioro empeora la situación porque deja vía libre a la continuidad de la corrosión.

La protección efectiva contra la corrosión de armaduras es proporcionada por una capa de óxido pasivante formada en la interfase acero-hormigón, autorregenerable, de espesor pequeño (en torno a $10 \mathrm{~nm}$ basada en la alcalinidad elevada del hormigón que la rodea). El cemento cuando fragua eleva el pH del hormigón a valores entre 12,5 y 13,5 cuando es correcta la dosificación agua/cemento.

Así se mantiene el acero pasivo, excepto que se produzca una disminución del valor del pH, según el Comité Euro-Internacional du Beton CEB, valores inferiores a 11 representa la rotura de la capa pasiva del acero [CEB; 1998], otros lo sitúan en 11,4 [Gjorv, O.E.; 1982] [Saeki, N., et al; 1984], o incluso en 9,5 como critico [Bonnet, D. y Rubaud, M.; 1976].

La disminución del $\mathrm{pH}$ se puede produce fundamentalmente por carbonatación del hormigón [Medina, E. y Bastidas, D.M.; 2013].

Para evitar la corrosión por iones despasivantes (cloruros), la normativa limita el contenido de cloruros en el hormigón fresco.

En España, según la instrucción la EHE-08, los cloruros que en el hormigón pueden provenir de los componentes o las materias primas (áridos, agua, aditivos acelerantes del fraguado, etc,), se limitan a un máximo de 0,4\% con relación al peso del cemento, o bien, $0,05-0,1 \%$ con relación al peso del hormigón [Durar, R.; 1997].

En la mayor parte de casos, la contaminación por cloruros proviene por estar la estructura sumergidas parcial o totalmente en el agua de mar, con contenido medio de sales diversas del 3,5\%, o por aportes en la superficie del hormigón durante su vida útil, a través de la niebla salina por cercanía de la costa o en forma de sales para el deshielo en el caso de los puentes de carretera en zonas de heladas.

Los iones cloruros son capaces de penetran por absorción capilar y posterior difusión en el hormigón, y cuando superan un umbral crítico de concentración en las proximidades de las armaduras, rompen de forma local la capa pasiva, aunque el $\mathrm{pH}$ sea elevado, desencadenando la corrosión en forma de picadura. 
En los primeros momentos los cloruros requieren del concurso del oxígeno y de los resquicios o heterogeneidades geométricas de la superficie del metal en la interfase acero-hormigón, para iniciar la corrosión. El proceso comienza en una etapa de aireación diferencial en los resquicios, que la presencia de cloruros transforma en una acidificación local progresiva hasta que se destruye la capa pasiva [González, J.A. y Miranda, J.; 2007]. Una vez iniciada la corrosión, el pH en la interfase acero-productos de corrosión es ácido, aún en el seno de un medio muy alcalino como el hormigón, por lo que no son necesarios los cloruros para propagar la corrosión [Cobo, A.; 2001].

El hormigón representa la barrera física del recubrimiento de las armaduras y a su vez con la capacidad para preservar las condiciones de elevado $\mathrm{pH}$ (necesarias para mantener las armaduras en estado pasivo), limitando la velocidad de penetración de sustancias ácidas externas.

La carbonatación del hormigón, la acción de los cloruros o combinacción de ambos, son factores necesarios, desencadenantes y acelerantes de la corrosión de las armaduras, pero los dos factores condicionantes que regulan la cinética del fenómeno son la disponibilidad del oxígeno y el grado de humectación del hormigón [González Fernández, J.A; 1989], donde la resistividad del hormigón es el parámetro que mejor se relaciona con los que miden la velocidad de corrosión [Andrade, C., et al; 2002].

Los iones despasivantes y la corrosión bajo tensión dan lugar a una corrosión de tipo localizado, mientras la reducción en el pH por carbonatación del hormigón permite una disolución completa de la capa pasivante generando una corrosión uniforme [Andrade, C. y González, J.; 1995].

El producto de la corrosión presenta un volumen hasta 6,5 veces superior al del propio acero [Otieno, M.B., et al; 2010], que genera una tensión sobre el recubrimiento de hormigón, superando su resistencia a tracción y provocando su rotura. Esto agrava el problema al dejar las armaduras más expuestas.

Según estudio de la durabilidad del hormigón en relación con la corrosión producida por carbonatación y la presencia de cloruros en el hormigón, Loreto, G., et, al. (2010) demostró que la resistencia a tracción disminuye cuando aumenta la carbonatación, sin embargo, aumenta la resistencia a tracción con el avance del ataque por cloruros.

Las armaduras de hormigón expuestas a la acción de los iones cloruro, necesitan inspecciones con periodicidad mínima, reparaciones más frecuentes y mantenimiento más costoso.

El cambio de las armaduras de acero dañadas por causa de corrosión puede suponer un valor económico de hasta el 20\% [Smith, F.N., et al; 1999]. Siendo apropiado aplicar sistemas que eviten la corrosión y alarguen la vida en 
servicio de las estructuras de hormigón, por lo menos de las expuestas a ambientes agresivos.

Los métodos para evitar la corrosión de las armaduras están divididos en los que actúan sobre el hormigón y los que actúan en las armaduras. Para los hormigones, está la mejora de su calidad y del recubrimiento, y la aplicación de protectores en la superficie del hormigón.

En cuanto a las armaduras, se halla la adición de inhibidores de corrosión y están los métodos electroquímicos, como la protección catódica, la extracción electroquímica de los cloruros o la realcalinización electroquímica (aunque minimizan las causas de la corrosión, no es suficiente para detener el proceso si las armaduras ya se encuentran en estado activo es un método preventivo, no un método de rehabilitación).

Y los que emplean armaduras especiales como acero al carbono recubiertas con epoxi, las galvanizadas (uno de los edificios más emblemáticos de Australia el "Sidney Opera House" está construido con armaduras de acero galvanizado en la Figura 2.3), las barras de polímeros reforzados con fibras de carbono o las armaduras de acero inoxidable, finalmente el único método eficaz que logra una gran durabilidad de las estructuras de hormigón, especialmente en ambientes agresivos y con presencia de cloruros [Miranda, J.M., et al; 2007] [Bastidas, D.M., et al; 2008 a].

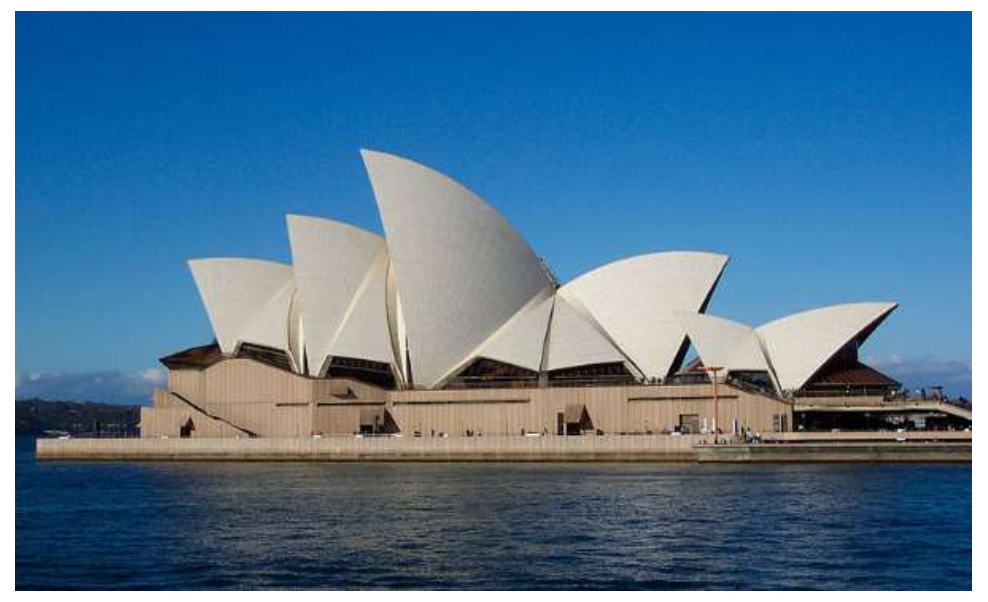

Figura 2.3 Teatro Sidney Opera House de Australia.

El ataque de los cloruros es un problema difícil de ser evitado. La característica que singulariza el corrugado de acero inoxidable frente al de acero al carbono es la gran resistencia a la corrosión por cloruros. Se ha demostrado que la estabilidad de la capa pasiva en ambos aceros es alta en ambientes con $\mathrm{pH}$ altos y que es mayor, en torno a un $2 \%$, la concentración necesaria de 
cloruros para iniciar la corrosión por picadura en el acero inoxidable que en acero al carbono [Gedge, G.; 2000].

Los autores Knudsen, A. et al. (2001) han indicado que ese nivel crítico de cloruros para el inicio de la corrosión es de cinco a diez veces superior en los aceros inoxidables austeníticos y en los dúplex que, en el acero al carbono, [Knudsen, A., et al; 2001] otros autores, García-Alonso et al. (2007 b) el nivel lo establecen directamente en diez veces [García-Alonso et al; 2007 b]. Y diez veces mayor cuando se usan grados dúplex, que refuerzan el acero al carbono [Medina, E., et al; 2012].

En 1941 en el embarcadero de Progreso, en el Golfo de México (Figura 2.4), se utilizó por primera vez el acero inoxidable en la estructura, equivalente al actual grado EN 1.4301 (AISI 304) para armar los arcos del embarcadero, que se extiende $2 \mathrm{~km}$ mar adentro. Actualmente se encuentra en perfecto estado de uso, sin reparaciones significativas.

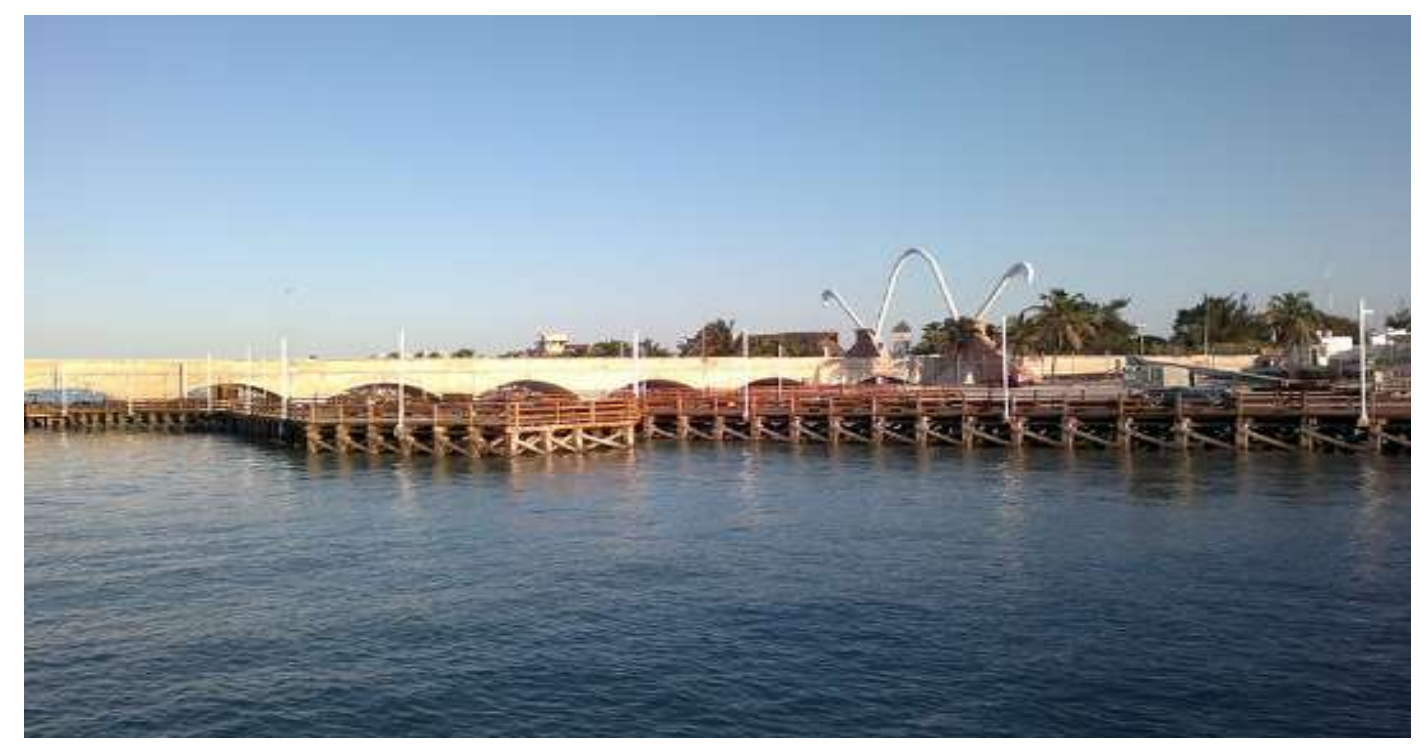

Figura 2.4 Embarcadero de Progreso, Yucatán (México) [Gedge, G.; 2003].

En una inspección realizada en 1999, las armaduras de acero inoxidable no presentaron señales de corrosión, aunque se registraron porcentajes de ión cloruro por encima del 1,9\% respecto al peso de hormigón a $20 \mathrm{~mm}$ de profundidad en el recubrimiento, lo que significa nivel de cloruros al menos diez veces más alto que el considerado como crítico para iniciarse la corrosión para un acero al carbono ordinario [ARMINOX; 1999]. En 2004 se realizó otra inspección hallando signos de corrosión en los ganchos de algunas barras [Torres Acosta, A.A.; 2006]. 


\subsubsection{CORROSIÓN ELECTROQUÍMICA}

Esta investigación analiza la posible corrosión electroquímica, creada por el contacto de las estructuras de hormigón armado con el ambiente exterior, que se desencadene en forma de picadura si hay $\mathrm{Cl}^{-}$, ó si el ataque es por la presencia de cloruros, que puedan estar presentes en las escorias de RSU debido a su composición química, dependiendo del origen de las mismas.

El proceso de corrosión del acero es un proceso electroquímico que se produce en una solución acuosa (humedad en los poros del hormigón), donde los átomos de mayor energía se ionizan pasando a la solución como cationes, dejando en el metal los electrones cedidos González Fernández, J.A.; 1989]. La reacción de doble sentido se expresa [2.2] así:

$$
\mathrm{Fe} \leftrightarrows \mathrm{Fe}^{2+}+2 \mathrm{e}^{-}
$$

Paralelamente, el oxígeno disuelto en el agua de los poros del hormigón que están en contacto con el acero se combinan con los electrones suministrados, dando lugar a la formación de iones hidroxilo [2.3]:

$$
\mathrm{O}_{2}+2 \mathrm{H}_{2} \mathrm{O}+4 \mathrm{e}^{-} \rightarrow 4 \mathrm{OH}^{-}
$$

Por último, los iones hidroxilo se combinan con los cationes de hierro para formar el hidróxido de hierro [2.4]:

$$
\mathrm{Fe}^{2+}+2 \mathrm{OH}^{-} \rightarrow \mathrm{Fe}(\mathrm{OH})_{2}
$$

A la primera reacción [2.2] se le denomina proceso anódico. Por tratarse de partículas cargadas, se crea una diferencia de potencial en la interface acerosolución que, al ir aumentando, se opone cada vez con más fuerza al paso de los nuevos iones, hasta que aun cierto valor de dicha diferencia de potencial (característico de cada combinación metal-solución) se alcanza un equilibrio, de forma que el continuo intercambio de partículas entre metal y solución se realiza a igual velocidad en ambos sentidos de la reacción.

A la segunda reacción [2.3] se la denomina proceso catódico, que rompe el equilibrio citado en el párrafo anterior, provocando y condicionando la velocidad de corrosión del acero. La humedad influye enormemente sobre la resistividad del hormigón $\rho$, factor que resulta controlante de la facilidad para moverse los iones en el medio y, por tanto, de la velocidad de corrosión [Andrade, C.; 1984]. En algunas situaciones desfavorables, el progreso de la corrosión depende de procesos distintos al catódico [González, J.A.; 2004].

El proceso de corrosión de las armaduras del hormigón armado se observa en la Figura 2.4, partiendo de dos procesos individuales anódico y catódico obteniendo el hidróxido de hierro. 


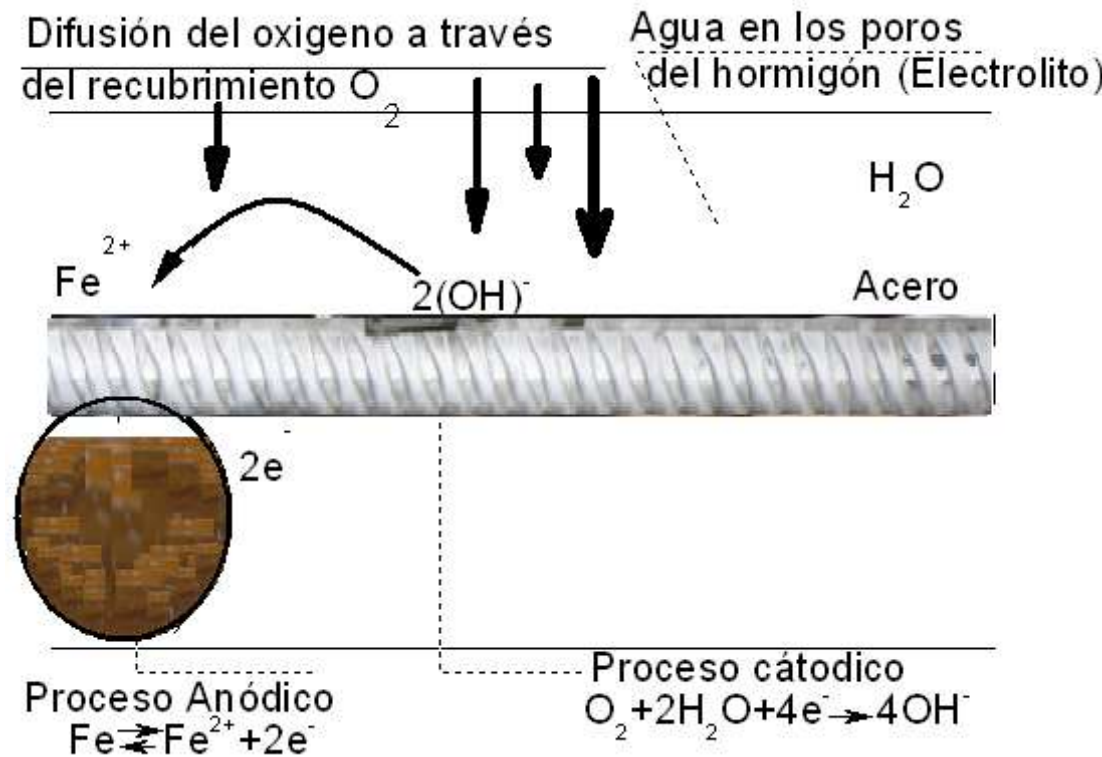

Figura 2.4 Esquema simplificado de corrosión de armadura.

Por la inevitable heterogeneidad del metal, la superficie de las armaduras (de reactividad elevada por las valencias insatisfechas, con menos enlaces que los átomos del interior), se dividen en zonas anódicas y catódicas, localizadas en lugares diferentes, desarrollándose en cada una las reacciones mencionadas.

En la reacción anódica se produce la oxidación del metal y en la reacción catódica reducción del oxígeno. El proceso global de corrosión lo constituye la reacción total de las zonas.

El flujo de electrones del ánodo hasta el cátodo, a través de la barra de acero, es generado por la diferencia de potencial existente entre ambos. A un potencial inferior, no se produce disolución del acero. El circuito eléctrico se completa por el movimiento de los aniones y cationes en el electrolito (solución acuosa en los poros del hormigón). Por la existencia de este transporte eléctrico a través del electrolito y esta forma de corrosión es llamada corrosión electroquímica o también llamada "pila de corrosión".

La reacción de corrosión depende no solo del potencial, también del pH del medio. De alguna manera los iones $\mathrm{H}+\mathrm{y} \mathrm{OH}^{-}$condicionan las reacciones de corrosión, pues los iones $\mathrm{Fe}^{2+}$ producidos en ellas dan lugar a hidróxidos en presencia de aquellos, a potenciales que ya dependen del $\mathrm{pH}$, compuestos que influyen sobre la velocidad de corrosión, a través de sus características más o menos protectoras. 
Se ha resumido de manera gráfica en el diagrama de Pourbaix en la Figura 2.5 que representa de forma simplificada el hierro sumergido en agua a $25^{\circ} \mathrm{C}$ [Pourbaix, M.; 1966]. En el eje vertical se representa el potencial del metal $E_{h}$ respecto al electrodo normal de hidrógeno (NHE). En el eje horizontal se representa el $\mathrm{pH}=-\log \left[\mathrm{H}^{+}\right]$. Entre las líneas de trazos superior e inferior el agua estable a 1 atm de presión. Por encima de la línea superior se desprende oxígeno en forma de gas, y por debajo de la línea inferior, hidrogeno.

En presencia de agua, la fase metálica sólo es estable a potenciales inferiores a los de equilibrio, en la zona denominada de inmunidad en el diagrama. En las demás zonas, el metal tiende a corroerse, salvo cuando los productos formados de la corrosión son insolubles y pueden reducir la velocidad de corrosión, separando totalmente el metal del medio agresivo y garantizando su estabilidad química, causando la pasividad del mismo.

Las armaduras embebidas en el hormigón se encuentran habitualmente en el punto $\mathrm{P}$ del diagrama, en estado pasivo por el alto $\mathrm{pH}$ del medio. Cuando el hormigón se carbonata, reduciendo su $\mathrm{pH}$, el punto $\mathrm{P}$ del diagrama se desplaza en horizontal hacia la izquierda, adentrándose en la zona rayada de corrosión. En la zona de inmunidad se mantienen los metales sometidos a protección catódica.

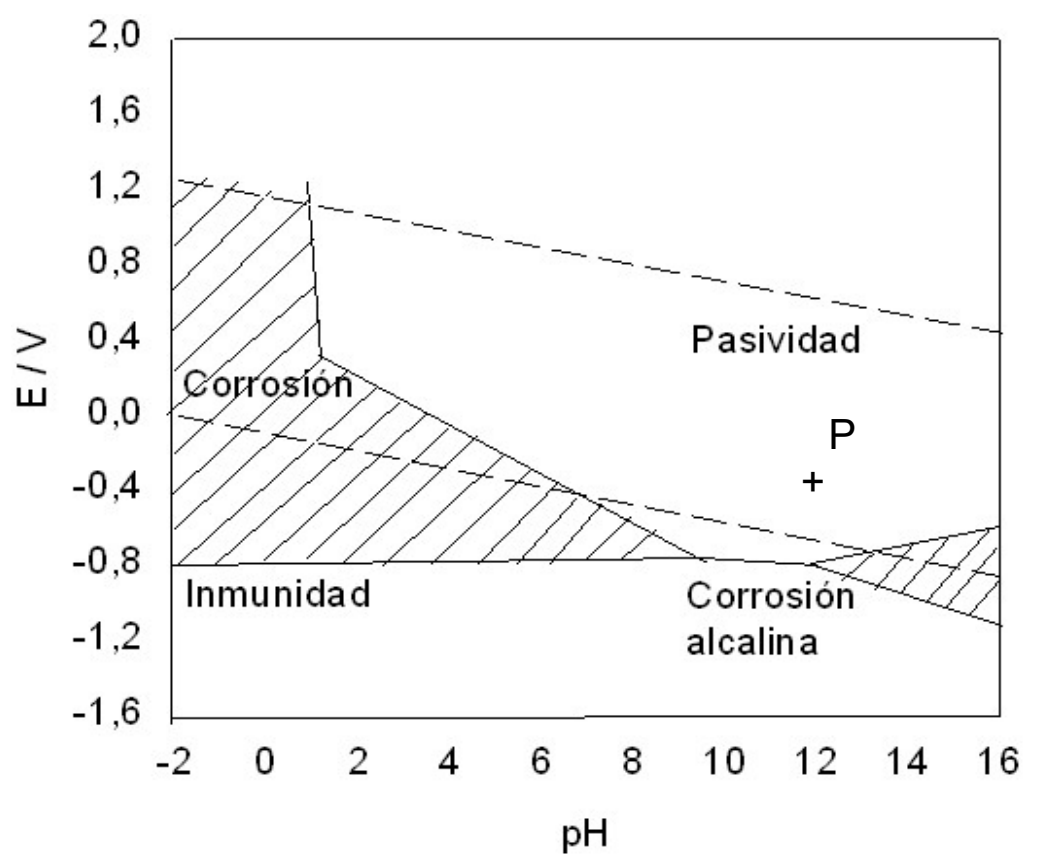

Figura 2.5 Diagrama simplificado de Pourbaix para el hierro en el agua $25^{\circ} \mathrm{C}$. 
La capa o película pasiva se rompe solo en pequeñas áreas, en la corrosión por cloruros, [González Fernández, J.A.; 1989]. La corrosión no se produce de forma general sino por picaduras de entre 0,1 y $1 \mathrm{~mm}$ de profundidad, en ocasiones inferiores [Di Caprio, G.; 1999], con una importante reducción de la sección de la armadura.

La zona anódica tiene muy poca superficie (centro de la picadura), en comparación con la zona catódica (anillo circundante), creando condiciones de flujo de corrientes anódicas de elevada densidad.

La zona catódica se extiende hasta $20 \mathrm{~cm}$ más allá de la fisura [Schiessi, P. y Raupach, M.; 1997].

Los iones cloruros presentes en el hormigón no siempre representan peligro para la corrosión. Una parte está ligada químicamente con el aluminato tricálcico del cemento formándose la Sal de Friedel o monocloroaluminato de calcio hidratado $3 \mathrm{CaO}: \mathrm{Al}_{2} \mathrm{O}_{3}: \mathrm{CaCl}_{2}: \mathrm{Al}_{2} \mathrm{O}_{3}: 10 \mathrm{H}_{2} \mathrm{O}$, estable aunque disminuya el $\mathrm{pH}$, otra parte queda inmovilizado por enlaces físicos (quedan adsorbidos a los silicatos cálcicos amorfos) y el resto queda en forma de cloruros libres en la solución de los poros del hormigón (la fracción de cloruros más peligrosa), que son los que pueden corroer el acero [Lannegrand, R.; 2001].

En el hormigón se pueden encontrar los cloruros, bien porque se añadan con sus componentes, situación poco habitual por el control ejercido sobre los mismos, ó bien por la penetración desde el exterior a través de los poros, situación que se da, por ejemplo, en ambientes marinos, en edificios que albergan piscinas cubiertas o cuando se utilizan sales de deshielo en el caso de puentes de carretera.

La concentración de cloruros que penetran en el hormigón por difusión decrece desde la superficie hacia el interior. Los ciclos de humectación y desecación de la superficie del hormigón con agua conteniendo cloruros, producen un aumento de estos en la capa superficial, que penetran por succión capilar [Meira, G.R., et al; 2007].

El tiempo que tardan los cloruros en llegar a las armaduras depende de la concentración de los mismos en el medio exterior, de la naturaleza del catión que acompaña al cloruro, de la calidad del hormigón (tipo y proporción del cemento, proporción de aluminato tricálcico, relación a/c, grado de hidratación o maduración, etc.), de la temperatura y del ancho y cuantía de las fisuras en el hormigón.

El proceso de degradación de las estructuras de hormigón se muestra en el diagrama de Tuutti [Tuutti, K.; 1982], de forma simplificada y cualitativa, más detallado por otros autores Li [Li, C.Q.; 2004]. En la Figura 2.6, se representan los diagramas de ambos autores (Tuutti y Li), [Otieno, M.B.; 2011]. 
Hasta el fallo estructural se distinguen cuatro fases: una primera de iniciación, con el ingreso de cloruros y $\mathrm{CO}_{2}$ a través del recubrimiento del hormigón, una segunda en la que se inicia la corrosión de las armaduras sin llegar a romper el hormigón, una tercera en la que aparecen las primeras fisuras y desprendimientos del recubrimiento y una cuarta, acelerada por el fácil acceso del oxígeno y el agua, hasta el colapso.

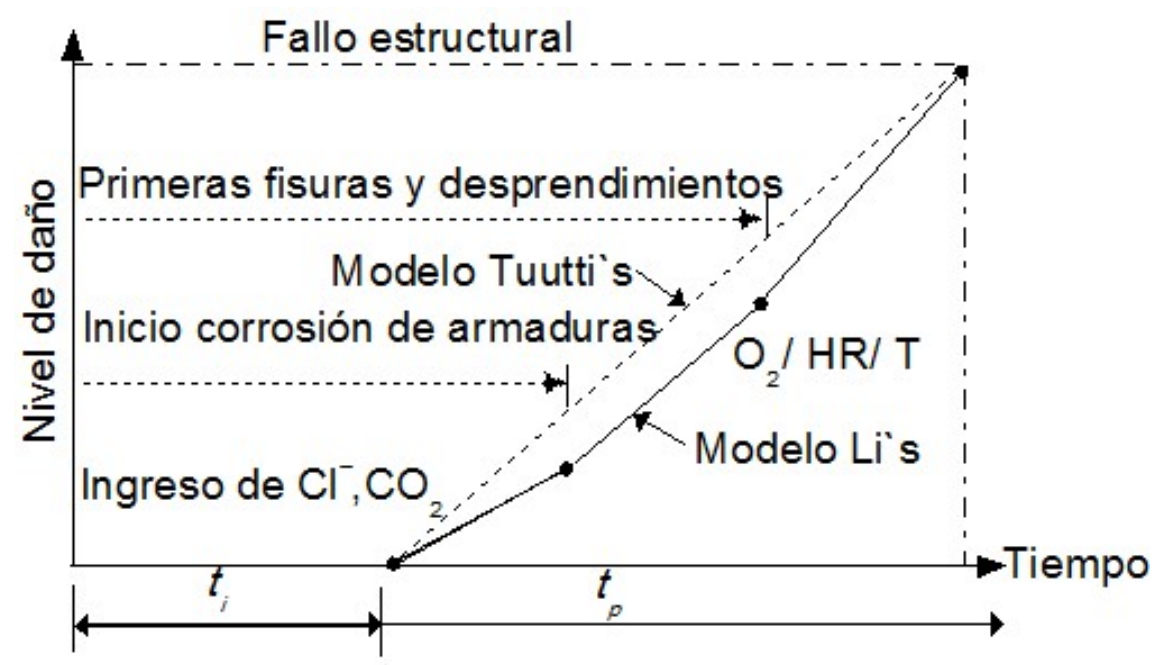

Figura 2.6 Fases de la corrosión y sus efectos en las estructuras de hormigón armado [Otieno, M.B.; 2011].

Los productos derivados de la corrosión son de dos a seis veces más voluminosos que el acero [Otieno, M.B., et al; 2010], provocando tensiones de tracción en el hormigón circundante que acaban fisurándolo y desprendiéndose el recubrimiento.

\subsection{ARMADURAS DE ACERO INOXIDABLE}

\subsubsection{DEFINICIÓN Y CLASIFICACIÓN DE LOS ACEROS}

Se define acero al que contiene hierro como material predominante, y el contenido de carbono suele ser inferior al $2 \%$, y contiene además otros elementos. Por su composición química los aceros son clasificados, en aceros no aleados, aceros inoxidables y otros aceros aleados [AENOR UNEEN 10020; 2001).

- Los aceros no aleados son los que el contenido de cualquiera de sus elementos es inferior al valor límite, conforme a la norma AENOR UNEEN 10020; 2001. 
Aquí se incluyen los aceros no aleados de calidad, que son a los que se les exige características específicas como, tenacidad, tamaño de grano y/o deformabilidad En este grupo se encuentra el acero al carbono B-500-SD, el más empleado en la construcción en España [Medina, E.; 2012].

- Los aceros inoxidables contienen un mínimo de 10,5\% - 12\% de cromo y un máximo de $1,2 \%$ de carbono (algunas veces supera el $2 \%$, este valor es el contenido límite habitual que separa el acero de la fundición).

El contenido mínimo de cromo permite la formación de una capa autoprotectora muy fina de óxido de cromo, haciéndolo resistente a la corrosión en la atmosfera a la temperatura ambiente o en una solución que dé lugar a condiciones de ataque electroquímico (como las armaduras embebidas en el hormigón que la corrosión penetra del exterior al interior).

Algunos tipos de aceros inoxidables contienen otros elementos aleantes. Los principales son el níquel y el molibdeno, y otros son el manganeso, el titanio, el niobio y el nitrógeno [Medina, E. y Bastidas, D.M.; 2013].

- Y finalmente, los otros aceros aleados, que no cumplen con la definición de acero inoxidable, debido a que el contenido de al menos uno de sus elementos es igual o superior al valor límite de la norma AENOR UNE-EN 10020; 2001.

\subsubsection{ACEROS INOXIDABLES}

Los aceros inoxidables por su microestructura se clasifican en: austeníticos, ferríticos, martensíticos, endurecidos por precipitación y austenoferríticos o dúplex. Los tipos austenítico y dúplex son los que tienen aplicaciones estructurales, para elaborar perfiles laminados y barras corrugadas para hormigón armado.

Según el contenido de níquel (aleación importante por el costo económico alto y desde mediados del año 2006 presenta grandes fluctuaciones del precio en el mercado), los aceros inoxidables, se dividen en dos grandes grupos: de bajo contenido en níquel cuando tiene menos del $2,5 \%$, y el resto de los aceros inoxidables.

El molibdeno es otro elemento aleante, junto al níquel (cuyo precio también es elevado, pero no es determinante en el coste final) y sufre fuertes fluctuaciones, aunque su porcentaje en la composición del acero inoxidable no suele superar el 3\%, no obstante, en los últimos años, se han desarrollado aceros inoxidables con bajo contenido en ambos aleantes, conocidos como aceros de baja aleación. 
Los diferentes tipos de aceros inoxidables se designan, según la norma ENE-EN 10088-1 [AENOR; 2006], por un código de cinco números, el primero designa el material acero, los dos números siguientes el grupo, las dos últimas cifras son secuenciales para cada aleación concreta. Y según la norma AISI (American Iron and Steel Institute) los tipos austeníticos se clasifican en la serie 300 y los dúplex con un número de cuatro cifras, las dos primeras indican el contenido de $\mathrm{Cr}$ y las dos siguientes de $\mathrm{Ni}$.

\subsubsection{ARMADURAS DE ACERO INOXIDABLE}

Las armaduras de acero inoxidable se fabrican como las tradicionales de acero al carbono, mediante laminación en caliente o en frío. Normalmente se utiliza el primer procedimiento para los diámetros de barra mayores (de 8 a 50 $\mathrm{mm}$ ) y el segundo para los menores (de 3 a $14 \mathrm{~mm}$ ) por la mayor precisión que proporciona en las dimensiones.

Las propiedades mecánicas de las armaduras de acero inoxidable que los fabricantes garantizan, están generalmente de acuerdo a la norma británica BS 6744 [Qian, S., et al; 2006].

Las armaduras de acero inoxidable laminadas en caliente tienen una ductibilidad muy superior a las de acero al carbono de alta ductibilidad B-500$\mathrm{SD}$, porque alcanza mayores ratios de endurecimiento $f_{s} / f_{y}(1,20-1,40$ del acero inoxidable frente a 1,20-1,23 del acero al carbono) y elevadas deformaciones máximas (18-30\% del acero inoxidable frente al $11-14 \%$ del acero al carbono).

En cambio, la deformación en frío de las barras de acero inoxidable incrementa mucho más que en las de acero al carbono las resistencias en el límite elástico y máxima (puede superar los $1000 \mathrm{~N} / \mathrm{mm}^{2}$ ), pero reduce notablemente la ductilidad, porque se acortan las ratios de endurecimiento $(1,03-$ $1,08)$ y las deformaciones máximas (entre el 5 y el $10 \%$ ).

El coeficiente de dilatación térmica de las armaduras de acero inoxidable varía con los grados, pero en general, es ligeramente superior al de las armaduras de acero al carbono. El coeficiente medio de los aceros dúplex, AISI 2304 y 2205 es de $13 \cdot 10^{-6}{ }^{\circ} \mathrm{C}$, y el de los austeníticos AISI 304 y 316 de $16 \cdot 10^{-}$ ${ }^{\circ} \mathrm{C}$, siempre entre 20 y $100^{\circ} \mathrm{C}$ [AENOR UNE-EN 10088-1; 2006], frente a $12 \cdot 10^{-}$ ${ }^{6}{ }^{\circ} \mathrm{C}$ del acero al carbono. No hay constancia de que suponga un inconveniente por fisuraciones en el hormigón que, en todo caso, tiene un coeficiente de dilatación idéntico al de los aceros dúplex.

Las características a destacar de las armaduras de acero inoxidable son dos: la resistencia a la corrosión y el comportamiento tenso-deformacional. 
La inversión económica que se genera con la utilización de armaduras de acero inoxidable, en lugar de las de acero al carbono, tiene una repercusión parcial sobre el coste total de la armadura de hormigón que depende de varios aspectos, como son el grado de acero elegido, el ahorro de armaduras si son de acero inoxidable por la posible relajación de las medidas de durabilidad del hormigón, o la utilización de dichas armaduras solo en los elementos estructurales más expuestos a los agentes agresivos.

La nueva armadura de acero inoxidable dúplex de bajo contenido en níquel EN 1.4482 (AISI 2001), es una opción a considerar muy interesante para alargar la vida útil de la estructura, con un sobrecoste inicial contenido que se amortiza rápidamente con el ahorro en los costes de mantenimiento a medio y a largo plazo.

Las barras corrugadas elaboradas con acero inoxidable, incluso las de tipo dúplex de bajo contenido en níquel, son en la actualidad de cuatro a siete veces más caras que las tradicionales de acero al carbono B-500-SD, dependiendo del grado elegido.

Esto se debe al sobrecoste que suponen los materiales aleantes. Además, el níquel es una aleación que viene presentando, desde el año 2006, fluctuaciones en el precio de mercado, lo que le convierte en el aleante más determinante en el precio final del acero inoxidable.

Por ese motivo, en los últimos años se están experimentando con nuevas aleaciones inoxidables que tengan las mismas o similares prestaciones que las clásicas y multifuncionales AISI 304 y AISI 316, pero cuyo precio sea más económico, basándose fundamentalmente en reducir el contenido de níquel, aunque eso suponga el incremento de otros aleantes como el manganeso o el cobre.

Buena prueba de ello son los aceros dúplex primero, y los austeníticos y dúplex de bajo contenido en níquel después. Sin embargo, ese sobrecoste del material de acero inoxidable tiene una repercusión parcial sobre el coste final de la estructura de hormigón, cuya valoración exacta se tiene que calcular para cada caso concreto.

En esta Tesis Doctoral se utilizan el convencional acero al carbono B-500SD y los aceros inoxidables austenítico EN 1.4301 (AISI 304), el dúplex 1.4362 (AISI 2304) y el dúplex bajo contenido en níquel EN 1.4482 (AISI 2001), con un diámetro de $\varnothing 6$. 


\section{Capítulo 3}

\section{TÉCNICAS EXPERIMETALES}

Las técnicas experimentales empleadas en la realización de esta Tesis Doctoral, son las siguientes:

- Análisis químico de las escorias de RSU.

- Clasificación granulométrica de las escorias de RSU.

- Caracterización mecánica de morteros de cemento Portland.

- Caracterización mecánica de hormigones de cemento Portland.

- Técnicas electroquímicas para el estudio de la corrosión en las armaduras embebidas en morteros elaborados con escorias de RSU.

\subsection{ANÁLISIS QUÍMICO DE LAS ESCORIAS DE RSU}

Para la determinación de Pérdidas por Calcinación (PxC) ó LOI (Loss of Ignition) y para el análisis químico de las escorias de RSU, las técnicas utilizadas son el Método Gravimétrico en Horno de Mufla y la Espectroscopía de Emisión de Fluorocencia de Rayos X por Dispersión de Longitudes de Onda (FRX-d $\lambda$ ) respectivamente. Los métodos son:

- La Gravimetría: la técnica consiste en separar la especie química que se quiere determinar del resto de los componentes de la muestra y proceder a su pesada. A partir de este valor se obtiene la concentración del analito en la muestra inicial.

La instrumentación básica necesaria para el análisis gravimétrico, son la balanza analítica, la estufa de secado regulable a las temperaturas que indiquen los métodos de aplicación y el horno mufla, igualmente regulable.

- Espectrometría de Fluorescencia de Rayos X: la técnica de Fluorescencia de Rayos $X$ se basa en el estudio de las emisiones de fluorescencia generadas después de la excitación de una muestra mediante una fuente 
de rayos $X$. La radiación incide sobre la muestra excitando los átomos presentes en la misma, que emiten a su vez radiación característica denominada fluorescencia de rayos $X$.

Esta radiación, convenientemente colimada, incide sobre un cristal analizador (con espaciado interatómico d) que la difracta en un ángulo $(\theta)$ dependiente de su longitud de onda $(\lambda)$ por la ley de Bragg (sen $\theta=n \lambda / 2 d$ ). Un detector que puede moverse sobre un determinado rango de dicho ángulo mide el valor de la intensidad de radiación en un ángulo determinado y por tanto para una longitud de onda específica, que es función lineal de la concentración del elemento en la muestra que produce tal radiación de fluorescencia.

\subsection{CLASIFICIACÓN GRANULOMÉTRICA DE LAS ESCORIAS DE RSU}

En esta Tesis Doctoral se utilizan escorias incineradas de RSU, provenientes de la Incineradora de Valdemingómez de Madrid. Las escorias tenían un tamaño original de $20 \mathrm{~cm}$ como máximo, se les ha realizado un proceso de trituración manual para reducir el tamaño máximo y para hacer el estudio de la granulometría.

Una vez trituradas las escorias de RSU, las granulometrías se han obtenido de acuerdo a las normas UNE-EN 933-1 [AENOR; 2012], y UNE-EN 933-2 [AENOR; 1996], según los requisitos de las Normas ISO 3310-1 e ISO 3310-2. También se ha comparado la curva granulométrica obtenida con la curva de referencia de Fuller [Fuller, W. y Thompson, S.E.; 1907].

La granulometría de los áridos es uno de los parámetros más importantes empleados en la dosificación del hormigón, ya que constituyen el esqueleto y tienen gran influencia en las propiedades del hormigón.

El análisis granulométrico de un árido consiste en determinar la distribución por tamaños de las partículas que lo forman, es decir, en separar el árido en diferentes fracciones de partículas del mismo tamaño, o de tamaños comprendidos dentro de determinado límite, y en hallar el porcentaje.

El estudio de la distribución por tamaños de un árido se hace cribándolo a través de una serie de tamices normalizados (en una tamizadora) y pesando la cantidad que queda retenida en cada uno de ellos.

El norteamericano Fuller demostró que los hormigones más trabajables, eran proporcionados por granulometrías continuas, que requieren menos energía de compactación. 
Se trata de que la granulometría de la mezcla de áridos (arena, grava) se adapte a una curva teórica tomada como referencia (parábola de Gessner), siendo la óptima desde el punto de vista de compacidad, trabajabilidad, entre otros. Una curva de referencia clásica es la de Fuller, está representada en la Figura 3.1.

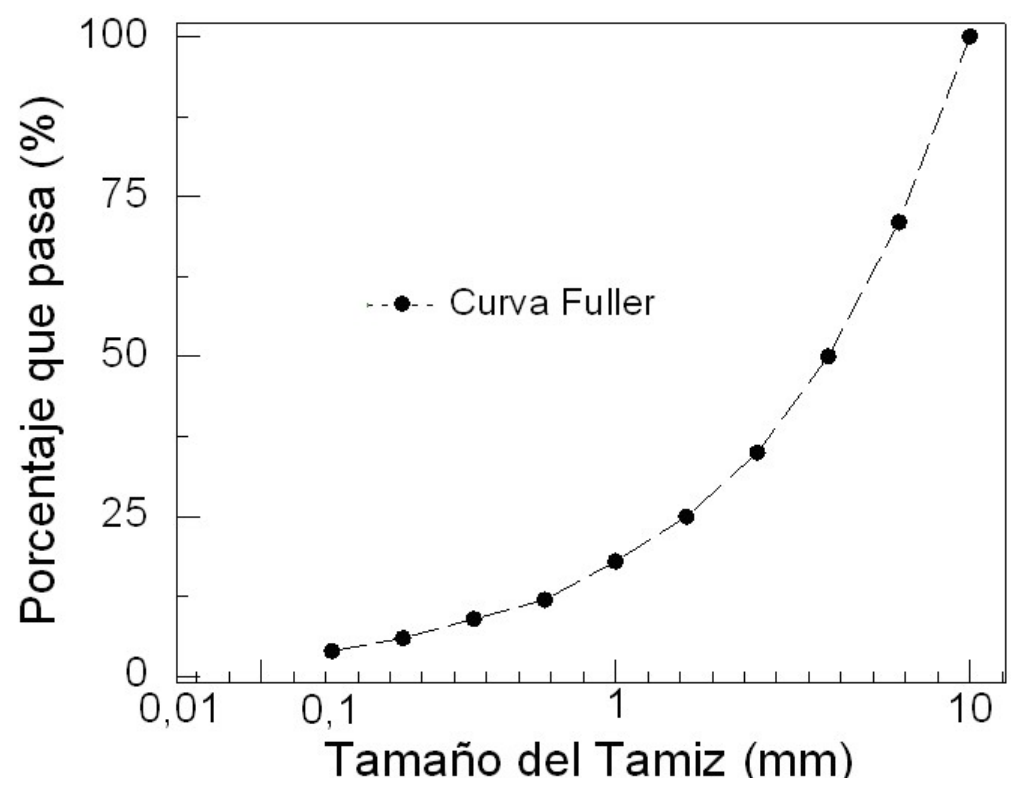

Figura 3.1 Curva clásica de Fuller.

\subsection{CARACTERIZACIÓN MECÁNICA DE MORTEROS DE CEMENTO PORTLAND}

Las características mecánicas de los morteros se definen principalmente por su resistencia a flexión y a compresión, su densidad y su consistencia.

\subsubsection{ENSAYOS DE ROTURA A FLEXIÓN DE MORTEROS}

Los ensayos de rotura a flexión (Figura 3.2) de las probetas de mortero de cemento Portland, se hacen de acuerdo a las normas UNE-EN 196-1 [AENOR; 2005] y UNE-EN 1015-11 [AENOR; 2000].

El procedimiento es que cada una de las probetas se apoya en una de las caras laterales del moldaje, sobre los rodillos de apoyo de la máquina de flexión marca lbertest, modelo Autotest 200 -10 SW. Posteriormente, se aplica una carga a través del rodillo superior con una fuerza $10 \mathrm{kN}$ a una velocidad de 0,03 $\mathrm{kN} / \mathrm{s}$. 
La máquina de flexión dispone de dos apoyos inferiores distanciados 100 $\mathrm{mm}$ entre si y un bloque compresor oscilante superior.
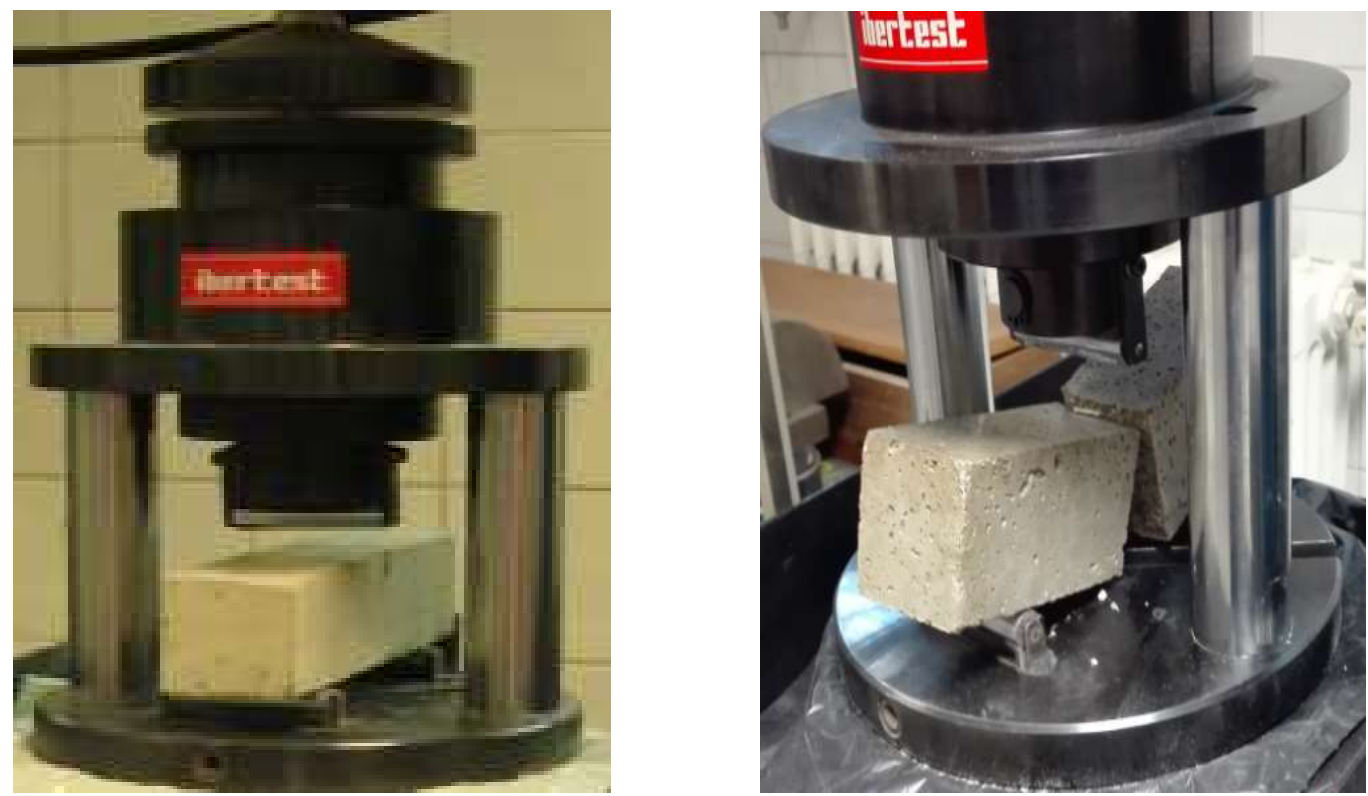

Figura 3.2 Ensayo a flexión de morteros.

\subsubsection{ENSAYOS DE ROTURA A COMPRESIÓN DE MORTEROS}

Con las dos mitades de probetas de mortero rotas obtenidas en el ensayo a flexión, se procede al ensayo a compresión (Figura 3.3), también se hacen de acuerdo a las normas UNE-EN 196-1 [AENOR; 2005] y UNE-EN 1015-11 [AENOR; 2000].

La manera que se hace es mediante la colocación de cada una de las mitades de las probetas rotas, entre las placas de la máquina a compresión marca lbertest, modelo Autotest 200 -10 SW, que aplica una fuerza de 200 kN a una velocidad de $0,05 \mathrm{kN} / \mathrm{s}$, se aplica la carga a las dos caras provenientes de las laterales del moldaje. 

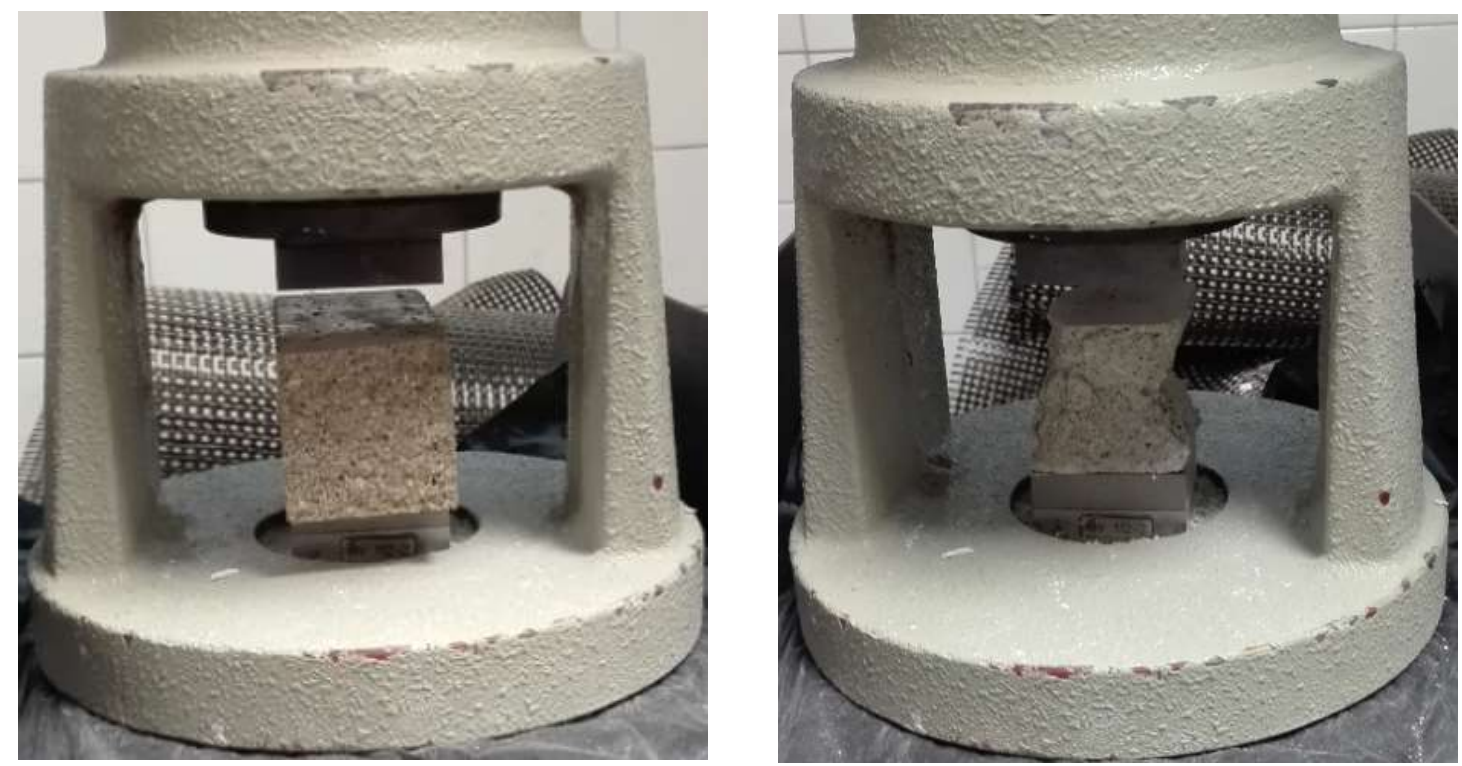

Figura 3.3 Ensayo a compresión de morteros.

\subsubsection{DENSIDAD Y CONSISTENCIA DEL MORTERO FRESCO}

La densidad del mortero está directamente relacionada con la de sus materiales componentes, así como con su contenido en aire. La densidad del mortero fresco se determina conforme a la Norma Europea UNE-EN 1015-6 [AENOR; 2007], esta norma describe un método de ensayo para determinar la densidad aparente de los morteros frescos, comprendiendo los morteros que contienen conglomerantes minerales y a la vez áridos pesados y ligeros.

Para el ensayo de escurrimiento se aplica la normativa UNE-EN 1015-3 [AENOR; 2000], esta norma específica un método de ensayo para determinar, por medio del valor del escurrimiento, la consistencia de los morteros frescos amasados, que comprende a los morteros que contienen conglomerantes minerales y a la vez áridos normales y ligeros. En función de dicha medida se distinguen tres tipos de consistencia, como se detalla en Tabla 3.1.

Tabla 3.1 Clasificación y denominación en función del escurrimiento (mesa de sacudidas) [AENOR UNE-EN 1015-6; 2007].

\begin{tabular}{ccc}
\hline Mortero fresco & $\begin{array}{c}\text { Consistencia, } \\
\text { escurrimiento, } \mathrm{mm}\end{array}$ & Designación \\
\hline Seco & $<140$ & $\mathrm{~S}$ \\
Plástico & 140 a 200 & $\mathrm{P}$ \\
Fluido & $>200$ & $\mathrm{~F}$ \\
\hline
\end{tabular}


La trabajabilidad se logra con morteros de consistencia plástica según UNE-EN 1015-6 [AENOR; 2007], que permiten a la pasta conglomerante bañar la superficie del árido. En los otros casos se forman morteros excesivamente secos no trabajables; o bien, muy fluidos con tendencia a la segregación.

La consistencia se adquiere mediante adición de agua a la masa de arena y conglomerante, esta propiedad se relaciona directamente con la proporción agua/cemento, crucial para el completo desarrollo de las propiedades resistentes del mortero.

\subsection{CARACTERIZACIÓN MECÁNICA DE HORMIGONES DE CEMENTO PORTLAND}

Para estudiar las características de los hormigones elaborados tanto convencionales, como con escorias de RSU en sustitución del árido natural (grava y arena) en diferentes dosificaciones, se determina la consistencia del hormigón fresco y la resistencia a compresión de probetas de hormigón curadas a diferentes edades, en nuestro caso a 28, 105 y 180 días.

Los ensayos de las probetas de hormigones se han realizado de acuerdo a las normas: UNE-EN 12390-1 [AENOR, 2001], UNE-EN 12390-2 [AENOR, 2009] y UNE-EN 12390-3 [AENOR, 2009].

\subsubsection{DETERMINACIÓN DE LA CONSISTENCIA DEL HORMIGÓN}

La resistencia a compresión es la característica mecánica más importante de un hormigón, convirtiéndose en un evaluador adecuado de la calidad del material. En ella influyen múltiples factores entre otros las características de los materiales, la dosificación, el sistema de compactación, el sistema de curado empleado y las condiciones ambientales.

Las propiedades más importantes del hormigón son:

- En estado fresco: la docilidad y la consistencia.

- Una vez fraguado: las características mecánicas y las reológicas.

Para valorar la docilidad del hormigón se hace a través de la consistencia, por la facilidad que posee el hormigón fresco para deformarse. La consistencia se obtiene por el asiento en el Cono de Abrams, que es un molde sin fondo de forma troncocónica (provisto de dos asas para manipularlo), de $30 \mathrm{~cm}$ de altura, rellenado con el hormigón fresco, y en el desmolde de la masa, esta experimenta una pérdida de altura (asiento), cuya medida en $\mathrm{cm}$ da el valor de la consistencia, según el baremo de la Tabla 3.2. 
Tabla 3.2 Baremo de consistencia del cono de Abrams [EHE-08].

\begin{tabular}{ccl}
\hline Tipo de consistencia & $\begin{array}{c}\text { Asiento, en }[\mathrm{cm}] \\
\text { (Tolerancia) }\end{array}$ & Tipo de vibrado \\
\hline Seca & $0-2(0)$ & Enérgico \\
Plástica & $3-5( \pm 1)$ & Normal \\
Blanda & $6-9( \pm 1)$ & Vibrado o picado \\
Fluida & $10-15( \pm 2)$ & Picado con barra \\
Líquida & $16-20( \pm 2)$ & - \\
\hline
\end{tabular}

De acuerdo a la normativa EHE-08, es recomendable en general en edificación, la consistencia plástica-blanda $(6 \mathrm{~cm})$.

Las características reológicas estudian la deformación de un material, ocasionada por causas tensionales, a lo largo del tiempo. Entre las que se encuentran, la retracción (producida en los primeros días de curado perdiendo agua) y la fluencia (al cargar un elemento de hormigón sufre una deformación instantánea elástica y con el paso del tiempo experimenta una deformación plástica denominada fluencia).

\subsubsection{ENSAYO DE RESISTENCIA A COMPRESIÓN DEL HORMIGÓN}

En la normativa Instrucción de Hormigón EHE-08, en el Apartado 86.3.2 se específica "que la resistencia del hormigón se comprobará mediante ensayos de resistencia a compresión sobre probetas fabricadas y curadas según UNEEN 12390-2" [AENOR; 2009].

La resistencia del hormigón a compresión se refiere a la resistencia de la amasada o de la unidad de producto, y se obtiene a partir de los resultados de ensayos de rotura a compresión en número igual o superior a dos, realizados sobre probetas cilíndricas o cúbicas, de 28 días de edad, según norma UNE.

La resistencia a compresión del hormigón varía notablemente con la edad. En la Tabla 3.3 se muestra la correlación para un hormigón de endurecimiento normal. Si se toma el valor unidad para los 28 días de edad, se ve como el hormigón endurecido normalmente llega a aumentar la resistencia un $35 \%$ al año de edad. El hormigón de endurecimiento rápido, incrementa su resistencia más deprisa en los primeros días, pero después pierde efectividad. 
Tabla 3.3 Correlación de valores: resistencia a compresión - edad hormigón.

\begin{tabular}{lccccc}
\hline \multicolumn{1}{c}{ Edad [días] } & 3 & 7 & 28 & 90 & 360 \\
\hline $\begin{array}{l}\text { Hormigón de endurecimiento } \\
\text { normal [\%] }\end{array}$ & 0,40 & 0,65 & 1,00 & 1,20 & 1,35 \\
\hline $\begin{array}{l}\text { Hormigón de endurecimiento } \\
\text { rápido [\%] }\end{array}$ & 0,55 & 0,75 & 1,00 & 1,15 & 1,20 \\
\hline
\end{tabular}

Se hace el ensayo a compresión de resistencia del hormigón (Figura 3.5), mediante la colocación de cada una de las probetas entre las placas de la máquina universal de ensayos lbertest, modelo MIB 60/AM, aplicando la carga a las dos caras provenientes de las laterales del moldaje.

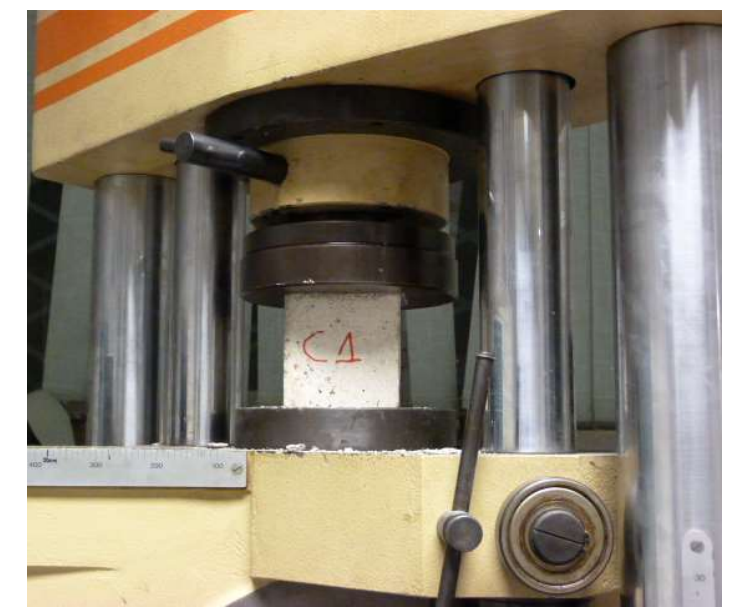

Figura 3.5 Ensayo a compresión de hormigones.

La forma de la rotura de las probetas cúbicas de hormigón, para los ensayos de resistencia a compresión, es de acuerdo a la norma UNE-EN 123903 [AENOR; 2009].

Para la normativa los ensayos de rotura a compresión de las probetas de hormigón cúbicas, deben ser iguales a la Figura 3.6, para que la rotura sea satisfactoria, donde se observa como las cuatro caras expuestas se rompen aproximadamente igual, generalmente con poco daño en las caras que se encuentran en contacto con los platos. Al final del proceso de rotura a compresión de las probetas de hormigón, se hace la rotura por explosión 

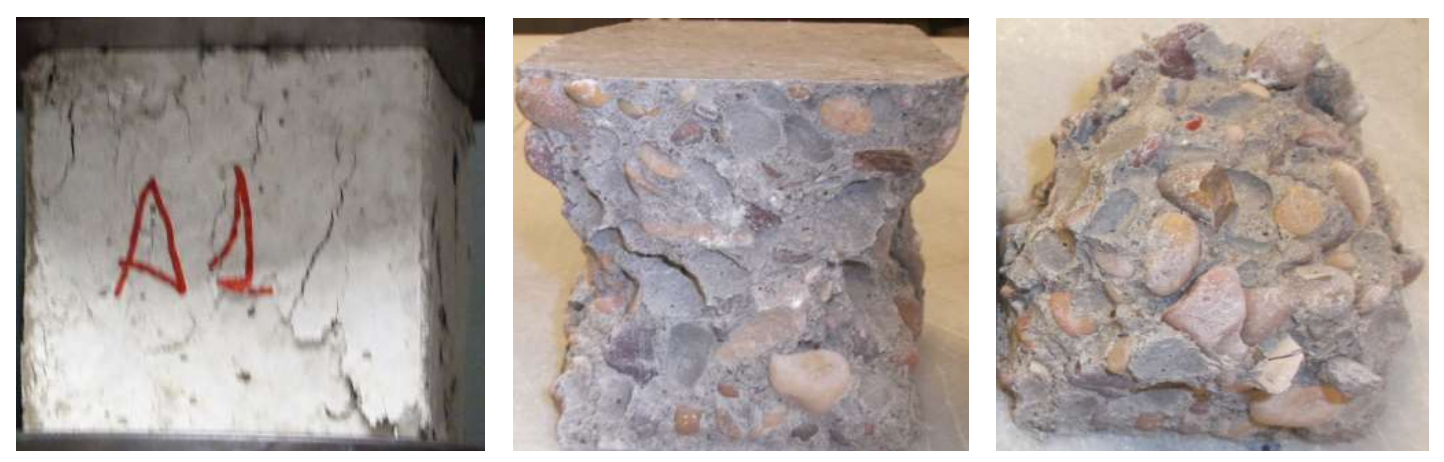

Figura 3.6 Roturas satisfactorias en las probetas cúbicas (Laboratorio).

La normativa contempla rotura de probetas cúbicas no satisfactorias, pero en ninguno de los ensayos realizados se han presentado dichas roturas para cualquiera de los tipos de hormigón.

La resistencia a compresión debe expresarse con aproximación de 0,1 $\operatorname{MPa}\left(\mathrm{N} / \mathrm{mm}^{2}\right)$.

\subsubsection{Comparación de las probetas cilíndricas y cúbicas de hormigón}

En relación con las probetas moldeadas, los tipos de probetas comúnmente usadas para determinar la resistencia a compresión del hormigón son las cúbicas y las cilíndricas. Las probetas cúbicas de $15 \times 15 \mathrm{~cm}$ se utiliza en países como Gran Bretaña, Alemania y en otros países de Europa, mientras que en países como Estados Unidos, Corea del Sur, Francia, Canadá, Australia la probeta normalizada es la cilíndrica de $15 \times 30 \mathrm{~cm}$ [Yi, S.T., et al; 2006].

En España se permite el uso de los dos tipos de probetas, aunque la cilíndrica es la más usada, así lo indica la vigente Instrucción Española de Hormigón Estructural EHE-08, donde todos los métodos de cálculo y especificaciones se refieren a características del hormigón endurecido obtenidas mediante ensayos sobre probetas cilíndricas de $15 \times 30 \mathrm{~cm}$.

Pero se pueden emplear también:

- Probetas cúbicas de $15 \mathrm{~cm}$ de arista, o

- Probetas cúbicas de $10 \mathrm{~cm}$ de arista, en el caso de hormigones con $f_{\mathrm{ck}} \geq$ $50 \mathrm{~N} / \mathrm{mm}^{2}$ y siempre que el tamaño máximo del árido sea inferior a 12 $\mathrm{mm}$. 
en cuyo caso los resultados deben afectarse del correspondiente factor de conversión, de acuerdo con la ecuación [3.1]:

$$
f_{c}=\lambda_{\text {cil,cub15 }} \cdot f_{c, \text { cúbica }}
$$

Donde:

$f_{c} \quad$ Resistencia a compresión, en $\mathrm{N} / \mathrm{mm}^{2}$, referida a probeta cilíndrica de $15 \times 30 \mathrm{~cm}$.

$f_{c, \text { cúbica }}$ Resistencia a compresión, en $\mathrm{N} / \mathrm{mm}^{2}$, obtenida a partir de ensayos realizados en probetas cúbicas de $15 \mathrm{~cm}$ de arista.

$\lambda_{\text {cil,cub15 }}$ Coeficiente de conversión, obtenido de la Tabla 3.4

Tabla 3.4 Coeficiente de conversión de resistencias $\frac{f_{c, c i l}}{f_{c, c u b}}$ [EHE-08].

\begin{tabular}{cc}
\hline Resistencia en probetas cúbica, $f_{c}\left(\mathrm{~N} / \mathrm{mm}^{2}\right)$ & $\lambda_{\text {cil,cub15 }}$ \\
\hline$f_{c}<60$ & 0,90 \\
$f_{c} \leq 60<80$ & 0,90 \\
$f_{c} \geqq 80$ & 1,00 \\
\hline
\end{tabular}

Es de gran importancia emplear factores de corrección si se ensayan probetas cúbicas. Cada vez más los laboratorios eligen para sus ensayos este tipo de probetas que a diferencia de las cilíndricas, no precisan refrentado, nivelación ni pulido lo cual contribuye al equilibrio ecológico y a la protección del medio ambiente, por ser menos nocivas y más fáciles de ensayar [Rojas-Henao, L., et al; 2013].

Las probetas cúbicas se ensayan en dirección perpendicular a la del hormigonado del molde, con lo cual siempre se dispone de las dos caras paralelas y perfectamente planas que proporcionan las caras de los moldes.

Pero la tendencia es que se prefieren las probetas cilíndricas en vez de las cúbicas, especialmente para investigación por existir la impresión de representar mejor la resistencia del hormigón [Mindess, S. y Young,J.F.; 1981] [Neville, A.M.; 1995].

Yi, S.T., et al. (2006) fabricaron probetas cúbicas y cilíndricas de diferentes dimensiones que fueron almacenadas durante 28 días en una cámara con una humedad estándar y a una temperatura de $20 \pm 3^{\circ} \mathrm{C}$. Las resistencias variaron entre 20 y $80 \mathrm{MPa}$. 
Por medio de un análisis de regresión por el método de mínimos cuadrados ordinarios los autores obtuvieron la ecuación [3.2] de ajuste

$$
f_{c, \text { cub }}=\frac{1,17 f_{c, \text { cil }}}{\sqrt{1+d / 2,6}}+0,62 f_{c, \text { cil }}
$$

donde $d$ es la arista de la cubeta cúbica en $\mathrm{cm}$. Los resultados de esta regresión se muestran en la Figura 3.4:

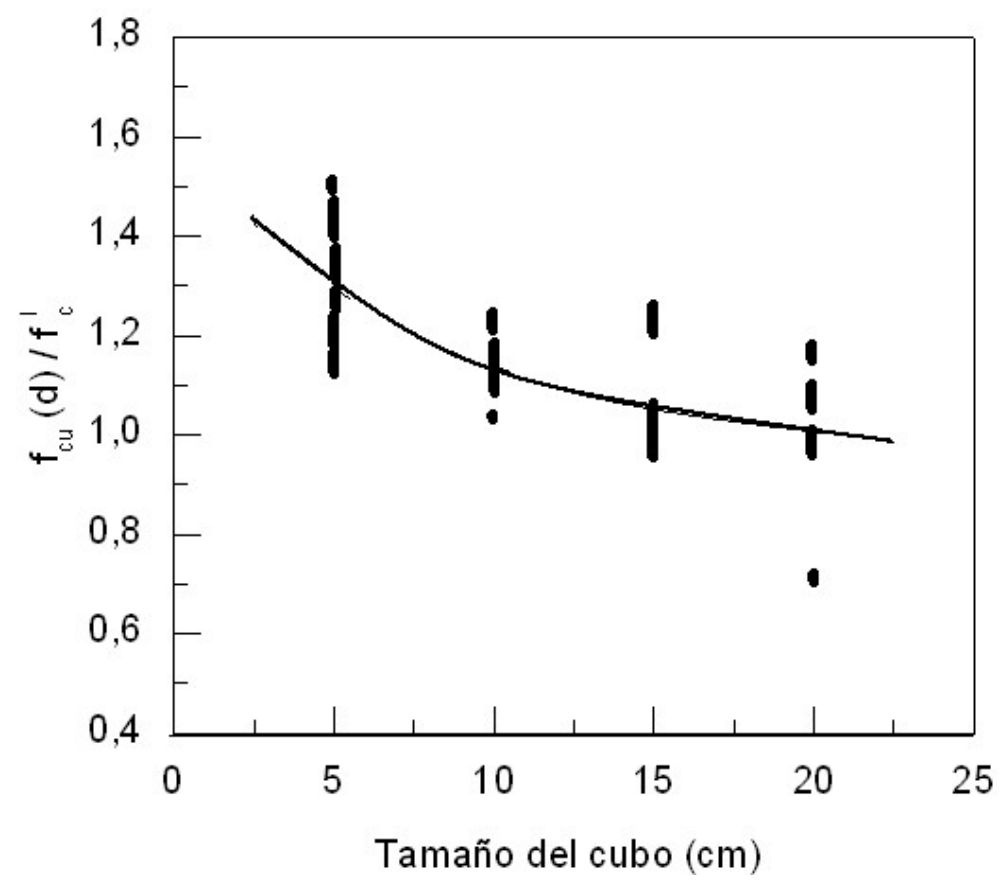

Figura 3.4 Relación entre la resistencia en probeta cúbica y cilíndrica en función de la probeta cúbica. Yi, S.T., et al. (2006).

Aunque la relación de la resistencia de la probeta cúbica con respecto a la cilíndrica disminuye a medida que la resistencia del hormigón aumenta, a menudo se admite que la resistencia de la probeta cúbica es cerca de 1,25 veces la resistencia de la probeta cilíndrica fabricada con el mismo hormigón [Mindess, S. y Young, J.F.; 1981].

Mansur \& Islam, (2002), señalan que la diferencia entre probetas cúbicas $(150 \times 150 \mathrm{~mm})$ y probetas cilíndricas $(150 \times 300 \mathrm{~mm})$, es prácticamente una constante independientemente del nivel resistente del hormigón, de acuerdo con la expresión [3.3]:

$$
\tilde{f}_{c, c u b}=1,01 f_{c, c i l}+9,94 .(\mathrm{MPa})
$$


esa diferencia constante es próxima a $10 \mathrm{MPa}$. La Tabla 3.5 muestra los resultados de los factores de corrección obtenidos de la ecuación precedente, además de otros con probetas de diferente tamaño.

Tabla 3.5 Factores para convertir la resistencia del hormigón en su resistencia equivalente en probeta cúbica normalizada de 150 mm [Mansur \& Islam.; 2002].

\begin{tabular}{ccccc}
\hline \multirow{2}{*}{$\begin{array}{c}\text { Resistencia a } \\
\text { compresión } \\
\text { del hormigón }\end{array}$} & \multicolumn{4}{c}{$\begin{array}{c}\text { Factores de corrección para la resistencia del hormigón } \\
\text { determinada por: }\end{array}$} \\
\cline { 2 - 5 }$(\mathrm{MPa})$ & $\begin{array}{c}\text { P. Cilíndrica } \\
150 \times 300[\mathrm{~mm}]\end{array}$ & $\begin{array}{c}\mathrm{P} \text {. Cilíndrica } \\
100 \times 200[\mathrm{~mm}]\end{array}$ & $\begin{array}{c}\mathrm{P} \text {. Cilíndrica } \\
100 \times 100[\mathrm{~mm}]\end{array}$ & $\begin{array}{c}\text { P. Cúbica } 100 \\
{[\mathrm{~mm}]}\end{array}$ \\
\hline 20 & 1,51 & 1,31 & 1,17 & 1,09 \\
30 & 1,34 & 1,21 & 1,09 & 1,03 \\
40 & 1,26 & 1,15 & 1,04 & 1,00 \\
50 & 1,21 & 1,12 & 1,02 & 0,98 \\
60 & 1,17 & 1,10 & 1,00 & 0,97 \\
70 & 1,15 & 1,08 & 0,99 & 0,96 \\
80 & 1,13 & 1,07 & 0,98 & 0,95 \\
90 & 1,12 & 1,06 & 0,97 & 0,95 \\
10 & 1,11 & 1,06 & 0,97 & 0,94 \\
\hline
\end{tabular}

En esta Tesis Doctoral se han utilizado las probetas cúbicas de $100 \times 100$ $\mathrm{mm}$, para el estudio de los hormigones elaborados con escorias incineradas de RSU y hormigones de referencia ( $0 \%$ de escorias), aplicando en todos los resultados el coeficiente 0,90 ( $\lambda_{\text {cil,cub15) }}$.

\subsection{TÉCNICAS ELECTROQUÍMICAS PARA EL ESTUDIO DE LA CORROSIÓN EN LAS ARMADURAS EMBEBIDAS EN MORTEROS ELABORADOS CON ESCORIAS DE RSU}

Las medidas electroquímicas son técnicas empleadas en la corrosión de las armaduras de hormigón, permiten detectar si existen corrosión o no, y en algunos casos buscar alternativas para estabilízalas.

En esta Tesis Doctoral se hacen probetas de mortero donde se sustituye el árido natural totalmente por escorias de RSU. Con fabricación paralela de probetas de mortero convencional para comparar los comportamientos en ambos casos.

De acuerdo a la norma UNE-EN 196-1 [AENOR; 2005], para la elaboración de las probetas de mortero fabricadas con un mortero de consistencia plástica, deben estar compuestas, de una parte, en masa de cemento, tres en masa de arena (normalizada CEN), o en sustitución de la arena, 
tres en masa de escorias de RSU (granulometría adecuada a la normativa, denominadas escorias finas tamaño máximo de $4 \mathrm{~mm}$ ), y media parte de agua (relación agua/cemento de 0,50).

La normativa permite utilizar arenas normalizadas CEN de diferentes orígenes y países, con la condición de que, al ser utilizadas, los resultados de las resistencias mecánicas no difieran de forma significativa de los obtenidos utilizando la arena de referencia CEN.

El amasado de las probetas de mortero, se ha realizado en una amasadora automática de la marca lbertest homologada planetaria, según normativa. El enmoldado de las probetas se realiza inmediatamente después de la preparación del mortero. Y para las mediciones electroquímicas, el desmoldado se hará como máximo en 24 horas después del enmoldado.

Las técnicas electroquímicas del estudio de corrosión han desplazado, por la superior sensibilidad de las medidas, a las técnicas gravimétricas clásicas. Aunque que la medición de la pérdida de peso por oxidación de una barra puede alcanzar una exactitud inferior a $1 \mathrm{mg}$, con la instrumentación electrónica actual se pueden medir intensidades de corriente con una sensibilidad de $1 \mathrm{nA}\left(10^{-9} \mathrm{~A}\right)$.

Una intensidad de corriente de $10 \mathrm{nA} / \mathrm{cm}^{2}$, fácilmente medible, actuando sobre el hierro durante una hora, produce una pérdida de peso de $10,4 \cdot 10^{-5} \mathrm{mg}$. Es decir, los métodos electroquímicos son unas $10^{6}$ veces más sensibles que los gravimétricos [Cobo Escamilla, A.; 2001].

En la medición de la corrosión para este trabajo, se han utilizado las técnicas electroquímicas, que son clasificadas como:

- Técnicas cualitativas:

Potencial de corrosión $E_{c o r r}$

- Técnicas cuantitativas:

- Método de Resistencia de Polarización Lineal $R_{p}$, que permite el cálculo de la densidad de corriente de corrosión ícorr. 


\subsubsection{POTENCIAL DE CORROSIÓN}

En el potencial de corrosión, la electroneutralidad de la materia impone que, con la ausencia de perturbaciones externas, existe una equivalencia entre la intensidad del proceso anódico la y catódicos parciales $I_{c}$, donde se cumple:

$$
\begin{aligned}
& \mathrm{I}_{\mathrm{t}}=\mathrm{I}_{\mathrm{a}}+\mathrm{I}_{\mathrm{c}}=0 \\
& \mathrm{I}_{\mathrm{a}}=\left|\mathrm{I}_{\mathrm{c}}\right|=\mathrm{I}_{\text {corr }}
\end{aligned}
$$

Donde lt es la intensidad externa o total, que es proporcional a la velocidad del fenómeno de corrosión. Al potencial del metal en ese momento, se le

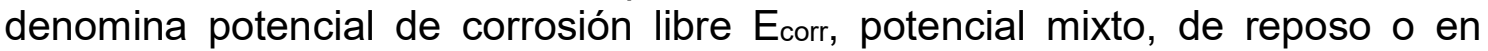
circuito abierto (OCP), tiene un valor intermedio entre los potenciales de equilibrio de procesos parciales anódico y catódico $E_{a}$ y $E_{c}$, y con él hay una transformación neta de metal M (Figura 3.7).

Para la medición del $E_{\text {corr }}$ se puede emplear un voltímetro comparándolo con un electrodo patrón de referencia. Inicialmente se utilizó un electrodo normal de hidrógeno $(\mathrm{ENH})$, al que por convenio se le asignó un valor de cero de potencial a cualquier temperatura. $Y$ es aquel que resulta de hacer burbujear el gas, a la presión de una atmósfera, por una solución ácida de actividad unidad, $\mathrm{pH}=0,1$, donde se encuentra sumergido una fracción de platino.

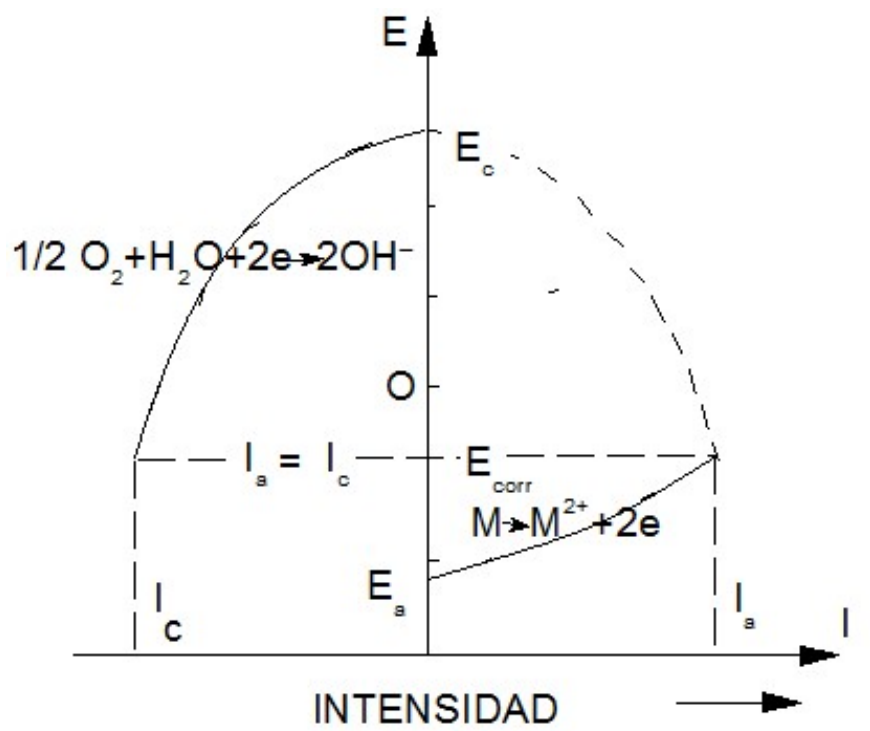

Figura 3.7 Proceso global de corrosión [González Fernández, J.A.; 1989].

Los electrodos de hidrogeno son muy sensibles y frágiles a la contaminación, se toman otros patrones. En los laboratorios el más usual es el electrodo de calomelanos ECS, consistente en mercurio liquido en contacto con 
cloruro mercurioso $\left(\mathrm{Hg} / \mathrm{Hg}_{2} \mathrm{Cl}_{2}\right)$, en una solución saturada de cloruro potásico. Cuyo electrodo adopta un potencial de $-0,24 \mathrm{~V}$ con respecto al electrodo de hidrógeno.

El valor del potencial informa, en combinación con el $\mathrm{pH}$ del medio, de los posibles estados de corrosión, dando incluso una indicación cinética cualitativa.

En general se puede decir que, si se mide el $E_{\text {corr }}$ con referencia SCE, la probabilidad de que se presente la corrosión en el caso de las armaduras de acero al carbono es [ASTM.; 1999]:

- Superior al $90 \%$ si es $\mathrm{E}_{\text {corr }}<-270 \mathrm{mV}$.

- Incierta si $-270 \mathrm{mV}<\mathrm{E}_{\mathrm{corr}}<-120 \mathrm{mV}$.

- Inferior al $10 \%$ si $E_{\text {corr }}>-120 \mathrm{mV}$

Para las mediciones electroquímicas se dispondrá de una celda electroquímica de tres electrodos (Figura 3.8) conectados al potenciostatogalvanostato modelo 273A de la marca EG\&G Princeton Applied Research y el sofware CorWare 3.1c (Figura 3.9). Los tres electrodos son:

- RE: electrodo de referencia de calomelanos SCE $\left(\mathrm{Hg} / \mathrm{Hg}_{2} \mathrm{Cl}_{2}-\right.$ sat. $\left.\mathrm{KCl}\right)$.

- CE: contraelectrodo o anillo de guarda, formado por un disco macizo de acero inoxidable de $7 \mathrm{~cm}$ de diámetro y $4 \mathrm{~cm}$ de altura con un taladro central de $8 \mathrm{~mm}$ para colocación del electrodo de referencia. Para asegurar un buen contacto, se intercala un paño húmedo entre la probeta de mortero y el contraelectrodo.

- WE: electrodo de trabajo, barra de acero sobre la que se realiza la medición.

Al conectarse a la probeta el potenciostato, durante 20 minutos se deja

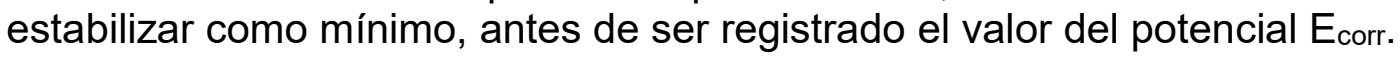




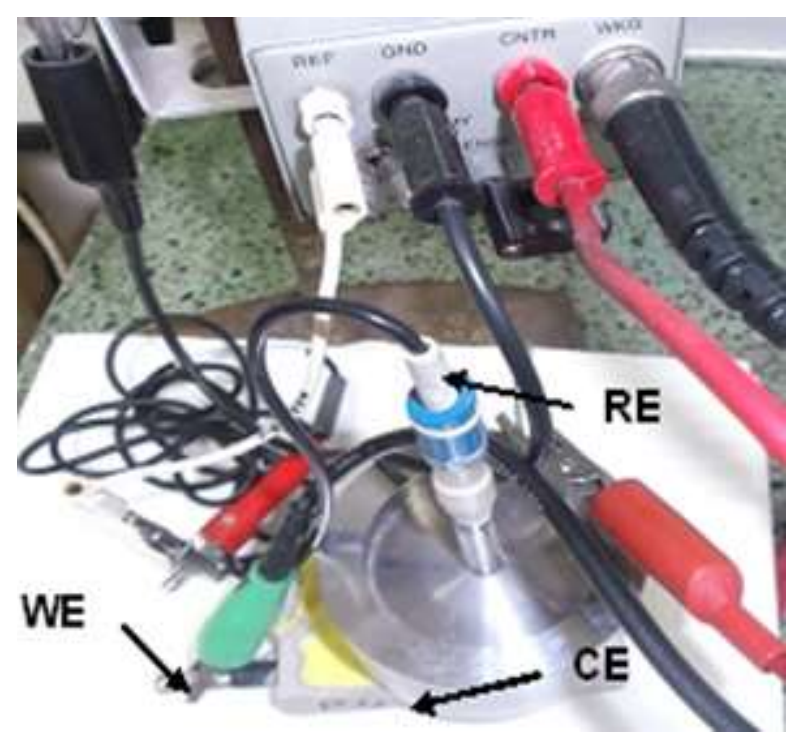

Figura 3.8 Probeta y celda electroquímica de tres electrodos.

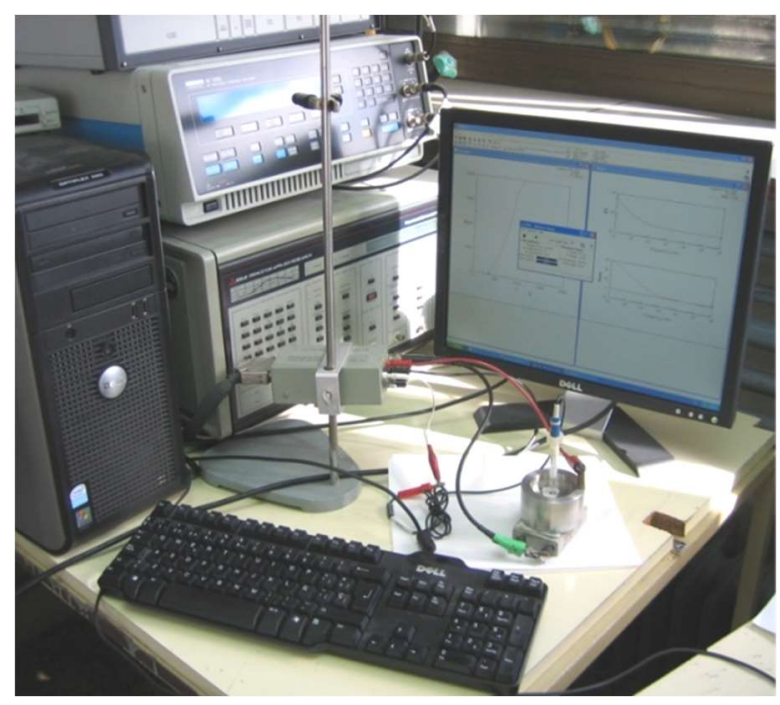

Figura 3.9 Potenciostato-galvanostato modelo 273A de la marca EG\&G.

\subsubsection{RESISTENCIA DE POLARIZACIÓN}

La intensidad de corrosión i̇corr, no se puede medir instrumentalmente de forma directa por la equivalencia [3.4], que ocasiona que no exista corriente neta. Siendo preciso imponer una alteración al sistema, que rompa la equivalencia y desplace el sistema de su situación de reposo. Se logra imponiendo por medio de un potenciostato, una señal eléctrica de potencial, es decir, una polarización $\Delta \mathrm{E}$ o un movimiento de potencial con respecto a $\mathrm{E}_{\text {corr }} \mathrm{y}$ estudiando la respuesta en corriente del sistema. 
La polarización implica un aumento de potencial al que se verifica la semirreacción anódica y una disminución en el potencial del proceso catódico que se representa en la Figura 3.10. Aunque las corrientes catódicas se consideran negativas, se suelen representarse sobre el mismo plano positivo.

En la polarización el potencial es desplazado a un nuevo valor (Punto $\mathrm{P}$ ), al que corresponde una velocidad de oxidación la (o loxid), y otra reducción lc (o Ired). La diferencia entre ambas es arrojada por el circuito externo (potenciostato) que causa la polarización y es apreciada instrumentalmente como una corriente total diferente de cero:

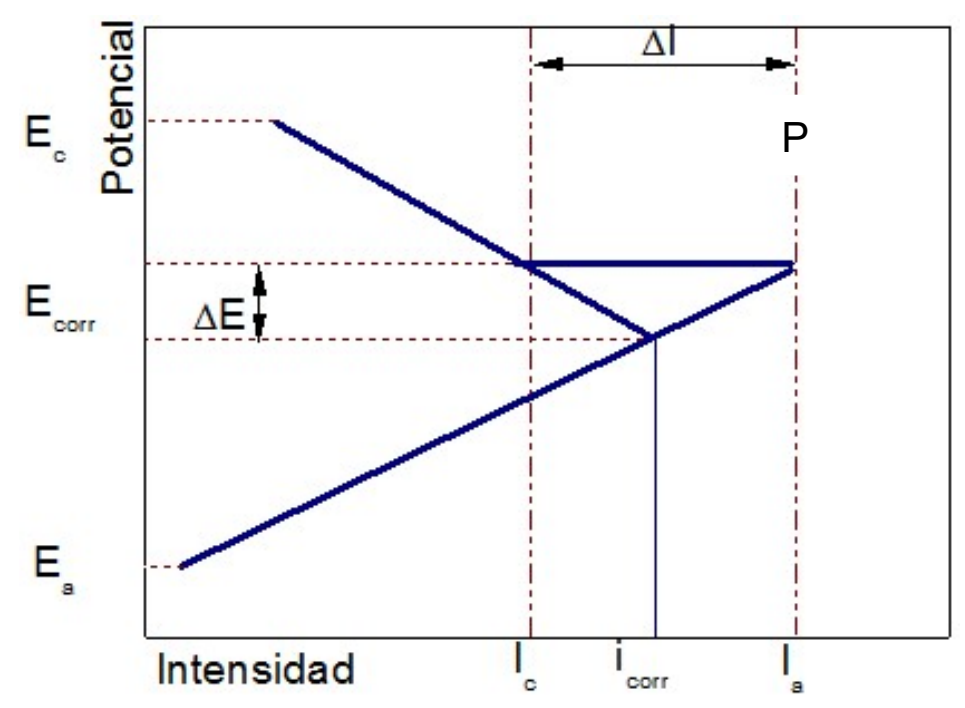

Figura 3.10 Aplicación de pequeña polarización de Evans para romper el equilibrio entre la e Ic [González Fernández, J.A.; 1989].

$$
\mathrm{I}_{\mathrm{t}}=\mathrm{I}_{\mathrm{a}}-\mathrm{I}_{\mathrm{c}}=\Delta \mathrm{l}=\mathrm{f}(\mathrm{E})
$$

Dicha relación entre el potencial impuesto y la intensidad medida es conocida por curva de polarización potenciostática del sistema.

La curva experimental obtenida no corresponde con las semirreacciones anódica o catódica, siendo la suma algebraica de ambas [3.4]. Por tanto, la curva aparente que resulta representa la intensidad media $I_{t}$ frente al potencial, es distinta de las curvas representativas de los procesos reales de disolución metálica y de reducción de oxígeno, son los que reflejan verdaderamente el fenómeno de la corrosión. 
El diagrama de polarización de Evans recogido en la Figura 3.11, representa en trazo continúo la curva de polarización aparente o experimental y en líneas de trazos las correspondientes a los procesos reales. La corriente catódica esta abatida sobre el semi-eje positivo, la propuesta de Evans facilita la visualización gráfica de $\mathrm{E}_{\text {corr }} \mathrm{e}$ i $\mathrm{icorr}_{\text {(icorr) }}$.

Los valores de intensidad están en coordenadas semilogarítmicas, dando lugar a tramos rectos para los procesos controlados por la polarización de activación, que obedece a la ley de Tafel. Tafel describió en 1905 que la velocidad de reacción, medida por la densidad de corriente, es una función logarítmica de [3.6]:

$$
\eta_{a}=\alpha+\beta \cdot \log i
$$

Donde $\eta_{a}$ es la polarización, i es la velocidad de oxidación o reducción en términos de densidad de corriente, y a y $\beta$ son constantes. La ecuación de Tafel [3.7], se puede expresar:

$$
\eta_{a}=-\beta \cdot \log i_{o}+\beta \cdot \log i
$$

Donde io es la corriente de intercambio y $\beta$ la denominada pendiente 0 constante de Tafel. Su valor que suele variar entre 0,05 y $0,15 \mathrm{~V}$, estando muy próximo a $10 \mathrm{~V}$.

Las curvas de polarización reales y las experimentales, coinciden por encima de $\mathrm{E}_{\mathrm{c}} \mathrm{y}$ por debajo de $\mathrm{E}_{\mathrm{a}}$.

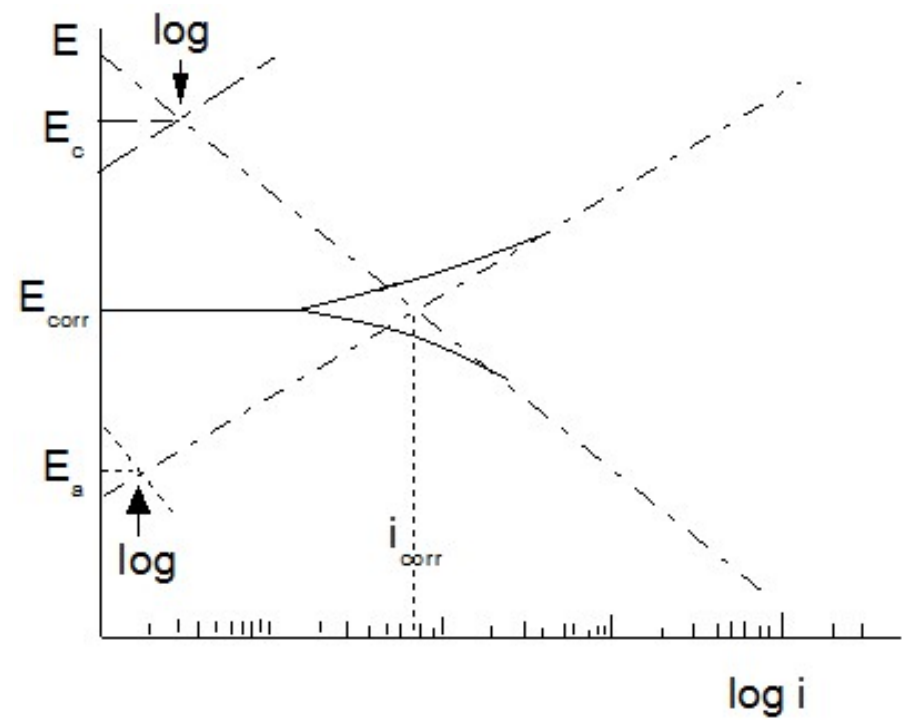

Figura 3.11 Diagrama de polarización, en coordenadas semilogarítmicas [González Fernández, J.A.; 1989]. 
Las curvas reales de polarización se pueden obtener por varios procedimientos, no siendo necesario en la práctica, pues se puede estimar la intensidad de corrosión a partir de las curvas aparentes o experimentales.

Las intensidades de los procesos anódico y catódico se ajustadas a las siguientes expresiones (obtenidas a partir de la teoría de cinética electroquímica):

$$
\begin{aligned}
& \mathrm{I}_{\mathrm{a}}=\mathrm{i}_{\text {corr }} \cdot \exp \left(\frac{\alpha \cdot \mathrm{n} \cdot \mathrm{F}}{\mathrm{R} \cdot \mathrm{T}} \eta\right) \\
& \mathrm{I}_{\mathrm{c}}=-\mathrm{i}_{\text {corr }} \cdot \exp \left(-\frac{\beta \cdot \mathrm{n} \cdot \mathrm{F}}{\mathrm{R} \cdot \mathrm{T}} \eta\right)
\end{aligned}
$$

Donde icorr es la intensidad buscada, $\alpha$ y $\beta$ son los coeficientes relacionados con la caída de potencial a través de la doble capa que rodea el electrodo (formando un valor cercano a $1 / 2$ ), $n$ es el número de electrones intercambiados en los procesos redox (reducción oxidación), $\mathrm{F}$ es la constante de Faraday ( 96.500 culombios $/ \mathrm{mol}$ ), $\mathrm{R}$ es la constante de gases perfectos, $\mathrm{T}$ la temperatura absoluta y $\eta$ la polarización aplicada.

Al imponer la polarización al electrodo, instrumentalmente se aprecia una corriente externa que es la suma algebraica de los dos procesos parciales anteriores. La curva de polarización E/l es la representación gráfica de esta expresión:

$$
\mathrm{I}_{\mathrm{t}}=\mathrm{I}_{\mathrm{a}}+\mathrm{I}_{\mathrm{c}}=\mathrm{i}_{\text {corr }}\left(\exp \left(\frac{\alpha \cdot \mathrm{n} \cdot \mathrm{F}}{\mathrm{R} \cdot \mathrm{T}} \eta\right)-\exp \left(\frac{-\beta \cdot \mathrm{n} \cdot \mathrm{F}}{\mathrm{R} \cdot \mathrm{T}} \eta\right)\right)[3.10]
$$

La velocidad de corrosión se puede obtener de la ecuación anterior, a través de dos métodos diferentes. El primero es el método de intersección, basado en aplicar polarizaciones suficientemente grandes al electrodo para lograr una recta de Tafel, cuya intersección con el valor $E_{\text {corr }}$ proporciona el valor de icorr (Figura 3.11). Dicho método tiene la desventaja de que la alta polarización aplicada puede modificar la superficie del electrodo (del acero o armadura objeto de estudio), por lo que sólo se puede aplicar una vez por probeta, para desecharla posteriormente. 
Por ello, lo habitual es aplicar el método de resistencia de polarización lineal LPR, que utiliza polarizaciones pequeñas $\left( \pm 10\right.$ a $20 \mathrm{mV}$ respecto al $\left.E_{\text {corr }}\right)$ que no afectan al electrodo, por lo que se puede repetir la medición tantas veces como sea necesario y seguir la evolución de la corrosión con el tiempo.

Stern y Geary dieron forma al método LPR [Stern, M. y Geary, A.L.; 1957]. Se basa en el principio de que las curvas de polarización son prácticamente rectas en un pequeño entorno de $\mathrm{E}_{\text {corr, }} \mathrm{y}$ su pendiente está relacionada con la velocidad de corrosión.

A partir de las Ec [3.8], [3.9] y [3.10], y para $\eta \rightarrow 0$ (polarización muy pequeña), se obtiene la fórmula de Stern y Geary:

$$
\mathrm{i}_{\text {corr }}=\frac{\mathrm{b}_{\mathrm{a}} \cdot\left|\mathrm{b}_{\mathrm{c}}\right|}{2,3\left(\mathrm{~b}_{\mathrm{a}}+\left|\mathrm{b}_{\mathrm{c}}\right|\right)} \frac{\Delta \mathrm{i}}{\Delta \mathrm{E}}=\mathrm{B} \frac{\Delta \mathrm{i}}{\Delta \mathrm{E}}=\frac{\mathrm{B}}{\mathrm{R}_{\mathrm{p}}}
$$

Donde, $b_{a} y b_{c}$ son las pendientes rectas de Tafel en ecuaciones [3.12]:

$$
\mathrm{b}_{\mathrm{a}}=\frac{2,3 \cdot \mathrm{R} \cdot \mathrm{T}}{\alpha \cdot \mathrm{n} \cdot \mathrm{F}} \quad \mathrm{b}_{\mathrm{c}}=\frac{-2,3 \cdot \mathrm{R} \cdot \mathrm{T}}{\beta \cdot \mathrm{n} \cdot \mathrm{F}}
$$

El $\Delta \mathrm{i}$ es la respuesta en densidad de corriente en $\mathrm{A} / \mathrm{cm}^{2}$, por unidad de superficie de metal expuesto (que es necesario conocer) a un pequeño escalón de potencial $\Delta \mathrm{E}$ aplicado al sistema (o viceversa). Su cociente, la resistencia de polarización $\mathrm{R}_{\mathrm{p}}$.

La constante B adopta valores con límites muy estrechos, porque el margen de variabilidad de las pendientes de Tafel, de manera que es posible la estimación aproximada de icorr si se parte de un valor de B. En cada sistema se podrían determinar con cierta aproximación la constante de B por varios procedimientos.

En las armaduras de acero al carbono, la constante $B$ toma valores de 26 $\mathrm{mV} / \mathrm{dec}$ cuando el acero está activo, a $52 \mathrm{mV} / \mathrm{dec}$ cuando esta pasivo [González, J.A. y Andrade, C.; 1982]. Dichos valores aproximados se mantienen para los aceros inoxidables [Criado, M., et al; 2011]. En ocasiones, para ambos aceros, se supone el menor valor citado de B [García-Alonso, M.C., et al; 2007 a].

En la práctica, para determinar la $R_{p}$ de las armaduras embebidas en probetas de mortero de este estudio, una vez estabilizado el potencial o, al menos, cuando su variación es lenta, y utilizando el mismo potenciostato y celda eletroquímica descritos antes, se aplicará una velocidad de polarización $\Delta \mathrm{E}$ de $10 \mathrm{mV} / \mathrm{min}$ y se registrará la variación de densidad de corriente $\Delta \mathrm{i}$ con el potencial en las proximidades de $E_{\text {corr. }}$ De este proceso se genera el gráfico de 
la curva de polarización (Figura 3.12). La $R_{p}$ se determina a partir de la pendiente

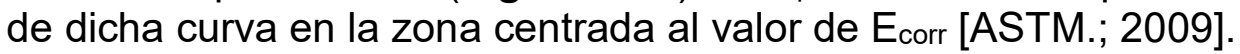

Al estar dotado el potenciostasto de un sistema de retroalimentación positiva que compensa instrumentalmente la caída óhmica entre el electrodo de trabajo y el de referencia, se minimizan los errores de medición de $R_{p}$ debido a la alta resistividad del mortero.

La corrosibilidad del metal será tanto mayor cuanto mayor sea la alteración del sistema ante la perturbación introducida, es decir, cuanto mayor sea la intensidad externa lt, para una polarización $\Delta \mathrm{E}$, o dicho de otra manera cuanto menor sea $R_{p}$. Una vez obtenido el $R_{p}$, y con un valor medio de la constante B, se calcula la densidad de corriente i̇corr en la ecuación [3.11].

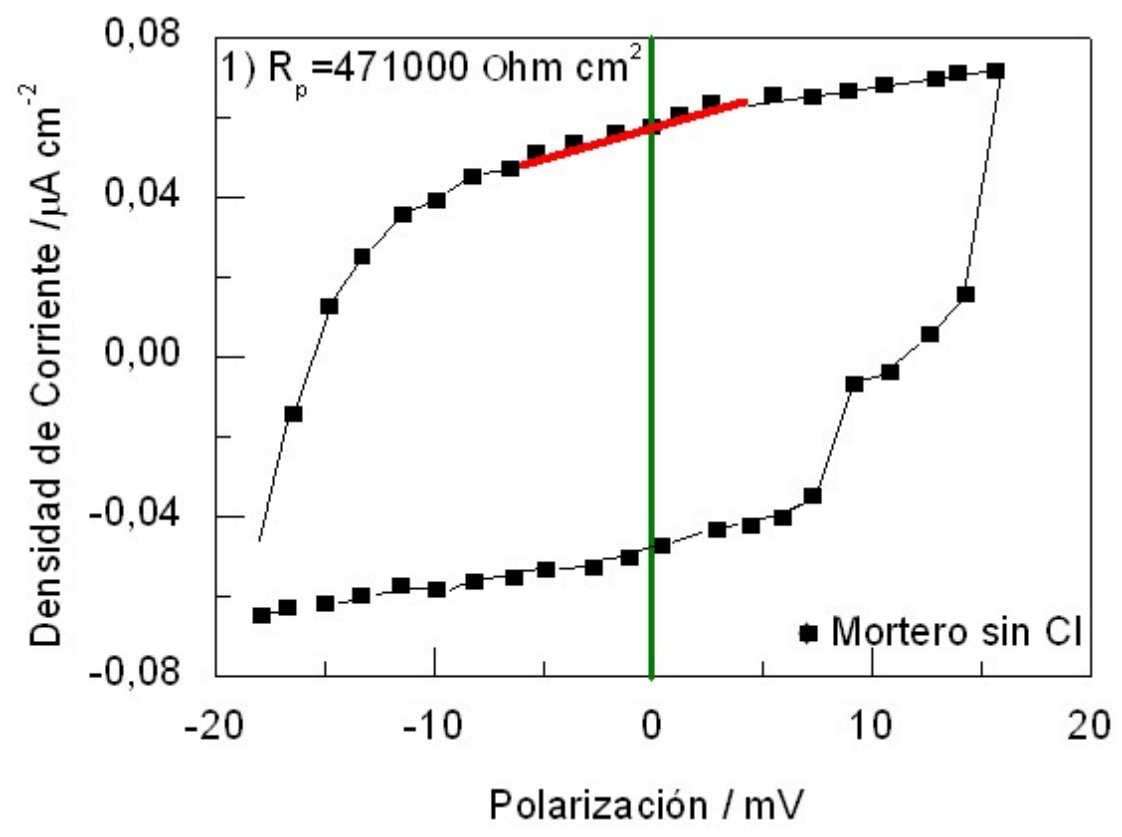

Figura 3.12 Método de Resistencia de Polarización Lineal. El valor de $\mathrm{R}_{\mathrm{p}}$ inverso es el de la pendiente (línea continua roja).

A través de la ley de Faraday, se puede calcular el avance de la corrosión

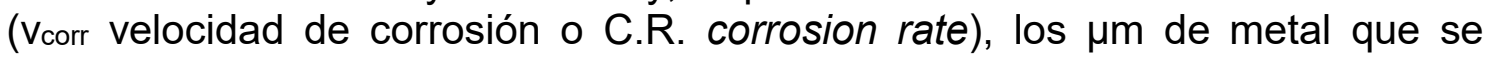
corroen en un año, según la siguiente expresión [3.13] [Gu, P., et al; 1996]:

$$
\mathrm{V}_{\text {corr }}[\mu \mathrm{m} / \mathrm{año}]=3,272 \cdot \frac{\mathrm{i}_{\text {corr }} \cdot \mathrm{M}}{\mathrm{n} \cdot \mathrm{d} \cdot \mathrm{A}}
$$


En la cual: ícorr está expresado en $\mu \mathrm{A} / \mathrm{cm}^{2}, \mathrm{M}$ es el peso atómico del acero (56), n es la carga iónica (2), d es la densidad del acero $\left(7,9 \mathrm{~g} / \mathrm{cm}^{3}\right)$ y A es el área expuesta de acero, en $\mathrm{cm}^{2}$. Operando: $V_{\text {corr }}=11,6 \cdot \mathrm{i}_{\text {corr }}$ por cada $\mathrm{cm}^{2} \mathrm{de}$ armadura expuesta a la corrosión [Vedalakshmi, R., et al; 2010]. Es decir, una densidad de $1 \mu \mathrm{A} / \mathrm{cm}^{2}$ equivale a una penetración en el acero de 11,6 $\mu \mathrm{m} /$ año.

El inconveniente de este método es que sólo se puede aplicar a una probeta en el laboratorio y no in situ a una estructura de hormigón, debido a que se debe conocer el área de la armadura expuesta.

En función de la velocidad de corrosión, en la Tabla 3.6 se reflejan de manera aproximada los valores de $R_{p}$, ícorr y el avance de la corrosión. En los hormigones secos con resistividades muy altas, están los valores de ícorr de 0,1 ó $0,2 \mu \mathrm{A} / \mathrm{cm}^{2}$.

En hormigones carbonatados húmedos (no saturados) y en hormigones con contenido medio de cloruros, se pueden medir valores de hasta $10 \mu \mathrm{A} / \mathrm{cm}^{2}$. $Y$ finalmente se aprecian en hormigones muy altamente contaminados de cloruros (es la máxima velocidad medida en hormigón sin actuación de corrientes galvánicas), valores entre 10 y $100 \mu \mathrm{A} / \mathrm{cm}^{2}$ [Andrade, C. y Feliu, S.; 1989].

Tabla 3.6 Parámetros electroquímicos y velocidad de corrosión [Andrade, C. y Feliu, S.; 1989].

\begin{tabular}{lrrr}
\hline $\begin{array}{c}\text { Velocidad de } \\
\text { corrosión }\end{array}$ & \multicolumn{1}{c}{$\begin{array}{c}\mathrm{Rp} \\
{\left[\mu \Omega \cdot \mathrm{cm}^{2}\right]}\end{array}$} & \multicolumn{1}{c}{\begin{tabular}{c} 
i $\begin{array}{c}\text { i corr } \\
{\left[\mu \mathrm{A} / \mathrm{cm}^{2}\right]}\end{array}$ \\
\hline Muy elevada
\end{tabular}} & $\begin{array}{c}\text { Avance de la corrosión } \\
{[\mu \mathrm{m} / \text { año] }}\end{array}$ \\
Elevada & $2,50-0,25$ & $10,00-100,00$ & $100,00-1000,00$ \\
Bajo / moderada & $25,00-2,50$ & $1,00-10,00$ & $10,00-100,00$ \\
Pasiva & $>250,00$ & $0,10-1,00$ & $1,00-10,00$ \\
\hline
\end{tabular}

En realidad, el valor de ícorr no está relacionado con la humedad relativa interior del hormigón, que representa el agua evaporable, sino exactamente con el contenido de agua líquida respecto al volumen de poros del hormigón [Andrade, C., et al; 2002].

El agrietamiento del hormigón suele ocasionarse, por penetraciones de corrosión en torno a 100-125 $\mu \mathrm{m}$ [Andrade, C.; 1984]. 


\section{Capítulo 4}

\section{TRABAJO EXPERIMENTAL}

siguientes:

Los trabajos experimentales realizados en esta Tesis Doctoral, son los

- Características de las escorias de RSU:

- Análisis químico

- Granulometría

- Estudio de morteros con escorias de RSU.

- Estudio de hormigones con escorias de RSU.

- Estudio de corrosión de armaduras embebidas en morteros elaborados con escorias de RSU

El análisis químico para el estudio de las escorias de RSU y las mediciones electroquímicas para el estudio de corrosión de armaduras con escorias de RSU, se han llevado a cabo en el Laboratorio del Centro Nacional de Investigaciones Metalúrgicas, CENIM-CSIC, en Madrid.

Los demás trabajos se realizaron en el Laboratorio de Materiales de la Escuela Técnica Superior de la Edificación de Madrid, ETSEM-UPM. 


\subsection{CARACTERÍSTICAS DE LAS ESCORIAS DE RSU}

\subsubsection{ANÁLISIS QUÍMICO}

Las escorias de RSU utilizadas en este trabajo, proceden de la Incineradora de Valdemingómez de Madrid, que utiliza un horno de lecho fluidizado donde se alcanzan temperaturas de $850^{\circ} \mathrm{C}$.

Las escorias han permanecido a la intemperie al menos dos meses en un vertedero controlado, por lo que en ese tiempo han podido liberarse de los posibles contenidos de cloruro, ya que durante dicho periodo algunas de las características químicas y mineralógicas de las escorias sufren cambios significativos [Chimenos, J.M., et al; 2003].

El tamaño original de las escorias no es homogéneo (alcanzaba tamaños de más de $10 \mathrm{~cm}$ ) por lo tanto, se ha procedido a triturarlas disminuyendo el tamaño, para la obtención de una granulometría acorde con la de los áridos naturales.

Para llevar a cabo el análisis químico, se han tomado muestras de las escorias de RSU en forma de polvo y se han preparado en forma de pastillas compactadas previamente al análisis. El análisis es semicuantitativo, realizado por Espectroscopía de Emisión de FRX-d $\lambda$, PHILIPS PW1404. Por configuración de cristales analizadores, es posible analizar desde el elemento $\mathrm{Na}$ hacia delante en la Tabla Periódica.

También se ha obtenido la determinación de Perdidas por Calcinación (PxC) ó LOI (Loss of Ignition), primero a $950^{\circ} \mathrm{C}$ y después, de la misma muestra, a $1100^{\circ} \mathrm{C}$. El ensayo se realiza por triplicado en Horno de Mufla.

\subsubsection{GRANULOMETRÍA}

Las escorias se han triturado, para limitar el tamaño máximo a $20 \mathrm{~mm}$, con una trituradora eléctrica de mandíbulas de laboratorio. Después se ha obtenido la granulometría a través del tamizado del conjunto, según normas UNE-EN 9331 [AENOR; 2012] y UNE-EN 933-2 [AENOR; 1996].

La curva granulométrica obtenida de las escorias de RSU, ha sido comparada con la curva de referencia clásica de Fuller.

Una vez obtenida la granulometría se han dividido las escorias trituradas en dos grupos:

- Escorias finas: de tamaño máximo $4 \mathrm{~mm}$ para la fabricación de los morteros y como árido fino para la elaboración de hormigones. 
- Escorias gruesas: de tamaño máximo $20 \mathrm{~mm}$ para utilizar como grava en la confección de hormigones.

\subsection{ESTUDIO DE MORTEROS CON ESCORIAS DE RSU}

Para estudiar cómo influyen, en las características mecánicas de los morteros tradicionales de cemento Portland, la dosificación con escorias procedentes de la incineración de RSU en sustitución parcial o total del árido natural, se han elaborado cinco tipos de morteros diferentes cuya dosificación en peso se recoge en la Tabla 4.2:

- El M1 es un mortero de referencia elaborado con arena natural de río, sin escorias de RSU.

- El M2, es un tipo de mortero elaborado con un $75 \%$ de arena natural y un $25 \%$ de escorias de RSU.

- El M3 es un tipo de mortero elaborado con un 50\% de cada uno de los materiales, tanto de arena natural y como de escorias de RSU.

- El M4 es un tipo de mortero, con una sustitución de un $75 \%$ de arena natural por escorias de RSU.

- El M5 es un mortero elaborado únicamente con escorias de RSU, sin árido natural.

Los cinco tipos de mortero tienen la misma proporción 1/3/0,5 de cemento/árido/agua; entendiendo por árido la arena natural y/o las escorias finas de tamaño máximo de $4 \mathrm{~mm}$.

Para la elaboración del mortero de referencia la dosificación, es una parte de cemento y tres de arena, en masa y con una relación agua/cemento de 0,5 . Para de los otros cuatro tipos de moteros la dosificación se ha mantenido, pero reemplazando la arena parcial o totalmente por escorias de RSU. 
Tabla 4.2 Dosificación relativa y en peso de los diferentes tipos de mortero estudiados. Cemento (c): arena (a): escorias finas (ef): agua (w).

\begin{tabular}{crrrrrrrr}
\hline \multirow{2}{*}{ Tipo de mortero } & \multicolumn{4}{c}{ Dosificación } & C & a & ef & w \\
& c & \multicolumn{1}{c}{ a } & ef & w & [gr] & [gr] & [gr] & [gr] \\
\hline M1 & 1 & 3 & - & 0,5 & 450 & 1350 & - & 225 \\
M2 & 1 & 2 & 1,0 & 0,5 & 450 & 900 & 450 & 225 \\
M3 & 1 & 1,5 & 1,5 & 0,5 & 450 & 675 & 675 & 225 \\
M4 & 1 & 1 & 2 & 0,5 & 450 & 450 & 900 & 225 \\
M5 & 1 & - & 3 & 0,5 & 484 & - & 1450 & 242 \\
\hline
\end{tabular}

Los materiales utilizados han sido cemento Portland Valderribas CEM II B-L 32,5 N, según norma UNE-EN 197-1 [AENOR; 2011], arena de río normalizada de la marca CEN-Normsand según DIN-EN 196-1 de $4 \mathrm{~mm}$ y escorias finas de $4 \mathrm{~mm}$ de tamaño máximo procedentes de la incineradora de Valdemingómez.

\section{Proceso de elaboración de los tipos de morteros}

Las probetas de mortero de cemento Portland se han elaborado de acuerdo la norma UNE-EN 196-1 [AENOR; 2005]:

- Amasado: se ha realizado con una amasadora automática lbertest homologada planetaria según normativa (Figura 4.3), cuyo amasado comienza en el momento en que se vierte el agua y el cemento dentro del recipiente, cuando entran en contacto los materiales, se pone en marcha la amasadora, iniciando los tiempos de mezclado Figura 4.4.

Después de un corto tiempo de amasado, se añade regularmente la arena (o escorias según sea el caso de los diferentes tipos de morteros), se continúa el amasado, luego se detiene la amasadora y en los primeros segundos se retira con una espátula de plástico todo el mortero adherido a las paredes laterales y al fondo del recipiente y se coloca en el centro de la amasadora, y se continúa el amasado, concluyendo a los pocos segundos. 


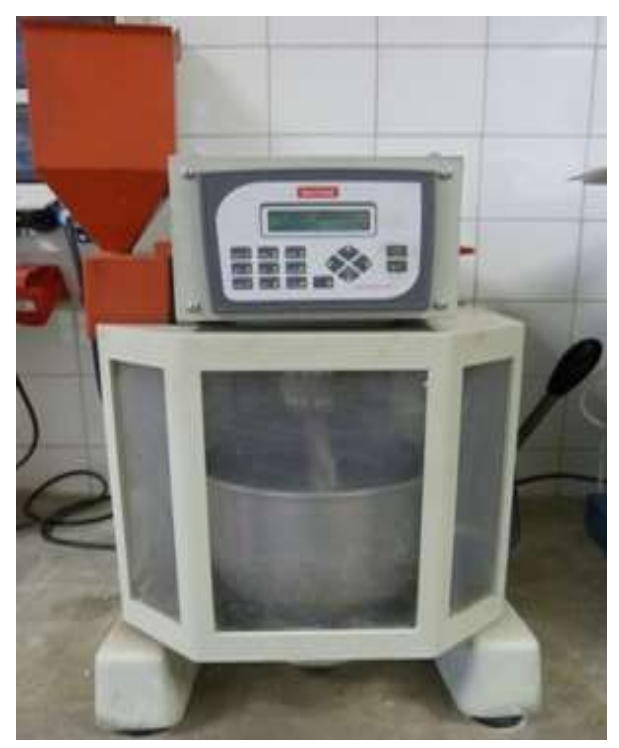

Figura 4.4 Amasadora Automática Ibertest.

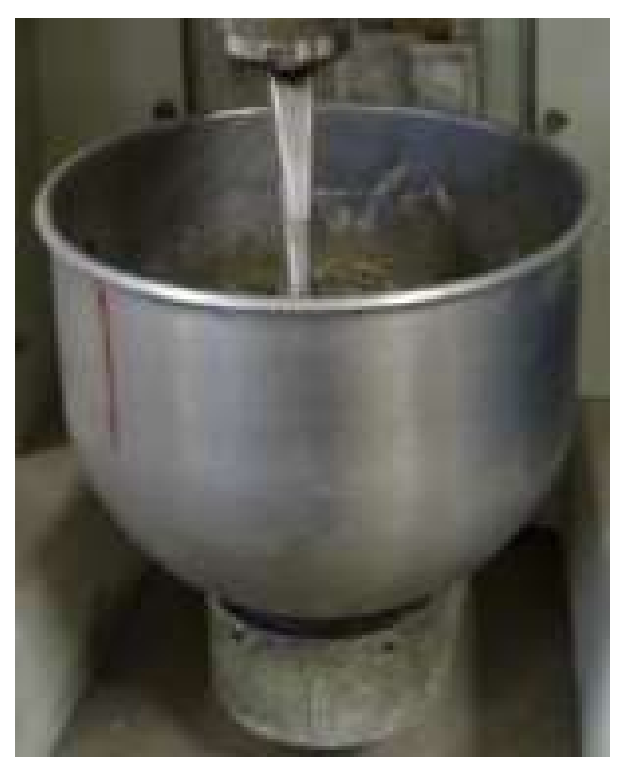

Figura 4.4 Amasado de mortero de referencia.

- Determinación del valor de la densidad y el escurrimiento: después del proceso de amasado, se ha logrado la densidad de los diferentes morteros, y también se ha obtenido el valor del escurrimiento del mortero fresco Figura 4.5.

Se ha obtenido la densidad del mortero fresco teniendo en cuenta el peso de cada tipo de amasada (o mortero), dividido entre la capacidad de contenido del vaso estándar $361 \mathrm{ml}$. 
El valor del escurrimiento se ha realizado midiendo el diámetro medio de una muestra de cada tipo de mortero fresco colocado, con la ayuda de un molde sobre el disco de una mesa de sacudidas definida, en donde se somete (cada tipo de mortero) a un determinado número de sacudidas verticales, levantando la mesa de sacudidas y dejándola caer libremente desde una altura determinada Figura 4.6.

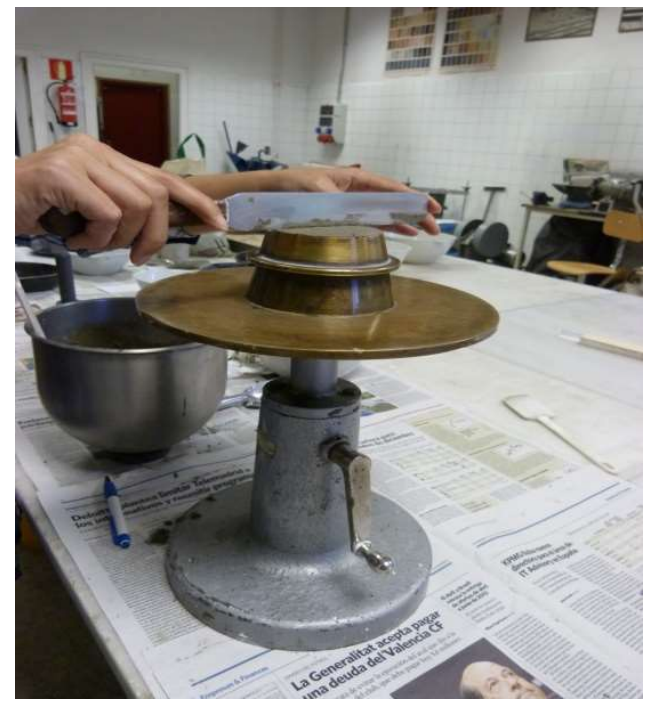

Figura 4.5 Enrasado del molde para realizar el ensayo de escurrimiento.

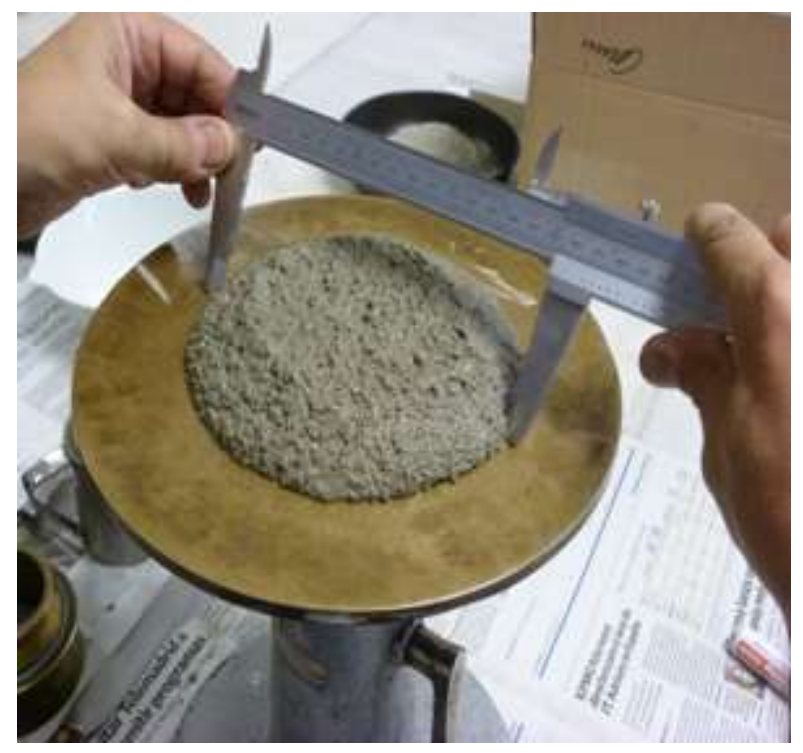

Figura 4.6 Medición del escurrimiento. 
- Montaje y relleno con mortero de los moldes: inmediatamente después del amasado y de obtener tanto el valor del escurrimiento como de la densidad, con una única amasada de cada tipo de mortero, se arma un molde (de acero) triple y la tolva unidos firmemente a la mesa compactadora.

Se introduce directamente desde la medición del escurrimiento, con una cuchara adecuada la primera de las dos capas de mortero (cada una aproximadamente de $300 \mathrm{~g}$ ) en cada uno de los tres compartimentos del molde, con la finalidad de confeccionar tres probetas prismáticas de $160 \times 40 \times 40 \mathrm{~mm}$, como se observa en la Figura 4.7. Se compacta esa primera capa de mortero con 60 golpes, se introduce la segunda capa y se vuelve a compactar con otros 60 golpes.

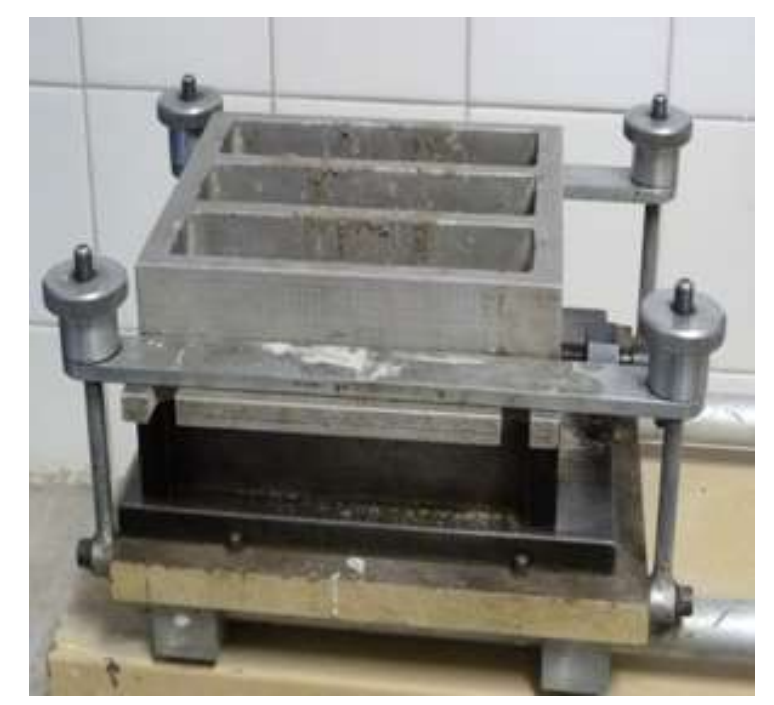

Figura 4.7 Moldes prismáticos para la confección de probetas de mortero montados sobre la mesa de sacudidas.

- Vibrado en la mesa de sacudidas: el mortero fresco es llevado a un nivel de consistencia definido antes de evaluar las propiedades que se utilicen para caracterizarlo, dicha consistencia es evaluada a través de la mesa de sacudidas.

Una vez concluido el relleno del mortero en los moldes, con precaución se retira el molde de la mesa de sacudidas y se separa la tolva, en seguida se elimina el exceso de mortero con la regla plana, alisando la superficie superior de las probetas. Y las probetas son etiquetadas (Figura 4.8). 


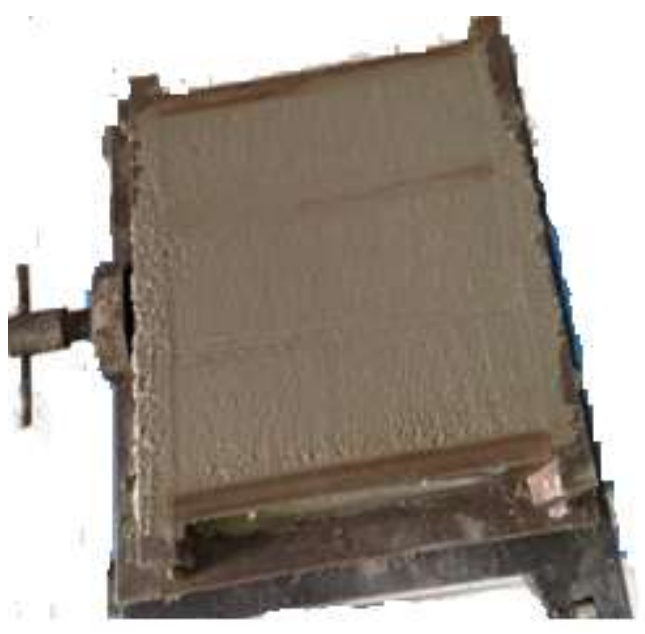

Figura 4.8 Fabricación de las probetas en los moldes.

- Conservación y manipulación antes de desmoldar: una vez compactado el mortero, cada molde es colocado sobre una superficie horizontal en la cámara durante 22 horas.

- Desmoldado de las probetas y determinación de la densidad de los diferentes morteros: para llevar a cabo el desmoldado se utiliza un martillo de goma, como los ensayos se llevarán a cabo a los 28 días de edad, el desmoldado de las probetas se realiza 22 horas, después del enmoldado Figura 4.9.

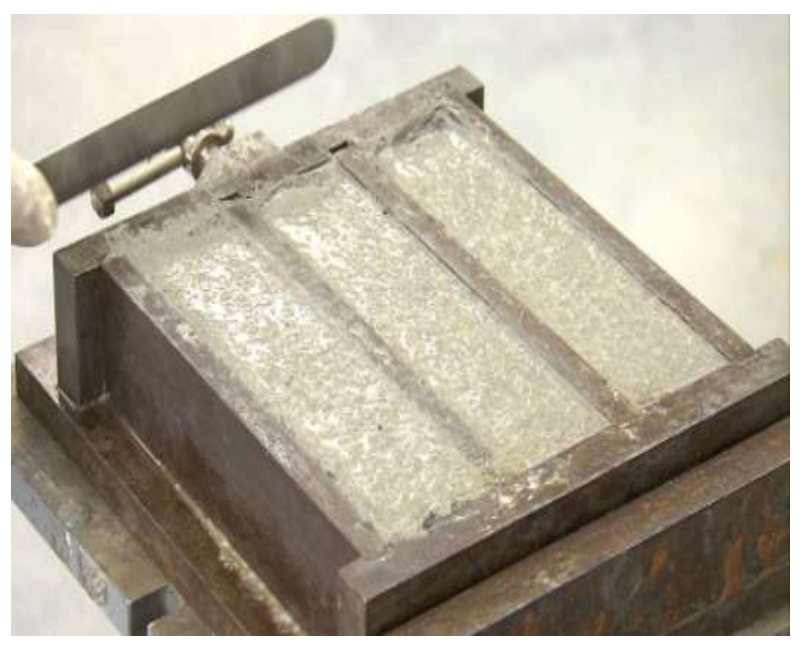

Figura 4.9 Las probetas en los moldes para desmoldar. 
- Cámara de curado: las probetas se han curado durante 28 días en una cámara lbertest, modelo CM200, regulada con una humedad relativa (HR) constante del $95 \%$ y una temperatura de $20^{\circ} \mathrm{C}$, Figura 4.10 .
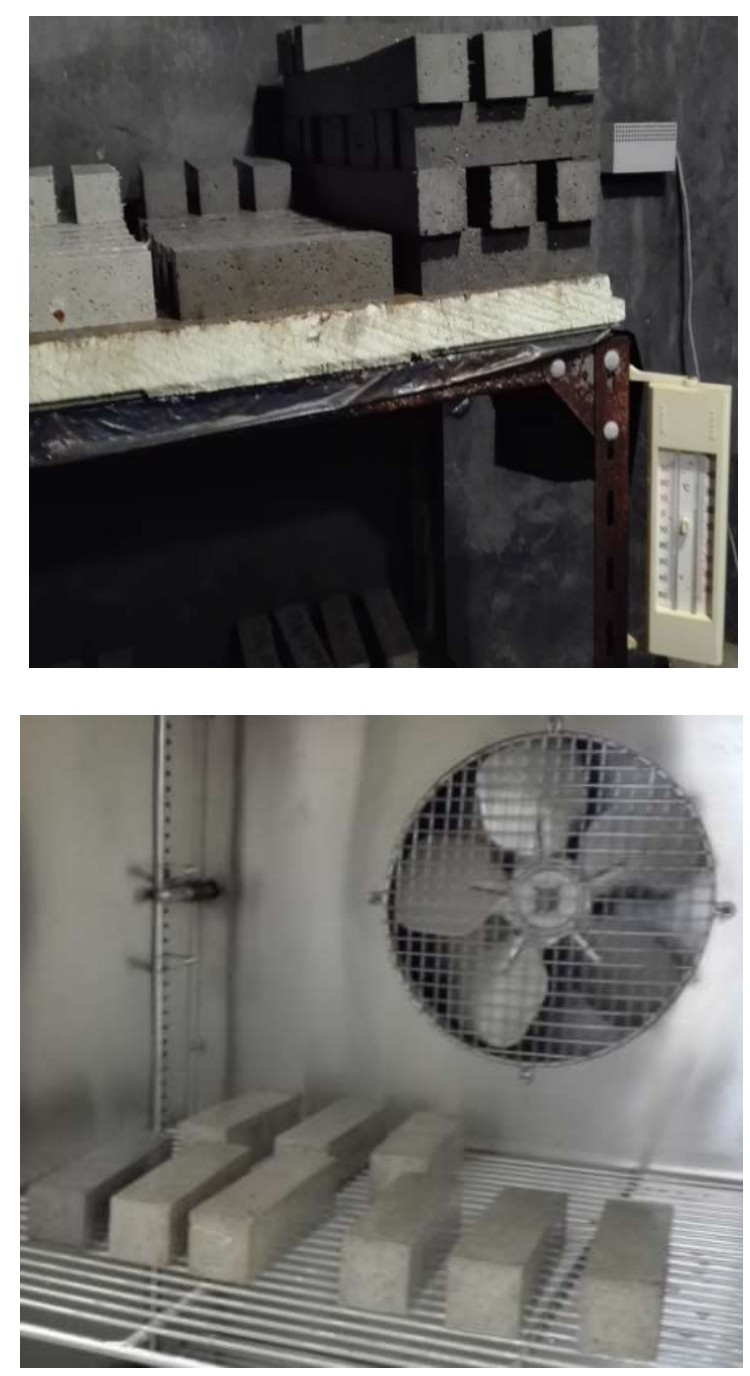

Figura 4.10 Cámara de Curado.

Una vez curadas a los 28 días tanto las roturas a flexión como a compresión, se ha realizado con una máquina de marca lbertest, modelo Autotest 200-10 SW. 


\subsection{ESTUDIO DE HORMIGONES CON ESCORIAS DE RSU}

Para analizar cómo influye en las características mecánicas de los hormigones, con una dosificación de escorias procedentes de la incineración de $\mathrm{RSU}$, en sustitución parcial o total de los áridos naturales (arena y grava), que se recogen en la Tabla 4.4. Se han elaborado cuatro tipos de hormigones de diferentes dosificaciones en peso:

- El H1 es un hormigón de referencia elaborado con arena natural de río y grava de canto rodado, sin escorias.

- $\quad$ El H2 es un hormigón elaborado con 33\% de escorias en sustitución tanto de arena como de grava.

- El H3 es un hormigón elaborado con escorias en un $66 \%$ sustituyendo la arena y la grava.

- El H4 es un hormigón elaborado completamente con escorias, sin árido natural.

Los cuatro tipos de hormigón tienen la misma proporción 1/1,85/3,32/0,5 de cemento/árido/grava/agua; entendiendo por árido la arena natural y grava y/o las escorias (tanto finas como gruesas).

En el caso del hormigón de referencia $(\mathrm{H} 1)$, es de dosificación, $1 / 1,85 / 3,32 / 0,5$ de cemento/árido/grava/agua. Se han amasado otros tres tipos de hormigones manteniendo la dosificación, pero sustituyendo tanto arena como grava por escorias de RSU, en diferentes porcentajes (Tabla 4.3).

Las escorias de RSU para las dosificaciones se han dividido en dos partes: las escorias finas de un tamaño máximo de $4 \mathrm{~mm}$ y las escorias gruesas de tamaño máximo de $20 \mathrm{~mm}$. En el caso de los hormigones las escorias finas son utilizadas para sustituir la arena y las gruesas en sustitución de la grava.

Tabla 4.3 Dosificación relativa y en peso de los diferentes tipos de hormigón estudiados: cemento (c): arena (a): grava (g): escorias finas (ef): escorias gruesas (eg): agua (w).

\begin{tabular}{|c|c|c|c|c|c|c|c|c|c|c|c|c|c|}
\hline \multirow{2}{*}{$\begin{array}{l}\text { Tipo de } \\
\text { hormigón }\end{array}$} & \multicolumn{6}{|c|}{ Dosificación } & \multirow{2}{*}{$\begin{array}{c}\text { Escorias* } \\
{[\%]}\end{array}$} & \multirow{2}{*}{$\begin{array}{c}\mathrm{c} \\
{[\mathrm{kg}]}\end{array}$} & \multirow{2}{*}{$\begin{array}{c}\mathrm{a} \\
{[\mathrm{kg}]}\end{array}$} & \multirow{2}{*}{$\begin{array}{c}\mathrm{g} \\
{[\mathrm{kg}]}\end{array}$} & \multirow{2}{*}{$\begin{array}{c}\text { ef } \\
{[\mathrm{kg}]}\end{array}$} & \multirow{2}{*}{$\begin{array}{c}\mathrm{eg} \\
{[\mathrm{kg}]}\end{array}$} & \multirow{2}{*}{$\begin{array}{l}\mathrm{w} \\
{[\mathrm{l}]}\end{array}$} \\
\hline & $c$ & $a$ & $\mathrm{~g}$ & ef & eg & w & & & & & & & \\
\hline $\mathrm{H} 1$ & 1 & 1,85 & 3,32 & - & - & 0,5 & 0 & 2 & 3,7 & 6,6 & - & - & 1,1 \\
\hline $\mathrm{H} 2$ & 1 & 1,23 & 2,22 & 0,62 & 1,11 & 0,5 & 33 & 2 & 2,5 & 4,4 & 1,2 & 2,2 & 1,1 \\
\hline $\mathrm{H} 3$ & 1 & 0,62 & 1,11 & 1,23 & 2,22 & 0,5 & 66 & 2 & 1,2 & 2,2 & 2,5 & 4,4 & 1,1 \\
\hline $\mathrm{H} 4$ & 1 & - & - & 1,85 & 3,32 & 0,5 & 100 & 2 & - & - & 3,7 & 6,6 & 1,1 \\
\hline
\end{tabular}

$\left({ }^{*}\right)$ Porcentaje de escorias finas y gruesas respecto al contenido total de los áridos utilizados. 
Las materias primas utilizadas para el amasado han sido cemento Portland Valderribas CEM II B-L 32,5 N, según norma UNE-EN 197-1 [AENOR; 2011], arena de río normalizada de la marca CEN-Normsand según DIN-EN 196-1 de tamaño máximo $4 \mathrm{~mm}$, grava de canto rodado de $20 \mathrm{~mm}$ tamaño máximo, escorias finas de $4 \mathrm{~mm}$ y escorias gruesas de $20 \mathrm{~mm}$, ambas con tamaño máximo de la incineradora de Valdemingómez - Madrid.

\section{Proceso de elaboración de los tipos de hormigones}

- Amasado: el amasado de los hormigones se ha realizado con una hormigonera de eje vertical. Para cada tipo se hormigón se ha realizado una única amasada.

- Determinación de la consistencia -cono de Abrams: una vez concluido el amasado, se ha obtenido la consistencia de cada amasada de hormigón por el asiento en el cono de Abrams (Figura 4.10), según UNE-EN 123502 [AENOR; 2009].

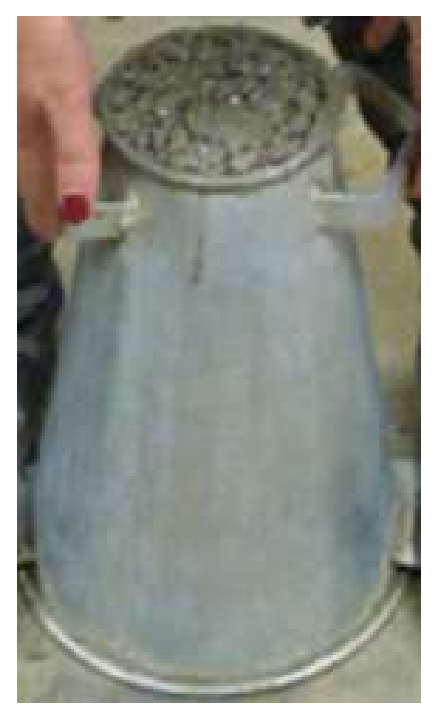

Diámetro de la base superior: $\quad 100 \mathrm{~mm} \pm 2 \mathrm{~mm}$

Diámetro de la base inferior: $\quad 200 \mathrm{~mm} \pm 2 \mathrm{~mm}$

Altura del tronco de cono: $\quad 300 \mathrm{~mm} \pm 2 \mathrm{~mm}$

Figura 4.10 Cono de Abrams.

- Montaje y relleno con hormigón de los moldes: una vez realizada la determinación de la consistencia de cada uno de los tipos de hormigón (ver Tabla 4.5), se arma cada molde vertiendo el amasado del hormigón. 
El hormigón se compacta inmediatamente después de su vertido en el molde, que es rellenado en dos capas, para obtener una compactación completa. A través de la compactación manual, se distribuye los golpes de la barra de compactar de manera uniforme sobre la sección transversal del molde, se somete el hormigón a 25 golpes por capa.

Con una única amasada por cada tipo de hormigón (ver Tabla 4.3), se han confeccionado cinco probetas cúbicas en moldes de $100 \mathrm{~mm} \times 100$ $\mathrm{mm} \times 100$ mm según UNE-EN 12390-1 [AENOR; 2001], se puede apreciar el molde en la Figura 4.11, elaborando un total de 20 probetas de hormigón.

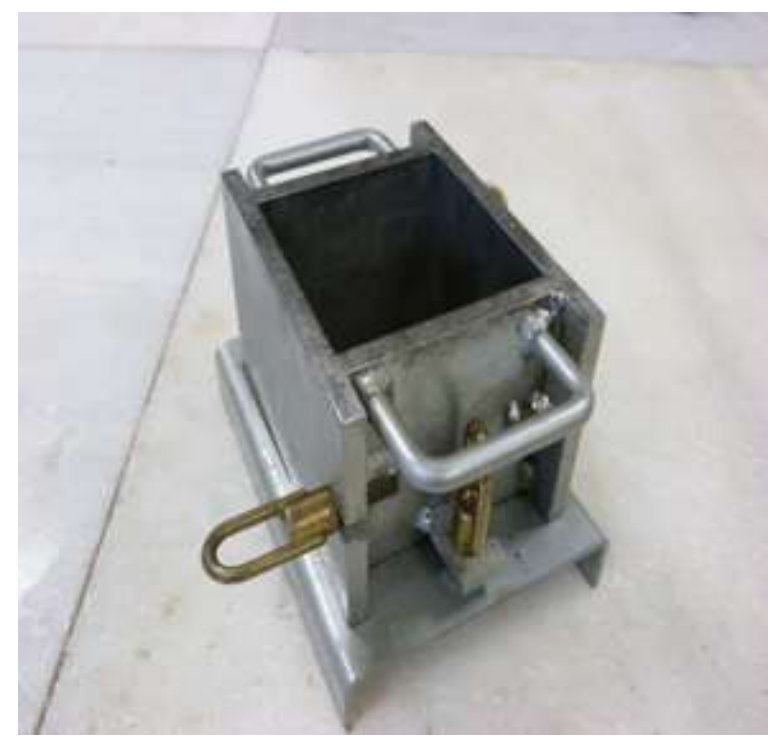

Figura 4.11 Molde cúbico para probeta de hormigón.

- Conservación y manipulación antes de desmoldar: una vez fabricadas las probetas de hormigón, se mantienen en el molde, convenientemente protegida durante 22 horas, posteriormente se desmoldan.

- Cámara de curado: después de retirar las probetas de los moldes se curan hasta inmediatamente antes del ensayo, las probetas se han curado durante 28, 105 y 180 días de edad, de cada uno de los cuatro tipos de hormigón (Figura 4.12), en una cámara marca lbertest, modelo CM200, regulada con una humedad relativa (HR) constante del $95 \%$ y una temperatura de $20^{\circ} \mathrm{C}$. 


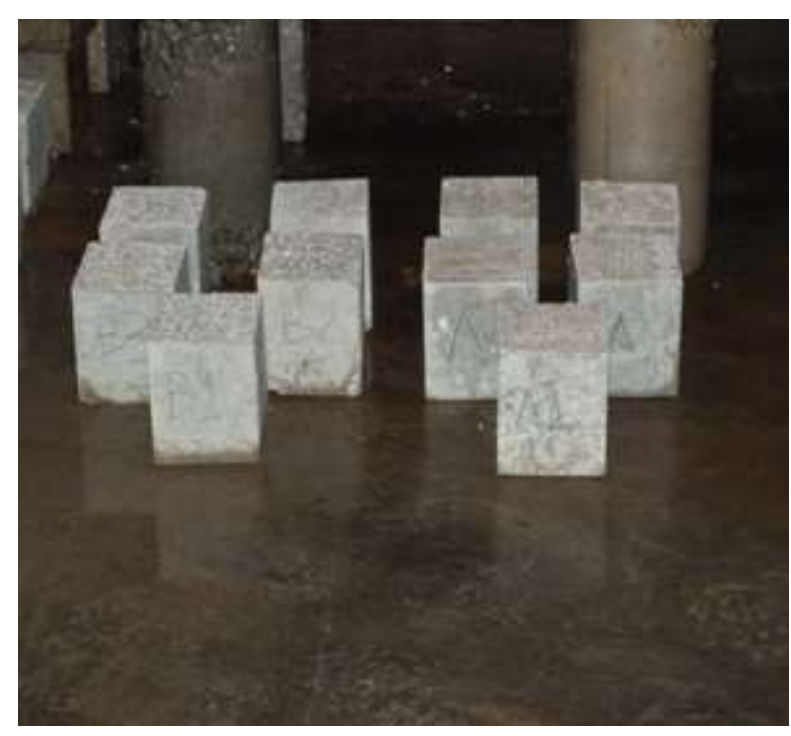

Figura 4.12 Cámara de curado con probetas de hormigón.

Una vez curadas las probetas de hormigón a los 28 días, 105 días y 180 días, se ha realizado la rotura a compresión en una máquina lbertest modelo MIB 60/AM.

\subsection{ESTUDIO DE CORROSIÓN DE ARMADURAS EMBEBIDAS EN MORTEROS ELABORADOS CON ESCORIAS DE RSU}

Para estudiar cómo influye la utilización de escorias en la corrosión de las armaduras embebidas en el hormigón, se han confeccionado cuatro probetas de mortero de cemento Portland elaborado sólo con escorias finas de RSU (tamaño máximo de $4 \mathrm{~mm}$ ), como sustituto total del árido natural, en las que se han embebido barras corrugadas laminadas en frío por parejas de un mismo acero, se han utilizado cuatro tipos de aceros, el tradicional acero al carbono, y los aceros inoxidables (austenítico, el dúplex y el dúplex de bajo contenido en níquel).

Para comparar con el mortero de referencia se han elaborado otras cuatro probetas con mortero convencional, es decir con arena de río, cemento y agua, sin escorias, para contrastar los datos obtenidos, con los mismos aceros descritos antes.

De cada una de las barras de acero embebidas en las ocho probetas de mortero, se han realizado mediciones electroquímicas del potencial de corrosión y de la resistencia de polarización, durante un periodo de tres años. 
Las probetas de mortero son de forma prismáticas de $8 \times 5,5 \times 2 \mathrm{~cm}$. Las mediciones electroquímicas se realizarán en el Laboratorio de Ingeniería de Superficies, Corrosión y Durabilidad del Centro Nacional de Investigaciones Metalúrgicas CENIM-CSIC.

El mortero amasado para las probetas de escorias finas, es de dosificación cemento/escorias-finas/agua 1/3/0,5 (c/ef/w), y el mortero de referencia cemento/arena/agua 1/3/0,5 (c/a/w), los materiales para los morteros se componen, de cemento Portland CEM II B-L 32,5 N, según norma UNE-EN 197-1 [AENOR; 2011], arena de río normalizada de la marca CEN-Normsand según DIN-EN 196-1, escorias finas de la incineradora de Valdemingómez tamaño máximo de $4 \mathrm{~mm}$.

El amasado se ha llevado a cabo en una amasadora automática de la marca lbertest, igual a la utilizada en el estudio de morteros con escorias de la incineración de RSU. La composición en peso de cada amasada, realizada para las probetas se refleja en la Tabla 4.4 y Tabla 4.5 respetivamente.

Las probetas de mortero se han designado como se indica en la Tabla 4.4, con la letra P en el caso del mortero con el $100 \%$ de escorias, y en la Tabla 4.5, con la letra $R$ para los moteros de referencia sin contenido de escorias, con números correlativos para cada tipo de acero corrugado, laminados en frío.

Tabla 4.4 Dosificación en peso del mortero con el 100\% de escorias de RSU y denominación de las probetas.

\begin{tabular}{ccccc}
\hline No. & \multicolumn{3}{c}{ Dosificación } & Barras \\
\cline { 2 - 4 } Probeta & Cemento [gr] & Escorias [gr] & Agua [gr] & corrugadas \\
\hline P1 & 272 & 816 & 136 & a1-a2 \\
P2 & 272 & 816 & 136 & b1 - b2 \\
P3 & 272 & 816 & 136 & c1 - c2 \\
P4 & 272 & 816 & 136 & d1 - d2 \\
\hline
\end{tabular}

Tabla 4.5 Dosificación en peso del mortero en referencia ( $0 \%$ escorias) y denominación de las probetas.

\begin{tabular}{ccccc}
\hline No. & \multicolumn{3}{c}{ Dosificación } & $\begin{array}{c}\text { Barras } \\
\text { Probeta }\end{array}$ \\
\cline { 2 - 4 } corrugadas \\
\hline R1 & Cemento [gr] & Arena [gr] & Agua [gr] & e1-e2 \\
R2 & 272 & 816 & 136 & $\mathrm{f} 1-\mathrm{f} 2$ \\
R3 & 272 & 816 & 136 & $\mathrm{~g} 1-\mathrm{g} 2$ \\
R4 & 272 & 816 & 136 & $\mathrm{~h} 1-\mathrm{h} 2$ \\
\hline
\end{tabular}


Se han cortado ocho barras corrugadas de $6 \mathrm{~mm}$ de diámetro, de $8,5 \mathrm{~cm}$ de longitud, para los morteros con escorias, así mismo otras ocho barras corrugadas para el mortero de referencia, de cada uno de los siguientes aceros:

a) Tradicional acero al carbono B-500-SD.

b) Austenítico AISI 304 (EN 1.4301).

c) Dúplex AISI 2304 (EN 1.4362).

d) Y dúplex de bajo contenido en níquel AISI 2001 (EN 1.4482).

Cada barra se ha enumerado y pesado, con una balanza Mettler AJ150 que tiene una precisión de 0,01 $\mathrm{mg}$. Los resultados se recogen en la Tabla 4.6 y se observan en la Figura 4.13.

Tabla 4.6 Numeración y peso de las barras corrugadas $\varnothing 6$, de cada acero.

\begin{tabular}{|c|c|c|c|c|c|c|c|}
\hline \multicolumn{8}{|c|}{ Tipo de acero } \\
\hline \multicolumn{2}{|c|}{ Carbono } & \multicolumn{6}{|c|}{ Inoxidables } \\
\hline \multicolumn{2}{|c|}{ B500SD } & \multicolumn{2}{|c|}{ AISI 304} & \multicolumn{2}{|c|}{ AISI 2304} & \multicolumn{2}{|c|}{ AISI 2001} \\
\hline $\begin{array}{c}\text { No. } \\
\text { Probeta }\end{array}$ & $\begin{array}{l}\text { Peso } \\
\text { [gr] }\end{array}$ & $\begin{array}{c}\text { No. } \\
\text { Probeta }\end{array}$ & $\begin{array}{c}\text { Peso } \\
\text { [gr] }\end{array}$ & $\begin{array}{c}\text { No. } \\
\text { Probeta }\end{array}$ & $\begin{array}{c}\text { Peso } \\
\text { [gr] }\end{array}$ & $\begin{array}{c}\text { No. } \\
\text { Probeta }\end{array}$ & $\begin{array}{c}\text { Peso } \\
\text { [gr] }\end{array}$ \\
\hline a1 & 21,28 & b1 & 21,05 & $c 1$ & 20,76 & d1 & 20,96 \\
\hline a2 & 20,85 & b2 & 21,39 & c2 & 20,28 & d2 & 21,02 \\
\hline e1 & 21,42 & $\mathrm{f} 1$ & 21,33 & g1 & 20,77 & h1 & 20,71 \\
\hline e2 & 22,07 & f2 & 21,24 & g2 & 20,56 & h2 & 20,32 \\
\hline
\end{tabular}

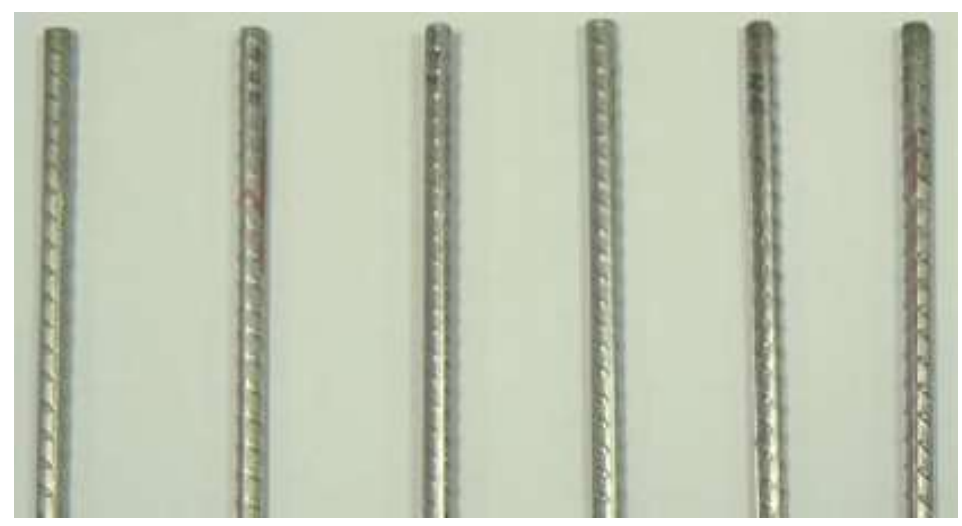

Figura 4.13 Armaduras $\varnothing 6$ de los aceros AISI 304, AISI 2304 y AISI 2001. 
Para elaborar las probetas de mortero, los moldes han sido fabricados y son desmontables de madera (Figura 4.14), revestida con pintura epoxi para evitar la absorción de agua del mortero. Se ha utilizado Desencofrante-D al aceite de la marca SIKA diluido en agua con una proporción en volumen 1:5 (desencofrante:agua).

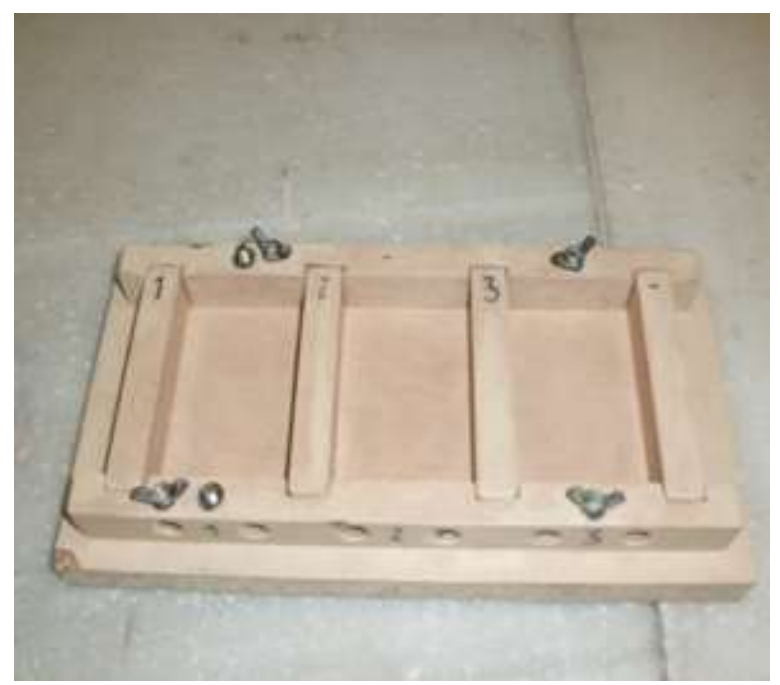

Figura 4.14 Molde para confección de probetas de mortero con armaduras embebidas para mediciones electroquímicas.

Las barras que van a ser embebidas por parejas de un mismo, acero en las probetas de mortero prismáticas de $8 \times 5,5 \times 2 \mathrm{~cm}$ (Figura 4.15). Dejando expuesta a la posible corrosión una superficie de $10 \mathrm{~cm}^{2}$ de cada barra en el centro de la probeta de mortero, para lo cual cada barra próxima al borde de la probeta se ha protegido con cinta aislante en el extremo final y en la zona de la barra próxima al borde de la probeta. El recubrimiento mínimo de mortero sobre la zona expuesta es de 6 mm (Figura 4.16). 


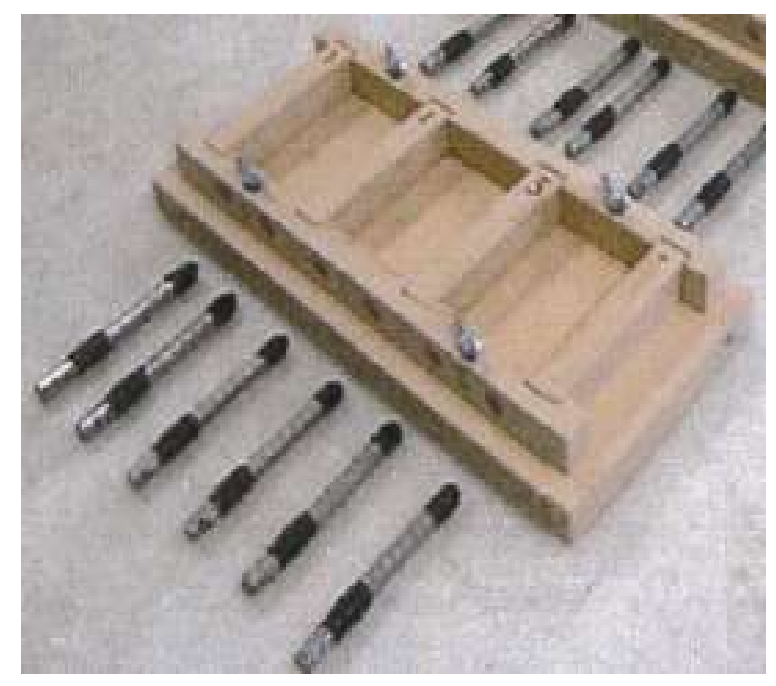

Figura 4.15 Barras de acero inoxidable preparadas para embeber en probetas de mortero.

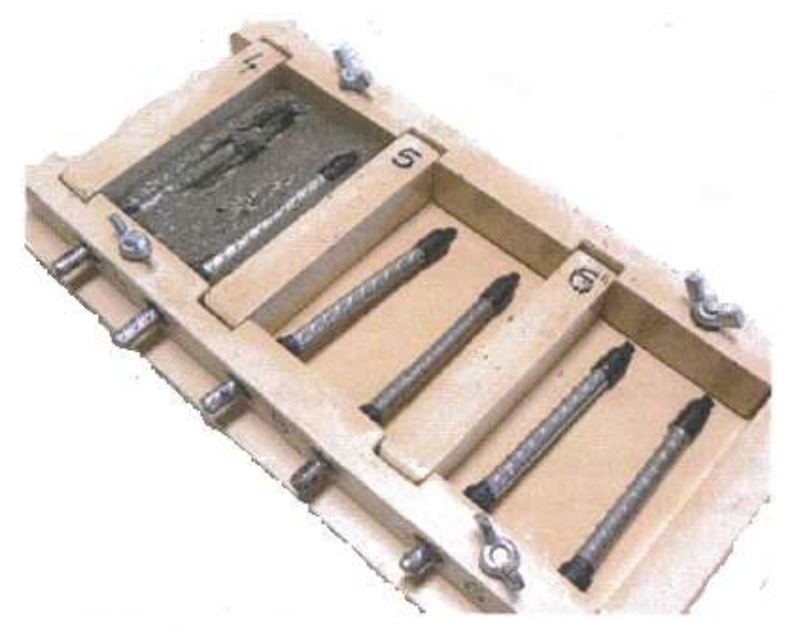

Figura 4.16 Barras de acero inoxidable embebidas en probetas de mortero.

Para conectar cada barra a los equipos de medición electroquímica, se deja libre y al exterior de la probeta de mortero uno de sus extremos, que se protegerá con un tapón de plástico entre mediciones para evitar su corrosión, en la Figura 4.17.

Las probetas se han curado durante 28 días en una cámara marca Ibertest, modelo CM200, regulada con una humedad relativa (HR) constante del $95 \%$ y una temperatura de $20^{\circ} \mathrm{C}$. 
Posteriormente, y durante el periodo que ha durado el estudio, las probetas se han conservado en el interior de un recipiente hermético con una humedad relativa constante del 95\%, extraídas únicamente para realizar las mediciones electroquímicas.

Estas mediciones se han realizado primeramente con frecuencia semanal, seguidamente quincenal, durante los primeros días de vida de las probetas, posteriormente mensual, después cada mes y medio, y finalmente se han ido ampliado los plazos al estabilizarse los resultados, hasta la última etapa del periodo estudiado.

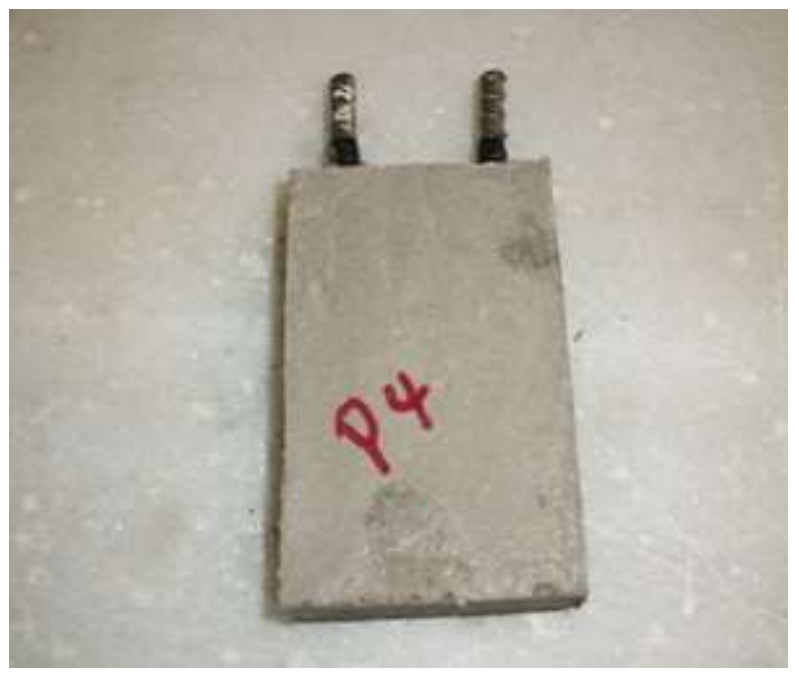

Figura 4.17 Probeta de mortero transcurridos 28 de días de curado. 


\section{Capítulo 5}

\section{RESULTADOS Y DISCUSIÓN}

\subsection{LAS ESCORIAS DE RSU}

\subsubsection{ANÁLISIS QUÍMICO}

Los resultados del análisis químico de las escorias de RSU obtenidas de la incineradora de Valdemingómez (Madrid), de la muestra original, se indican en la Tabla 5.1. Se han realizado por métodos gravimétricos y por espectroscopia de emisión de fluorescencia de rayos $X$ por dispersión de longitudes de onda (FRX-d $\lambda$ ) sobre una muestra de escorias en forma de polvo.

Tabla 5.1 Análisis químico de escorias procedentes de la incineradora Valdemingómez.

\begin{tabular}{crcr}
\hline Elemento & wt [\%] & Elemento & wt [\%] \\
\hline $\mathrm{Na}_{2} \mathrm{O}$ & 0,51 & $\mathrm{TiO}_{2}$ & 0,62 \\
$\mathrm{MgO}$ & 5,44 & $\mathrm{~V}_{2} \mathrm{O}_{5}$ & 0,09 \\
$\mathrm{Al}_{2} \mathrm{O}_{3}$ & 9,70 & $\mathrm{Cr}_{2} \mathrm{O}_{3}$ & 1,60 \\
$\mathrm{SiO}_{2}$ & 20,48 & $\mathrm{MnO}$ & 4,53 \\
$\mathrm{P}$ & 0,14 & $\mathrm{Fe}_{2} \mathrm{O}_{3}$ & 32,04 \\
$\mathrm{~S}$ & 0,32 & $\mathrm{CuO}$ & 0,05 \\
$\mathrm{Cl}$ & $\mathrm{ZnO}$ & 0,20 \\
$\mathrm{~K}$ & 0,03 & $\mathrm{PbO}$ & 0,02 \\
$\mathrm{CaO}$ & 0,13 & Resto & 0,69 \\
& 23,39 & Total & 100 \\
\hline
\end{tabular}

Otros datos de interés de las escorias son su densidad, entre 2,60 y 2,70 $\mathrm{g} / \mathrm{cm}^{3}$, superficie, entre 0,22 y $0,39 \mathrm{~m}^{2} / \mathrm{g}$ (\% en peso) [Goñi, S., et al; 2007], y la absorción de agua, 2,36\% [Pera, J., et al; 1997].

En el análisis químico de las escorias se observa claramente que el contenido de $\mathrm{Cl}$ es $0,03 \%$, mientras que las investigaciones de otros autores (Tabla 2.5) lo han clasificado entre 0,70 y 3,60\%, por lo tanto, los datos reflejan que las escorias obtenidas para este trabajo pueden ser adecuadas para su 
utilización como sustitutas de los áridos naturales en la confección de hormigón sin que tal vez favorezcan la corrosión de la armaduras de forma significativa.

También han sido analizados los elementos de Perdidas por Calcinación (PxC) ó LOI (Loss of Ignition) a $950^{\circ} \mathrm{C}$ y $1100^{\circ} \mathrm{C}$. Los ensayos se realizaron por triplicado en Horno de Mufla, del producto calcinado a diferentes temperaturas.

Los resultados muestras que no hay $\mathrm{P} \times \mathrm{C}$ a $950^{\circ} \mathrm{C}$; (ver Tabla 5.2) incluso en las determinaciones "B" y "C", se da G×C (Ganancias por Calcinación). Estos resultados son lógicos ya que se tiene en cuenta que el proceso de incineración de origen se realiza a $850^{\circ} \mathrm{C}$.

El análisis se ha repetido con otra muestra de escorias previamente calcinada a $950^{\circ} \mathrm{C}$, dando similares porcentajes de composición al compararlas con las escorias de las muestras originales.

Después, se ha tomado otra muestra de escorias calcinadas a $1100^{\circ} \mathrm{C}$ para realizar otro análisis. Obteniendo los resultados que se observan en la Tabla 5.2, para todas las determinaciones realizadas se produce $\mathrm{G} \times \mathrm{C}$ (Ganancias por Calcinación).

Tabla 5.2 Análisis de la determinación de pérdidas por calcinación a $950^{\circ} \mathrm{C}$ y $1100^{\circ} \mathrm{C}$.

\begin{tabular}{|c|c|c|}
\hline \multirow{3}{*}{ Determinaciones } & \multicolumn{2}{|c|}{ Perdidas por calcinación (ó LOI) } \\
\hline & $950^{\circ} \mathrm{C}$ & $1100^{\circ} \mathrm{C}$ \\
\hline & \multicolumn{2}{|c|}{$\%$ en masa } \\
\hline$A$ & 0,14 & $-0,26$ \\
\hline $\mathrm{B}$ & $-0,30$ & $-0,27$ \\
\hline C & $-0,35$ & $-0,17$ \\
\hline
\end{tabular}

Los porcentajes varían entre $+0,14 \%$ y $-0,35 \%$, por lo que apenas hay pérdidas por calcinación. $Y$ con excepción de la primera determinación " $A$ " $950^{\circ} \mathrm{C}$, en todas las demás determinaciones se producen ganancias por calcinación. 


\subsubsection{GRANULOMETRÍA}

Los resultados de la granulometría de las escorias de RSU, después del proceso de trituración y tamizado, se reflejan en la Tabla 5.3.

Tabla 5.3 Granulometría de escorias de RSU incinerados procedente de Valdemingómez una vez molidas.

\begin{tabular}{rrrr}
\hline \multicolumn{2}{c}{ Escorias finas } & \multicolumn{2}{c}{ Escorias gruesas } \\
\hline Tamiz $[\mathrm{mm}]$ & {$[\%]$} & Tamiz $[\mathrm{mm}]$ & {$[\%]$} \\
\hline 4 & 19,40 & 20,00 & \\
2 & 27,15 & 12,50 & 3,80 \\
1 & 22,90 & 10,00 & 32,65 \\
0,5 & 13,20 & 8,00 & 26,42 \\
0,25 & 8,00 & 6,30 & 19,31 \\
0,125 & 4,45 & 5,00 & 15,12 \\
0,063 & 5,20 & 4,00 & 3,18 \\
Total & 100 & Total & 100 \\
\hline
\end{tabular}

Una vez obtenida la granulometría se han dividido las escorias trituradas en dos partes: escorias finas de tamaño máximo $4 \mathrm{~mm}$ y escorias gruesas de tamaño máximo $20 \mathrm{~mm}$. Los morteros se confeccionarán con las primeras, y los hormigones con una mezcla de ambas.

En el gráfico de la Figura $\mathbf{5 . 1}$ se ha representado también la granulometría resultante de dos posibles mezclas de escorias finas y escorias gruesas para confeccionar hormigón. La Mezcla 1 contendría un $70 \%$ de escorias finas y el resto escorias gruesas, y se corresponde con la que teóricamente se aproxima mejor a la curva de referencia clásica de Fuller. La Mezcla 2 contiene un $36 \%$ de escorias finas y un $64 \%$ de escorias gruesas, que es la proporción que se ha empleado para confeccionar las probetas de hormigón.

La dosificación empleada de escorias de RSU para confeccionar el hormigón en sustitución de la arena y la grava, ha sido el $36 \%$ de escorias finas y un $64 \%$ de escorias gruesas, por ser la dosificación más adecuada para obtener un hormigón de resistencia característica $25 \mathrm{~N} / \mathrm{mm}^{2}$.

A las escorias no se les ha aplicado ningún otro tratamiento, que en la práctica supondría un sobrecosto para la confección de los morteros o los hormigones, para comprobar que es interesante económicamente su utilización como sustituto de los áridos naturales. 


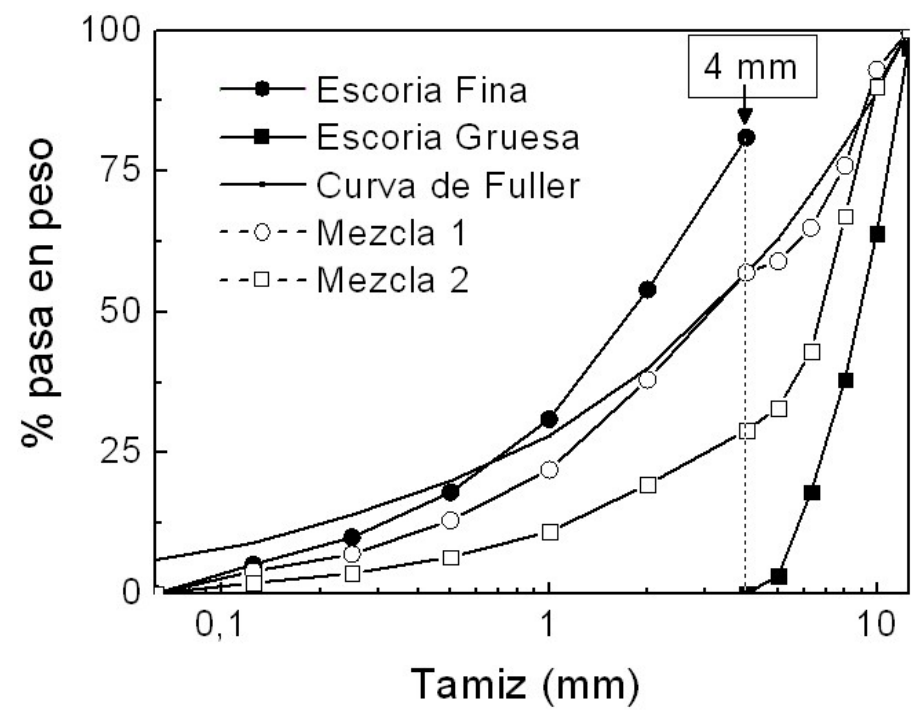

Figura 5.1 Granulometría de las escorias finas y gruesas después del proceso de trituración, curva de Fuller de referencia y granulometría de dos mezclas de áridos: Mezcla 1 con el $70 \%$ de escorias finas y $30 \%$ de escorias gruesas, y Mezcla 2 con el $36 \%$ de escorias finas y $64 \%$ de escorias gruesas.

\subsection{ESTUDIO DE MORTEROS CON ESCORIAS DE RSU}

La densidad de los morteros elaborados con escorias de RSU, es mayor conforme aumenta el contenido de estas, en relación con el mortero elaborado sólo con árido natural, conforme a los datos de la Tabla 5.4. Respecto al escurrimiento, los morteros elaborados con escorias muestran una consistencia más blanda por el contenido leve de metales y metaloides, cuyos datos se ven en la misma tabla. En los cinco tipos de morteros se ha obtenido una consistencia plástica.

Tabla 5.4 Resultados de la densidad y el escurrimiento de los diferentes tipos de morteros. Cemento (c): arena (a): escorias finas (ef): agua (w).

\begin{tabular}{|c|c|c|c|c|c|c|}
\hline \multirow{2}{*}{$\begin{array}{l}\text { Tipo de } \\
\text { mortero }\end{array}$} & \multicolumn{4}{|c|}{ Dosificación } & \multirow{2}{*}{$\begin{array}{c}\text { Densidad } \\
{[\mathrm{gr} / \mathrm{ml}]}\end{array}$} & \multirow{2}{*}{$\begin{array}{l}\text { Escurrimiento } \\
{[\mathrm{mm}]}\end{array}$} \\
\hline & $\mathrm{C}$ & $a$ & ef & W & & \\
\hline M1 & 1,00 & 3,00 & - & 0,50 & 2,19 & 137,50 \\
\hline M2 & 1,00 & 2,00 & 1,00 & 0,50 & 2,31 & 149,50 \\
\hline M3 & 1,00 & 1,50 & 1,50 & 0,50 & 2,39 & 157,50 \\
\hline M4 & 1,00 & 1,00 & 2,00 & 0,50 & 2,46 & 155,00 \\
\hline M5 & 1,00 & - & 3,00 & 0,50 & 2,61 & 159,00 \\
\hline
\end{tabular}


Las probetas de mortero una vez fraguadas a los 28 días de edad desde su fabricación, se desmoldan y se rompen, según procedimiento normalizado, a través de los ensayos a flexión y a compresión.

Los ensayos a flexión de todas las probetas de mortero, se han realizado aplicado una fuerza de $10 \mathrm{kN}$ con una velocidad de $0,03 \mathrm{kN} / \mathrm{s}$.

Se han ensayado a flexión hasta la rotura un total de 15 probetas ( 3 probetas de cada dosificación), la primera dosificación está elaborada con mortero convencional de referencia (Figura 5.2) y las demás están elaboradas con escorias de RSU como sustituto parcial o total de los áridos naturales, en porcentajes crecientes.

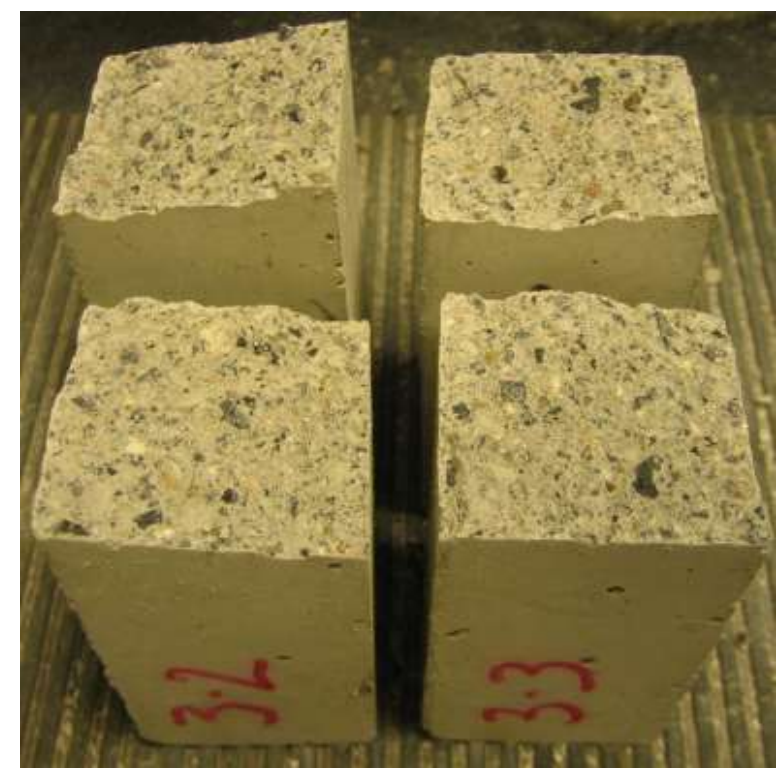

Figura 5.2 Probetas de mortero después de ensayo a flexión.

Los resultados de los ensayos de flexión (3 probetas por cada tipo de mortero) se reflejan en la Tabla 5.5., así como la media y respectiva desviación.

Por cada tipo de mortero, los resultados de los ensayos de resistencia a flexión se calculan como la media aritmética de los tres resultados individuales, obtenidos de la determinación realizada sobre un conjunto de tres probetas. 
Tabla 5.5 Resultados de los ensayos de rotura a flexión de las probetas de mortero a 28 días de edad: cemento (c): arena (a): escorias finas (ef): agua (w).

\begin{tabular}{|c|c|c|c|c|c|c|c|c|}
\hline \multirow{2}{*}{$\begin{array}{l}\text { Tipo de } \\
\text { mortero }\end{array}$} & \multicolumn{4}{|c|}{ Dosificación } & \multirow{2}{*}{$\begin{array}{c}\text { No. } \\
\text { Probeta }\end{array}$} & \multirow{2}{*}{$\begin{array}{c}\text { Flexión } \\
\text { [MPa] }\end{array}$} & \multirow{2}{*}{ Media } & \multirow{2}{*}{ Desviación } \\
\hline & $\mathrm{C}$ & a & ef & w & & & & \\
\hline \multirow[t]{3}{*}{ M1 } & 1 & 3 & - & 0,5 & 1 & 5,02 & & \\
\hline & & & & & 2 & 5,42 & 5,40 & 0,37 \\
\hline & & & & & 3 & 5,76 & & \\
\hline \multirow[t]{3}{*}{ M2 } & 1 & 2 & 1 & 0,5 & 1 & 5,49 & & \\
\hline & & & & & 2 & 5,92 & 5,80 & 0,27 \\
\hline & & & & & 3 & 5,98 & & \\
\hline \multirow[t]{3}{*}{ M3 } & 1 & 1,5 & 1,5 & 0,5 & 1 & 5,73 & & \\
\hline & & & & & 2 & 5,57 & 5,91 & 0,45 \\
\hline & & & & & 3 & 6,42 & & \\
\hline \multirow[t]{3}{*}{ M4 } & 1 & 1 & 2 & 0,5 & 1 & 5,83 & & \\
\hline & & & & & 2 & 5,52 & 5,78 & 0,23 \\
\hline & & & & & 3 & 5,98 & & \\
\hline \multirow[t]{3}{*}{ M5 } & 1 & - & 3 & 0,5 & 1 & 5,39 & & \\
\hline & & & & & 2 & 4,81 & 5,23 & 0,37 \\
\hline & & & & & 3 & 5,49 & & \\
\hline
\end{tabular}

Las dos mitades obtenidas de cada probeta ensayada a flexión, se someten al ensayo de compresión como se observa en la Figura 5.3, se han realizado aplicando una de fuerza $200 \mathrm{kN}$ a una velocidad de $0,05 \mathrm{kN} / \mathrm{s}$.

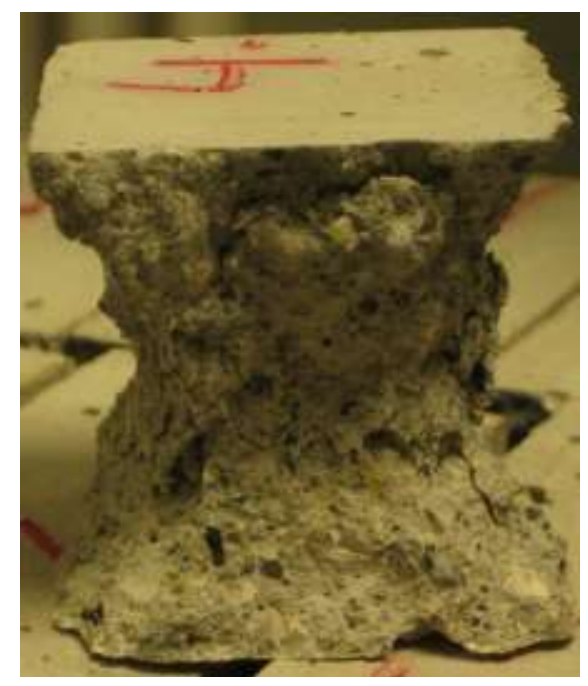

Figura 5.3 Probeta de mortero después del ensayo a compresión. 
Los resultados de los ensayos a compresión (6 medias probetas por cada tipo de mortero resultante del ensayo anterior), se presentan en la Tabla 5.6, también indica la media aritmética y la desviación.

Los resultados de cada tipo de mortero, de los ensayos de resistencia a compresión se calculan como la media aritmética de los seis resultados individuales, obtenidos de las seis determinaciones realizadas en un conjunto de tres probetas.

Tabla 5.6 Resultados de los ensayos de rotura a compresión de las probetas de mortero a 28 días de edad: cemento (c): arena (a): escorias finas (ef): agua (w).

\begin{tabular}{|c|c|c|c|c|c|c|c|c|c|}
\hline \multirow{2}{*}{$\begin{array}{l}\text { Tipo de } \\
\text { mortero }\end{array}$} & \multirow[b]{2}{*}{ C } & \multicolumn{3}{|c|}{ Dosificación } & \multirow{2}{*}{$\begin{array}{c}\text { No. } \\
\text { Probeta }\end{array}$} & \multicolumn{2}{|c|}{ Compresión [MPa] } & \multirow[b]{2}{*}{ Media } & \multirow[b]{2}{*}{ Desviación } \\
\hline & & $a$ & ef & w & & $\begin{array}{c}\text { Probeta } \\
\text { "a" }\end{array}$ & $\begin{array}{c}\text { Probeta } \\
\text { "b" }\end{array}$ & & \\
\hline \multirow[t]{3}{*}{ M1 } & 1 & 3 & - & 0,5 & 1 & 24,99 & 23,93 & & \\
\hline & & & & & 2 & 25,25 & 24,62 & 24,77 & 0,54 \\
\hline & & & & & 3 & 25,37 & 24,47 & & \\
\hline \multirow[t]{3}{*}{ M2 } & 1 & 2 & 1 & 0,5 & 1 & 28,38 & 26,86 & & \\
\hline & & & & & 2 & 27,01 & 26,72 & 27,26 & 0,59 \\
\hline & & & & & 3 & 27,28 & 27,28 & & \\
\hline \multirow[t]{3}{*}{ M3 } & 1 & 1,5 & 1,5 & 0,5 & 1 & 27,55 & 26,41 & & \\
\hline & & & & & 2 & 26,03 & 25,5 & 26,33 & 0,92 \\
\hline & & & & & 3 & 27,23 & 25,25 & & \\
\hline \multirow[t]{3}{*}{ M4 } & 1 & 1 & 2 & 0,5 & 1 & 27,85 & 25,43 & & \\
\hline & & & & & 2 & 26,06 & 26,03 & 26,28 & 1,20 \\
\hline & & & & & 3 & 27,54 & 24,76 & & \\
\hline \multirow[t]{3}{*}{ M5 } & 1 & - & 3 & 0,5 & 1 & 26,77 & 25,85 & & \\
\hline & & & & & 2 & 25,91 & 26,35 & 26,08 & 0,45 \\
\hline & & & & & 3 & 26,16 & 25,46 & & \\
\hline
\end{tabular}

Todos los resultados se comparan, con la media de cada tipo de mortero tanto a flexión como a compresión, en la Figura 5.4, obteniendo las siguientes conclusiones:

a) Resistencia a flexión: los valores de resistencia media a flexión de las probetas elaboradas con una parte de sus áridos naturales sustituidos por escorias son similares, o levemente mayores, que los valores medios de las probetas elaboradas sólo con áridos naturales.

b) Resistencia a compresión: la resistencia media a compresión de los tipos de morteros elaborados con escorias, en sustitución parcial o total del 
árido natural, ha resultado ser, al menos, un $6 \%$ superior que la resistencia media del tipo de mortero de referencia elaborado sólo con árido natural.

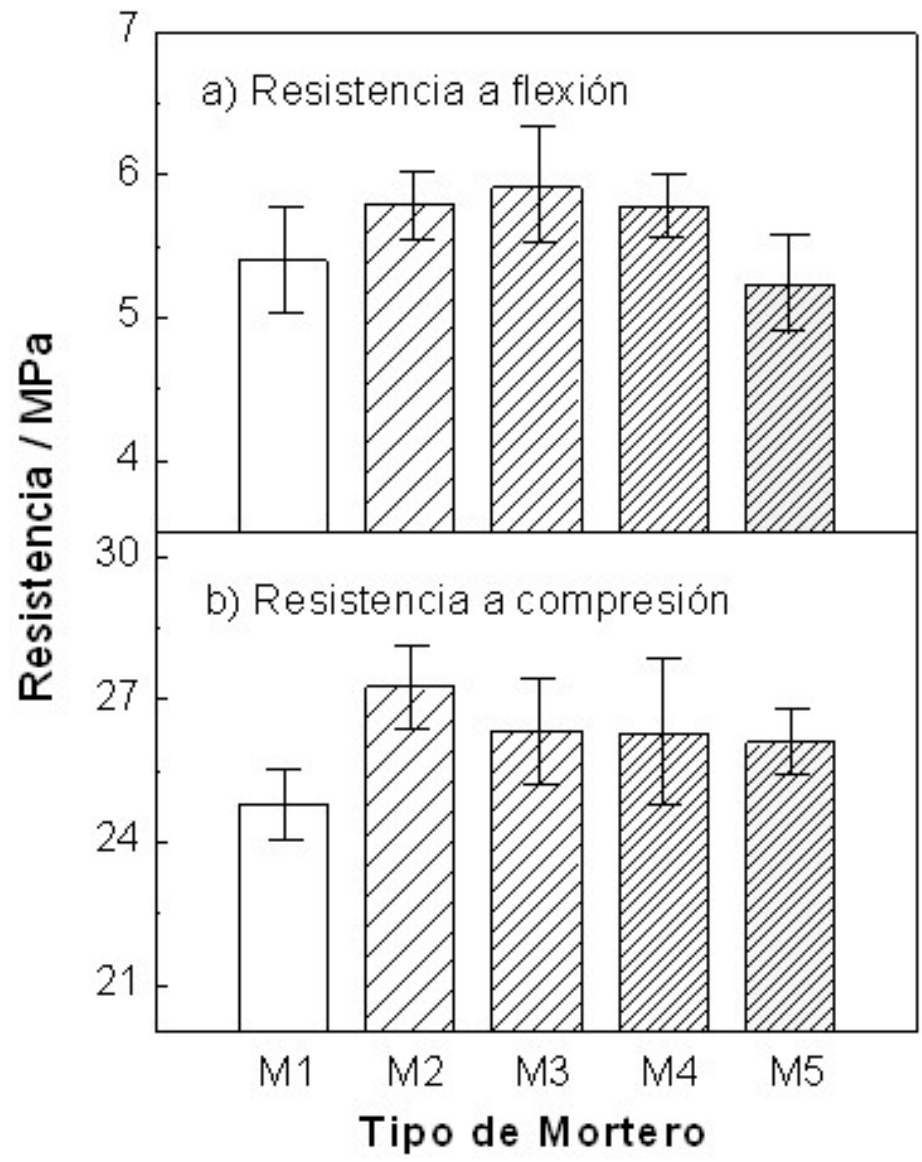

Figura 5.4 Comparativa de las resistencias medias: a) flexión y b) compresión, entre los diferentes tipos de mortero.

Las probetas elaboradas con una mezcla de arena de río y escorias procedentes de RSU incinerados, presentan mayor resistencia a flexión y a compresión que las elaboradas sólo con árido natural. Aquellas probetas que tienen el $100 \%$ de escorias, arrojan resultados levemente inferiores a flexión, mientras que a compresión mejoran, por lo tanto, podría considerarse viable la utilización de las escorias de RSU para mejorar las características mecánicas de los morteros. 


\subsection{ESTUDIO DE HORMIGONES CON ESCORIAS DE RSU}

De la determinación de la consistencia de cada uno de los tipos de hormigón a través del cono de Abrams, los resultados en todos los casos han sido un asiento entre 10 y $15 \mathrm{~cm}$ (consistencia fluida para picado con barra), como se detalla en la Tabla 5.7, encontrándose leves diferencias entre el hormigón elaborado sólo con áridos naturales y los confeccionados con escorias de RSU, resultando asientos mayores en estos últimos.

Tabla 5.7 Consistencia según el cono de Abrams de cada amasada o tipo de hormigón: cemento (c): arena (a): grava (g): escorias finas (ef): escorias gruesas (eg): agua (w).

\begin{tabular}{|c|c|c|c|c|c|c|c|c|}
\hline \multirow{2}{*}{$\begin{array}{l}\text { Tipo de } \\
\text { hormigón }\end{array}$} & \multicolumn{6}{|c|}{ Dosificación } & \multirow{2}{*}{$\begin{array}{c}\text { Escorias* }^{*} \\
{[\%]}\end{array}$} & \multirow{2}{*}{$\begin{array}{l}\text { Asiento Cono de } \\
\text { Abrams }[\mathrm{cm}]\end{array}$} \\
\hline & C & a & $g$ & ef & eg & W & & \\
\hline $\mathrm{H} 1$ & 1 & 1,85 & 3,32 & - & - & 0,5 & 0 & 10 \\
\hline $\mathrm{H} 2$ & 1 & 1,23 & 2,22 & 0,62 & 1,11 & 0,5 & 33 & 14 \\
\hline $\mathrm{H} 3$ & 1 & 0,62 & 1,11 & 1,23 & 2,22 & 0,5 & 66 & 12 \\
\hline $\mathrm{H} 4$ & 1 & - & - & 1,85 & 3,32 & 0,5 & 100 & 15 \\
\hline
\end{tabular}

$\left({ }^{*}\right)$ Porcentaje de escorias finas y gruesas respecto al contenido total de los áridos utilizados.

Una vez trascurrido el tiempo de curado de los cuatro tipos de hormigones a diferentes edades tanto a los 28 días, como a los 105 días y a los 180 días de edad desde su elaboración, se desmoldan y se rompen, de acuerdo a procedimientos normalizados, a través de los ensayos de rotura a compresión.

Los ensayos de compresión de las probetas de hormigón se realizarán en el Laboratorio de Materiales de Construcción de ETSEM, con la misma máquina empleada en los ensayos de las probetas de morteros.

Para comprobar las características mecánicas de las probetas de hormigones, se han ensayado a compresión Figura 5.6, hasta la rotura 20 probetas, (con diferentes edades) de las cuales 5 están elaboradas como hormigón convencional de referencia y 15 probetas que están elaboradas con escorias de RSU como sustituto parcial o total del árido natural, con porcentajes crecientes. 


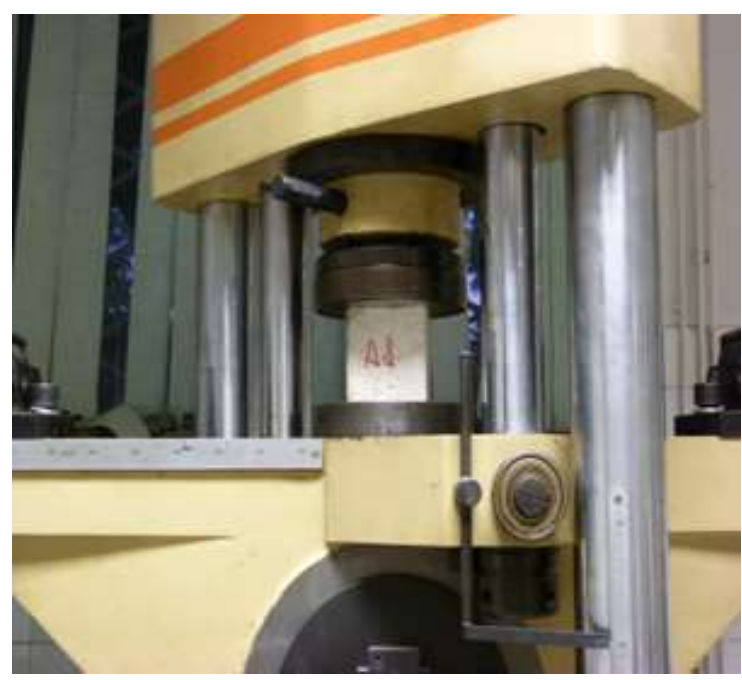

Figura 5.6 Rotura de probeta de hormigón.

Los ensayos de rotura a compresión se llevaron a cabo después de 28 días para dos probetas por cada tipo de hormigón, a los 105 días también se ensayaron dos probetas para cada tipo de hormigón y a los 180 días con una probeta por cada tipo de hormigón.

Los ensayos a compresión de todas las probetas de hormigón, se hicieron en modo control por carrera de $0,5 \mathrm{~mm} / \mathrm{min}$ que corresponden en el modo de control de fuerza a $0,05 \mathrm{kN} / \mathrm{s}$.

La rotura a compresión de las probetas de hormigón es similar en todas independientemente de la edad y del contenido de escorias, observando siempre grietas verticales Figura 5.7. 


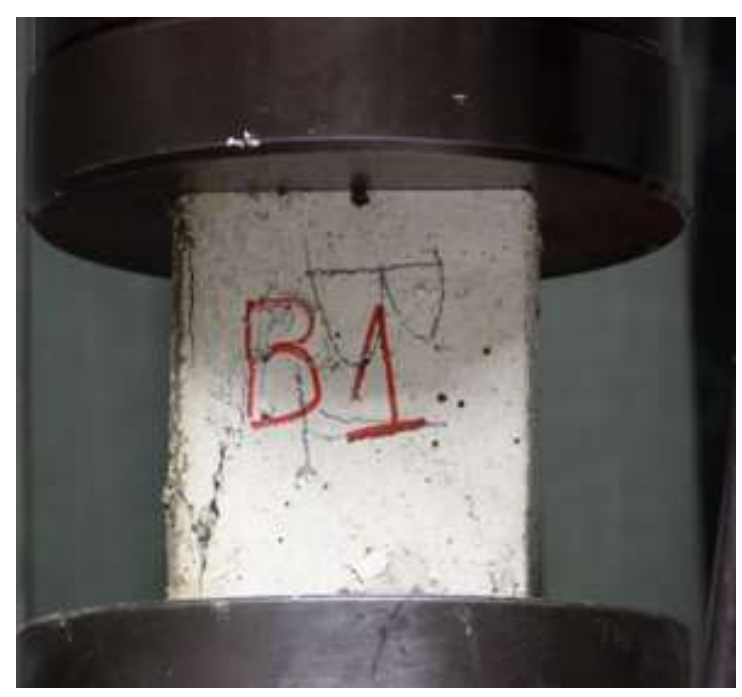

Figura 5.7 Rotura de probeta de hormigón.

A medida que el porcentaje de escorias de RSU aumenta, las probetas después de la rotura a compresión, como se muestra en la Figura 5.8 , son de color más oscuro, que va en aumento como se observa en la Figura 5.9.

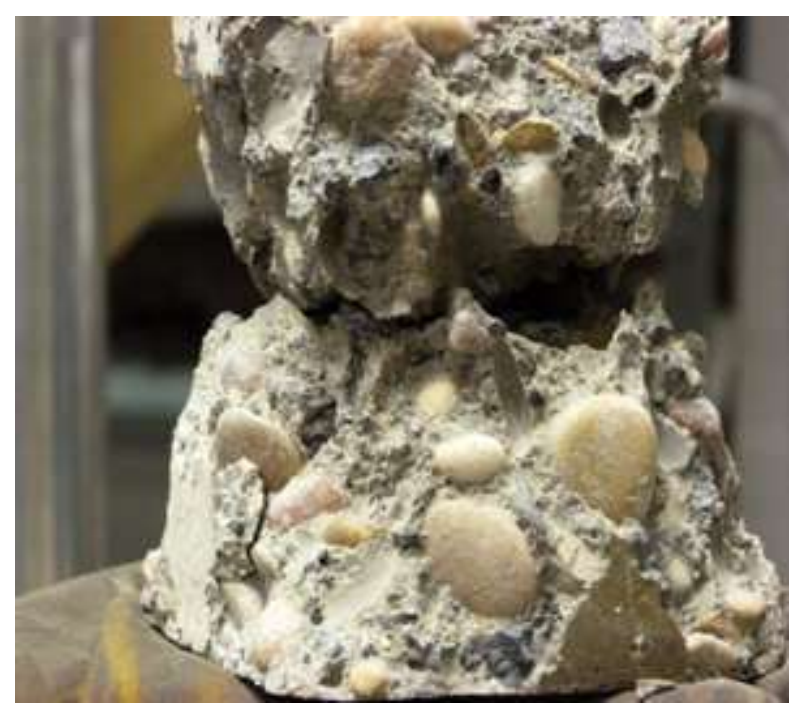

Figura 5.8 Rotura de la probeta de hormigón. 


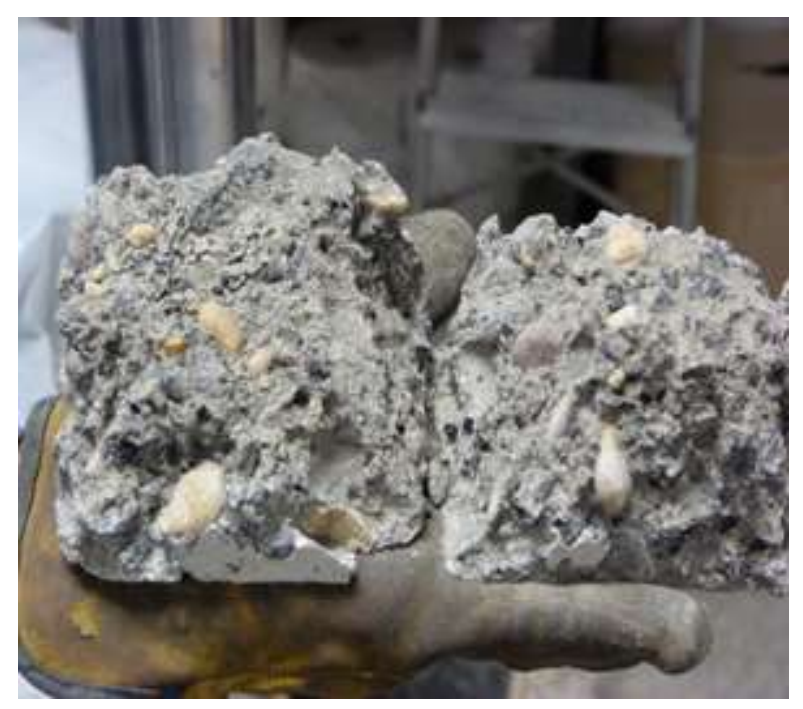

Figura 5.9 Detalles de materiales de la probeta de hormigón.

En los resultados a compresión de cada uno de los tipos de hormigón, se ha tenido en cuenta la dosificación en peso y el número de probeta tanto a los 28, 105 y 180 días de edad, como se refleja en la Tabla 5.8.

Tabla 5.8 Dosificación en peso de los diferentes tipos de hormigón estudiados y denominación de las probetas: cemento (c): arena (a): grava (g): escorias finas (ef): escorias gruesas (eg): agua (w).

\begin{tabular}{ccrrrrrrr}
\hline $\begin{array}{c}\text { Tipo de } \\
\text { hormigón }\end{array}$ & $\mathrm{c}$ & $\mathrm{a}$ & $\mathrm{g}$ & ef & eg & $\mathrm{w}$ & $\begin{array}{c}\text { Escorias* } \\
{[\%]}\end{array}$ & $\begin{array}{c}\text { Nos de } \\
\text { Probeta }\end{array}$ \\
\hline $\mathrm{H} 1$ & 1 & 1,85 & 3,32 & - & - & 0,5 & 0 & A1 a A5 \\
H2 & 1 & 1,23 & 2,22 & 0,62 & 1,11 & 0,5 & 33 & B1 a B5 \\
H3 & 1 & 0,62 & 1,11 & 1,23 & 2,22 & 0,5 & 66 & C1 a C5 \\
H4 & 1 & - & - & 1,85 & 3,32 & 0,5 & 100 & D1 a D5 \\
\hline
\end{tabular}

$\left(^{\star}\right)$ Porcentaje de escorias finas y gruesas respecto al contenido total de los áridos.

Al obtener los resultados de la rotura a compresión de las probetas de hormigón, paralelamente se han calculado los valores de la resistencia teórica si las probetas hubieran sido cilíndricas según la EHE-08. Y los datos por cada edad de las probetas cúbicas son los siguientes:

a) Probetas cúbicas a los 28 días: la resistencia a compresión de los hormigones elaborados con escorias sustituyendo el árido natural parcial o totalmente, ofrecen como resultado un $9 \%$ de media superior a la 
resistencia del hormigón de referencia elaborado únicamente con árido natural $(\mathrm{H} 1)$, resultados en la Tabla 5.9.

Tabla 5.9 Resultados de los ensayos de rotura a compresión de las probetas cúbicas de hormigón a los 28 días de edad (con la media y la desviación), y el valor de la resistencia teórica si las probetas hubieran sido cilíndricas según EHE-08.

\begin{tabular}{|c|c|c|c|c|c|c|}
\hline \multirow{3}{*}{$\begin{array}{c}\text { Tipo de } \\
\text { hormigón }\end{array}$} & \multirow{3}{*}{$\begin{array}{c}\text { Escorias* } \\
{[\%]}\end{array}$} & \multirow{3}{*}{$\begin{array}{c}\text { No. } \\
\text { Probeta }\end{array}$} & \multicolumn{4}{|c|}{ Resistencia a compresión } \\
\hline & & & & Cúbic & & Cilíndricas \\
\hline & & & {$[\mathrm{MPa}]$} & Media & Desviación & [MPa] \\
\hline \multirow[t]{2}{*}{$\mathrm{H} 1$} & 0 & A1 & 18,44 & \multirow{2}{*}{18,75} & \multirow{2}{*}{0,44} & 16,60 \\
\hline & & $\mathrm{A} 2$ & 19,06 & & & 17,15 \\
\hline \multirow[t]{2}{*}{$\mathrm{H} 2$} & 33 & B1 & 19,97 & \multirow{2}{*}{18,79} & \multirow{2}{*}{1,67} & 17,97 \\
\hline & & B2 & 17,61 & & & 15,84 \\
\hline \multirow[t]{2}{*}{$\mathrm{H} 3$} & 66 & $\mathrm{C} 1$ & 20,18 & \multirow[b]{2}{*}{22,29} & \multirow[t]{2}{*}{2,98} & 18,16 \\
\hline & & $\mathrm{C} 2$ & 24,40 & & & 21,96 \\
\hline \multirow[t]{2}{*}{$\mathrm{H} 4$} & 100 & D1 & 21,32 & \multirow{2}{*}{20,73} & \multirow{2}{*}{0,83} & 19,18 \\
\hline & & D2 & 20,14 & & & 18,12 \\
\hline
\end{tabular}

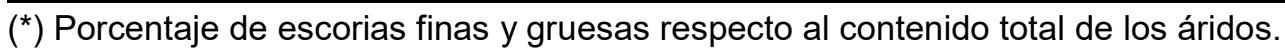

- Modo control por carrera de $0,5 \mathrm{~mm} / \mathrm{min}$

b) Probetas cúbicas a los 105 días: la resistencia de los hormigones elaborados con escorias sustituyendo el árido natural parcial o totalmente, es un $16 \%$ de media superior que la del hormigón de referencia elaborado con árido natural. Resultados en la Tabla 5.10. 
Tabla 5.10 Resultados de los ensayos de rotura a compresión de las probetas cúbicas de hormigón a los 105 días de edad (con la media y la desviación), y el valor de la resistencia teórica si las probetas hubieran sido cilíndricas según EHE-08.

\begin{tabular}{|c|c|c|c|c|c|c|}
\hline \multirow{3}{*}{$\begin{array}{c}\text { Tipo de } \\
\text { hormigón }\end{array}$} & \multirow{3}{*}{$\begin{array}{c}\text { Escorias* } \\
{[\%]}\end{array}$} & \multirow{3}{*}{$\begin{array}{c}\text { No. } \\
\text { Probeta }\end{array}$} & \multicolumn{4}{|c|}{ Resistencia a compresión } \\
\hline & & & & Cúbicas & & Cilíndricas \\
\hline & & & {$[\mathrm{MPa}]$} & Media & Desviación & [MPa] \\
\hline \multirow[t]{2}{*}{$\mathrm{H} 1$} & 0 & A3 & 24,09 & \multirow{2}{*}{23,23} & \multirow{2}{*}{1,22} & 21,68 \\
\hline & & A4 & 22,36 & & & 20,12 \\
\hline \multirow[t]{2}{*}{$\mathrm{H} 2$} & 33 & B3 & 25,49 & \multirow{2}{*}{25,98} & \multirow{2}{*}{0,69} & 22,94 \\
\hline & & B4 & 26,46 & & & 23,81 \\
\hline \multirow[t]{2}{*}{$\mathrm{H} 3$} & 66 & C3 & 28,53 & \multirow{2}{*}{28,25} & \multirow{2}{*}{0,40} & 25,67 \\
\hline & & C4 & 27,97 & & & 25,17 \\
\hline \multirow[t]{2}{*}{$\mathrm{H} 4$} & 100 & D3 & 27,90 & \multirow{2}{*}{28,37} & \multirow{2}{*}{0,66} & 25,11 \\
\hline & & D4 & 28,83 & & & 25,95 \\
\hline
\end{tabular}

$\left({ }^{*}\right)$ Porcentaje de escorias finas y gruesas respecto al contenido total de los áridos.

- Modo control por carrera de $0,5 \mathrm{~mm} / \mathrm{min}$.

c) Probetas cúbicas a los 180 días: la resistencia de los hormigones elaborados con escorias parcial o totalmente sustituyendo al árido natural, resulta un $11 \%$ de media superior que la del hormigón de referencia elaborado con árido natural. Los resultados en la Tabla 5.11.

Tabla 5.11 Resultados de los ensayos de rotura a compresión de probetas cúbicas de hormigón a los 180 días de edad, y el valor de la resistencia teórica si las probetas hubieran sido cilíndricas según EHE-08.

\begin{tabular}{crccc}
\hline $\begin{array}{c}\text { Tipo de } \\
\text { hormigón }\end{array}$ & $\begin{array}{c}\text { Escorias* } \\
{[\%]}\end{array}$ & No. Probeta & $\begin{array}{c}\text { Resistencia a compresión } \\
\text { Cúbicas } \\
\text { [MPa] }\end{array}$ & $\begin{array}{c}\text { Cilíndricas } \\
{[\mathrm{MPa}]}\end{array}$ \\
\hline H1 & 0 & A5 & 26,43 & 23,79 \\
H2 & 33 & B5 & 27,10 & 24,39 \\
H3 & 66 & C5 & 29,50 & 26,55 \\
H1 & 100 & D5 & 32,90 & 29,61 \\
\hline
\end{tabular}

$\left(^{*}\right)$ Porcentaje de escorias finas y gruesas respecto al contenido total de los áridos.

- Modo control por carrera de $0,5 \mathrm{~mm} / \mathrm{min}$.

De los resultados recogidos en las tablas se puede decir que la resistencia media a compresión de los tipos de hormigones por cada edad (28,105 y 180 días), elaborados con escorias sustituyendo parcial o totalmente el árido natural, ha sido siempre superior entre un $9 \%$ y $16 \%$, con respecto al hormigón de referencia elaborado sólo con árido natural, con una resistencia a compresión entre $18,44 \mathrm{MPa}$ y $26,43 \mathrm{MPa}$. 


\section{Diagramas tensión-deformación de probetas de hormigón por dosificación de escorias de RSU}

Se ha analizado los diagramas tensión-deformación obtenidos en los ensayos de rotura a compresión para cada tipo de hormigón, a través de las probetas con los diferentes porcentajes de escorias (0\%,33\%, 66\% y 100\%), para comparar, cómo se alcanza la resistencia a compresión en cada situación en particular, curadas a los 28, a los 105 y a los 180 días de edad.

En la Figura 5.10 el gráfico de tensión-deformación de las probetas del tipo de hormigón convencional con $0 \%$ de escorias, a las diferentes edades 28 , 105 y 180 días.

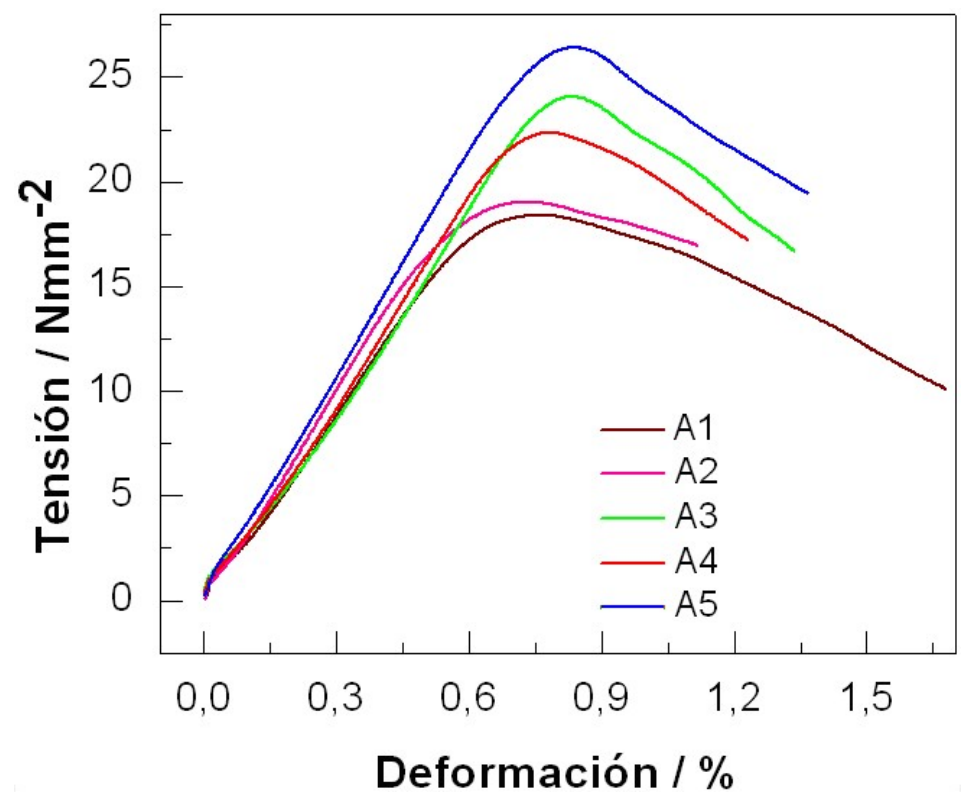

Figura 5.10 Diagramas tensión-deformación de las probetas de hormigón con 0\% de escorias: A1 y A2 de 28 días, A3 y A4 de 105 días y A5 de 180 días.

Como se observa en el gráfico de la Figura 5.10, las probetas con $0 \%$ de escorias muestran mayores resistencias a compresión conforme aumenta la edad de rotura, es decir A3, A4 y A5 frente a A1 y A2.

En la Figura 5.11 el gráfico tensión-deformación de las probetas de hormigón con el $33 \%$ de escorias, es decir el tipo $\mathrm{H} 2$, para detallar el comportamiento a diferentes edades 28, 105 y 180 días. 


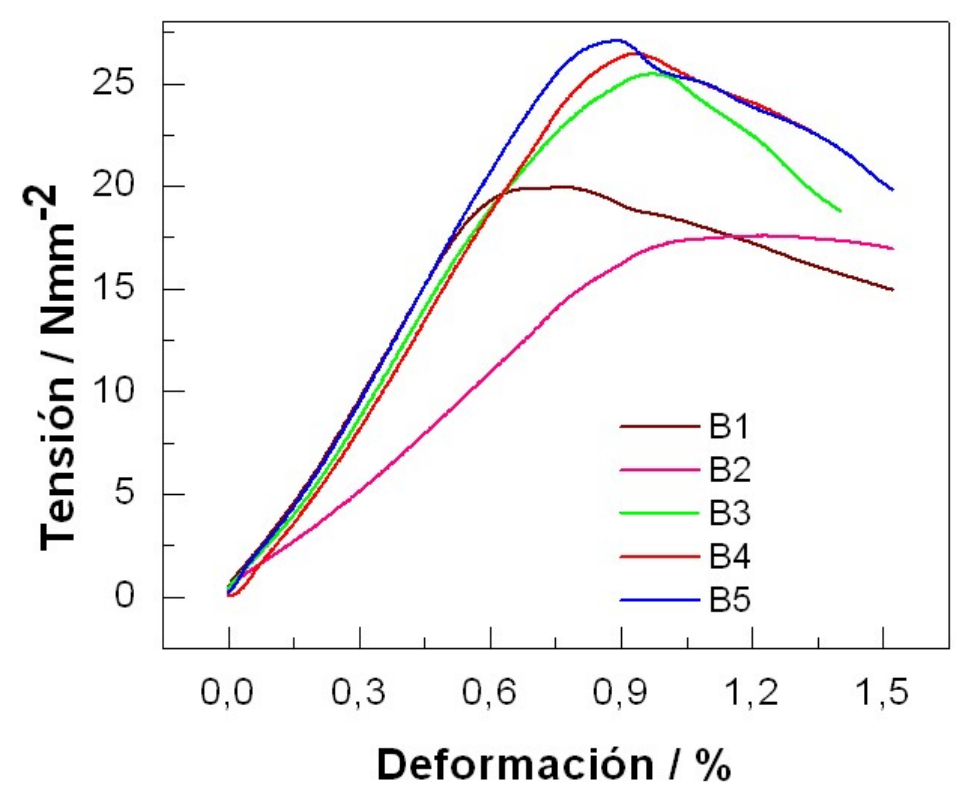

Figura 5.11 Diagramas tensión-deformación de las probetas de hormigón con $33 \%$ de escorias: B1 y B2 de 28 días, B3 y B4 de 105 días y B5 de 180 días.

En el gráfico de la Figura 5.11, las probetas con el 33\% de escorias muestran mayor resistencia a compresión conforme aumenta la edad de rotura, donde las probetas B1, B2 (28 días de edad) tienen una rotura a compresión de 19,97 MPa como máximo, mientras las probetas B3 y B4 (105 días de edad) presentan una rotura a compresión de $26,46 \mathrm{MPa}$ la más alta y la probeta B5 (180 días de edad), la rotura la compresión es de 27,10 MPa.

En la Figura 5.12 el gráfico de tensión-deformación de las probetas de $66 \%$ de escorias o hormigón tipo H3, con las edades de 28, 105 y 180 días para ver sus diferencias. 


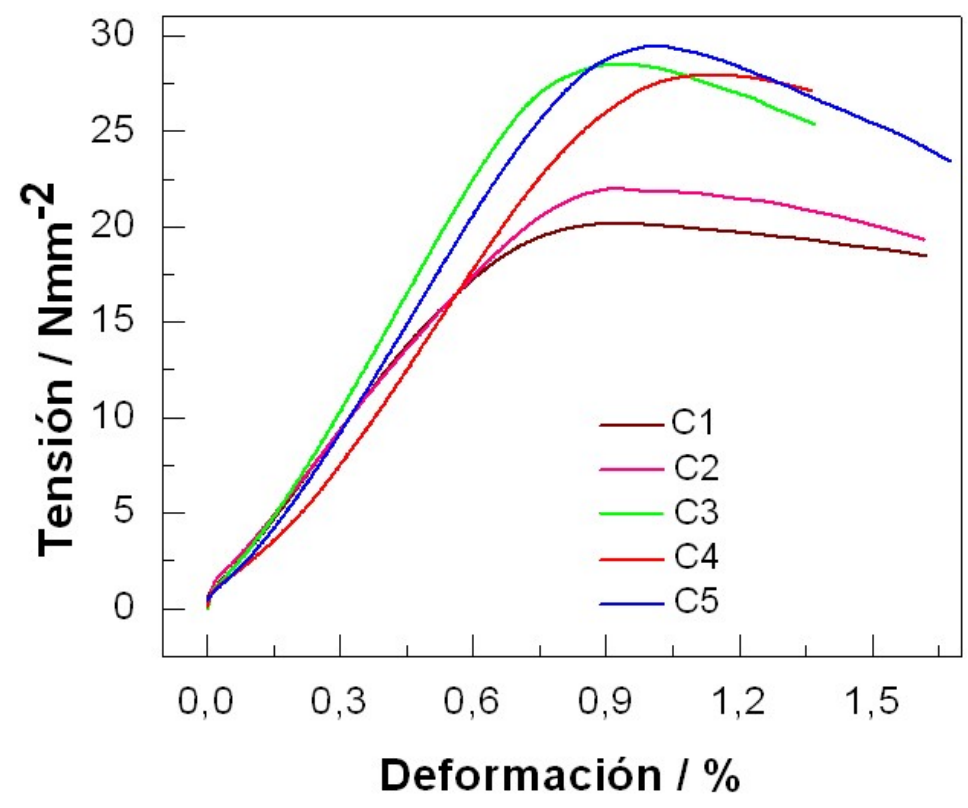

Figura 5.12 Diagramas tensión-deformación de las probetas de hormigón con 66\% de escorias: C1 y C2 de 28 días, C3 y C4 de 105 días y C5 de 180 días.

En la Figura 5.12 se observa que las probetas con $66 \%$ de escorias a mayor edad de rotura muestran mayores resistencias a compresión. Se señala, que las probetas $\mathrm{C} 1, \mathrm{C} 2$ tienen menor resistencia a compresión, comparadas con C3, C4 y por último la C5 que su resistencia es mayor.

En la Figura 5.13 el gráfico tensión-deformación las probetas de hormigón con $100 \%$ de escorias $(\mathrm{H} 4)$, sin árido natural, con edades de 28,105 y 180 días, y así ver cómo cambia la resistencia en cada caso. 


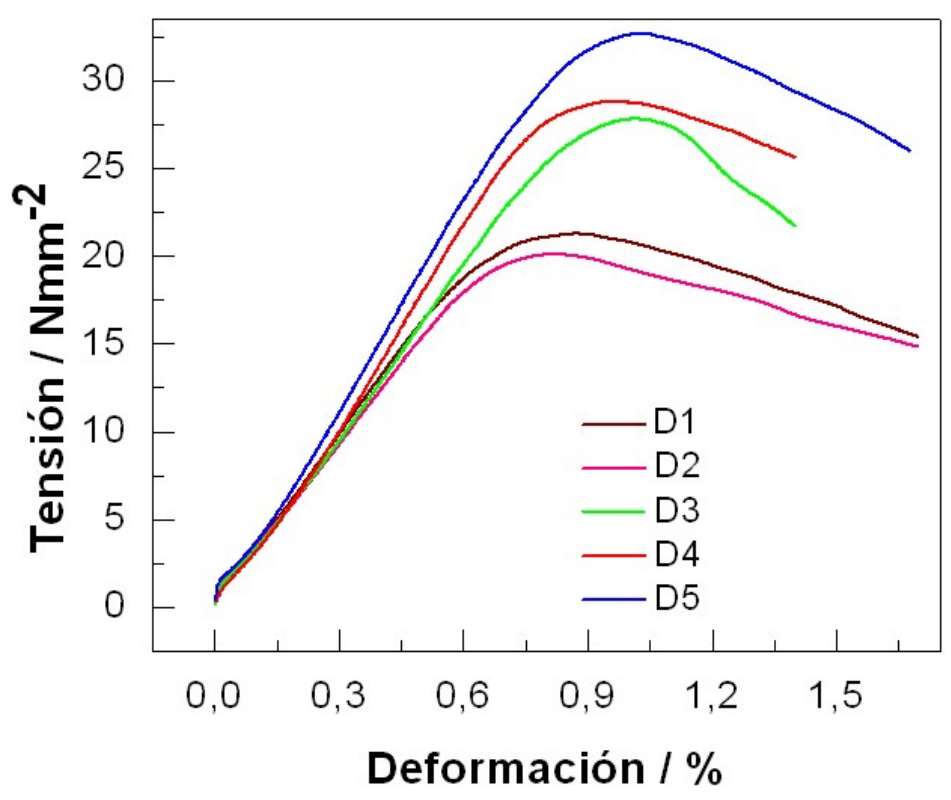

Figura 5.13 Diagramas tensión-deformación de las probetas de hormigón con 100\% de escorias: D1 y D2 de 28 días, D3 y D4 de 105 días y D5 de 180 días.

En el gráfico Figura 5.13, se observa que las probetas de hormigón con $100 \%$ de escorias presentan mayores resistencias a compresión, al aumentar la edad de rotura, mientras D1, D2 son inferiores a $22 \mathrm{~N} / \mathrm{mm}^{2}$, D3, D4 aumentan y en cuanto D5 está por encima de $30 \mathrm{~N} / \mathrm{mm}^{2}$.

Se ve en todos los gráficos comparados por edades que a mayor edad de las probetas la resistencia a compresión mejora y en cuanto a los tipos de hormigón los que más cantidad de escorias de RSU tiene tienen una mayor resistencia a compresión.

\section{Diagramas tensión-deformación de probetas de hormigón comparados por edades}

Para detallar el comportamiento de rotura a compresión de cada uno de los tipos de hormigón elaborados con diferentes porcentajes de escorias de RSU $(0 \%, 33 \%, 66 \%$ y $100 \%)$, se han comparado la rotura a compresión de cada una de las probetas por edades a los 28, 105 y 180 días, en diagramas de tensióndeformación.

En la Figura 5.14 se recoge el gráfico tensión-deformación de la rotura a compresión de las probetas con 28 días de edad, de los cuatro tipos de hormigón A, B, C y D. 


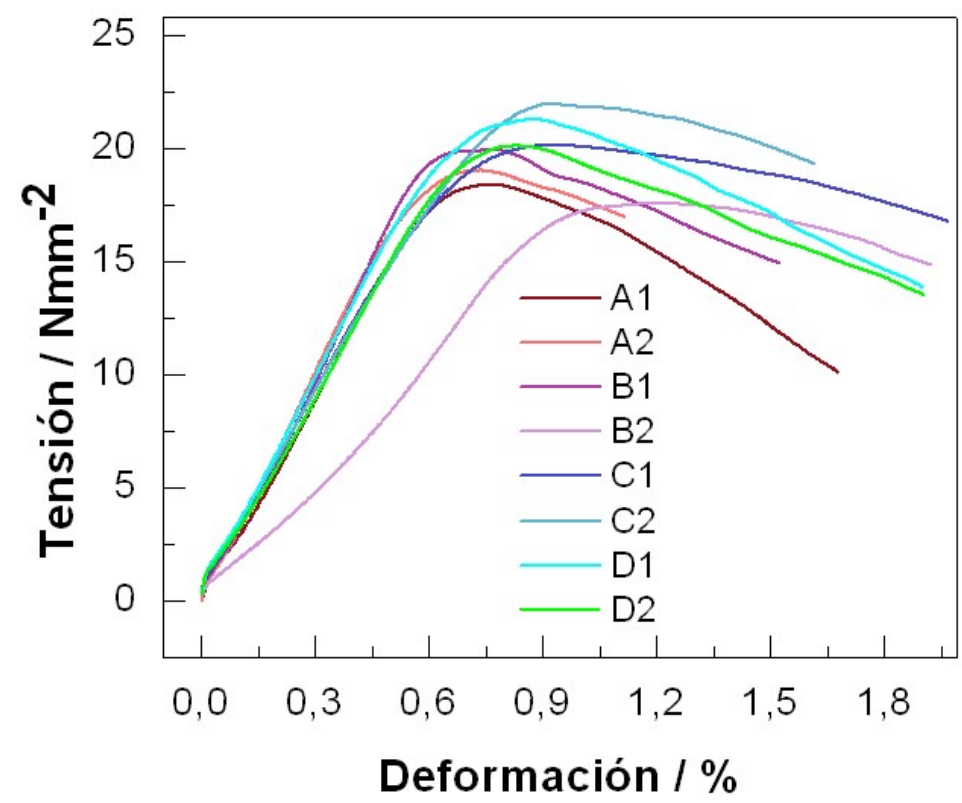

Figura 5.14 Diagramas tensión-deformación de las probetas de hormigón a la edad de 28 días: A1 y A2 0\% de escorias, B1 y B2 con 33\% de escorias, C1 y C2 con $66 \%$ de escorias y D1 y D2 con $100 \%$ de escorias.

Se observa en el gráfico Figura 5.14 cómo las probetas de 28 días de edad con mayor porcentaje de escorias (C1, C2, D1 y D2) presentan mayor resistencia a compresión, que las probetas con menor porcentaje de escorias (B1, B2) y las que no tienen escorias (A1, A2). Sin embargo, para mayor exactitud se compararán los resultados de rotura a compresión de cada uno de los tipos de hormigón en la Figura $\mathbf{5 . 1 7}$

En la Figura 5.15 el gráfico tensión-deformación de las probetas de 105 días de edad, de los cuatro tipos de hormigón tanto de las probetas de hormigón de referencia, como de las probetas de hormigón que tienen escorias de RSU con porcentajes crecientes. 


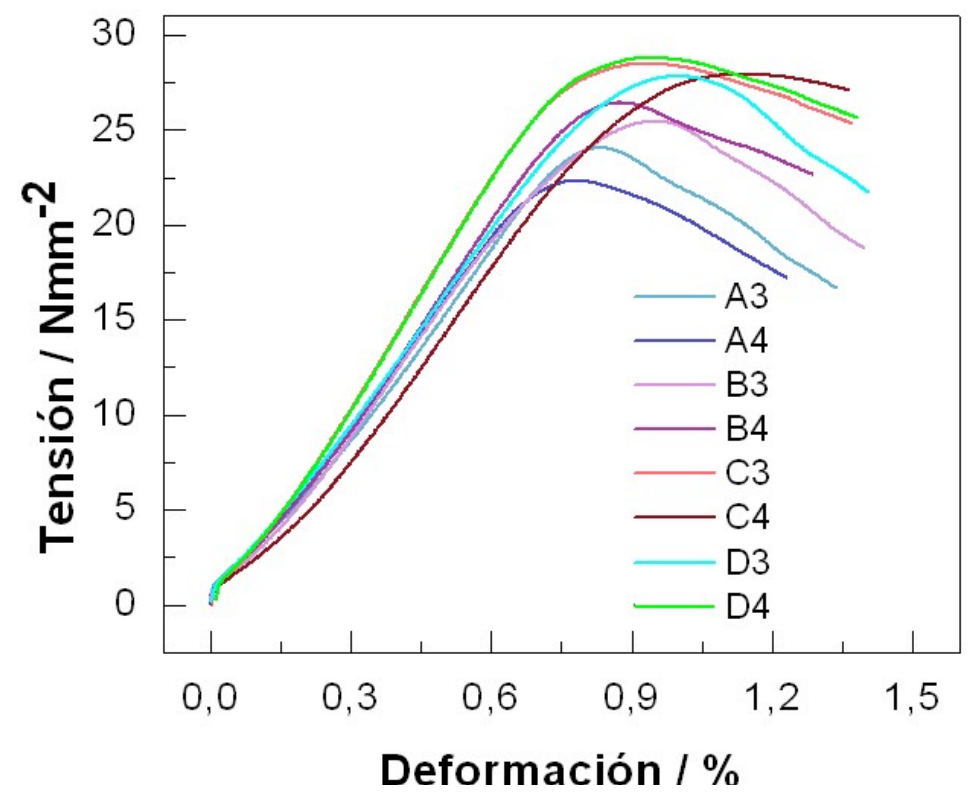

Figura 5.15 Diagramas tensión-deformación de las probetas de hormigón a la edad de 105 días: A3 y A4 0\% de escorias, B3 y B4 con 33\% de escorias, C3 y C4 con $66 \%$ de escorias y D3 y D4 con $100 \%$ de escorias.

Observando el gráfico de la Figura 5.15, las probetas de hormigón de 105 días de edad con mayor cantidad (\%) de escorias (D3, D4), alcanzan mayores resistencias a compresión, respecto a aquellas probetas de hormigón (B3, B4, $\mathrm{C} 3, \mathrm{C} 4)$ con menores cantidades de escorias. $\mathrm{Y}$ las probetas que no tienen escorias tienen aún más baja resistencia a compresión (A3, A4).

En la Figura 5.16 el gráfico tensión-deformación de las probetas de 180 días de edad, una probeta por cada tipo de hormigón, tanto del tipo de hormigón convencional, como de los tipos de hormigón con sustitución del árido natural por escorias en porcentajes crecientes. 


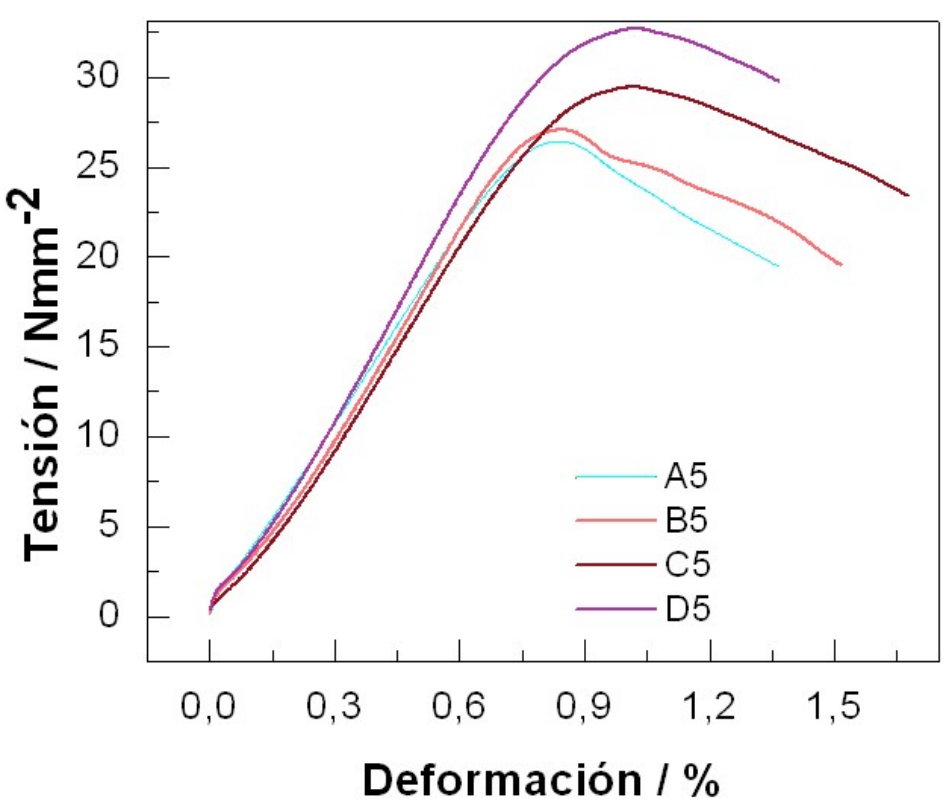

Figura 5.16 Diagramas tensió-deformación de las probetas de hormigón a la edad de 180 días: A5 0\% de escorias, B5 con 33\% de escorias, C5 con $66 \%$ de escorias y D5 con $100 \%$ de escorias.

Como se aprecia en el gráfico Figura 5.16, las probetas de hormigón de 180 días de edad, sin escorias (A5) y con menor porcentaje de escorias (B5), presentan una resistencia a compresión inferior, con respecto a las probetas que tienen mayor cantidad de escorias (C5 y D5).

En todos los casos en la comparación de las probetas de hormigón analizando la rotura a compresión, a través de los diagramas tensióndeformación por edades $(28,105$ y 180 días), aquellos tipos de hormigones que tiene más cantidad (o porcentaje) de escorias de RSU, tiene mayor resistencia.

\section{Comparativa, por edades, de las resistencias a compresión del hormigón según la dosificación}

Finalmente, los resultados de los valores de la resistencia a compresión de las probetas, las medias por cada tipo de hormigón se comparan, a los 28 , 105 y 180 días de edad, en los gráficos de la Figura 5.17 


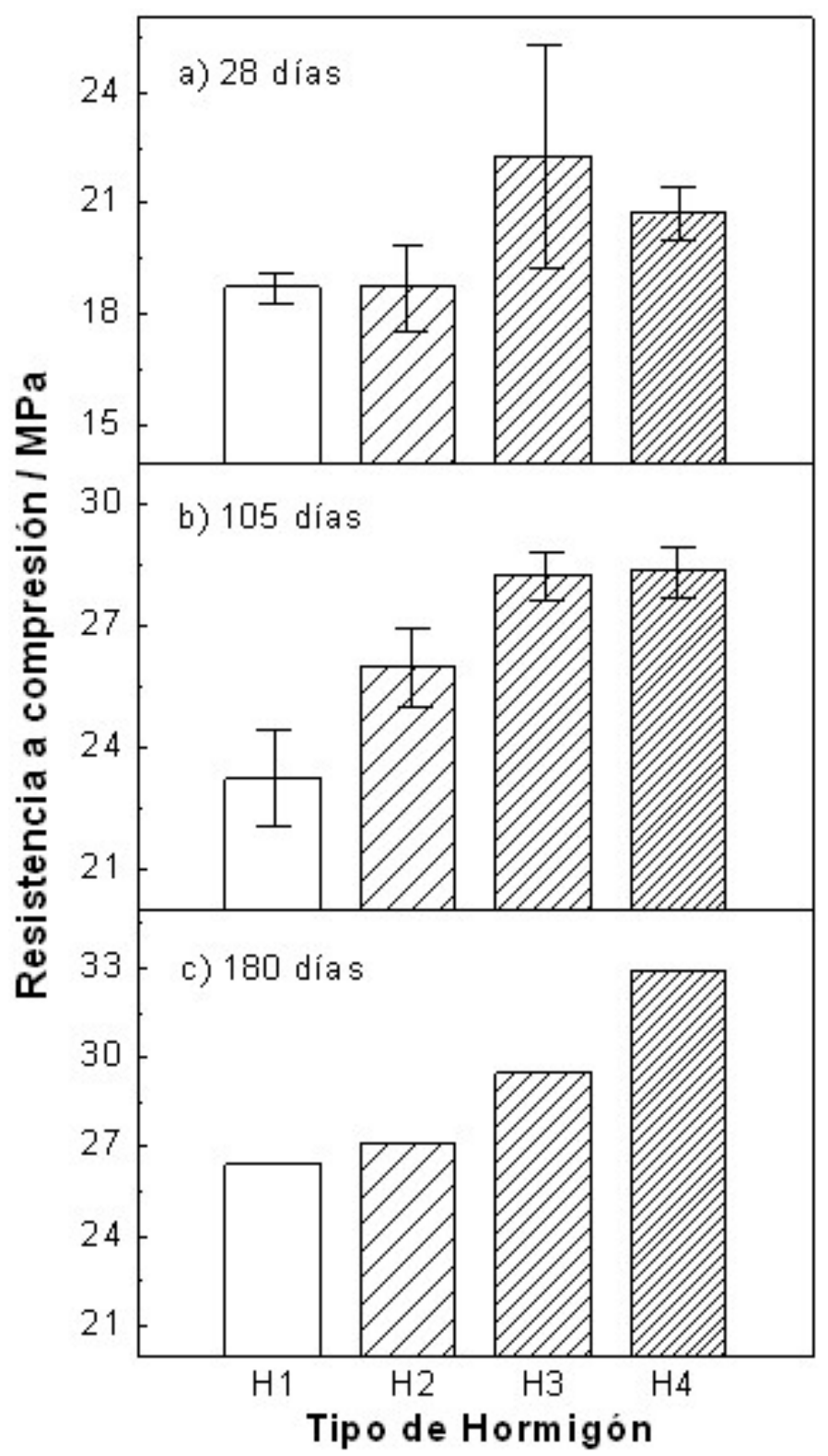

Figura 5.17 Comparativa de las resistencias a compresión: a) 28 días, b) 105 días y c) 180 días, entre los diferentes tipos de hormigón.

La resistencia media de los hormigones elaborados con escorias, sustituyendo parcial o totalmente el árido natural, ha sido siempre superior al hormigón de referencia (H1) elaborado sólo con árido natural, concretamente un $9 \%$ de media superior a los 28 días, un $16 \%$ a los 105 días y un $11 \%$ a los 180 días. Todos los hormigones con escorias han obtenido mejores resultados, incluso los elaborados sólo con escorias $(\mathrm{H} 4)$. 
Esto se sigue cumpliendo independientemente de la edad de ensayo de rotura de las probetas a 28, 105 y 180 días. En todos los tipos de hormigón elaborados con escorias la resistencia a compresión mejora, demostrando que podría ser factible la reutilización de las escorias de RSU, para mejorar las características mecánicas de los hormigones.

Los resultados son bastantes optimistas para seguir trabajando con este tipo de materiales reciclados (como son las escorias de RSU).

\section{Comparativa del Módulo de elasticidad del hormigón}

El módulo de deformación longitudinal E del hormigón tiene una marcada dependencia del tipo de árido con el que se ha fabricado [COMISIÓN PERMANENTE DEL HORMIGÓN; 2008], por ello, se han obtenido los valores de los módulos de cada tipo de hormigón (el módulo de elasticidad es la pendiente de la recta inicial del diagrama tensión-deformación en la fase elástica del ensayo), que se recogen en la Tabla 5.12 y se han comparado en los gráficos de la Figura 5.18.

Tabla 5.12 Valores de los módulos de elasticidad E de los diferentes hormigones, obtenidos a partir de los diagramas tensión-deformación de los ensayos de rotura a compresión de las probetas:

\begin{tabular}{rrrrr}
\hline Días & No. Probeta & $E\left[\mathrm{~N} / \mathrm{mm}^{2}\right]$ & No. Probeta & $E\left[\mathrm{~N} / \mathrm{mm}^{2}\right]$ \\
\hline 28 & & & & \\
& A1 & 26652 & A2 & 31766 \\
& B1 & 29131 & B2 & 15602 \\
& C1 & 29100 & C2 & 27810 \\
& D1 & 29802 & D2 & 26702 \\
& & & & \\
& A3 & 25609 & A4 & 28242 \\
& B3 & 28494 & B4 & 29218 \\
& C3 & 33393 & C4 & 25566 \\
& D3 & 29856 & D4 & 33384 \\
& A5 & 33330 & C5 & 30254 \\
& B5 & 30746 & D5 & 38751 \\
\hline
\end{tabular}

Como durante el ensayo se producen asientos de la máquina de ensayo sobre las caras de las probetas, los valores obtenidos son dispares y no permiten extraer conclusiones definitivas. Concretamente, como puede observarse en el gráfico de la figura, la probeta B2 tiene una pendiente claramente inferior a las demás, es decir, el cálculo arrojó un módulo de elasticidad muy bajo. 
Las demás probetas tienen un módulo de elasticidad comprendido entre 25566 y $38751 \mathrm{~N} / \mathrm{mm}^{2}$, no encontrándose diferencias significativas por el tipo de hormigón, ni por la edad del ensayo a rotura, por lo que no se puede concluir cómo influyen las escorias en los valores del módulo de elasticidad del hormigón.

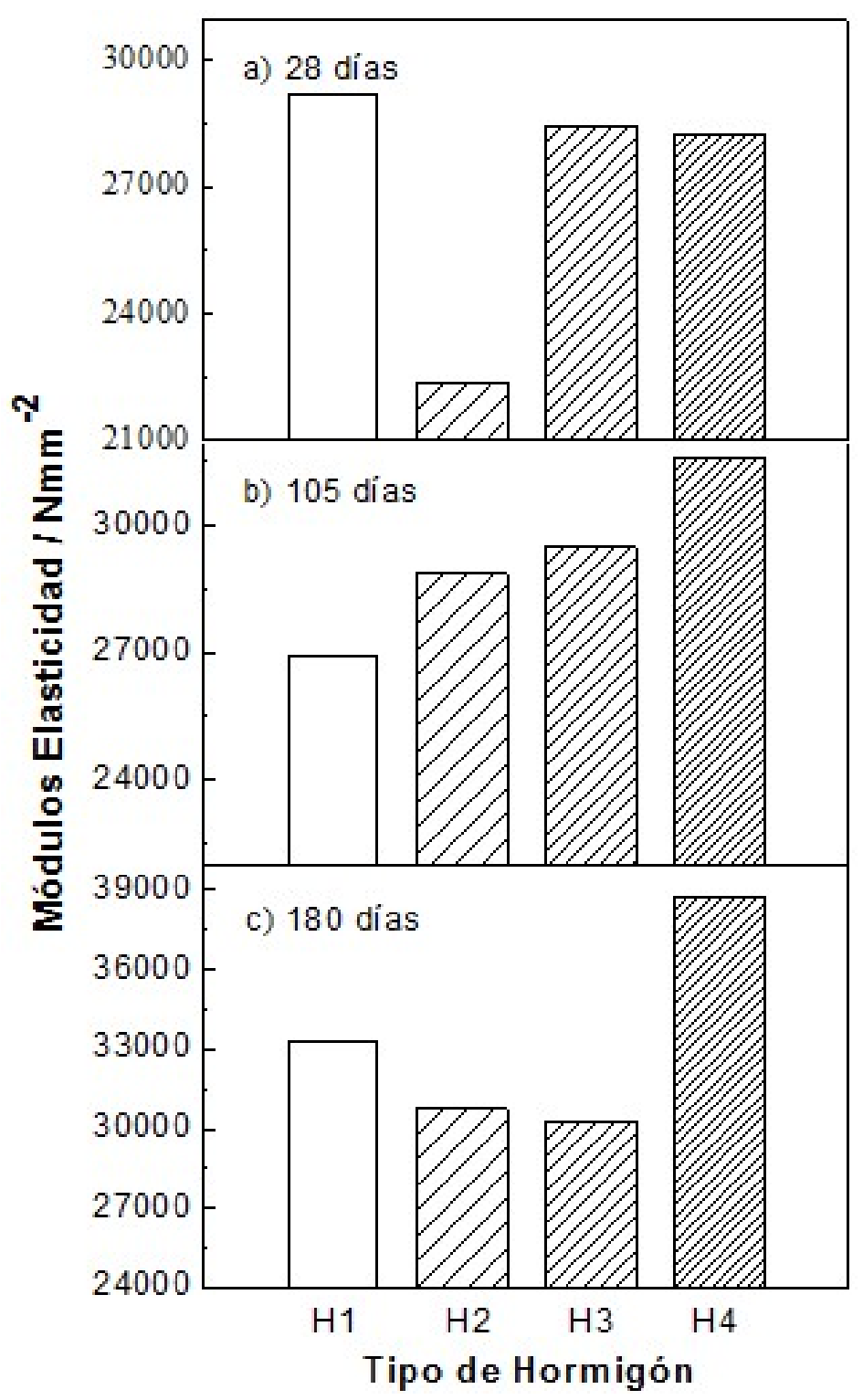

Figura 5.18 Comparativa módulos de elasticidad: a) 28 días, b) 105 días y c) 180 días, para los diferentes tipos de hormigón. 


\subsection{ESTUDIO DE CORROSIÓN DE ARMADURAS EMBEBIDAS EN MORTEROS ELABORADOS CON ESCORIAS DE RSU}

La mediación se ha realizado tanto en las dos barras de acero de cada una de las probetas de mortero elaboradas con el $100 \%$ de escorias de RSU, como de las dos barras de acero de cada una de las probetas de mortero de referencia, durante tres años. Los resultados obtenidos de las dos barras de cada probeta han sido comparables entre sí, sin diferencias significativas entre ellas, por lo que aquí se darán los valores medios de ambas barras. siguiente:

El proceso que se ha llevado a cabo para la medición de cada barra es el

- Se ha dejado estabilizar el potencial de corrosión Ecorr, durante veinte minutos, registrando el valor final.

- Seguidamente se ha aplicado el método de resistencia de Polarización Lineal (RPL) determinando la resistencia de polarización $R_{p}$, para lo cual se impone a cada barra una polarización de $\pm 15 \mathrm{mV}$ respecto a $E_{\text {corr, }}$ con una velocidad $0,1667 \mathrm{mV} / \mathrm{s}$, generándose el diagrama intensidadpotencial (I vs. E). La pendiente de la tangente al diagrama en el intervalo de $E_{\text {corr }} \pm 5 \mathrm{mV}$ es la $R_{p}$ buscada. A partir de $R_{p}$ es calculada la intensidad de corrosión icorr.

Las mediciones se han llevado a cabo con una frecuencia semanal, seguidamente quincenal, durante los primeros días de vida de las probetas, posteriormente mensual, después cada mes y medio, y finalmente se han ido ampliado los plazos al estabilizarse los resultados, hasta la última etapa del periodo estudiado.

En la Figura 5.19, se representan los resultados obtenidos durante el periodo estudiado para el potencial de corrosión Ecorr en función del tiempo, del convencional acero al carbono y los tres aceros inoxidables comparados, embebidas en el mortero elaborado con el $100 \%$ de escorias de RSU. 


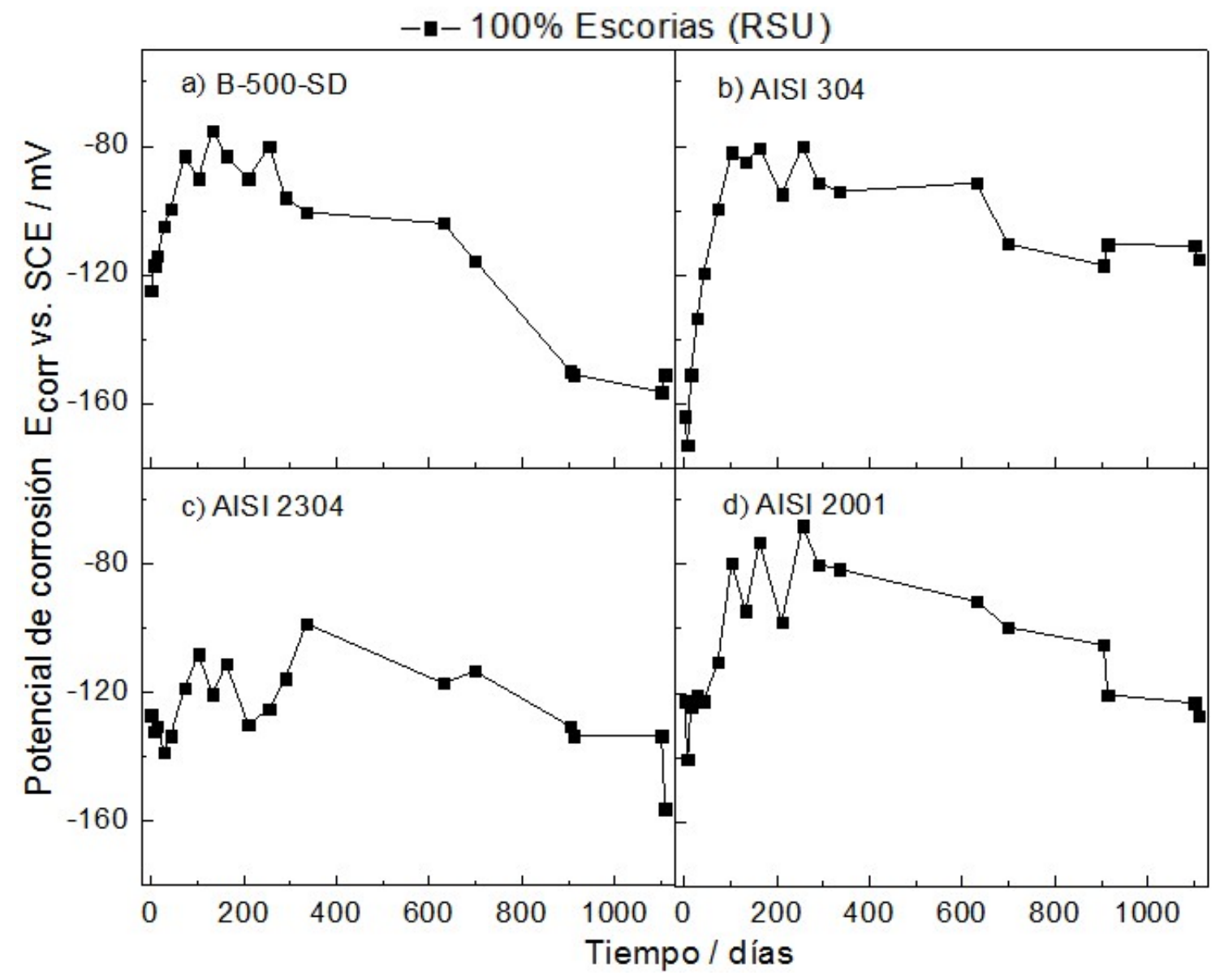

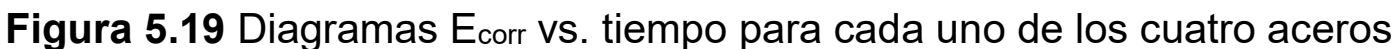
empleados: a) B-500-SD, b) AISI 304, c) AISI 2304 y d) AISI 2001, embebidos en probetas de mortero Portland elaboradas con el $100 \%$ de escorias de RSU

(Media de 2 barras corrugadas por cada probeta).

Durante los tres años estudiados, los valores de $E_{\text {corr }}$ presentan valores similares para todos los aceros, variando entre -68 y $-173 \mathrm{mV}$, para los embebidos en las probetas de mortero con el $100 \%$ de escorias de RSU, estabilizándose en valores entre -100 y $-150 \mathrm{mV}$ al cabo de los tres años.

En la Figura 5.20 se representan los resultados del potencial de corrosión Ecorr en función del tiempo, de los cuatro aceros estudiados, comparando las probetas embebidas en el mortero elaborado con el 100\% de escorias de RSU con las probetas embebidas en el mortero de referencia elaborado con el $100 \%$ de árido natural.

Los resultados de los valores de $\mathrm{E}_{\text {corr, }}$ son similares para todos los aceros, variando entre -68 y $-192 \mathrm{mV}$, tanto para los embebidos en las probetas de mortero con el $100 \%$ de escorias de RSU, como los embebidos en probetas de 
mortero de referencia ( $0 \%$ de escorias), estabilizándose en valores entre -70 y $150 \mathrm{mV}$ al cabo de los tres años.

Para el acero al carbono, se considera que si $E_{\text {corr }}$ es mayor de $-120 \mathrm{mV}$, la probabilidad de que se presente la corrosión en las armaduras es inferior al $10 \%$, si se encuentra entre $-120 \mathrm{mV}$ y $-270 \mathrm{mV}$ la probabilidad es incierta, y si es inferior a $-270 \mathrm{mV}$ la probabilidad es superior al 90\% [ASTM, 1999].

En nuestro caso, según los resultados obtenidos de todas las probetas ( $\sin$ escorias y con el $100 \%$ de escorias en sustitución del árido natural) estudiadas, de $E_{c o r r}$, se puede considerar que todos los aceros se mantienen en estado pasivo, durante el tiempo de medición.

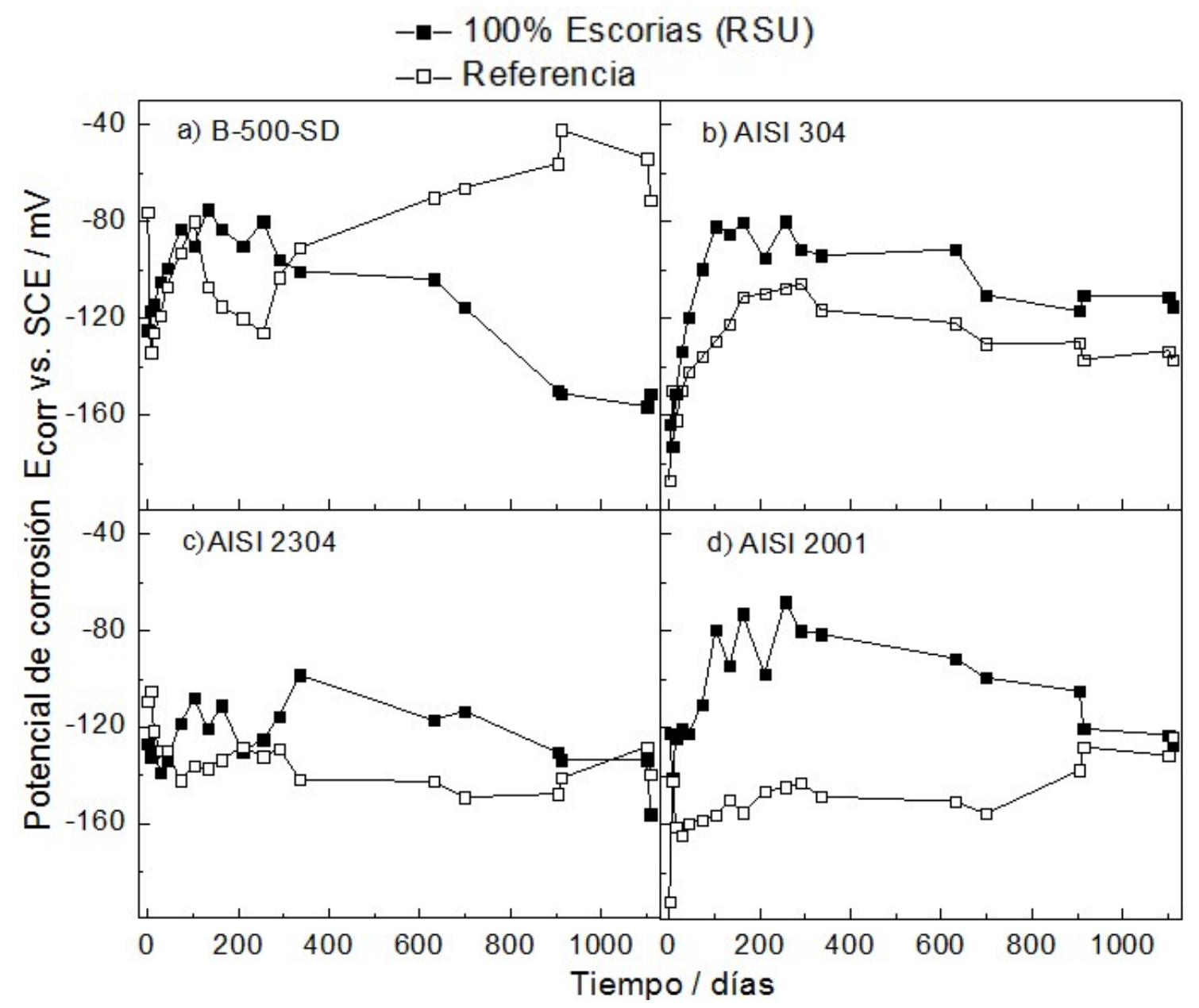

Figura 5.20 Diagramas $\mathrm{E}_{\text {corr }}$ vs. tiempo para cada uno de los cuatro aceros estudiados: a) B-500-SD, b) AISI 304, c) AISI 2304 y d) AISI 2001, embebidos en probetas de mortero Portland elaboradas con el $100 \%$ de escorias de RSU y probetas de referencia elaboradas con árido natural (Media de 2 barras corrugadas por cada probeta). 
En la Figura 5.21, se representan las medias de la evolución de los valores de las mediciones de resistencia de polarización $R_{p}$, en función del tiempo, de los cuatro aceros al carbono y los tres aceros inoxidables analizados, embebidos en probetas con $100 \%$ de escorias de RSU.

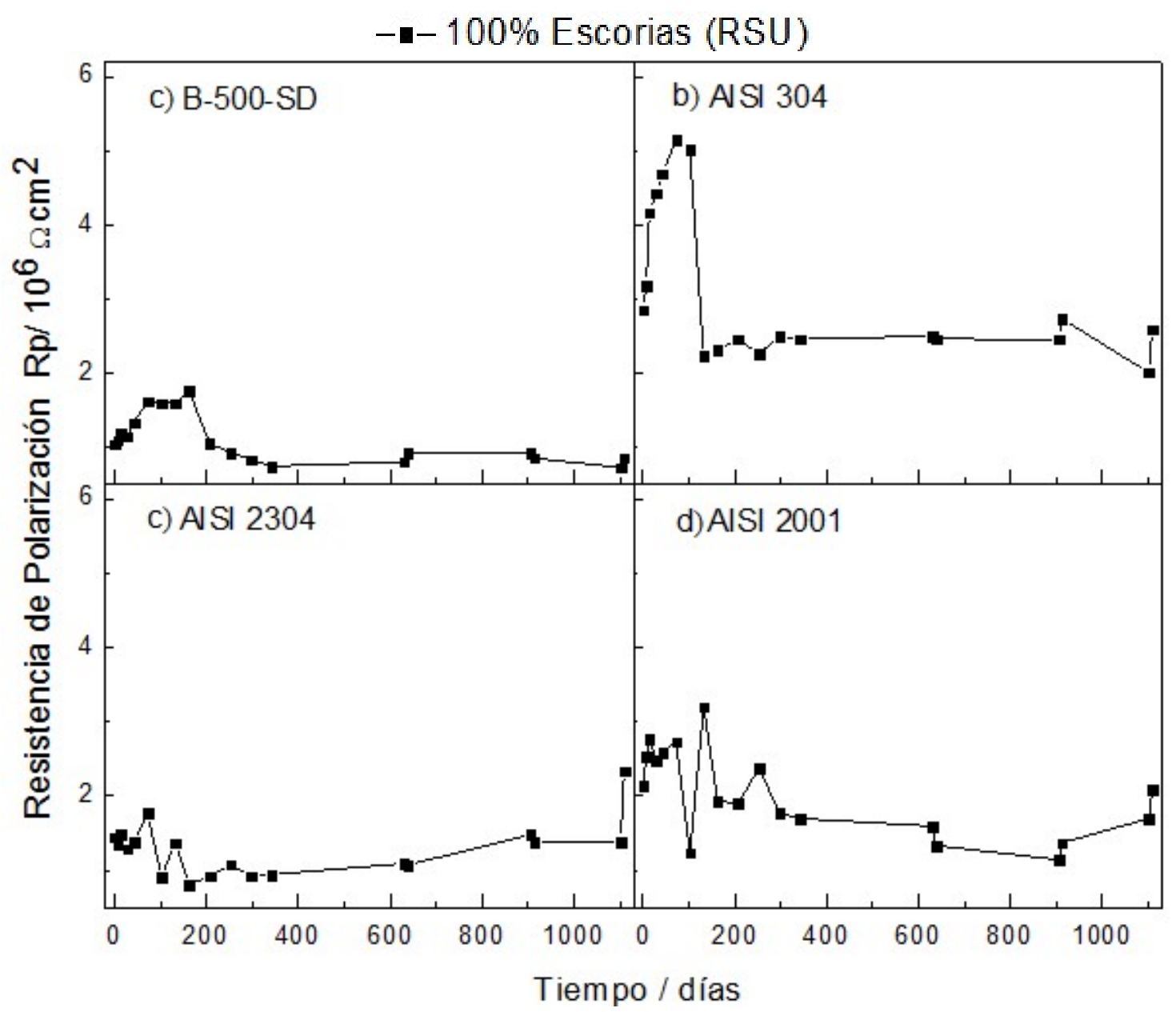

Figura 5.21 Diagramas $R_{p}$ vs. tiempo para cada uno de los cuatro aceros empleados: a) B-500-SD, b) AISI 304, c) AISI 2304 y d) AISI 2001, embebidos en probetas de mortero Portland elaboradas con el $100 \%$ de escorias de RSU

(Media de 2 barras corrugadas por cada probeta).

Los valores de $R_{p}$, durante los tres años de medición de las probetas se encuentran entre $0 \cdot 10^{6}$ y $6 \cdot 10^{6} \Omega \cdot \mathrm{cm}^{2}$ para los cuatros aceros, uno al carbono y tres inoxidables, embebidos en probetas de mortero Portland elaboradas con el $100 \%$ de escorias de RSU. Los valores más altos se han registrado en los aceros AISI 304 y AISI 2001, sobre todo en las primeras mediciones, hacia la mitad del periodo se han estabilizado y han permanecido en la mitad, siendo las barras poco activas. 
Los valores más bajos se han visto en las barras B500SD y AISI 2304, que significa una mayor actividad.

En la Figura 5.22, se han comparado los resultados de $\mathrm{R}_{\mathrm{p}}$ tanto de los aceros al carbono como de los aceros inoxidables, embebidos en probetas de mortero elaboradas con el $100 \%$ de escorias de RSU con las embebidas en las probetas de referencia elaboradas con árido natural.

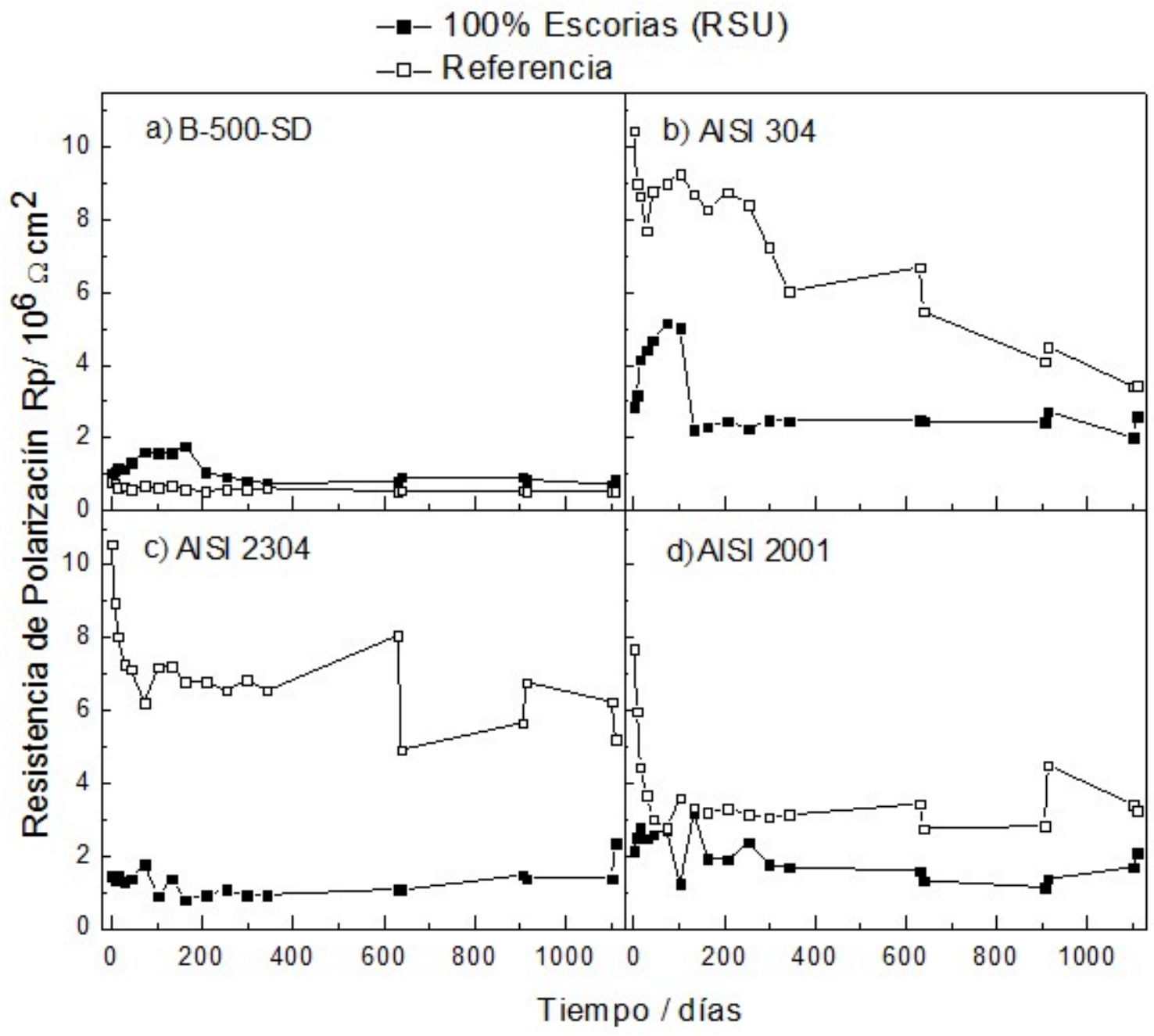

Figura 5.22 Diagramas $R_{p}$ vs. tiempo para cada uno de los cuatro aceros empleados: a) B-500-SD, b) AISI 304, c) AISI 2304 y d) AISI 2001, embebidos en probetas de mortero Portland elaboradas con el $100 \%$ de escorias de RSU y probetas de referencia elaboradas con árido natural (Media de 2 barras corrugadas por cada probeta). 
Los valores de $R_{p}$, durante los tres años de medición de las probetas se encuentran entre $0 \cdot 10^{6}$ y $10,50 \cdot 10^{6} \Omega \cdot \mathrm{cm}^{2}$ para los cuatros aceros, en las diferentes probetas de escorias de RSU, y de árido natural. En el acero B-500S$D$ el $R_{p}$ está más cerca al $0 \cdot 10^{6}$ en los dos tipos de probetas, en los aceros AISI 304 y AISI 2304 comienzan en valores cercanos a $10 \cdot 10^{6}$ en las probetas con mortero de referencia, y el acero AISI 2001 se mantiene en valores intermedios inferiores a $5 \cdot 10^{6}$.

A partir de los valores de $R_{p}$, se han obtenido los valores de la densidad de corriente de corrosión ícorr de cada acero mediante la ecuación [5.1]:

$$
\mathrm{I}_{\text {corr }}=\mathrm{B} / \mathrm{R}_{\mathrm{p}}
$$

tomando $52 \mathrm{mV}$ como valor del coeficiente B de Stern-Geary [Stern, M.; 1957], que es el que se corresponde a un acero en estado pasivo.

La evolución de los valores de icorr a lo largo del tiempo en el periodo estudiado se ha representado en la Figura 5.23, de las probetas de mortero elaboradas con el $100 \%$ de escorias. 


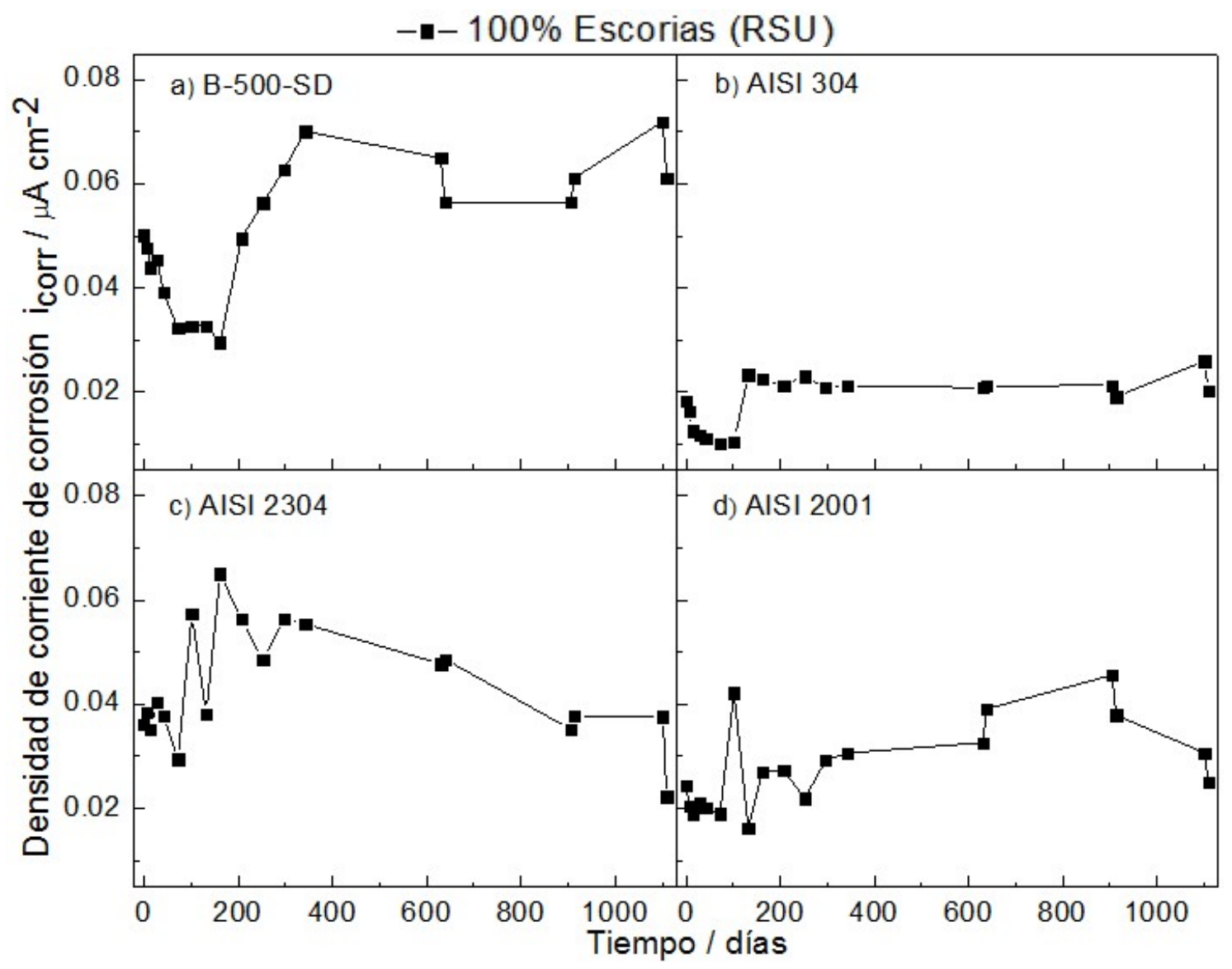

Figura 5.23 Diagramas i icorr vs. tiempo para cada uno de los cuatro aceros estudiados: a) B-500-SD, b) AISI 304, c) AISI 2304 y d) AISI 2001, embebidos en probetas de mortero Portland elaboradas con el $100 \%$ de escorias de RSU (Media de 2 barras corrugadas por cada probeta).

Los valores son bajos, variando entre 0,010 y $0,072 \mu \mathrm{A} / \mathrm{cm}^{2}$, no se presenta diferencias significativas, todos los aceros se encuentran en el mismo orden de magnitud.

Y en la Figura $\mathbf{5 . 2 4}$ se han comparado las probetas de mortero elaboradas con $100 \%$ de escorias de RSU con las probetas de mortero de referencia $(0 \%$ escorias).

Los valores son muy bajos en todos los casos, variando entre 0,05 y 0,09 $\mu \mathrm{A} / \mathrm{cm}^{2}$, por lo que ningún acero presenta diferencias significativas respecto a los otros, todos se encuentran en el mismo orden de magnitud, e indica que todos se encuentran en estado pasivo al encontrarse por debajo de $0,1 \mu \mathrm{A} / \mathrm{cm}^{2}$ [Bastidas, D.M., et al; 2008 b], es decir, su densidad de corriente de corrosión es tan baja que el avance de la corrosión en $\mu$ m/año es inferior a la unidad, lo que es insignificante en términos de durabilidad de la estructura de hormigón. 


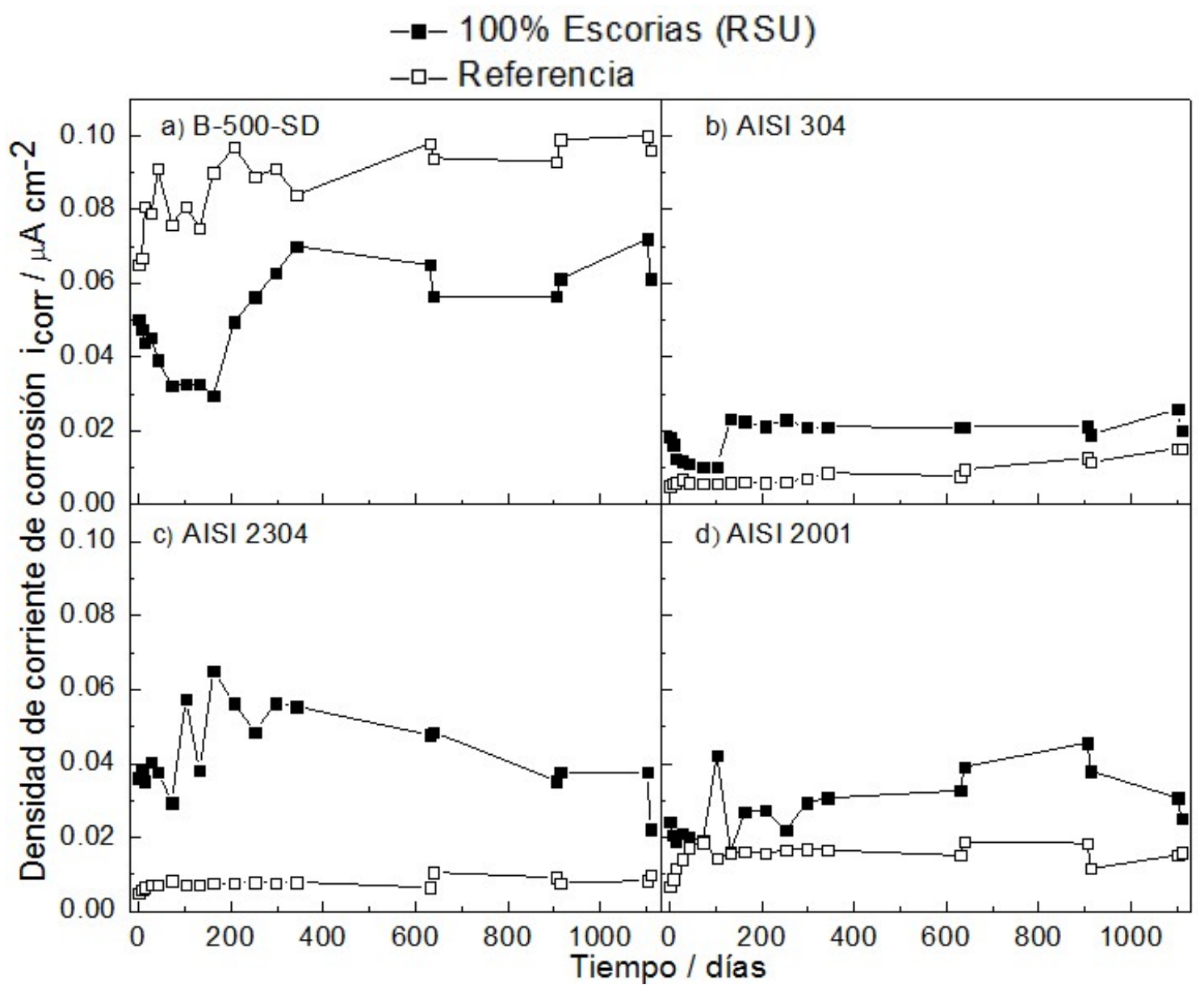

Figura 5.24 Diagramas ícorr vs. tiempo para cada uno de los cuatro aceros empleados: a) B-500-SD, b) AISI 304, c) AISI 2304 y d) AISI 2001, embebidos en probetas de mortero Portland elaboradas con el 100\% de escorias de RSU y probetas de referencia elaboradas con árido natural (Media de 2 barras corrugadas por cada probeta). 


\section{Capítulo 6}

\section{CONCLUSIONES}

Los resultados obtenidos de los estudios realizados con escorias de RSU incinerados, indican que su utilización como sustitutas de los áridos naturales en la elaboración de morteros y hormigones es viable y, en algunos casos altamente ventajosa.

Los estudios realizados con probetas de morteros de cemento Portland elaboradas con una mezcla variable de áridos naturales y escorias procedentes de la incineración de los RSU, han presentado mejores resultados en la resistencia a flexión que las probetas de mortero de referencia elaboradas solo con áridos naturales, excepto las que tienen el $100 \%$ de escorias, donde el resultado de la resistencia a flexión ha sido levemente inferior.

Por otra parte, las probetas de morteros con escorias de RSU han presentado en todos los casos mejores resultados en la resistencia a compresión que los morteros de referencia elaborados sólo con áridos naturales, cualquiera que fuera el porcentaje de dosificación con escorias.

Dichos resultados óptimos permitieron que se avanzara satisfactoriamente en la presente investigación, procediendo a la elaboración de las probetas de hormigón con escorias.

La resistencia media a compresión de las probetas de hormigón elaborados con escorias, considerando todas la dosificaciones y edades de rotura estudiadas, ha sido de $25,90 \mathrm{MPa}$, mientras que la resistencia media de las probetas de referencia elaboradas sólo con áridos naturales ha sido de 22,80 $\mathrm{MPa}$, es decir, un $12 \%$ menor.

Por lo tanto, en todos los casos se ha obtenido que la utilización de escorias de incineración de RSU, como sustituto de los áridos naturales para la confección de morteros y hormigones de cemento Portland, ha mejorado la resistencia a compresión de las probetas, cualquiera que sea el porcentaje de sustitución, incluso cuando esa sustitución es del $100 \%$ del árido natural por escorias. 
Por otra parte, las mediciones electroquímicas de resistencia a la corrosión realizadas durante tres años en barras corrugadas, de acero al carbono y de acero inoxidable de diferentes calidades, embebidas en morteros de cemento y escorias como sustitutas de la arena, comparadas entre sí y con las mismas barras corrugadas embebidas en un mortero de referencia elaborado con arena natural, demuestran que las barras han permanecido en estado pasivo durante todo el tiempo estudiado, por lo que las escorias no han favorecido ni empeorado ningún proceso de corrosión.

Los valores de $\mathrm{i}_{\text {corr }}$ fueron muy bajos en todos los casos, entre 0,05 y 0,095 $\mu \mathrm{A} / \mathrm{cm} 2$, lo que indica que todos los aceros están en estado pasivo, ya que están por debajo de 0,1 $\mathrm{A} / \mathrm{cm}^{2}$. Por lo tanto, el uso de escorias de RSU, en hormigón armado, no presenta ningún problema de corrosión para su aplicación.

Por tanto, la utilización de escorias procedentes de RSU como sustitutas en diferentes porcentajes del árido natural (tanto de la arena como de la grava), ha mejorado la resistencia de los morteros (a flexión y a compresión) y de los hormigones (a compresión), y en ningún caso se han presentado riesgos de corrosión para las armaduras.

La reutilización de las escorias de RSU, contribuye a mantener el medio ambiente, porque permite disminuir los impactos negativos generados en la explotación de los áridos naturales y su entorno, reducción de las escorias de RSU de los vertederos y las escorias son un subproducto del hormigón en beneficio del desarrollo sostenible. 


\section{Capítulo 7}

\section{FUTURAS LÍNEAS DE INVESTIGACIÓN}

Para continuar con la investigación sobre la viabilidad de la reutilización de las escorias de RSU en morteros y hormigones sustituyendo al árido natural, y confirmar como influyen en las características mecánicas, es necesario ampliar el número de ensayos realizados, tanto en cuanto al número de probetas de morteros y hormigones como a las dosificaciones utilizadas.

La ampliación del número de probetas permitiría obtener resultados más concluyentes, tanto en los ensayos a flexión como a compresión en los morteros, y en los ensayos a compresión y los módulos de elasticidad en los hormigones.

También sería necesaria la continuación de las mediciones electroquímicas por un periodo de tiempo más amplio para el estudio, de las armaduras de acero al carbono y de los aceros inoxidables embebidos en probetas de mortero elaboradas para estudiar la resistencia a la corrosión.

Sería también interesante realizar los nuevos ensayos con escorias de la central de Valdemingómez recogidas en diferentes épocas del año, para estudiar como varían su composición química, si es que lo hace, y cómo influye en los resultados de resistencia y corrosión. Igualmente, sería interesante conseguir escorias de otras incineradoras, que fueran del mismo tipo de horno que la de Valdemingómez y de otros tipos, lo que sin duda dará diferentes composiciones y resultados.

Además de los estudios de resistencia, sería necesario comprobar como las escorias pueden influir en la adherencia de las armaduras en el hormigón.

Otro estudio interesante puede ser el utilizar escorias activadas para reutilizarlas como adición al cemento.

Por último, para completar el estudio de la resistencia a la corrosión de las armaduras embebidas en probetas de mortero con escorias, se pueden confeccionar morteros con agentes agresivos incorporados, como cloruros, para comparar su evolución con respecto a morteros confeccionados con áridos naturales y los mismos agentes agresivos. 


\section{BIBLIOGRAFÍA}

ABREU, C.M., CRISTOBAL, M.J., MONTEMOR, M.F., NOVOA, X.R., PENA, G., PÉREZ, M.C., (2002): "Galvanic couplinic between carbón steel and austenitic stainless steel in alkaline media". Electrochimica Acta, 47, 2271-2279.

ACI, (1993): Guía para la Selección de Proporciones de alta resistencia de hormigón con cemento Portland y cenizas volantes. ACI 226.4R. ACl Comité 211 Informe, American Concrete Institute, Farmington Hills, MI.

ACl, (2001): Guía para la durabilidad del hormigón. ACI 201.2R-01. ACI Comité 201 Informe, American Concrete Institute, Farmington Hills, MI.

$\mathrm{ACl}$, (2003): El uso de cenizas volantes en concreto. ACl 232.2R-03. Comité ACl 232 Informe.

AENOR-CEN (1996): UNE-EN 933-2 Ensayos para determinar las propiedades geométricas de los áridos. Parte 2: Determinación de la granulometría de las partículas. Tamices de ensayo, tamaño nominal de las aberturas. Asociación Española de Normalización (AENOR).

AENOR-CEN (1999): UNE-EN 1744-1 Ensayos para determinar las propiedades químicas de los áridos. Parte 1: Análisis químico. Asociación Española de Normalización (AENOR).

AENOR-CEN (2000): UNE-EN 1015-11 Métodos de ensayo de los morteros para albañilería. Parte 11: Determinación de la resistencia a flexión y a compresión del mortero endurecido. Asociación Española de Normalización (AENOR).

AENOR-CEN (2000): UNE-EN 1015-3 Métodos de ensayo de los morteros para albañilería. Parte 3: Determinación de la consistencia de mortero fresco (por la mesa de sacudidas). Asociación Española de Normalización (AENOR).

AENOR-CEN (2001): UNE-EN 10020 Definición y clasificación de los tipos de aceros. Asociación Española de Normalización (AENOR).

AENOR-CEN (2001): UNE-EN 12390-1 Ensayos de hormigón endurecido. Parte 1: Formas, medidas y otras características de las probetas y moldes. Asociación Española de Normalización (AENOR). 
AENOR-CEN (2005): UNE-EN 196-1 Métodos de ensayos de cementos. Parte 1: Determinación de resistencias mecánicas. Asociación Española de Normalización (AENOR).

AENOR-CEN (2006): UNE-EN 10088-1 Aceros inoxidables. Parte 1: Relación de aceros inoxidables. Asociación Española de Normalización (AENOR).

AENOR-CEN (2007): UNE-EN 1015-6 Métodos de ensayo de los morteros para albañilería. Parte 6: Determinación de la densidad aparente del mortero fresco. Asociación Española de Normalización (AENOR).

AENOR-CEN (2009): UNE-EN 12350-2 Ensayos del hormigón fresco. Parte 2: Ensayos de asentamiento. Asociación Española de Normalización (AENOR).

AENOR-CEN (2009): UNE-EN 12390-2 Ensayos de hormigón endurecido. Parte 2: Fabricación y curado de probetas para ensayos de resistencia. Asociación Española de Normalización (AENOR).

AENOR-CEN (2009): UNE-EN 12390-3 Ensayos de hormigón endurecido. Parte 3: Determinación de la resistencia a compresión de probetas. Asociación Española de Normalización (AENOR).

AENOR-CEN (2009): UNE-EN 12620:2003+1A Áridos para hormigón. Asociación Española de Normalización (AENOR).

AENOR-CEN (2011): UNE-EN 197-1 Cemento. Parte 1: Composición, especificaciones y criterios de conformidad de los cementos comunes. Madrid: Asociación Española de Normalización y Certificación (AENOR).

AENOR-CEN (2012): UNE-EN 933-1 Ensayos para determinar las propiedades geométricas de los áridos. Parte 1: Determinación de la granulometría de las Partículas. Método de tamizado. Asociación Española de Normalización (AENOR).

AENOR-CEN (2013): UNE-EN 450-1 Cenizas volantes para el hormigón. Parte 1: Definiciones, especificaciones y criterios de conformidad. Asociación Española de Normalización (AENOR).

ALBA, N., VAZQUEZ, S., GASSO, J.M., (2002): "Baldasano, Stability/solidification of urban solid incineration residues in cement matrices". Durability relative to carbonation, cemento-hormigón, 73 (833), 13-20, 4-10

ALONSO. M.C. y DE LUXAN. M.P., (1995): Aplicaciones de las cenizas volantes en el campo de la construcción. Una experiencia española. Monografía del Instituto Eduardo Torroja de la Construcción y el Cemento. 
ANDRADE, C. (1984): "Corrosión localizada del acero en contacto con el hormigón". Rev. Iberoamericana de corrosión y protección, 15 (4), 27-34.

ANDRADE, C. y ALONSO, M.C. (1998): "Vida útil y vida residual de obras en medios marinos". Cemento-hormigón, 788, 1004-1019.

ANDRADE, C. y FELIU, S. (1989): Manuel inspección de obras dañadas por corrosión de armaduras. Madrid: CSIC.

ANDRADE, C. y GONZÁLEZ, J. (1995): "Vida útil de las estructuras de hormigón armado: obras nuevas y deterioradas". Curso de Estudio de Mayores de la Construcción, CEMCO-95, Seminario Reparación de Estructuras de Hormigón Dañadas por Corrosión, Instituto Eduardo Torroja.

ANDRADE, C., ALONSO, C., SARRIA, J. (2002): "Corrosion rate evolution in concrete structures exposed to the atmosphere". Cement \& Concrete Composites, 24 (1), 55-64, doi: http://dx.doi:10.1016/S0958-9465(01)00026-9.

ARMINOX, (1999): "Pier in Progreso, Mexico. Inspection report, Evaluation of the stainless steel reinforcement". www.arminox.con.

ASTM (2009): G61-86 Standard Test Method for Conducting Cyclic Potentiodynamic Polarization Measurements for Localized Corrosion Susceptibility of Iron-, Nickel-, or Cobalt-Based Alloys. Filadelfia, P.A. EEUU: American Society for Testing and Materials.

ASTM, (1999): C876 Standard test method for half-cell potentials of uncoated reinforcing steel in concrete. Foladelfia. P.A. EEUU: American Society for Testing and Materials.

AUBERT, J.E., HUSSON, B., SARRAMONE, N. (2006): "Utilization of municipalwaste incineration (MSWI) fly ash in blended cement. Part 1: Processing and characterization of MSWI fly ash". Journal of Hazardous Materials, 136 (3), 624-631, doi: http://dx.doi:10.1016/j.jhazmat.2005.12.041.

BAKKER, R. (1980): "On the Cause of Increased Resistance of Concrete Made from Blast Furnace Cement to the Alkali-Silica Reaction and to Sulfate Corrosion". Tesis, RWTH, Aachen, 118.

BASTIDAS, D.M., COBO, A., OTERO, E., y GONZÁLEZ, J.A. (2008 a): "Electrochemical rehabilitation methods for reinforced concrete structures: advantages and pitfalls". Corrosion Engineering, Science and Technology, 3, Vol. 43, 248-255. 
BASTIDAS, D.M., FERNÁNDEZ-JIMÉNEZ, A., PALOMO, A., GONZÁLEZ, J.A. (2008 b): A study on the passive state stability of Steel embedded in activated fly ash mortars. Corrosion Science 50, 1058-1065, doi: http://dx.doi.org/10.1016/j.corsci.2007.11.016.

BERGE, E.R. y NEAL, J.A. (1998): "Concrete masonry unit mix designs using municipal solid waste bottom ash". ACl Materials Journal, 470-479.

BERTOLINI, L., CARSANA, M., CASSAGO, D., QUADRIO CURZIO, A., COLLEPARDI, M. (2004): "MSWI ashes as mineral additions in concrete". Cement and Concrete Research, 34 (10), 1899-1906, doi: http://dx.doi.org/10.1016/j.cemconres.2004.02.001.

BONNET, D. y RUBAUD, M. (1976): "Contribution á l'elude du comportment des métaux dans les bétons carbonates". Cahiers du Centre Scientifique et Technique Du Batiment, № 168. Cahier nº 1371.

CASTELLS, X.E. (2000): Reciclaje de residuos industriales. Madrid: Ediciones Díaz de Santos S.A.

CEB (1998): Ductility of reinforced concrete structures. Bulletin $n^{\circ} 242$. Stuttgart: Comité Eurointernacional du Béton.

CENTRO DE ESTUDIOS Y EXPERIMENTACIÓN DE OBRAS PÚBLICAS (2007): CEDEX "Ficha Técnica escorias y cenizas de incineradora de Residuos Sólidos Urbanos (RSU)". Madrid: Ministerio de Fomento.

CENTRO DE ESTUDIOS Y EXPERIMENTACIÓN DE OBRAS PÚBLICAS (2007): CEDEX "Ficha Técnica Escorias de Acería LD". Madrid: Ministerio de Fomento.

CENTRO DE ESTUDIOS Y EXPERIMENTACIÓN DE OBRAS PÚBLICAS (2011): CEDEX "Ficha Técnica cenizas volantes de carbón y cenizas de hogar o escorias". Madrid: Ministerio de Fomento.

CENTRO DE ESTUDIOS Y EXPERIMENTACIÓN DE OBRAS PÚBLICAS (2011): CEDEX "Ficha Técnica Escorias de Horno Alto". Madrid: Ministerio de Fomento.

CENTRO DE ESTUDIOS Y EXPERIMENTACIÓN DE OBRAS PÚBLICAS (2011): CEDEX "Ficha Técnica Escorias de Acería de Horno de Arco Eléctrico". Madrid: Ministerio de Fomento.

CENTRO DE ESTUDIOS Y EXPERIMENTACIÓN DE OBRAS PÚBLICAS (2012): CEDEX "Ficha Técnica escorias y cenizas de incineradora de Residuos Sólidos Urbanos (RSU)". Madrid: Ministerio de Fomento. 
CHENG, A. (2012): "Effect of incinerator bottom ash properties on mechanical and pore size of blended cement mortars". Materials and Design, 36, 859-864.

CHIMENOS, J.M., FERNÁNDEZ, A.I., MIRALLES, L., SEGARRA, M., ESPIELL, F. (2003): "Short-term natural weathering of MSWI bottom ash as a function of particle size". Waste Management, 23 (10), 887-895, doi: http://dx.doi.org/10.1016/S0956-053X(03)00074-6.

CHIMENOS, J.M., FERNANDEZ, A.I., NADAL, R., ESPIELL, F. (2000): "Shortterm natural weathering of MSWI bottom ash". Journal of Hazardous Materials, B79, 287-299.

CHIMENOS, J.M., SEGARRA, M., FERNÁNDEZ, M.A., ESPIELL, F. (1999): "Characterization of the bottom ash in a municipal solid waste incinerator". Journal of Hazardous Materials, 64 (3), 211-222, doi: http://dx.doi:10.1016/S0304-3894(98)00246-5.

COBO ESCAMILLA, A. (2001): "Corrosión de armaduras en estructuras de hormigón armado: causas y procedimientos de rehabilitación". Madrid: Fundación Escuela de la Edificación.

COLLIVIGNARELLI, C. y SORLINI, S. (2002): "La reutilización de las cenizas volantes de residuos sólidos urbanos de incineración en las mezclas de concreto". Waste Management, 22, 909-912

COMISIÓN EUROPEA, MEDIO AMBIENTE (2015): EUROSTAT (Statistics explained). Ámbito de actuación, residuos. Estadísticas de residuos. Unión Europea.

COMISIÓN PERMANENTE DEL HORMIGÓN (2008): EHE-08 Instrucción de hormigón estructural. Madrid: Ministerio de Fomento.

CONGRESO NACIONAL DE MEDIO AMBIENTE (2014): CONAMA "Estudio de la situación actual de las plantas de tratamiento mecánico-biológico en España”. Madrid: Ministerio de Medio Ambiente.

CRIADO, M., BASTIDAS, D.M., FAJARDO, S., FERNANDEZ-JIMENEZ, A. у BASTIDAS, J.M. (2011): "Corrosion behaviour of a new low-nickel stainless steel embedded in activated fly ash mortars". Cement \& Concrete Composites, $33,644-652$.

DEL VALLE-ZERMEÑO, R., CHIMENOS, J.M., GIRÓ-PALOMA, J., FORMOSA, J. (2014 a): "Use of weathered and fresh bottom ash mix layers as a subbase in road constructions: Environmental behavior enhancement by means of a retaining barrier". Chemosphere, 117, 402-409. doi: http://dx.doi.org/10.1016/j.chemosphere. 2014.07.095. 
DEL VALLE-ZERMEÑO, R., FORMOSA, J., CHIMENOS, J.M., MARTÍNEZ, M., FERNÁNDEZ, A.I. (2013): "Aggregate material formulated with MSWI bottom ash and APC fly ash for use as secondary building material". Waste Management, $33 \quad$ (3), 621-627, http://dx.doi.org/10.1016/j.wasman.2012.09.015.

DEL VALLE-ZERMEÑO, R., FORMOSA, J., PRIETO, M., NADAL, R., NIUBÓ, M., CHIMENOS, J.M. (2014 b): "Pilot-scale road subbase made with granular material formulated with MSWI bottom ash and stabilized APC fly ash: Environmental impact assessment". Journal of Hazardous Materials, 266, 132140.

DEL VALLE-ZERMEÑO, R., MEDINA, E., CHIMENOS, J.M., FORMOSA, J., LLORENTE, I., BASTIDAS, D.M. (2017): Influence of MSWI bottom ash as unbound granular material on the corrosion behaviour of reinforced concrete. Jornal of Material Cycles and Waste Management, 19, 124-133, doi: http://dx.doi.org/10.1007/s10163-015-0388-5.

DEL VALLE-ZERMEÑO, R., ROMERO-GÜIZA, M.S., CHIMENOS, J.M., FORMOSA, J., MATA-ALVAREZ, J., ASTALS, S. (2015): "Biogas upgrading using MSWI bottom ash: An integrated municipal solid waste management. Renewable Energy, 80, 184-189.

DIARI OFICIAL DE LA GENERALITAT DE CATALUNYA (1996): DOGC, 2181. Ordre de 15 de Febrer de 1996. Sobre valorització d'escóries. 13 de March. Generalitat de Catalunya.

DIRECCIÓN GENERAL DEL PARQUE TECNOLOGICO VALDEMINGÓMEZ (2012): DGPTV "Memoria de actividades año 2012". Madrid: Área de Gobierno de Medio Ambiente y Movilidad.

DI CAPRIO, G. (1999): Los aceros inoxidables: martensíticos, ferríticos, austeníticos, dúplex, endurecidos por precipitación. GRUPINOX. Barcelona: Inoxcenter S.A. $2^{\mathrm{a}}$ edición.

DURAR, R. (1997). "Manual de inspección, evaluación y diagnóstico de corrosión en estructuras de hormigón armado". CYTED, Programa Iberoamericano de Ciencia y Tecnología para el desarrollo. Eds. Troconis, O., Romero, A., Andrade, C., Helen, P., Díaz, I., Río de Janeiro, Cap I, pp. 17-65.

FERNÁNDEZ CÁNOVAS, M. (2007): Hormigón. Madrid: Colegio de Ingenieros de Caminos, Canales y Puertos.

FLATT, R.J., ROUSSEL, N., CHEESEMAN, C.R. (2012): "Concrete: An eco material that needs to be improved". Journal of the European Ceramic Society, 32 (11), 2787-2798, doi: https://doi.org/10.1016/j.jeurceramsoc.2011.11.012. 
FORTEZA, R., LEJOS, M., SEGUÍ, C., CERDÁ, V. (2004): "Characterization of bottom ash in municipal solid waste incinerators for its use in road base". Waste Management, 24 (9), 899-909, doi: http://dx.doi:10.1016/j.wasman.2004.07.004.

FRÍAS, M., SAN JOSÉ, J.T., VEGAS, I. (2010): "Árido siderúrgico en hormigones: proceso de envejecimiento y su efecto en compuestos potencialmente expansivos". Materiales de construcción, 60 (297), 33-66.

FULLER, W. y THOMPSON, S.E. (1907): The laws of proportioning concrete. Transactions of the American Society of Civil Engineers. Paper, 1053, 67-143.

GARCíA-ALONSO, M.C., ESCUDERO, M.L., MIRANDA, J.M., VEGA, M.I., CAPILLA, F. CORREIA, M.J., SALTA, M., BENNANI, A. y GONZALEZ, J.A. (2007 a): "Corrosion behaviour of new stainless steels reinforcing bars embedded in concrete". Cement and Concrete Research, 37, 1463-1471.

GARCÍA-ALONSO, M.C., GONZÁLEZ, J.A., MIRANDA, J., ESCUDERO, M.L., CORREIA, M.J., SALTA, M., BENNANI, A. (2007 b): "Corrosion behaviour of innovative stainless steels in mortar". Cement and Concrete Research, 37 (11), 1562-1569, doi: http://dx.doi:10.1016/j.cemconres.2007.08.010.

GEDGE, G. (2000): Strutural propierties of stainless steel rebar. Symposium "Structural applications of stainless steel in building and architecture". EUROINOX. Septiembre 2000. Bruselas. (www.euro-inox.org).

GINÉS, O., CHIMENOS, J.M., VIZCARRO, A., FORMOSA, J., ROSELL, J.R. (2009): "Combined use of MSWI bottom ash and fly ash as aggregate in concrete formulation: environmental and mechanical considerations". Journal of Hazardous Materials, $169 \quad$ (1-3), 643-650, doi: http://dx.doi:10.1016/j.jhazmat.2009.03.141.

GJORV, O.E. (1982): Steel corrosion in reinformed and prestressed concrete structures. Nordisk Betong, 2-4, 147-151.

GOÑI, S., GUERRERO, A., MACIAS, A. (2007): "Obtaining cementitious material from municipal solid waste". Materiales de construcción, 57 (286), 41-51, doi: http://dx.doi.org/10.3989/mc.2007.v57.i286.46.

GOÑI, S., GUERRERO, A., MACIAS, A., LORENZO, M.P. (2011): "Materias primas alternativas para la fabricación de cementos más eficientes de baja energía". Alconapac, 1 (1), 17-29.

GONZÁLEZ FERNÁNDEZ, J.A. (1989): Control de la corrosión. Estudio y medida por técnicas electroquímicas. Madrid: CSIC. 
GONZÁLEZ, J.A. y ANDRADE, C. (1982): "Effect of carbonation, chlorides and relative ambient humidity on the corrosion of galvanized rebars embedded in concrete". British Corrosion Journal, vol. 17, N 1, 21-28.

GONZÁLEZ, J.A. y MIRANDA, J. (2007): Corrosión en las estructuras de hormigón armado: Fundamentos, medida, diagnosis y prevención. Madrid: CSIC.

GREENPEACE; (2015): "Radiografía social del medio ambiente en España". www.greenpeace.es.

GU, P., ELLIOTT, S., BEAUDOIN, J.J. y ARSENAULT, B. (1996): "Corrosion resistance of stainless steel in chloride contaminated concrete". Cement and Concrete Research, Vol. 26, N 8, 1151-1156.

INSTITUTO GEOLÓGICO MINERO DE ESPAÑA (2012): IGME "Panorama Minero 2014" Madrid: Ministerio de Economía y Competitividad.

INSTITUTO NACIONAL DE ESTADÍSTICA (2012): INE "Encuesta sobre la recogida y el tratamiento de residuos año 2010". Madrid: Ministerio de Economía, Industria y Competitividad.

INSTITUTO PARA LA DIVERSIFICACIÓN Y AHORRO DE ENERGÍA (2011): IDAE Situación y potencial de valorización energética directa de residuos. Estudio técnico Per 2011-2020. Madrid: Ministerio de Energía, Turismo y Agenda Digital.

IZQUIERDO, M.P. (2007): Análisis del comportamiento a corrosión de armaduras embebidas en probetas de mortero, con sustitución parcial de áridos y cemento por escorias blancas de horno cuchara. Tesis Doctoral. Madrid: E.T. de Arquitectura Técnica. Universidad Politécnica de Madrid.

JURIC, B., HANZIC, L., ILIC, R., SAMEC, N. (2006): "Utilization of municipal solid waste bottom ash and recycled aggregate in concrete". Waste Management., 26 (12), 1436-1442, doi: http://dx.doi:10.1016/j.wasman.2005.10.016.

KNUDSEN, C., SKOYSGAARD, A. (2001): "Stainless steel reinforcement". Concrete Engineering Internacional, 3, (5), 59-62.

KOSSON, D., GARRABRANTS, A., DELAPP, R., VAN DER SLOOT (2014): "pHdependent leaching of constituents of potential concern from concrete materials containing coal combustion fly ash". Chemosphere, 103, 140-147, doi: http://doi.org/10.1016/j.chemosphere.2013.11.049. 
LAM, C.H.K., IP, A.W.M., BARFORD, J.P., MCKAY, G. (2010): "Use of incineration MSW ash: a review". Sustainability, 2 (7), 1943-1963, doi: http://dx.doi:10.3390/su2071943.

LANNEGRAND, R., RAMOS, G. y TALERO, R. (2001): "Estado del conocimiento sobre la sal de Friedel". Materiales de Construcción, Vol. 51, Nㅜ262, 63-70.

LEY 10 (1998): de 21 de abril de Residuos. (BOE. Núm. 96 de 22/04/1998). Madrid.

LEY 22 (2011): de 28 de julio de residuos y suelos contaminados. (BOE Núm. 181 de 29/07/2011). Madrid.

LI, M., XIANG, J., HU, S., SUN, L., SU, S., LI, P., SUN, X. (2004): "Characterization of solid residues from municipal solid waste incinerator". Fuel, 83 (10), 1397-1405, doi: http://dx.doi:10.1016/j.fuel.2004.01.005.

LIN, K.L., CHANG, W.C., LIN, D.F. (2008): "Pozzolanic characteristics of pulverized incinerator bottom ash slag". Construction and Building Materials, 22 (3), 324-329, 10.1016/j.conbuildmat.2006.08.012.

LÓPEZ JIMENO, C. (1994): Áridos. Manual de prospección, explotación y aplicaciones. Madrid: Editorial Entorno Gráfico.

LORETO, G., VARRIALE, C., IOVINO, R. (2010): "Experimental evaluation of concrete durabilty". XXXVII IAHS, World Congress on Housing, Spain.

MANSUR \& ISLAM (2002): "Interpretation of concrete strength for nonstandard specimens". Journal of Materials in Civil Engineering, 14, 151.

MARTíNEZ-LAGE, I., MARTÍNEZ-ABELLA, F., VÁZQUEZ-HERRERO, C., PÉREZ-ORDOÑEZ, J.L. (2012): "Properties of plain concrete made with mixed recycled coarse aggregate". Construction and Building Materials, 37, 171-176.

MEDINA, E. (2009): Construcción de estructuras de hormigón armado en edificación. Biblioteca técnica universitaria. Madrid: E.T. de Arquitectura Técnica. Universidad Politécnica de Madrid. (Editorial Bellisco ediciones técnicas y científicas).

MEDINA, E. (2012): Evaluación del comportamiento mecánico, estructural y frente a la corrosión de una nueva armadura de acero inoxidable dúplex bajo en niquel. Tesis Doctoral. Madrid: E.T. de Arquitectura Técnica. Universidad Politécnica de Madrid.

MEDINA, E. y BASTIDAS, D.M. (2013): Análisis económico de estructuras de hormigón con armaduras de acero inoxidable. En Bastidas, D.M. \& Medina, E. (Ed.), Armaduras de acero inoxidable (1-22). Madrid: Cedinox. 
MEDINA, E., COBO, A., BASTIDAS, D.M. (2012): "Evaluation of structural behaviour and corrosion resistance of austenitic AISIS 304 and duplex AISI 2304 stainless steel reinforcements embedded in ordinary Portland cement mortars". Revista Metalurgia Madrid 48, 445-458, doi: http://dx.doi.org/10.3989/revmetalm.1203.

MEHTA, P. IC. (1981): Sulfate Resistance of Blended Portland Cements Containing Pozzolans and Granulated Blast Furnace Slag," $5^{\circ}$ Simposio Internacional sobre Tecnología del Hormigón, Universidad Autónoma de Nuevo Leon, Monterrey, N. L., México, pp. 35-50.

MEIRA, G.R., ANDRADE, C., PADARATZ, I.J., ALONSO, C. y BORBA Jr. J.C. (2007): "Chloride penetration into concrete structures in the marine atmosphere zone. Relationship between deposition of chlorides on the wet candle and chlorides accumulated into concrete". Cement and Concrete Composites, 29, 667-676, doi: 10.1016/j.cemconcomp.2007.05.009.

MINDESS, S. y YOUNG, J.F. (1981): Concrete. Prentice-Hall Englewood Cliffs, NJ. 671

MIRANDA, J.M, COBO, A., OTERO, E. y GONZÁLEZ, J.A. (2007): "Limitations and advantages of electrochemical chloride removal in corroded reinforced concrete structures". Cement and Concrete Research, 37, 596-603, doi: 10.1016/j.cemconres.2007.01.005.

MIRANDA, M. y LOPEZ, W. (1988): Estudio de velocidad de corrosión de los refuerzos metálicos en estructuras de concreto. Tesis de Licenciatura. Univ. Nac. Aut. de México, Facultad de Química.

MOTH, H. y GEISELER, J. (2001): "Products of steel slags an opportunity to save natural resourses". Waste Management, 21 (3), 285-293, doi: 10.1016/S0956053X(00)00102-1.

MÜLLER, U. y RÜBNER, K. (2006): "The microstructure of concrete made with municipal waste incinerator bottom ash as an aggregate component". Cement and concrete research, 36 (8), 1434-1443, doi: http://dx.doi.org/10.1016/j.cemconres.2006.03.023.

NEVILLE, A.M. (1995): Properties of concrete. Forth edition, Longman. London.

ORNA, M., GONZÁLEZ. J., SANCHEZ. J.C., FERNANDEZ. L., ADE. R., QUERO. F. (2010): "Reciclado de escorias de fondo de central térmica para su uso como árido en la elaboración de componentes prefabricados de hormigón". Materiales de construcción, 60 (300), 99-113, doi: 10.3989/mc.2010.52109.

OTERO, I., ESPLUGA, A.P., ORTEGA C. (1991): "Sellado y recuperación de antiguos vertederos de residuos sólidos urbanos". Informes de la construcción, Vol. 42 N. 411. 
OTIENO, M.B., ALEXANDER, M. y BEUSHAUSEN, H.D. (Comp.) (2010): Transport mechanisms in concrete. Corrosion of steel in concrete. Assessment of corrosion. Ciudad del Cabo: Concrete Materials and Structural Integrity Research Group.

PECQUEUR, G., GRIGNON, C., QUÉNÉE, B. (2001): "Behaviour of cementtreated MSWI bottom ash". Waste Management, 21 (3), 229-223, doi: http://dx.doi:10.1016/S0956-053X(00)00094-5.

PERA, J., COUTAZ, L., AMBROISE, J., CHABABBET, M. (1997). "Use of incinerator bottom ash in Concrete". Cement and Concrete Research, 27 (1), 1 5, doi: http://dx.doi:10.1016/S0008-8846(96)00193-7.

PÉREZ-QUIROS, J.T., TERAN, J., HERRERA, M.J., MARTÍNEZ, M. y GENESCA, J. (2008): "Assessment of stainless steel reinforcements for concrete structures rehabilitation". Journal of Constructional Steel Research, doi: 10.1016, jcsr.2008.07.024.

POLETTINI, A., POMI, R., SIRINI, P., TESTA, F. (2001): "Properties of Portland cement-stabilised MSWI fly ashes". Journal of Hazardous Materials, 88 (1): 123138, doi: http://dx.doi:10.1016/S0304-3894(01)00292-8.

POURBAIX, M. (1966): Atlas of Electrochemical Equilibria in Aqueous Solutions. Oxford: Pergamon Press Ltd.

PRIETO M.I., COBO, A., RODRÍGUEZ, A. CALDERÓN, V. (2013): "Corrosión behavior of reinforcement bars embedded in mortar specimens containing ladle furnace slag in partial substitution of aggregate and cement". Construction and Building Materials, 38, 188-194, doi: http:/dx.doi:10.1016/j.conbuildmat.2012.08.044.

QIAN, S., QU, D., y COATES, G. (2006): "Galvanic couplinic between carbón steel and stainless steel reinforcements". Canadian Metallurgican Quarterly, 4, (45), 475-484, doi: http://dx.doi.org/10.1179/cmq.2006.45.4.475.

QUINA, M.J., BORDADO, J.C., QUINTA-FERREIRA, R.M. (2008). "Treatment and use of air pollution control residues from MSW incineration: An overview". Waste Management, 28, 2097-2121, doi: https://doi.org/10.1016/j.wasman.2007.08.030.

RASHID, R.A. y FRANTZ, G.C. (1992): "MSW incinerator ash as aggregate in concrete and masonry". J. Mater. Civil Eng., 4 (4): 353-368, doi: http://dx.doi.org/10.1061/(ASCE)0899-1561(1992)4:4(353).

ROJAS-HENAO, L., FERNANDEZ-GÓMEZ, J., LÓPEZ-AGÜI, J.C. (2013): "Factores de corrección para predecir la resistencia a compresión in-situ de un hormigón autocompactante". Materiales de construcción, 63 (312), 497-514. 
SAEKI, N., TAKADA, N. y FUJITA, Y. (1984): "Influence of carbonation and sea water on corrosion of steel in concrete". Transport Japanese Concrete Institute, $6,155-162$.

SAIKIA, N. y KATO.T. (2007): "Production of cement clinkers from municipal solid waste incineratión (MSWI) fly ash". Waste Management, 27, 1178-1189.

SAIZ DE OMECAÑA, J.A. y SAIZ DE OMECAÑA, J., (1996): "Impacto medioambiental de las incineradoras". Informes de la Construcción, 47, 441-442.

SAKAI, S. y HIRAOKA, M. (2000): "Municipal solid waste incinerator residue recycling by thermal processes". Waste Management, 20 (2-3), 249-258, doi: https://doi.org/10.1016/S0956-053X(99)00315-3.

SCHIESSI, P. y RAUPACH, M. (1997): "Laboratory studies and calculations on the influence of crack width on chloride induced corrosion of steel in concrete". ACI Materials Journal, 94 (n¹), 56-62.

SIDDIQUE, R. (2010 a): "Use of municipal solid waste ash in concrete. Resources". Conservation and Recycling, 2 (55), 83-91, doi: http://dx.doi.org/10.1016/j.resconrec.2010.10.003.

SIDDIQUE, R. (2010 b). Use of municipal solid waste (MSW) ash in cement and mortar. Resources, Conservation and Recycling, 54, 1037-1047, doi: http://dx.doi.org/10.1016/j.resconrec.2010.05.002.

SMITH, F.N. y TULLMIN, M. (1999): "Using stainless steel as long-lasting rebar material". Materials Performance, Vol. 38, N 5, 72-76.

STERN, M., y GEARY, A.L., (1957): "Electrochemical polarization: I. A theoretical analysis of the shape of polarization curves". Journal of Electrochemical Society, 104 (1), 56-63, doi: http://dx.doi: 10.1149/1.2428496.

THOMAS, C., SETIEN, J., POLANCO, J.A., ALAEJOS, P., SANCHEZ DE JUAN, M. (2013): "Durability of recycled aggregate concrete". Construction and Building Materials, 40, 1054-1065.

TORRES ACOSTA, A.A., PÉREZ-QUIROS, J.T., RAMÍREZ, A.J. y MARTÍNEZ, M., (2006): "Estudio de la corrosión de barras de acero inoxidable en concreto contaminado por cloruros cuando se le aplican esfuerzos residuales". IMT $\mathrm{N}^{\circ}$ 287, Sanfandila, Qro, México.

TUUTTI, K. (1982): Corrosion of steel in concrete. Tesis Doctoral, Swedish Cement and Concrete R.I., en "Manual: Inspección de obras dañadas por corrosión de armaduras" de C. Andrade y S. Feliu, CSIC. Madrid (1989), pp.19. 
VEDALAKSHMI, R., BALAMURUGAN, L., SARASWATHY, V. KIM, S.H. y ANN, K.Y. (2010): "Reliability of galvanostatic pulse technique in assessing the corrosion rate of rebar in concrete structures: laboratory vs field studies". KSCE Journal of Civil Engineering, 14 (6), 867-877.

WOODS, H. (1968): Monograph No. 4, American Concrete Institute/lowa State University Press, Farmington Hills, Mich., 187.

YI, S.T., YANG, E. I., CHOI, J. C. (2006): "Effect of specimen sizes, specimen shapes, and placement directions on compressive strength of concrete". Nuclear Engineering and Design, $236 \quad(2), \quad 115-127$, doi: http://dx.doi.org/10.1016/j.nucengdes.2005.08.004. 